\title{
The effects of study abroad experience on students' vocational identity
}

\section{Dissertation}

In Fulfillment for the Doctor Degree of Social Sciences

at the Faculty of Social Sciences of the Georg-August-University Göttingen

\section{Presented by}

Leticia Rangel Chavez, M.A.

Born in Monterrey, Mexico

$* * * * *$

Göttingen 2010 
Evaluators:

Prof. Dr. Christina Krause

Dr. Stephanie Brickman

Date of Doctoral Defense: 22.03.2010 
Copyright

Leticia Rangel Chavez 


\section{Content}

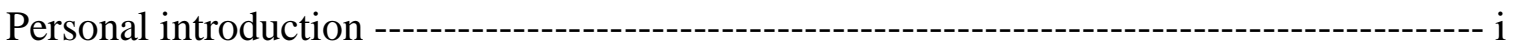

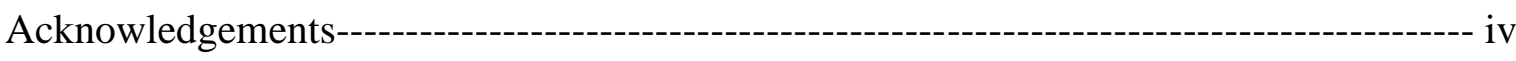

Tables and Diagrams ------------------------------------------------------------------------------- vii

\section{Chapter 1: Introduction}

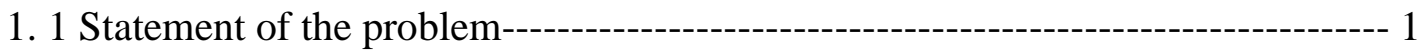

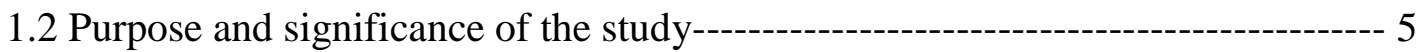

Chapter 2: Literature Review

\subsection{Identity and Self development}

2.1 1 Identity theories ---------------------------------------------------------------------- 10

2.1.2 Relationship of self and identity development ----------------------------------- 14

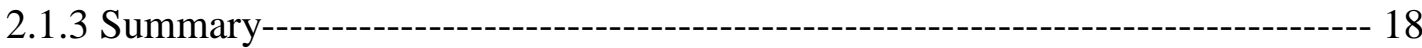

\subsection{Identity formation and vocational development during adolescence}

2.2.1 Importance of identity development --- 18

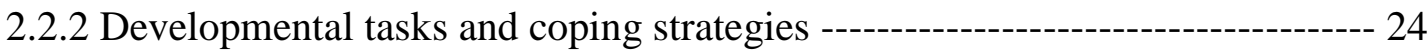

2.2.3 The self-concept, self-esteem and vocational exploration------------------------ 28

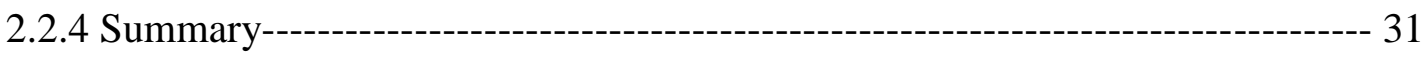

\subsection{Career development theories and vocational identity formation}

2.3.1 Vocational choice and identity formation by John Holland---------------------- 33

2.3.2 Vocational development and the role of Self-concept-------------------------- 36

2.3.3 Socio-cognitive career theories and the role of self-efficacy ------------------- 39

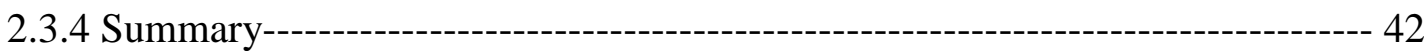

\subsection{Study abroad programs in the United States}

2.4.1 Promotion of study abroad programs in US academic institutions--------------- 43

2.4.2 Goals, functions and effects of study abroad programs--------------------------- 46

2.4.3 Effects of study abroad experience on vocational identity development------- 48

2.4.4 Self-exploration and vocational development by studying abroad-------------- 54

\section{Chapter 3: Methodology}

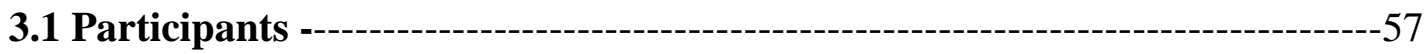

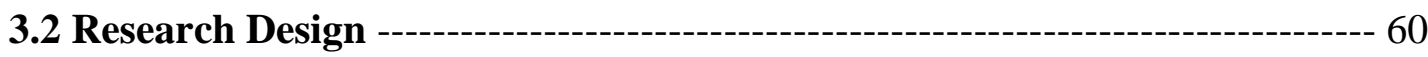




\subsection{Quantitative instruments}

3.3.1 Survey "The vocational career development of college students"------------- 62

3.3.2 The Frankfurter Selbstkonzept Skala (FSKN)-------------------------------- 63

3.3.3 Holland's Self-Directed-Search Inventory---------------------------------------- 66

\subsection{Qualitative instrument}

3.4.1 Semi-structured interview 67

3.5 Procedures for data collection

\subsection{Procedures for data analysis}

3.6.1 Quantitative data analysis 71

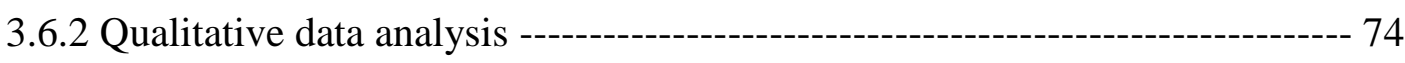

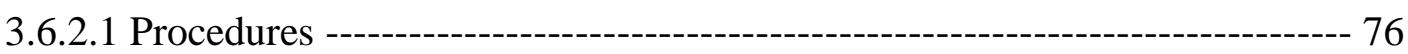

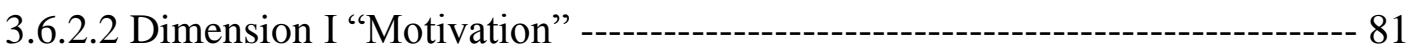

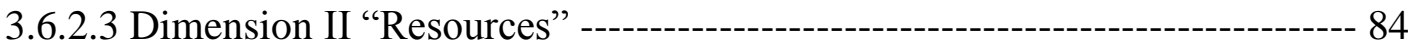

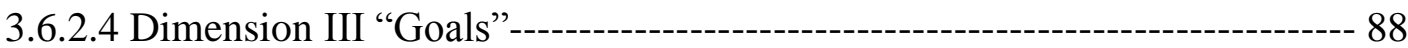

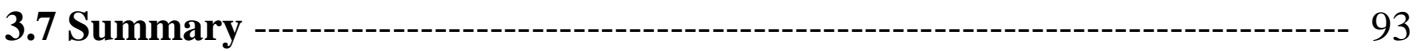

\section{Chapter 4: Results}

4.1 Descriptive results before study abroad experience $(n=12)$

4.1.1 Survey I "Vocational career development of college students"---------------- 95

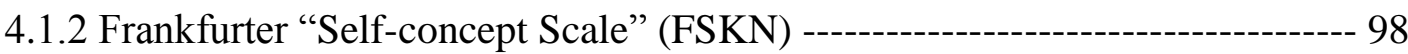

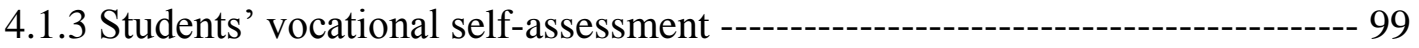

4.1.4 Descriptive results of semi-structured interviews ---------------------------100

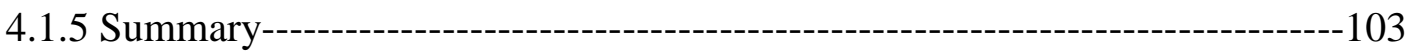

4.2 Descriptive results after study abroad experience $(n=14)$

4.2.1 Survey II "Vocational career development of college students" ------------- 105

4.2.2 Frankfurter "Self-concept Scale” (FSKN) ---------------------------------108

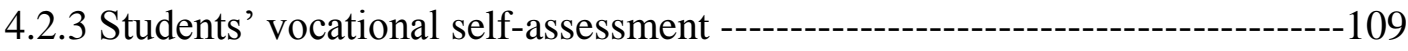

4.2.4 Descriptive results of semi-structured interviews --------------------------110

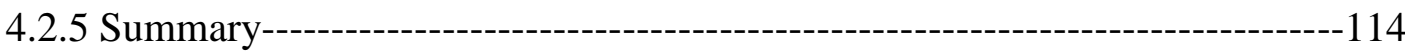

4.3 The impact of study abroad experience on students' vocational identity: comparative presentation of data.

4.3.1 Career decision and vocational identity status ------------------------------- 115

4.3.2 Frankfurter “Self-concept Scale” (FSKN) --------------------------------- 117

4.3.3 Students' vocational assessment by domain ------------------------------ 119

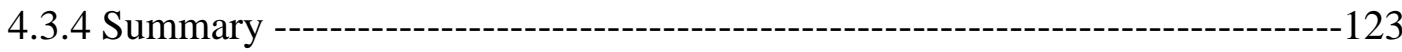


4.4 Analysis and interpretation of four cases before and after their study abroad experience

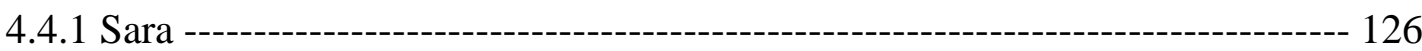

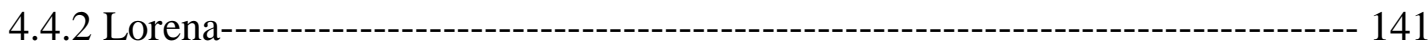

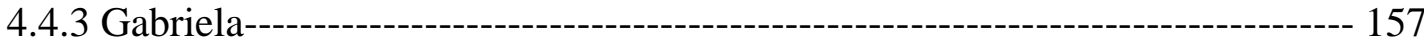

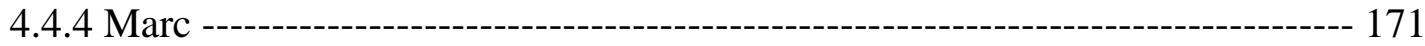

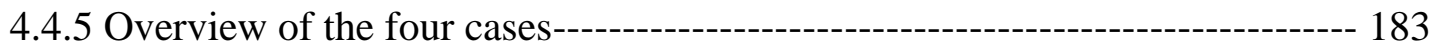

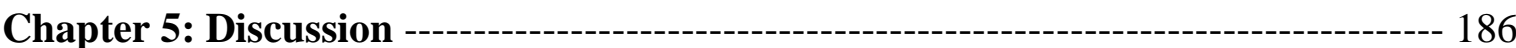

Chapter 6: Conclusions

6.1 Implications for further research studies ---

6.2 Implications for counseling and advisement services -------------------- 211

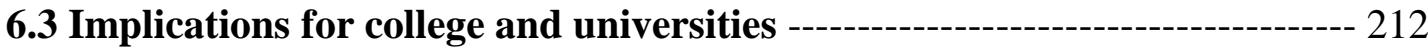

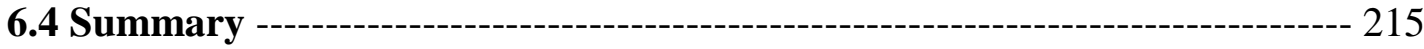

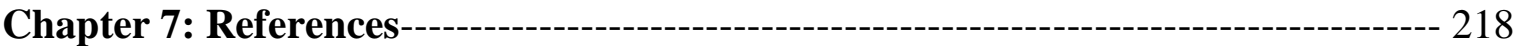

Appendixes:

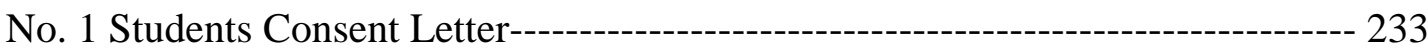

No. 2 Survey I \& II "Vocational career development of college students"--------- 236

No. 3 "Frankfurt Self-Concept Scale" (in English and in German) ----------------- 240

No. 4 Holland's “Self-Directed-Search”, Form R 4th Edition---------------------- 250

No. 5 Interview guidelines before and after SAE -------------------------------------- 265

No. 6 Interview with Sara before and after study abroad---------------------------------267

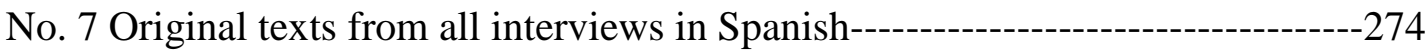

\section{Curriculum Vitae}




\section{Personal introduction}

This study was inspired by relevant and transitional life events throughout my crosscultural experience as a student and professional accumulated in Mexico, Germany, and in the United States of America. The time spent in each country has given me the opportunity to learn and reflect a lot about myself, in particular, in regards to my vocational and professional identity. The cross-cultural events that I experienced have significantly shaped my personal and vocational identity.

I was born and raised in the northern Mexican city of Monterrey, an industrial city and the capital of the state of Nuevo Leon. I lived in Monterrey until the age of 21, the year I finished my teaching certification school as an elementary school teacher. At that time, I discovered that I was born to devote my life to be an Educator of children and adolescents.

I was fortunate enough to be awarded scholarships by the Exchange and Academic German Services (DAAD). The DAAD is the German national agency for international cooperation in higher education which serves to promote international academic relations through the funding of exchange students and faculty between Germany and other countries.

When I arrived in Göttingen for the first time in 1985, I developed an attraction to the German language. Being Mexican, and coming from a very traditional and culturally family oriented society, the interface of a new culture and communication led me to an indepth self-reflection process. This self-reflection process was not only in reference to my Mexican culture, background and education, but also my personal and vocational identity.

In order to achieve my educational goals, and to positively benefit from my stay in Germany, I decided to interact more with the Germans students in order to learn their language properly and at a fast pace. After 2 years of intensive language courses, I passed the language exam required to enter the University Georg-August in Göttingen. At that time, I was compelled to make a career choice (major and minor) that would build on my already existing degree in teaching, and to continue my post-grad studies. The German educational system was somewhat flexible and ideal to pursue my professional knowledge in pedagogy, because I had the opportunity to combine the areas of my vocational interest (pedagogy, psychiatry of children and adolescents, physical education). 
After the completion of my Masters degree at the University Georg-August of Göttingen in 1993, I returned home, where I continued teaching at the postgraduate level at the Universidad Autónoma de Nuevo Leon (UANL) in Monterrey, Mexico. In 1996 inspired by post-grad students request for the improvement of vocational and educational guidance services at the high-school level, I initiated an exploratory research study with 1,300 participants in their last semester of high school. The main purpose of this study was to appreciate thoroughly students' personal and vocational needs. The results of this previous study, specifically the high rate of high-school students without a decided career, called to my attention the relevance of students' career development and vocational guidance programs.

In 1998, I developed a research study which was dedicated to career definition of highschool students. The purpose was to develop a pedagogical and vocational career program to support Mexican students in their career-choice and vocational definition process. This research study marked the beginning of an Agreement of Cooperation between the Universidad Autónoma de Nuevo Leon (UANL) and the Georg-August University of Göttingen. With the cooperation of the German university, and the strong necessity of vocational and educational career services at UANL, a Masters Program in Vocational and Educational Guidance was developed as a joint Masters Program to professionalize highschool teachers, as Vocational and Educational Orientation Teachers.

The fortune of living in a foreign country, and having traveled around Europe for more than 10 years, gave me the idea to carry out a research study where, we as educators could be more aware and informed about student's career-oriented achievements and needs while they are abroad. The purpose of this study is to introduce a qualitative point of view for study abroad programs which allows the consideration of student's identity and vocational development while studying abroad.

In a global community, it is essential that adolescents are exposed, or encouraged to participate in intercultural learning activities such as study abroad or exchange programs. It has been recognized by several researchers that the benefits of long-term study abroad programs brings us to realize the opportunities that institutions can utilize for an enriched academic achievement and student's personal and vocational development. This challenges institutions in higher education to develop well-planned, designed, and assessed career-oriented study abroad programs. 
My four years of professional experience as a study abroad advisor, and my personal experience studying abroad, helped me to appreciate the importance of a well-designed, delivered, assessed and efficiently managed study abroad program. The majority of the students, whom I advised, did not know which classes to take, how to learn in a new and different environment, or what to expect from it. In some cases, before and after being advised, they even expressed confusion in their career choice status. Before, during and after my study abroad advisements services, I realized the necessity of collaborative academic support and counseling intervention services. It is, of course, these issues that entail a robust pedagogical awareness and appreciation, as well as professional qualification and cross-cultural experience in regards to all personnel working at academic institutions and international offices.

From all of the aforementioned issues emerged the idea of developing this research study, and the proposal of comprehensive and effective assistance for our college students in order to make their learning and achievement before during and after their study abroad program successful and sustainable. 


\section{Acknowledgements}

A dissertation, especially a doctoral degree, is not the accomplishment of a single person, but instead a collaboration of a community of people. This community consisted of: my two beautiful daughters, my wonderful husband, my always supportive parents, my spiritually motivating mother and father in-law as well as my extended family, my closest friends (from Argentina, Colombia, France, Germany, Iran, Mexico, Peru, Philippines, Poland, Spain, Turkey, and USA), and my extraordinary American and German faculty supervisors. Each one of these people bestowed upon me countless gifts and values among which are patience, belief, generosity, faith, perseverance, honesty, and unconditional love.

It is difficult to put in words my deepest gratitude and merit owed to all my family for their unconditional support, love, and guidance. My endless love and heartfelt appreciation goes especially to my lovely daughters Gabriela and Sara, who patiently allowed me to work at home, and to my incomparable husband, Gabriel, who unconditionally supported and helped me in each and every way, in particular for his resilience during the process of translating, refining and combining my ideas from Spanish, German and English.

I would also like to acknowledge the life-long support, patience and love of my wonderful parents, Melita and Dario, who always were there for me when I needed them, especially, when they had to travel by car or bus from Monterrey, Mexico to McAllen, Texas to take care of my daughters while I was in Germany, and during the many hours I spent on data collection, literature research etc. Gracias a mis adorables padres que de una manera insaciable me mostraron su amor y apoyo durante toda mi carrera y programa doctoral, gracias por siempre!

To my lovely mother in-law Mary Ellen, I would like to take time to acknowledge her support, prayers and love, and to my father in-law John for his support and humor.

I would like to take this opportunity to especially recognize the members of my international doctoral committee: Prof. Dr. Christina Krause and Prof. Arnd Krüger from the Georg-August University of Göttingen, also Dr. Stephanie Brickman, Full Associate Professor at the University of Texas-Pan American whose friendship, support, and 
encouragement throughout this process has been invaluable. I look forward to having you forever as friends and colleagues.

Prof. Dr. Christina Krause, a phenomenal advisor, has been my academic mentor and advisor for the past twelve years, as well as my teacher and guide over the course of my graduate studies. I appreciate how, since our first meeting in regards to my first proposal back in 1996, she has always recognized the value of, and supported my desire for educational academic improvement, I am also grateful for how she provided structure and guidance when I needed it, and afterward gave me the freedom and space to be creative and work things out on my own. Whenever we met, in Germany or in Mexico, our educational philosophy converged, and it was a continuous learning process which stimulated me with new approaches and elucidated the understanding of the task at hand. Herzlichen Dank für deine wertvolle Unterstützung, deine Betreuung und vor allem deine liebe Freundschaft!

Especial thanks are dedicated to another one of my international doctoral committee members, Dr. Stephanie Brickman, Full time professor at The University of Texas-Pan American, who, since I met her in the spring of 2007, has made me feel fully identified in my field as well as comfortable and highly motivated whenever we met. I am so happy to have found someone like her in a foreign academic community who held the same interest in my subject matter. With her positive feedback, she definitely kept me focused on my vocational identity goal. Thank you so much for believing in me!

Another faculty member, who has made an indelible impression on me, is Prof. Arnd Krüger. Since I was a graduate student in the Sports Science Department at the GeorgAugust University, and over the last twenty years, Arnd has been a supportive professor of my research developmental interest as well as my own personal journey.

In the process of this dissertation, I worked closely with a group of people I would not have otherwise met, the 15 students who accepted to participate in this research study, and shared with me their thoughts, their feelings, their uncertainties and doubts. I learned from them more than I can say; I appreciate their trust in me while sharing the details of their experiences and academic careers.

We did it! 
This work is dedicated with deep love to:

My two beautiful daughters who were my inspiration,

Gabriela and Sara;

For his unceasing support, my partner, and best friend,

Gabriel;

And for their unconditional support and absolute encouragement, my parents

Melita and Dario;

I'll always love you! 


\section{Tables}

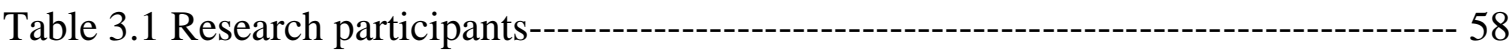

Table 3.2 Example of Holland's' Self-Directed-Search summary--------------------------- 72

Table 4.1 Characteristics of research participants $(n=15)$------------------------------ 97

Table 4.2 Students' career decision and vocational identity status before SA ( $\mathrm{n}=12)$-----97

Table 4.3 Students' expectations of study abroad on vocational identity before $(\mathrm{n}=12)--98$

Table 4.4 Frankfurter Self-Concept-Scale results by domain before SA ( $\mathrm{n}=12$-----------99

Table 4.5 Mean scores of vocational self-assessment by domain before SA ( $\mathrm{n}=12)-----100$

Table 4.6 Students' motivation before SA $(n=12)$-------------------------101

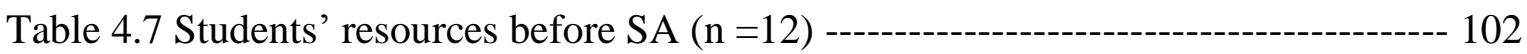

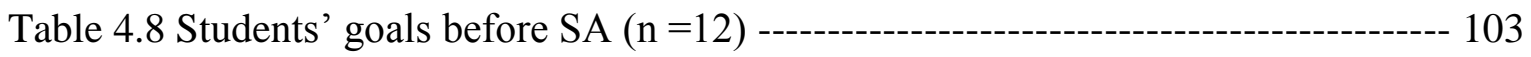

Table 4.9 Students' career decision and vocational identity status after SA ( $\mathrm{n}=14)------107$

Table 4.10 Students' expectations of study abroad on vocational identity

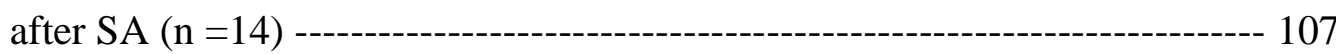

Table 4.11 Frankfurter Self-Concept-Scale results by domain after SA ( $\mathrm{n}=14)$----------109

Table 4.12 Mean scores of vocational self-assessment by domain after SA $(n=14)$-----110

Table 4.13 Students' motivation after SA $(n=14)$------------- 111

Table 4.14 Student's resources after SA (n=14) -------------------------------------113

Table 4.15 Students' goals after SA (n =14) -----------------------------------------------113

Table 4.16 Career decision and vocational identity status before and after SA $(n=11)--116$

Table 4.17 Expectations on vocational identity before and after SA (n= 11) ------------ 117

Table 4.18 Students' FSKN scores by domain before and after SA $(n=11)$--------------118

Table 4.19 Impacts on students' self-concept domains before and after SA $(n=11)$---- 119

Table 4.20 Vocational activities by personality type before and after SA $(n=11)$------- 121

Table 4.21 Vocational competencies by personality type before and after SA $(n=11)--121$

Table 4.22 Vocational occupations by personality type before and after SA $(n=11)$----122

Table 4.23 Vocational self-estimates by personality type before and after SA $(n=11)-122$

Table 4.24 Identity status, vocational codes before and after SA, and the status of------

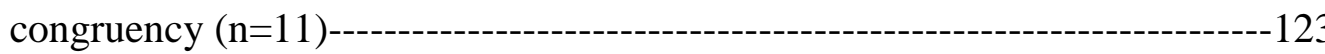




\section{Diagrams}

Diagram 2.1The four types of vocational identity status ----------------------------------22

Diagram 3.1 Frankfurter Self-Concept Scale domains-----------------------------------------64

Diagram 3.2 Qualitative data analysis--------------------------------------------------------- 73

Diagram 3.3 Step model of deductive category application (Mayring 2000) ---------------77

Diagram 3.4 Dimensions and categories emerged from the qualitative data analysis -----80

Diagram 3.5 Dimension I “Motivation”------------------------------------------------------------ 81

Diagram 3.6 Dimension II “Resources” --

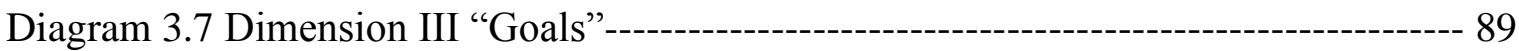

Diagram 4.1 Sara's vocational self-assessment before and after SA------------------------130

Diagram 4.2 Sara's Self-Concept assessment before and after SA--------------------------131

Diagram 4.3 Lorena's vocational self-assessment before and after SA---------------------147

Diagram 4.4 Lorena's Self-Concept assessment before and after SA-----------------------150

Diagram 4.5 Gabriela's vocational self-assessment before and after SA-------------------160

Diagram 4.6 Gabriela's Self-Concept assessment before and after--------------------------163

Diagram 4.7 Marc's vocational self-assessment before and after SA----------------------175

Diagram 4.8 Marc's Self-Concept assessment before and after SA ------------------------177 


\section{Chapter 1}

\section{Introduction}

\subsection{Statement of the problem}

For many universities, especially in the United States (US), professional achievement and success in a global and multicultural society is dependent upon students' personal development in cross-cultural learning and international settings. The promotion of study abroad program experiences is becoming a major trend in intercultural personal development. Participants in such study abroad programs are given an opportunity to develop the necessary personal and professional skills and competencies for a greater global awareness, and overall success in a multicultural and inter-independent global society.

Trends in higher education, e.g. globalization, internationalization and intercultural awareness are challenging academic societies and institutions to enhance student's global understanding through education abroad (e.g. Dixon 2006; Burriss 2006; Sindt 2007; Gardner \& Whiterell 2008). In line with these openings and challenges, education abroad in US universities are making an attempt to provide college students with a wide umbrella of variants to develop a global awareness and international competencies for the demands of the $21^{\text {st }}$ Century.

Kagan \& Steward (2004) and Bok (2006), agree on the increasing necessity to develop and provide students with special programs for global education. Unfortunately, these trends of international education and global mobilization are rapidly surpassing institutional, academic research and expertise (e.g. Bok 2006), as well as assessment capacities, in particular for students' vocational education. Consequently, this challenges all practitioners involved in higher education, especially in the awareness of global competencies and the demands on students' personal and vocational career development issues.

International Education has been offered by US universities in various ways including exchange and studying abroad programs which have become an affordable alternative for 
numerous students. As reported by Open Doors (2007), the Institute of International Education (IIE) on American students' participation in study abroad programs revealed that the number of academic program enrollment increased $150 \%$ over the past decade.

Based on the escalating need for college students to gain a global education, the National Association of International Educators (NAFSA) is supporting new institutional management strategies to meet these educational challenges by strengthening study abroad programs (NAFSA 2008). As per NAFSA's January 2008 Report, people who are involved in the international educational setting need to create and reinforce appropriate programs with international exposure. The educational demand of colleges and universities on students is to acquire a high level of international competencies in order to be able to develop an intercultural awareness and understanding. There are very clear objectives for the application and purpose of study abroad programs. NAFSA expressed:

"In order to thrive in the global marketplace and lead effectively in a global context, college graduates must learn foreign languages, experience other cultures and societies, and have an understanding of how the international system functions at both the macro and micro level" (NAFSA's Report 2008, p. 13).

This statement might also suggests that, in order to meet the demands of a global education, it is necessary to develop well-structured study abroad and exchange programs that can ensemble, not only students' international competencies and skills, but also the success of career vocational needs. To achieve and support these initiatives, international study abroad programs need to maintain pedagogical and measurable approaches (e.g. Myers, Hill \& Hardwood 2005) which provide educators and programs advisors involved in education abroad with students' personal needs, such as strengths and weaknesses, and furthermore with a vocational assessment device that present student's personal career aspirations with the objective to improve his or her accomplishments abroad.

After reviewing the majority of studies derived from study abroad experiences, it seemed somewhat apparent that intercultural study or program experiences, especially long-term study abroad, had an impact on students' personal and academic outcomes. Studies carried out on study abroad impacts (in only one country) are on cross-cultural adaptation (Pitts 2005), on personal identity (Herman 1996; O’Callaghan 2006; Williams 2006) and on 
career aspirations (Myers, Hill \& Hardwood 2005). Currently there has been less importance placed on vocational identity development.

Developmental tasks, such as choosing the right major and finding the right career choice and occupation, nowadays represent an important and high valued challenge for students.

Students, today, seem to be -positively- exhorted by the $21^{\text {st }}$ century trends in higher education to constantly develop up to date career competencies and skills based on supply and demand (e.g. Brown 2003), nevertheless the focus on a congruent balance of personal and vocational development, still remains a challenge. While students nowadays seem to have more opportunities for professional development and career paths variants, this equates to new challenges for their vocational career development and definition. In line with vocational career development, Chickering and Reisser (1993) strongly believe that "we discover our vocation by discovering what we love to do, what energizes and fulfills us, what uses our talents and challenges us to develop new ones, and what actualizes our potentials for excellence" (p. 212). With that said, the new challenges students encounter, seem to increase personal exploration or discovering activities that provide accurate facts about themselves, implying a well self-awareness. A vocational congruency between the person's abilities and their intrinsic calling (what he or she feels and enjoys doing) could lead to a long-lasting self-efficacy and career satisfaction.

As far as the relevance of developmental tasks, Havighurst (1972), a classic American developmental psychologist and educator, highly recognizes the value of accomplishment (success or failure) as a significant task-outcome predictor for future tasks. This would also refer to a sense of self-efficacy and the perception of being self-satisfied. He describes developmental tasks as follows:

"A task which arises at or about a certain period in the life of the individual, successful achievement of which lead to his happiness and to success with later tasks, while failure leads to unhappiness in the individual, disapproval by the society, and difficulty with later tasks" (p. 2).

Therefore, adolescents are facing a constant personal developmental task which is to search for their own identity and, furthermore, vocational identity. The identity formation as a central task in adolescence traits has been the foci of multiple theoretical roots, such as Erikson's conception of psychosocial development (1953, 1968, 1974, 1980). 
For Erikson the dynamic of the identity formation is also called a time of "crisis" (1968, 1974). He theorized eight stages of a person's life cycle; these stages present the periods of time when the person, in interaction with the environment, is shifting his or her personal development through crises from one stage to another. Indeed, for people at college level, the fifth stage, identity versus identity confusion is the most dominant coping task.

Most publications regarding the identity formation offer various conceptions of identity. Marcia's (1980) and Erikson's $(1968,1974,1980)$ theories on identity definition are the central basis of the theoretical framework for this study. Moreover respected research studies have found that explorational activities have been regarded as an excellent predictor of identity formation (e.g. also Schmitt-Rodermund \& Vodracek 1999).

Erikson's theory has served a series of subsequent empirical studies (e.g. Hurlock, 1989; Fend 1991; Chickering \& Reisser 1993; Bohleber 1996). Concerning the identity development at college level, the term identity was defined as "understanding one's abilities, interest, and personality" (Pascarella \& Terenzini 2005, p. 216). The identity formation along with students' career choice process must be considered as a distinctive form because they are crucial factors of students' developmental needs. The students, during their career-choice-process, are looking for a compatible career choice to their identity, which indeed allows them to express themselves.

Additionally, the search for personal and vocational identity, within international mobility through exchange and study abroad programs, is becoming very challenging for students. In fact the vocational identity enhances, during the college period, and challenges students with questions like, "Who am I? What am I going to be? What do I want to be? What am I interested in? What am I capable of and able to do?" The vocational identity and the career exploration process are mainly shaped in a multifactorial way that, at the same time, is determined through degrees of exploration and commitment developed, either through personal initiative or socio-contextual influences (Erikson 1953, 1980, 1988). Based on this premise, educators, counselors and international advisors should consider study abroad experience, in the $21^{\text {st }}$ Century, as an exploration activity that might elucidate, develop or shape students' identity and vocational interests. 


\subsection{Purpose and significance of the study}

As previously mentioned, the US institutional effort of outlining the benefits of international education and education abroad on global and intercultural development has been well documented (e.g. Praetzel 1996, 1999; Duke 2000; Demetry \& Vaz 2002; Robinson 2003; Dwyer \& Peters 2004; Bloom 2005; Dirkx 2006; Bok 2006; NAFSA's Report 2008). International education through study abroad and exchange programs also involves vocational education. Still, the effects of experience abroad on students' vocational development have received less attention.

The purpose of this study was to investigate how a semester of study abroad program experience might shape students' self-perceptions and their vocational choice and satisfaction.

The idea that there is a relationship between an individual's personal preferences, interests, and the need to choose a major toward a career according to one's personal characteristics has deep roots in vocational theory and research (Super 1957, 1963a, 1963b; Holland \& Nichols 1964; Holland \& Lutz 1968; Osipow 1991). These theoretical ideas postulate that an occupation is an expression of one's personality and that congruence between personality and the chosen career contributes to satisfaction, stability and achievements which are what is being referred to here as vocational identity achievement.

The effects of college environments on students' learning and achievement have been well researched by Pascarella and Terenzini (1991, 2005). They conducted a series of intensive studies to measure the effect of out-of-class students' involvement (e.g. study abroad program experience) and the relationship within their academic achievement and performance. As far as the effects of study abroad experience Zorn (1996) admitted that there has been limited research regarding "longer terms of study abroad might have greater effects than shorter" (Zorn 1996; in Pascarella \& Terenzini 2005, p. 316). Other larger studies on the analysis of data from the larger Study Abroad Evaluation Project (SAEP) found that study abroad students, versus control group, revealed greater "scores on measures of cultural interests and the importance that attached to promoting peace and international cooperation" (Pascarella \& Terenzini 2005, p. 317). 
Sending students abroad just to learn a foreign language or promoting studies abroad, such as another alternative or lucrative way of traveling or for paid practice or internship possibilities, is not enough to gain a satisfactory approach to their vocational identity development. The role of promoting vocational identity development, though study abroad program, is a collective function among a network of academic and institutional practitioners.

The potential influence of college life and social interaction on students' identity development has been noticeably recognized (Erikson 1974; Fend 1991; Chickering \& Reisser 1993) as has been the role of self-concept development within academic and vocational achievement (Fend 1991; Chickering \& Reisser 1993; Pascarella \& Terenzini 2005). The influence of the college environment and out-of-class experience on the students' self-concept and their performance has been well established (e.g. Teranishi 2006). Beyond this, academic influence is finally the students' challenging task to seek a satisfactory sense of personal identity and, more importantly, to follow their intrinsic call (motivation and interests) to a career and vocational path based on their meaningful interest which results in life satisfaction.

Due to the growing importance of the role of vocational development and its relationship to self-concept during adolescence, the importance of "self-knowledge" used by Brown (2003) is another important factor to consider. This factor may add to self-exploration activities and be the foundation that serves career development.

There is an agreement within the identity and career development theories when considering that a level of exploration and commitment process contributes extensively to the formation of identity (Erikson 1968, 1980; Marcia 1976, 1980). In conjunction with career choice and vocational maturity development, a study abroad experience could be considered as a potential setting for constructive learning experiences (e.g. Toncar \& Cudmore 2000; Teranishi 2007) that promote the self-exploration development (e.g. Williams 2006) through diverse self-concept roles (e.g. Super 1957, Chickering \& Reisser 1993), which are well considered as foundations in the process of career-decision (e.g. Keller, Piotrowski \& McLeod 1991) and achieving a vocational identity (e.g. Grotevant, Cooper \& Kramer 1986; Grotevant 1987). The identity itself is a process of sociocognitive interactions. The formation of personal and vocational identities is not a simple process; thus, the degree of exploration seems to be an essential ingredient within the 
process of identity formation and vocational career choice. This result can only be achieved through a self-exploration and self-knowledge process which itself provides the study abroad experience as an applied learning form.

According to the roots of vocational development theories, exploration activities are a crucial part of vocational maturity (Super 1953, 1957; Crites 1969; Super \& Hall 1978; Grotevant, Cooper \& Kramer 1986). The students need to explore different careers or occupational options and environments that enable them either to enhance or facilitate their vocational choice process. Exploration activity (educational adventure and applied learning) as a process in terms of self-awareness and self-knowledge is certainly a place for self-reflection with an educational function (Bauer 2001).

In reality, the vocational identity is discovered mostly in a form of cognitive process, which will guide the students continuously to their vocational goals and job satisfaction. According to Haußer (1995), the basis of a vocational identity is vocational satisfaction, which will be achieved when one finds one's occupation, career or work, attractive. Psychosocial research conducted by Tamminen (2006) among an adult population on relationships between culture and individuals, has emphasized the meaning of identity from a cognitive point of view, in which "identity is both a subjective experience and a tie to the human environment and its culture" (p. 604). Cultural environment has a considerable impact on students' personal and vocational identities. Therefore, the experience gained throughout a study abroad program experience could be seen as a potential source of adaptability for future professional vocational competence and performance. Unfortunately, there is still a lack of study abroad assessment that provides the researchers with qualitative data.

Surely, any individual's experience and self-perception depends on many factors and varies according to his or her culture where she or he is or has been immersed. Although those factors, as part of socio-cultural process, are very important, the focus of this study is not to analyze the impact of the different foreign cultures on the students' personal perception but to show how the students perceive their identity regarding vocational and career development before and after a cultural immersion while studying abroad.

This study represents a psycho-pedagogical concern for the design, implementation and assessment of study abroad programs, including institutional advisements services of 
exchange and study abroad programs in higher education. The main focus is to create a professional awareness in higher institutions and program advisement services for the development and assessment of study abroad programs that enhance an overall students' vocational self- efficacy and global prospective that enables them to face present day challenges in the workplace.

Despite the long list of studies, it was difficult to find adequate and sustainable literature that provides more detailed information about assessments of effectiveness and a relationship between semester study abroad programs and their effect on students' selfperception and vocational interest. Therefore, within the international academic responsiveness, the students' vocational aspects surrounded by students' personal and identity development still remains a challenge. For that reason, an academic challenge is to begin creating study abroad programs with a comprehensive approach and to promote a high qualitative personal development of students in terms of career and vocational identity development.

Due to the lack of qualitative data that support effects of long-term study abroad programs on vocational identity, the main purpose of this study is to examine how college students at a University in Texas have been impacted regarding their cognitive self-perception and satisfaction with their chosen career by a semester of study abroad experience.

This study examines the self-awareness that the students perceived from what they gained from their study abroad program experience and how it impacted their vocational interest and choice after their experience abroad. This research study is designed with a heuristic purpose which represents a first step into study abroad programs outcomes regarding students' vocational identity development. This qualitative research study concentrates on examining how the experiences abroad by college students might have a positive or negative effect on their vocational interest development and status.

The main questions of this research study are:

1. How does a semester study abroad experience impact students' career choice status and vocational satisfaction?

2. How is students' self-concept characterized before and after a study abroad experience?

3. How do study abroad experiences impact students' vocational identity? 
a.How do students perceive their motivation and goals within their career development before and after their experience abroad?

b.How do students perceive their strengths and weaknesses toward their personal and career development before and after their experience abroad?

c.How do learning experiences contribute to students' vocational identity development?

4. How can colleges improve their benefits of a long term study abroad experience which promotes and supports students' vocational identity development? 


\section{Chapter 2}

\section{Literature Review}

Chapter 2 is divided into four segments $(2.1,2.2,2.3$ and 2.4) which includes the major theoretical frameworks for this research.

The first segment (2.1), the self and the theoretical development of identity, in particular, the attached relationship of identity formation with the development of the self will be discussed. In the second section (2.2), the importance of developing an identity and vocation during adolescence as part of a developmental task, as well as its role within selfconcept, self-esteem and the vocational exploration process, will be addressed. The third segment (2.3) will discuss career development theories (e.g. Super 1957; Holland 1985, 1991; Bandura 1977, 2001) which are relevant for the formation of a vocational identity, including the role of self-concept and self-efficacy within the vocational career development. The last segment (2.4) will address the role of study abroad programs within US colleges and universities, as well as their goals and effects on students' development, including the possible effects that they have on students' vocational identity development.

\subsection{Identity and Self development}

\subsubsection{Identity theories}

The epistemological development for the identity's definition is quite complex. The word comes from the Latin word, "identitas", which in German means, "vollkommene Gleichheit" (Reese-Schäfer 1999, pp. 14-15) and in English means "sameness" or "the same" (identity n. d.).

Identity development and formation theories have been introduced and discoursed in diverse contextual understandings such as a socio-psychological process (e.g. Erikson 1968, 1980; Fend 1991) or as a socio-psychological construct of social development (e.g. Reese-Schäfer 1999; Keupp, Ahbe, Gmür, Höfer, Mitzscherlich, Kraus \& Strauss 2006). 
Subsequently, in the social and political sciences, it seems that the term "identity" is merely presented as a socio-structural product of political interests for human development (Reese-Schäfer 1999). The identity's terminus has been applied and interpreted to diverse areas of interest (social, educational, political, cultural, psychological and psychoanalytical). The postmodern discussion of a classical identity formation phenomenon unfolds from an individual level up to a macro level (Keupp et al. 2006). In contrast to a sociopolitical discourse of identity formation, this study is focused on the formation of identity from the individual perspective, although socio-academical forces have certainly contributed substantial portions (e.g. Chickering \& Reisser 1993; Fend 1991, 1997; Pascarella \& Terenzini 1991, 2005).

Constructing a stable identity is a life-long task. "Who am I?" and "Who do I want to be?" are questions that are answered either individually or in relation to a certain type of work, job, occupation or profession. Additional questions might also emerge relevant to form one's identity, e.g. who am I in relation to what others think of me? How do others want me to be? The identity is rationally formed through trials of different roles and experiences, and continues to develop in new situations when new information is collected and integrated into a new identity structure.

Keupp et al. (2006) have concluded that "up until now, the labor of identity formation is an evaluative process in which the person integrates, interprets and assesses their experience" (Translated by the Author).

"Identitätsarbeit wuerde bisher entwickelt als ein evaluativer Prozeß, innerhalb dessen die Person ihre Erfahrungen integgriert, interpretiert und bewertet“ (p. 217).

In line with Keupp's et al. identity formation theory, a relevant complementary aspect of this evaluative process, such as the career choice process, is part of an exploratory behavior which integrates close matching characteristics of the person (e.g. Super 1957). Hereby, an identity is structurally constructed through constant explorative reflections about oneself and the new environmental experiences that are integrated within the self. Once these socio-environmental experiences are integrated, the individual will be more likely to recognize new information (e.g. characteristics) in him or herself.

Relevant research studies have contributed to understand identity construction and development (Erikson 1968, 1980; Marcia 1980; Grotevant 1987; Haußer 1995, 
Chickering \& Reisser 1993; Soenens, Berzonsky, Vansteenkiste, Beyers \& Goossens 2005). These studies have shown irrevocable support for theoretical and practical foundations of the development of identity conceptions, especially within the educational and psychological disciplines.

Berzonsky (1990, 1993, 2003), "considers identity to be a self-theory or a conceptual structure that integrates an individual's assumptions, hypotheses, and constructs about the self as experienced in interaction with the physical and social world" (Berzonsky 1990, 1993, 2003; in Soenens et al. 2005, p. 428). In conjunction with Berzonsky's theoretical understanding regarding the formation of one's identity, it is indisputable, to separate the "self" from the self-constructed image in relation to the development of one's vocational and occupational knowledge as an experienced interaction of the social world.

The vocational identity is rooted in the overall identity formation. Howard (2000) believes that occurs through a dynamic of cognitive information process about one's self. According to Howard (2000), "self-schemas include organized knowledge about one's self, the cognitive response to the question of identity: "Who am I?"(p. 368). For theoretical understanding, these questions include personal characteristics, preferences, goals, behavior and career patterns that individuals associate with themselves. Under this umbrella of development, the identity would be in relation to an association with a certain career, profession or occupation. This type of career choice, in terms of professional group schemas, embraces not only social and cognitive aspects of the self, but also emotional satisfaction of one's professional and occupational identity with the internal information of one's self. In this study, this is referred to as vocational identity (i.e. the purpose of one's personal life achievement).

Chickering and Reisser (1993) emphasize the importance of identity development of college students. They recognized seven vectors in the student's personal development. These seven vectors symbolize general developmental directions (pp. 38-39):

1. Developing Competence: from low to high level of competence; from lack of confidence in one's abilities to strong sense of competence.

2. Managing Emotions: from little control over disruptive emotions to flexible control and appropriate expression. 
3. Moving though autonomy toward interdependence: poor self-direction or ability to solve problems to instrumental independence (inner direction, persistence, and mobility).

4. Developing Mature Interpersonal Relationships: from lack of awareness of differences to tolerance and appreciation of differences.

5. Establishing Identity: from confusion about "who I am" and experimentation with roles and roles styles to clarification of self-concept though roles and lifestyles; from dissatisfaction with self to self-acceptance and self-esteem.

6. Developing Purpose: form unclear vocational goals to clear vocational goals.

7. Developing Integrity: from dualistic thinking and rigid beliefs to humanizing values; from discrepancies between values and actions to congruency and authenticity.

The fifth and sixth vectors named by Chickering and Reisser (1993) "Establishing Identity" and "Developing Purpose" corresponds as well to theoretical foundations toward vocational identity formation. As per the vector of "establishing identity", Chickering and Reisser (1993) underline Josselson's (1987) identity conception, “as a dynamic fitting together of parts of the personality with the realities of the social world so that a person has a sense both of internal coherence und meaningful relatedness to the real world" (Chickering \& Reisser 1993, pp. 173-208). Based on this dynamic fitting process of personality and the real world, Grotevant (1987) directs this practice into an identity exploratory method. He defines the identity as the process of exploration, namely as "problem-solving behavior aimed at eliciting information about oneself or one's environment in order to make a decision about an important life choice" (p. 204). His theoretical postulation also suggests that the work for identity formation is addressed in different manners and domains. The majority of the identity development theories, pertaining to adolescence, have been based on Erikson's work (e.g. Grotevant 1987; Blos 1989; Hurlock 1989; Fend 1991; Chickering \& Reisser 1993; Haußer 1995; Soenens et al. 2005). Most authors agree that the adolescent is constantly looking for a stable identity and a relative sense of autonomy and belief of control across environments. 


\subsubsection{Relationship of self and identity development}

Compared to previous theories, the cognitive relationship between identity development and self is here discussed. There is sufficient theoretical evidence based on research studies that document the strong relationship between the phenomenon of identity and self development (Frey and Haußer 1987; Blos 1989; Fend 1991, 1994; Haußer 1995; Bohleber 1996, Krause, Wiessman \& Hannich 2004). While the formation of identity is an elaborate dynamic of external and internal acquired information that match or fit into one's personal image, the self is a sum of perceptions and memories (e.g. Remschmidt 1992; Haußer 1995).

Remschmidt's (1992) conception regarding the "self" differentiates clearly the "self" from the "self-concept" by rationalizing that the "self" embodies the perceptions and memories, and the "self-concept" is an abstraction of all substantial characteristics of the "self" in their own view, and in the view of others (p. 111). This refers to the subjective perceptions of adolescents that might be constructed through an intensive introspection and selfreflection. It is to assume that students are constantly attempting and challenging to prove their self-constructed assumptions which are necessary to update their own self-concept perceptions.

Within the identity development, there are further and relevant aspects that need to be discussed. James (1890) differentiates the "I" as internal perspective, such as how students perceive themselves in terms of vocational abilities, skills and preferences, from the "me" as external perspective, such as how students perceive themselves in relation to vocational or occupational profile. For James (1980), the "I" is the person who one perceives, and the "me" is the person who others perceive (James 1890; in Haußer 1995, p. 38). Hereby, the "I" actively plays the role of engaging the students in vocational activities and accomplishments. With that said, one might believe that in order for students to execute their vocational goals, they need to increase their sense of an approaching internal perspective, and to also develop a clear sense of vocational identity.

The main challenge within the self-reflection process is finding not only the personal identity but also the vocational choice that corresponds with his or her self- visualization. In order to gain a better understanding of the "Self" development, one speaks about the need for a high ego, or narcissistic attributions that also are indispensable within the 
protection of self-esteem. According to Blos (1989), the process of self-reflection refers to a kind of narcissistic quality of adolescent personality and positive self-evaluation activities that are part of the personality development. These needs could be gained through expanding perceptions of oneself in other cultures and environments (e.g. Williams 2006), where the adolescents are interacting and are faced with new and independent activities (e.g. solving problems).

It is relevant to accentuate the role of the current "real me" and future vocational vision "ideal me" in the vocational identity development and satisfaction. The theory by Rosenberg $(1965,1979)$ represented the developmental process of the "Self" by finding a congruence, consistency and coherence between the "real me" and the "ideal me" (Rosenberg 1965, 1979; in Fend 1994, pp. 204-205). In other words, one strives mainly for an agreement and balance between the "real me" and the "ideal me". In the best case scenario, everything goes as expected, such as when the "me" and the "self" come together and merge, where one finally can say: the "way I am how I would like to be and the way I strive to be, is also who I am" (e.g. Fend 1991). With this in mind, one might speak from an achieved personal identity: if the cognitive and the emotional psychological elements, in particular the positive self-esteem, are in agreement, namely the "ideal me" is congruent with "real me." This seems to show a sense of congruency, and once this is accomplished, the level of self-esteem becomes a predictor for greater engagement in career exploration activities.

While self-concept represents the cognitive aspects of one's self, self-esteem corresponds to the emotionally valued aspects of self-concept, e.g. positive or negative feelings about one's self (e.g. Haußer 1995; Krause, Wiesmann \& Hannich 2004). The self-concept, selfesteem and personal beliefs of control are considered the three main components within the identity development (Haußer 1995, p. 26). Haußer's (1995) conception leads educators to appreciate the identity formation as a process which moves from generalization into specification. The three components interact together moving in a circular-dynamic form in which the identity development attempts to shift from a globalstable field and time, to a specific-situational or stable place or time and vice versa.

Corresponding to Haußer's (1995) conception regarding the formation of identity, the selfconcept is certainly an effective motivational factor. Authors agree that the self-concept is the basis for all motivational conduct (Franken 1994; Huitt 2004). It is to be assumed that 
a positive sense of self-esteem might serve as a strength that guides one to fulfill successes, even though one is experiencing negative feedback of one's actions. Other theorists such as McInerney and McInerney (2006) correlate the formation of self-concept within a dynamic of "social interaction and comparisons" (p. 502). This might also include unfamiliar environments, because one copes with new interactions and comparisons, differentiating one from the others (e.g. Williams 2006).

The self-concept embodies internal and external information that forms a cognitive selfperception. According to Holland's (1985) understanding, individuals that have a clear and stable picture of the self which is congruent with their personal interests, goals and talents, have formed an identity (p. 5). In line with Holland's theory regarding the concept of identity, Zunker (1998) expressed, "individuals who have many occupational goals, as opposed to a few, have low identity" (p.55). In summary, the individual goals and personal visions such as the "ideal me" that one has of oneself certainly imply one's occupational images, vocational environments and identities. A congruency between the "ideal me", the "real me" and the type of environment might be understood as a motivational goal for one's career.

The epistemological origin of the term "vocation" comes from the Latin "vocatio/vocationis" which, in English, means "calling". In Spanish, vocation means "llamado o invitacion" (Marin Benet 1998, p. 323) translated into English, means calling or invitation (Translated by the Author). Brown's (2003) understanding supports the notion that "vocation is linked to the idea that people are called to a certain occupation" (p. 7). Vocation is basically linked, in this study, to the idea that students are called or believe to be attracted to a certain profession or occupation that fit their own self-image. Super's (1942) theoretical understanding regarding vocational development discusses a process of vocational and avocational adjustment. For example, whether or not students are called or attracted to a certain subject or career that resembles their desired profession.

The topic of personal identity development stands in the foreground. In this context, and in relation to the vocational career development, Fend (1991) defines vocational identity as: "what one is, can be and would like to be... it is also the time of experimenting, discovering and finding, what fits, constructs and distinguishes the own person; it is where one finds himself, where one can identify" (translated by the author). In his own words, Fend rationalizes as follows: 
"was man ist, sein könnte und sein möchte ,... es ist auch die Zeit des Experimentierens, herauszufinden, was zu einem gehört, was die eigene Person ausmacht, wo man sich wiederfindet, wo man sich identifizieren kann" (p. 22).

As previously mentioned, it is unavoidable to separate the "Self" from the identity formation. In line with Waterman's (1985) representation of identity definition, the self directs people (i.e. adolescents) to the type of goals, values, and convictions that are important to them (p. 5).

In contrast to Waterman's perceptions, Molla (1997) considers the theoretical concept of identity formation as self-strengthening and characterizes the identity development as strengthening the "Ego". He contemplates, that during the formation of identity, adolescents undergo an experience of adaptation and strengthen the "I" which is in the loop of finding equilibrium and integrity.

There is another social aspect of identity formation process identified by Habermas (1973, 1976) the "I-Identity". In accordance with James (1890) conception concerning the self, Haußer (1995) defines the "I", the "Ich" in German, as the knowledge of the person, and the "me "or "Selbst" in German, as "the acquaintance, of another experienced one" (p. 38). The "I" and the "Me" are key elements into students' self-perceptions that are being processed cognitively and emotionally. The development of one's identity is an integration process, e.g. between the "I" and "Me", there are two forms of self-perceptions, the realimage and the ideal-image (Haußer 1995). For example, the real-image could be considered, how the students perceive themselves, and the ideal self-concept would be how they want to see themselves. This theory has an important focus on the building of a personal and vocational identity.

There is sufficient theoretical evidence in believing that academic environments potentially influence personal development, especially students' self-concept and selfconfidence development (e.g. Astin 1977, 1998; Fend 1991; Chickering \& Reisser 1993; Pascarella \& Terenzini 2005). These authors' studies have shown that the interaction with the primary agents of socialization during college, peers and faculty members, influences the level of academic or intellectual self-concept. Thus, they argue that until now, there is no sufficient examination of who has the most influence, peers or faculties. 


\subsubsection{Summary}

In summary, the formation of the identity and the self-concept are formed through a constant life-long dynamic of cognitive, emotional and social evaluations which are highly accentuated and perceived during adolescence. This continuous self-assessment becomes intensive in the loop of a search for job, occupation, or profession. This is what is called "vocation." Its importance during adolescence will be discussed in the next section.

\subsection{Identity formation and vocational development during adolescence}

\subsubsection{Importance of identity development}

The formation of identity and vocational choice is a primary task during adolescence and is, therefore, a primary theoretical aspect of this study. An overview of adolescence's psychological dynamics process of identity formation and its relationship to the task of vocational choice will be discussed in the following section.

During the last fifty years, identity formation has been a worthy focus of considerable and theoretical and empirical research studies. Some worthwhile examples and valuable contributions into the identity formation and construction have occupied empirical research and studies (Erikson 1968, 1980; Marcia 1976, 1980; Erwin 1982; Fend 1991; Chickering \& Reisser 1993; Cerulo 1997; Reese-Schaefer 1999; Garlichs, Leutzinger \& Bohleber 1999; Soenens et al. 2005; Keupp et al. 2006). Despite these empirical and valuable contributions, the vocational identity development, and how it develops across cultures and borders, is still unclear.

Adolescence, as defined by Super (1963a), is "literally, growing up, becoming an adult" (p. 80). For Blos (1989) the adolescence is the period of an individuation process (from child to becoming an adult), where the adolescent seeks detachment from their parents and achieves his or her own independence. This individuation process supports students' personal identity development, and increases their beliefs of self-control and selfmotivation.

The typical changes in theoretical understanding of adolescence involve two important key changes in personal characteristics. The first are the strong and striking physical changes, 
and the second are the noteworthy changes in thinking, behavior, emotions and feelings. Although the physical changes interact and influence the psychodynamic changes, this study will concentrate on the psycho-dynamic and psychosocial changes of students ages 19 to 24 years who have already dealt with their physical changes (Super 1957; Brown 2003). This transitional phase of vocational exploration to a vocational establishment of a career has special meaning because of the psychological and psycho-social changes that take place. Those changes of adjustments and the role of exploratory activities (SchmittRodermund \& Vondracek 1999) shape personal development, stimulate identity formation and vocational development.

While Remschmidt (1992) and Super (1957) see adolescence as the life phase which marks the transition from the childhood to the adult age, Williams (1975) describes it "as the period of experiencing and resolving the turbulence which is set into action by the biological process of puberty" (p. 12). In conjunction to William's understanding, Meyerson (1975) expresses that during adolescence some crises with ambiguities and ambivalences of identity confusion can develop (p. 46). These confusions and crises could be based on lack of self-knowledge and of self-efficacy. An identity is achieved through personal development and also from understanding oneself, according to Pascarella and Terenzini (2005).

The term "adolescence" has been used as a synonym for "puberty." However, adolescence is considered as a transitional phase. Remschmidt (1992) clearly explains that puberty, in contrast to adolescence, comprises the biological and physiological changes which are connected to physical and sexual maturity. In this context, Oerter and Montada (1987) speak about adolescence as a period of turbulence, extreme fluctuations of feelings, and rebellion. Naturally, those changes might occur differently in each society. Cultural factors (e.g. values, family, environment, etc.) have a close relationship within the development of identity. Tamminen (2006), based on his study on the relation between culture and identity for mental health of infants that was carried out in Finland, concludes that culture promotes early development of identity, because identity is "the subjective experience and a tie to the human environment and its culture" (p. 604).

Furthermore, inspired by the subject, Fend $(1991,1994,1997)$ carried out a set of valuable longitudinal investigations focusing on adolescence main characteristics and their 
particularities. He found three relevant areas of students' personal development, from which adolescence develops.

1. The "I "development (die Entwicklung des Ichs): hereby, the development of personal identity is adjacent to the physical body changes, and with the accentuation of the gender role, the "I" acts as it is currently known. Hereby, the adolescent begins to experience personal achievements (e.g. I can do this, I am able to do more) by developing his/her sense of an ability to perform well at something, (Bandura 1977, 1997); this is called a sense of self-efficacy.

2. The development of social relations (such as parents, siblings and friends), and the development of a conscience and awareness become the second largest focus of adolescence.

3. Relationships in the school environment (Fend 1994, 1997), especially in those educational environments (college) in which adolescents are getting the most significant advice and structural paths for their career and identity development (e.g. Chickering \& Reisser 1993; Pascarella \& Terenzini 2005).

The most exceptional studies regarding identity development have been conducted by Erikson (1968, 1974, 1980), and Marcia (1966b, 1980). Most identity development always leads back to the phases of the psychosocial development described by Erikson (1968, 1980, 1988). Erikson's (1980) theoretical understanding regarding the fundamentals of an identity formation is specifically based on his psychosocial conceptions about personality development. He presents an epistemological view of the identity development over a life-long perspective, in which a reciprocal effect occurs between the individual and society. Erikson (1953) perceives the personality development as a life-long passage, which he named the eight human stages:

Phase 1: Vertrauen im Gegensatz zu Mißtrauen (Basic trust vs. Mistrust) Phase 2: Autonomie vs. Scham und Zweifeln (Autonomy vs. Shame and doubt) Phase 3: Initiative vs. Schuldgefühle (Initiative vs. Guilt) Phase 4: Tätigkeit vs. Minderwertigkeitsgefühle (Industry vs. Inferiority) Phase 5: Identität vs. Identitätsverwirrung (Identity vs. Role confusion) Phase 6: Intimität vs. Isolierung (Intimacy vs. Isolation) Phase 7: Schöpferische Tätigkeit vs. Stagnation (Generativity vs. Self-absorption) Phase 8: Integrität vs. Verzweiflung (Ego integirty vs. Despair) $)^{l}$

\footnotetext{
${ }^{1}$ Translation is based on McInerney \& McInerney (2006, P. 454).
} 
Throughout these phases, Erikson's theories established a theoretical understanding for the psychosocial process of a human's life. According to Erikson's life-stages, adolescence is crucial for identity formation. Erikson (1974) believes that there are relevant challenging experiences; whereas each stage contains a certain level of crisis. His theory points out that each stage is not a closed and resolved cycle of adolescent task. He knows that an adolescent has to go through a process of integration of his talents and social role, attempting to gain and maintain equilibrium of personal identity, which finally includes the development of one's vocational identity. Erikson's conceptualization makes clear that a crisis should be considered as a challenge as well as a constructive aspect of personality development. Similar to Erikson's conceptions, Chickering and Reisser (1993) added, "the nature of the response to the challenge determines the direction of development" (p. 175). However, a healthy development of one's personality will be achieved, once one has accomplished stage-corresponded tasks with success (McInerney \& McInerney 2006). The identity formation, according to Erikson, takes place during the stage of adolescence e.g. identity vs. role confusion. The choice for a profession, occupations and career are main tasks of adolescents' identity formation.

Marcia (1980) built on Erikson's proposition by concluding that the identity's explorations and definitions turn out to be a central goal during adolescence. In line with the identity formation, both authors agreed in perceiving two types of constant psychological tasks: crisis and commitment. These developmental tasks were seen, rather, as a stimulus, as a psychological or physical signal which might determine the course of students' development. Valuable studies from Marcia (1966a, 1966b, 1980) have received respected recognition. He has developed the identity status paradigm through more than 40 years of empirical research on Erikson's theory of identity development. In agreement with Erikson's postulate, Marcia (1980) recognizes that the formation of identity is defined according to two dimensions: exploration and commitment. Exploration refers to the degree to which individuals actively examine values, beliefs, and goals, and experiments with different social roles, plans, and ideologies. Commitment refers to establishing dedication to a set of convictions, goals and values.

In Marcia's $(1966,1976,1980)$ framework about the identity status, the various routes for students to select a self-chosen identity (including the professional-occupational identity) are defined by four identity statuses. These types of identity statuses provide a theoretical 
foundation to comprehend how students assess themselves regarding their identity status. It shows how students evaluate their level of commitment and exploration invested in their overall activities to find an achieved vocational identity.

Diagram 2.1The four types of vocational identity status.

\begin{tabular}{|l|c|c|}
\hline \multicolumn{1}{|c|}{ Identity status } & $\begin{array}{c}\text { High level of exploration in } \\
\text { searching }\end{array}$ & $\begin{array}{c}\text { Low level of exploration in } \\
\text { searching }\end{array}$ \\
\hline High level of Commitment & Achievement & Foreclosure \\
\hline Low level of Commitment & Moratorium & Diffusion \\
\hline
\end{tabular}

Identity Diffusion - is the status where the student does not have an impression of having choices: he or she has not yet made a commitment. The adolescent has not discovered or chosen his or her occupational identity.

Identity Foreclosure - is the status, the adolescent seems willing to commit to some relevant roles, values, or goals for the future. Adolescents in this stage have not encountered an identity crisis. They tend to conform to the expectations of others regarding their future. These adolescents have not explored or discovered a variety of options. They seem to be pretty well decided on a career because of external sources (i.e. parents).

Identity Moratorium - is this status, the adolescent is currently in a crisis of insecurity, exploring various activities and is ready to make choices, but without a commitment. The adolescent is in the middle of exploration.

Identity Achievement - in this status, the adolescent has gone through an identity crisis, and has made a commitment to a sense of identity (i.e. certain role or value) that he or she has chosen. The adolescent has made a commitment to a specific decision after a wise exploration.

Adolescents may not go through the identity status in an orderly manner; it depends on life events which could drastically move adolescents from one status to other. According to Waterman and Archer (1990) an achieved identity could also move to moratorium status. 
Schmitt-Rodermund and Vondracek (1999) agree that a "person might be forced to revaluate previous decisions, if they experience a loss of an employment or relative" (p. 299). Within career development, Marcia's (2003) commentary about personal persistence, identity development and suicide, emphasizes the relationship between cognitive development and identity development. He said: "if we expect to be able to intervene effectively, whether on an individual or social basis, we must know about those underlying processes, both what enhances them and what derails them" (p. 137). For Marcia (2003) "an advanced identity formation is associated with advanced reasoning ability" (p. 133). Marcia (2003) strongly encourages counselors to assist youths in the development of a healthy identity by advising them to achieve a sense of self-continuity and self- persistence.

Looking at the big picture regarding the identity formation during adolescence, the role of exploration activities possesses a crucial function in the process of self-knowledge. Emphasizing the exploration process as an important activity for identity (Grotevant \& Cooper 1986), Grotevant (1987) sheds light on the importance of crucial tasks e.g. problem-solving and decision- making. Grotevant (1987) conceives vocational exploration as "problem-solving behavior aimed at eliciting information about oneself or one's environment in order to make a decision about an important life choice" (p. 204). He elucidates the role of effective outcomes (e.g. the feeling of positive results and satisfaction experienced with success) and cognitive outcomes (e.g. constructive information that form a better sense of identity) by the engagement of identity explorations activities. Jordan (1963) describes the vocational exploration as "the process of clarifying the self-concept and translating it into occupational terms, of acquiring the understanding of occupations necessary for this translation, and of trying out this vocational self-concept in vocationally relevant activities" (p. 54).

Authors such as Fend (1991, 1997), Chickering and Reisser (1993), Pascarella and Terenzini (2005), Garbrecht (2006), all agree in the close relationship between students' identity development, vocational development and the influence of college (schools) during adolescence. In line with the identity and vocation development, vocation plays the role of an intrinsic calling.

In summary, adolescence is a crucial and critical period which is characterized by constant strife and identity crisis that is then necessary to be resolved by the adolescent. For this 
particular reason, it is necessary for career advisement and counseling services at college and universities to identify students' personal and professional interest and motivation prior to study abroad participation, and to distinguish, whether the career decisions made by students are based on their personal interest and vocational aspirations or whether they are made to compensate for personal or career related experienced failures.

\subsubsection{Developmental tasks and coping strategies}

The psychological aspects of life's decision making process during adolescence should be given considerable attention. Viewed from a psychoanalytical point of view, Blos (1989) sees adolescence as a period of growth. During the two first decades of adolescence, he finds an especially progressive differentiation and integration of the personality. The psychological development flows, according to Fend (1994), not only into daily coping strategies but also into fundamental life decisions. These decisions are mostly directed toward life planning and future expectations for vocational choice which also shape their personality. By the formation of the personality, Fend (1994) has observed that there are some idealistic thoughts, either in form of fantasies or in form of desired characteristics and realities that increase to a large extent. Those trials of idealistic beliefs are legitimate and, for the students, they represent other ways to learn about themselves and their future vocational identity. Personal trials (e.g. experimentations) in relations to career might also occur in study abroad experiences. For example, adolescents are constantly assessing themselves, in particular with what they believe is valuable for their own success. Some questions abroad could be: Who am I? How do others perceive me as a person? How do I visualize myself professionally? These questions and others lead the students to vocational identity development. In order to answer these questions, the adolescents need to encounter relevant tasks that lead to an increase of self-efficacy and accomplishments.

The theoretical basis of developmental tasks by adolescents in studies carried out by Dreher and Dreher (1985), Dreher (1985), and Dreher and Oerter (1985) point strongly to the valuable works of Havighurst.

Havighurst (1972), a well-acknowledged American developmental psychologist, defines a developmental task as "a task which arises at or about a certain period in the life of the individual, successful achievement of which leads to his happiness and to success with 
later tasks, while failures lead to unhappiness [...] and difficulty with later tasks" (p. 2). Havighurst (1972) leans, as well, on Erikson's psychological understanding of identity achievement, and postulates eight fundamental tasks of development for adolescence:

\section{Achieving new and more mature relations with age-mates of both sexes}

\section{Achieving a masculine or feminine social role}

\section{Accepting one's physique and using the body effectively}

\section{Achieving emotional independence from parents and others}

This fourth task is crucial within the vocational identity development and achievement. Havighurst (1972) expresses that the school is not primarily responsible for this task, but "school and college can do some things to raise the level of accomplishment" (p. 58). In reference to this educational implication, study abroad programs could provide the level of accomplishment in achieving a certain emotional independence, which is fundamental within the vocational and personal identity development.

\section{Preparing for marriage and family life}

While students are far away from home and family, they develop a greater sense of independence and self-confidence that provides them social maturity, and also prepares them to enter into marriage and family life. This task is highly valued, in particular by students with a Hispanic background who seem to have a strong family bond. Sullivan (2002) agrees that the concept "Hispanic" involves a group people from different cultures, from Hispanic speaking countries (e.g. Mexico, Cuba, Venezuela, Central and South America etc). Especially for students, with a Hispanic heritage culture, the family, as Craig, Contreras and Peterson (2000) expressed, "is the most valued institution" (p. 26).

\section{Preparing for economic career}

This is the main task of students' lifespan project on which this research study is based, and whereas the vocational choice and identity development also plays an essential role in adolescents' need for self-esteem satisfactions. In accordance with this idea, Havighurst (1972) expressed that somehow living away from home will support students' 
independence. As proof, he refers to an alternative activity which means "depart from parental home, with or without money ... and live independently for a time" (p. 63).

7. Acquiring a set of values and an ethical system as a guide to behavior-developing an ideology.

8. Desiring and achieving socially responsible behavior (Havighurst 1972, pp. 43-82).

Those developmental tasks are being used, similarly regarded and formulated also by other authors such as Dreher and Dreher (1985), Dreher (1985) and Dreher and Oerter (1985). Supported by their own investigation findings, they added further developmental tasks based on the students' points of view:

9. Incorporation into intimate relations with the partners (boyfriend or girlfriend).

10. Gaining self-knowledge, how they see themselves.

This task is also highly regarded by Erikson $(1968,1974)$ as central topic of adolescence (identity versus diffusion role).

11. Development of future perspectives (Dreher \& Dreher 1985, p. 36).

This developmental task refers to personal life-planning and setting goals.

Generally, human development is mainly dependent on decision-making process. Each life decision is basically oriented toward one's personality development and vocational identity formation. Coping strategies play a central role in adolescent development and problem solving particularly when contemplating career choice and vocational aspirations. These strategies could appear as a form of dealing with problems or coping with problems (Oerter 1985; Oerter \& Montada 1987), as defense mechanism (Caplan, Naidu \& Tripathi 1984) or as a form of task management (Oerter \& Montada 1987).

As indicated by Oerter (1987), one might only lean on a further developmental task, if some coping probabilities are present, or could be constructed. He had specified four coping groups: skills, competencies, mastering process forms, and the coping and defense strategies (pp. 125-126). Some of these coping strategies (e.g. problem solving skills, selfefficiency) have also been assessed in this research study through a quantitative instrument, the "Frankfurter Self-Concept Scale" (Deusinger 1986). 
Olbrich (1985) recognizes that coping is a constructive process of adjustment. Therefore, students might use these coping strategies to construct their own vocational identity. It is necessary to understand the coping process as a dynamic and coordinated activity which, in its development, is composed, by a large extent of cognitive information process (Olbrich 1985). In line with the identity formation process, it has been found that the "Iprocess" (Hann 1977) and the identity process regularization (Haußer 1995) refer to Piaget's theories regarding cognitive development, namely the processes of assimilation and accommodation which are crucial pillars of developmental tasks. These two processes might serve as a substantial basis for the organization of coping strategies within the decision-making process, especially regarding the vocational career or occupation choice. Piaget (1973) believes in a developmental adaptation process of functional interaction between the person and its milieu which he calls equilibrium. "The organism constantly assimilates the milieu to its structure while, simultaneously, accommodates the structure to its milieu; the adaptation can be defined as equilibrium between such changes." (p. 166)

Hereby, the meaning of assimilation seems to appear as a process of acquiring and integrating experiences from the environment (e.g. abroad environment) in relation to the already developed structures in the individual. For Piaget (1973) there are three general forms of assimilation: "1) functional or reproductive assimilation, consisting of repeating an action and of consolidating it by its repetition; 2) recognitive assimilation, consisting of discriminating the assimilable objects in a given scheme; 3) generalizing assimilation, consisting of extending the field of this scheme" (p. 70).

These mental processes outlined, from a developmental psychology point of view, represent constructive forms of human cognitive understanding and adaptation. In the framework of study abroad experience, students are coping, not only with the new cultural environmental issues, but also with their own personal and vocational issues (career ability and skills) that include an assimilation and accommodation process of the new information.

First, the students need to assimilate new knowledge from their daily experience abroad while interacting with others, e.g. what kind of person they are and what their career skills and abilities are. Second, they have to accommodate the new knowledge into their personal identity and vocational interest. On a par with Piaget's theory, McInerney and McInerney (2006) interpreted that the combination of both process might lead to an 
achieved equilibrium. This is especially true if students are out of their own cultural and safe environment, such as it is when they study abroad; they experience an evaluation of self-perception on issues of vocational interest through others, which helps them to form a new knowledge about themselves.

\subsubsection{The self-concept, self-esteem and vocational exploration}

Relevant research studies have revealed substantial evidence with regards to the valuable benefit of self-esteem (affective element) for a healthy student's personality and academic achievement (Krause 1990; Krause, Hannich, Stückle, Widmer, Rohde \& Wiesmann 2000; Krause, Wiesmann \& Hannich 2004). Furthermore, its relationship within the identity development has been very well documented (e.g. Fend 1991, 1994; Craig, Contreras \& Peterson 2000; Soenens et al. 2005).

Self-esteem, according to Schwalbe (1985) and Krause et al. (2004), is the emotional assessment of the "Self". It results from self-evaluation processes based on meaningful information about the self. The information resulting from an emotional evaluation plays an important role in the formation of a personal identity, especially, if the resulting information reveals positive feedback on the person's abilities and skills.

Self-concept and self-esteem have been identified as main influences within the personal career development (e.g. Schwalbe 1985; Owens, Mortimer \& Finch 1996; Craig, Contreras \& Peterson 2000). These two self-assessments are also closely related to social and academic achievement and integration (Pascarella \& Terenzini 2005). Huitt (2004) assumes that there are several components of self-concept, which play a relevant dynamic in the appreciation of personal identity: a) the physical self-concept, which relates to one's body and b) the academic self-concept which relates to students success at school and learning outcomes. He describes two different levels: the general academic self-concept (how effective we are overall) and the specific content-related self-concept (how our efficiencies are in math, sciences, languages, arts and social sciences). The social selfconcept describes the person in relation to other people (family, peers, classmates, etc).

A high level of self-esteem might predict an acceptable self-defense mechanism for a sense of well-being by the person. Cast and Burke (2002) consider a higher level of self- 
esteem as a positive defense mechanism, when the self-verification process is disrupted. Students are always in the search of a balanced and well satisfied self-concept and happiness. The real activities that can promote a positive and balanced self-esteem are those that students like and enjoy doing, and furthermore, those activities from which they gain a well sense of achievement. Activities that provide students with high doses of selfvalue will generate engagement in further career exploration activities.

Havighurst and Taba (1956) espouse building an ideal self. The ideal self "is especially important in directing behavior and shaping character during the years of adolescence when major life decisions are made" (Havighurst \& Taba 1956, p. 70), such as career and vocational choice. How students visualize themselves occupationally through an idealself, and how they set their career values and goals, might predict their vocational identity development path and success of achievement.

The term self-concept embraces all characteristics of the self from both internal and external perspectives. As a common denominator among researchers, the self-concept has been found to be a consequential product of cognitive representation activity. Because the self-concept is a process of cognitive dynamics, people, by interaction with others, acquire new forms and values about themselves. Those assessments, related to their person become positive or negative stimuli when they are applied to their own self-image. The emotional assessment views of their own self are called self-esteem, self-attention, and self-confidence (e.g. Krause et al. 2004). Hereby, Krause et.al have introduced an important and comprehensive definition which is the self-picture or self-image. This denotes the sum of all cognitive and emotional valued aspects of self.

The cognitive representations, namely the students' perceptions toward their ability or their emotional self-evaluative aspects regarding career aspiration, are a special part of their personal development, achievement and well-being. Within career development theories, researchers suggest that self-concept development starts with self-awareness. Brown (2003) states: "The self concept development is a continuing, lifelong process that begins with the individual's first awareness of self as a person" (p. 342).

Tomas and Oliver (2004) support their study about the assessment of self-concept on classics and relevant theories of Rosenberg (1979): "Self-concept can be defined as the perceptions that an individual has about himself; or the totality of thoughts and feelings of 
the individual that refer to himself" (p. 285). One may also perceive the self-concept as self-knowledge.

Self-concept (self-knowledge) is a very important component occupying a central component in vocational and occupational development. If a self-knowledge process by adolescents is more active and conscious, then, their interests, desires and abilities become more visible, in order for them to decide on a corresponding career (occupation) that satisfactorily reassembles their sense of personal identity development.

Even though the concept of identity and self-concept are being used in the same meaning frame, they are different. Nunner-Winkler (1988) identified four differences and similarities that have also served as the theoretical framework of this research study.

First, Nunner-Winkler (1988) defines self-concept through consciousness ability and cognitive representations. The identity is not limited to conscious portions, but the author leans against Erikson's view and understands it as lifelong development, which runs unconsciously.

Second, the self-concept is believed to be a construct of internal perspective; in contrast, the identity is considered to be a construct of both, as a form of internal and external perspective.

Third, the self-concept is deemed to be a descriptive term, namely the cognitions, which persons have about themselves. In contrast, the identity is a complex construct, from which developmental theories have regarded, first: as a process of task maintenance of one's own abilities by the uniformity and continuity (vocational), and second, from a sociological view (occupational), as a task for the maintaining of continuity and consistency.

Fourth, the self-concept is regarded as a universal unhistorical (non historical) variable, which remains the same in all cultures. In contrast, the identity formation has been historically considered and discussed (e.g. modernization, differentiation or pluralism of the society) (p. 248).

The majority of the literature regarding identity development assumptions express that a communal conception has been found and it describes identity formation as a signal of 
identification of self (Reese-Schaefer 1999) or identity as an understanding of one's self (Furrow \& Wagener 2003). While Haußer (1995) sees the identity development within a process of differentiation and distinction, Cast and Burke (2002) conceive the identity formation within a process of verification, "a set of meanings that represent the understanding, feelings, and expectations that are applied to the self as an occupant of a social position. The process of self-verification is not [only] a function of one's activity but also...in relations to other's activities" (pp. 1044-1044).

In accordance with various meanings and concepts regarding the identity, vocational identity is potentially increased by two different processes: self-exploration (through diverse challenge environments) and self-knowledge (through process of verifications and differentiations).

\subsubsection{Summary}

The identity formation is simply a life-long process, nevertheless, receives a considerable emphasis during adolescence, in particular during the ages of 19 to 24 . Attributed to this important stage, there are a wide variety of psycho-dynamic and psychosocial changes that somehow contribute to the formation of identity, e.g. personal and vocational identity. It is a period where crucial life-decisions and self-exploration activities are highly accented and which ultimately shape one's identity. In addition to this, affective and cognitive outcomes resulting from the exploratory identity process may lead to a current sense of identity and positive effects of satisfaction experienced with success. Hereby, fundamental tasks (problem solving and decision making) for development are faced by adolescents, e.g. preparing for a professional or occupational career. Even more significant during the exploratory phase for the formation of vocational identity is the fundamental task of problem-solving process which includes identity exploratory elements such as experimentation, investigation, trial, search or hypothesis-testing (Jordan 1963, p. 54).

One of young adults' most important life-tasks during adolescence is defining one's identity and the choice of a vocation. These distinct tasks merge personal and professional paths that later develop one's vocational identity, which is formed or shaped through constant social interactions, differentiations and clarifications of vocational roles. 
Considering the important role of self-esteem and the self in the vocational development, further theories are indispensables to understand students' vocational choice and motivation. The theories of career development, such as the person-environment fit theories, help counselors and advisors to understand socio-cognitive aspects of students' vocational development.

\subsection{Career development theories and vocational identity formation}

As discussed in the previous section, the formation of identity and vocation are relevant tasks that develop throughout one's life. These life tasks include one's career plan, including the choice of a college major, which represents one of the stepping stones to one's occupational or professional activity. Career developmental theories identify the relevant role of a good sense of self-efficacy within a career plan.

Discussed in the following section will be the theoretical concepts of vocation within career development, as well as the significance of three major career development theories as fundamental and theoretical foundations of this study regarding personal and vocational identity development.

Primarily presented will be the theoretical and practical implications of the vocational personality and work environment structure developed by Holland $(1985,1991)$, which are the most noteworthy to analyze vocational-person development, moreover the relationship between the career choice and the grade of congruency and consistency in students vocational career. Also, discussed will be the theoretical foundations of Super for a better understanding of vocational development, in particular the strong relationship between the vocational choice and the self-perception. The third theoretical focus of this research study is the socio-cognitive theory of Bandura (1986) regarding the sense of self-efficacy, and its theoretical application within career development from Lent, Brown and Hackett (1994). This theory concentrates on students' career expectations and goals as part of vocational development. 


\subsubsection{Vocational choice and identity formation by John Holland}

A well-known and highly recognized model of interest structure is Holland's (1985), RIASEC model. His theory of vocational personalities and work environments transforms the comprehension of career development across cultures (e.g. Van-Dijk \& Kluger 2004; Ashton \& Lee 2008) and vocational interest assessments in higher education (e.g. Gottfredson 1999; Hogan \& Blake 1999; Darcy \& Tracy 2007; Duffy \& Sedlacek 2007).

According to Holland's (1985) theoretical understanding, people search for environments and vocations that permit them to satisfy and express their personalities according to their selected major (i.e. career). In line with the identity formation and vocational development, the career college choice might represent the student's personality type and vocational interest (e.g. Holland 1985, 1991), nevertheless not limited to further engagement in exploratory activities to define their personal identity and occupational role (Super 1957; Jordan 1963; Grotevant 1987).

Even though students have diverse motives to study abroad, they have personal commitments toward vocational exploratory activities that are (sometimes without being identified) still occurring as they pursue career vocational interests.

Holland's $(1985,1991)$ primary factors within vocational choice development are an individual's personality traits and interests. The personality will develop in the interaction between the hereditary characteristics, the activities to which the students are exposed, and the interests and competencies that grow out of these activities. With that said, it is assumed that the formation of the personality and the identity will definitely take place within students' interactions, e.g. with their environment abroad. Holland's (1985) personality inventories, e.g. the Self-Directed-Search (1994), certainly give researchers a guideline of personality types of students' vocational interests.

Relevant to Holland's vocational choice theory is that the students' identities are implicit in their vocational goals (Brown 2003). The students will select a vocational goal according to their own perceptions concerning (current) personal characteristics and goals. Especially during the adolescence, the task that students face is preparing for a professional career, specifically selecting a career (major) based on limited opportunities regarding career-related exploration, and on erroneous ideas or assumptions about themselves and the chosen career (major). 
Holland's (1985) theory holds that individuals and occupational environments can be characterized using six types of personality and interest environments (i.e. Realistic, Investigative, Artistic, Social, Enterprising and Conventional).

Realistic: students in this category are less subjective; they deal with the environment in an objective manner. They are more interested in outdoor activities, and show interest in technical, skilled trade, and engineering vocation.

Investigative: students in this category demonstrate a high interest in intellectual work activities. They prefer scientific vocation, and theoretical tasks, reading, collecting, foreign languages, etc.

Artistic: students with this type of personalities present interest in musical, dramatic, or other creative expressions.

Social: These types of personalities deal with their environments by using skills to interact with and relate to others.

Enterprising: These personalities' types cope with environments where they can experience adventure, dominance, enthusiasm (promotion, leadership, recognition and power).

Conventional: These personalities deal with environments where they can carry social approval (having to do with clerical, routine oriented and highly structured work environments).

According to Holland (1985), a person could be classified into those categories, for example, by expressing or demonstrating vocational interest, by employment or by points obtained on instruments such as: Vocational Preference Inventory (VPI), the Strong Interest Inventory, or Self-directed-Search (SDS). The Self-Directed-Search (1994) $4^{\text {th }}$ edition was developed by Holland, which represents an excellent psychological selfassessment resource.

The theoretical relationships between the types of environments have been found to be well represented by a hexagon. He recognizes that all six types (RIASEC) express a type of personality, and that the top three letters, ranked by the individual, are the most revealing factors. Holland's (1985) model presents theoretical propositions, e.g. existing 
of distinct types, specified typology ordering, implications of code constancy or inconsistency, and the person-environment congruency. His theory manifests that individuals organize their thinking in a similar way. While consistency is defined as the proximity of the two dominant types of personality and environment, congruency is the matching degree between the personality types with the type of environment (Gati \& Meir 1982). If there is congruence by matching the person-environment, the result of a vocational choice leads to a career stability, greater vocational success, better academic performance, stability, and greater overall satisfaction (Brown 2003). According to Holland's (1985) theory, the formation of identity results from the consistency and differentiation process. might be considered in the clearness and transparency of personal goals and self-perceptions. In addition to the process of consistency and differentiation within the framework of identity formation from Holland (1985), Super (1942) speaks about strategies for vocational adjustments. According to Super (1942), students achieve a greater sense of vocational adjustments by experiencing avocational activities. These vocational processes from Holland $(1985,1991)$ and Super $(1942,1957)$ are closely related to the formation of vocational identity.

As it has been previously presented, adolescence is the crucial life-stage of developmental task adjustments, especially in the career preparation process. Skorikov (2007) recognizes the insufficient attention dedicated to career preparation during adolescence. The vocational choice and identity are two processes that develop simultaneously, in particular to one's occupational future perspectives (e.g. Fend 1991). As Chickering and Reisser (1993) have stated: " we discover our vocation by discovering what we love to do, what energizes and fulfills us, what uses our talents and challenges us to develop new ones, and what actualizes our potentials for excellence" (p. 212).

The idea of "discovering" defined by Chickering and Reisser (1993), ensembles the relevance of the self-exploration activities within the self-knowledge construction and the vocational identity within students' career development.

The vocational identity development starts with one's occupational and professional choices. The vocational choice, according to Marin Benet (1998), is supposed to encounter a confident equilibrium between what the students possess internally (related to unconscious motivation) and externally (related to what one says one wants to do). In reference to the vocational choice process, goals and motivation are important and 
innovative constructs within the career decision-making and planning process (Dik, Sargent \& Steger 2008), and the career development research and practice (Flores 2008).

With a systematic point of view, Holland $(1985,1991)$ speaks about the choice of an occupation, in terms of vocational environments; whereas, the vocational environments have been designed by the similar personality characteristics. This study considers the vocational identity development from the point of view of the person, therefore the terminus vocational choice is preferred to be used instead of vocational career (Brown 2003).

One of the major contributors to vocational behavior is Crites (1969). He defines vocational psychology as "the study of vocational behavior and development" (p. 16), defining vocational behavior as "all responses the individual makes in choosing and adjusting to an occupation" (p. 16). Hereby, vocational behaviors develop and apply to students abroad in terms of their chosen careers (majors). The relationship of career development, vocation, and the identity formation has served as an inspiration for further research during adolescence (Wallace-Broscious, Serafica \& Osipow 1994). These researchers found that that there is a close relationship between the identity achievement status and the level of career decidedness and planning in ninth and twelfth graders. They also believe that with a matured identity achievement students are more likely to express their occupational choices and make concrete plans to achieve short or long-term goals (Wallace-Broscious et al. 1994, p. 143).

In relationship to the vocational choice and identity, Holland's theories are defining the influence of environmental aspects into the students' vocational behavior development; he speaks more about identity environments (Holland 1985, 1991). On the other hand Super's theories (1957, 1963b), understand the vocational choice and adjustments as expressions of self, namely through self-evaluation of learning experiences. This will be discussed in the next section.

\subsubsection{Vocational development and the role of Self-concept}

The link between self-concept and career choice is an essential ingredient within vocational identity development. This concerns the extent to which one integrates life's 
events, roles (personal and career identity) and environmental setting into one's own vocational development. The career development, as definition, was first proposed by Gysbers and Moore in 1973, and with it, they defined it as "self-development over the lifespan through the interaction and integration of the roles, setting, and events of a person's life" (Gysbers, Heppner \& Johnston 2003, p. 8). One's vocational development is a main human developmental task. Vladimir (2006) criticizes that, although choosing a career is considered a major developmental task, there is still less emphasis on empirical research. He suggests that vocational development is a lifelong process, and it should result in the individual's well being, social integration and achieving vocational satisfactions.

Even though work is considered an instrumental activity, it represents a central focus in one's life, revealing itself, through people's individuality (e.g. Super 1957). It does not always represent a complete people's personality, but partially. Work is also an activity that sometimes results from socio-economic circumstances; sometimes, individuals must perform and preserve. The work is specifically an enterprise that is believed to provide one with feelings of competences, value, contribution, belonging, independence, autonomy, and the development of self-esteem (Brown 2003, pp. 8-10). However, beyond the simple work performance, one's life goal is an attempt to get and achieve a real satisfaction of a one's vocational (future occupational) choice.

The other side of this vocational commitment is not always what students vocationally will fulfill; rather it is, sometimes, a product or result of socio-academic forces. Supers' (1957, 1963a, 1963b) theoretical conception postulate that vocational behavior is a developmental process where the person attempts to apply the self-concept by choosing an occupation that most likely will permit that person to express him or herself. Super (1957) also believes in vocational maturity. This maturity starts with the acknowledgment of one's occupational role in life. After gaining available knowledge regarding this career, which at times may be limited, the student begins looking for a vocational choice which would be, in most of the cases, established by the academic system of each university. Vocational choice, such as academic courses towards a degree plan of a career major, is the first step of vocational development and maturity.

Specifically, with the successful accomplishment of each vocational task, individuals are progressing positively in their career, as well as more clearly defining their vocational 
self-concept. It seems to be that vocational identity development and maturity is developed during a lifelong process. Super (1957) originally defined vocational maturity as "the place reached on the continuum of vocational development from exploration to decline" (p. 186). In essence, career maturity is one's readiness in terms of career development, depending on one's life stage. Therefore, the college years are highly relevant, if one considers the importance of the role of exploration and preparation for goal specifying for vocational counseling (Super 1965, pp. 127-128), and in particular for the vocational identity directness.

Super (1957) theorized vocational maturity occurs in two processes: exploration and establishment. The two processes are comprised of five dimensions: orientation to vocational choice, information and planning about preferred occupation, consistency of vocational preferences, crystallization of personality, and wisdom of vocational preferences. During adolescence, namely college years, students are immersed in their career exploration process, pursuing a long lasting career choice. Students should never be limited to adequate vocational career exploration activities, in particular while studying abroad.

Super (1965) believes that an accomplished vocational self-concept is attributed to the level of exploration. Behavior exploratory leaning activities predict a probable definition of current vocational and the visualized vocational self-concept and a congruent vocational career choice. Super (1965) defines exploratory behavior as "its best involves, asking, selfrelevant questions about something while trying it, evaluating the outcomes of trial, and basing subsequent decisions on this and other evaluations" (p. 129). Within the theories of career development, one might compare exploratory performance to a process of selfknowledge through trials and outcomes.

As presented, self-concept and vocational identity appear linked explicitly or implicitly in the history of vocational psychology and in several of the modern theories of vocational interest and choice. Inspired by the sociological perspectives of work and career development, Krumboltz, Mitchell and Gelatt (1975) developed the social learning theory which focuses on the ways people learn and make career decisions. He defines four types of factors that might influence career decision: Genetic endowment and special abilities, environmental conditions and events, learning experiences and task approach skills (Krumboltz et al. 1975; in Zunker 2003, pp. 58-59). The factor that is expected to 
influence students' career and vocational identity is the learning experience because it is being qualitatively (through students self-perception outcomes) analyzed.

Under this lens, it will be understood, how students perceive their learning experience, by studying abroad, and how this experience influences their educational and career decision making. For a better understanding of personal behavior and its effect on self-regulatory activities (such as study abroad), we must consider the socio-cognitive theories.

\subsubsection{Socio-cognitive career theories and the role of self-efficacy}

The following section will highlight the importance of Bandura's (2001) socio-cognitive theoretical (SCT) understanding, and the socio-cognitive career theories (SCCT) on personal development.

In order for students to be able to define their identity and its vocation, they must face difficult tasks which require, but are not limited to a high level of exploration commitments. Students, during their vocational self-definition, need to fulfill first developmental goals that maintain and guide them into desired vocational and professional goals. Students' change in terms of career development while studying abroad. The sociocognitive career theories (SCCT) from Bandura (1986) and Lent, Brown and Hackett (1994) is a suitable theory, using the role of self-efficacy, as well as outcome expectations and personal goals as a sustainable guideline to keep motivation within vocational behavior.

The SCCT theories are accurate theoretical foundations to understand self-regulatory activities. Study abroad programs are an international experiential learning, where the students' self-perception develops new structures and knowledge in regards to their personal agency. The socio-cognitive theory of Bandura $(1977,2001)$ provides the personal agents that maintain students' behavior, especially in terms of vocation. He postulated that personal agency and social structure operate inter-dependably (Para. 29).

His theory provides an appropriate understanding, not only regarding career development, but the theoretical foundation to identify the personal agency elements such as self- 
efficacy, personal goals and outcomes expectation that lead the students into changes within a cultural context.

According to Gysbers, Heppner and Johnston (2003), this theory is relatively new within the career behavior development. In comparison to the foundation of the theories of Holland and Super, this socio-cognitive theory focuses on the formation of career meanings that students deposit in events (such as going abroad) related to the career decision-making process (p. 36). This SCCT conceptualization gives this researcher the theoretical understanding to analyze how students' career developmental tasks explain their vocational behavior.

The awareness of competency (such as belief in one's self) and self efficacy experience, according to Bandura's (1986) theoretical understanding, is a motivational factor for adolescents. Bandura's (1977, 1997, 2001) position regarding self-efficacy declares that one's self-efficacy is one of the best predictors of successful achievement and vocational behavior. He also states that one's mastering experiences related to success is the major influence on one's self-efficacy. Due to the fewer opportunities that classroom control and dynamic leave for students' decision making, choice and self-management, study abroad programs present, in this study, an alternative that engages students in a immediate aperture for self-management and career decisions. Bandura's (1977) theory provides a fundamental base to understand students' capability in vocational behavior. In addition, Gysbers et al. (2003) postulate that self-efficacy and outcomes expectation predict career interest (p. 36). With that said, the beliefs in one's self regarding ones' abilities and probable positive outcomes lead the students to a better sense of self-management and independence, as well as to a satisfactory vocational identity.

Self-efficacy beliefs experiences could be mastered and learned while abroad, because the students are alone and unaided, in an unfamiliar environment. The effects of long-term programs have been found to be positive (e.g. Dwyer, 2004; Thomas 2006). Some of the findings in this study will represent these aforementioned mastery experiences. Here, it is important to underline the role of coping strategies such as problem solving, sense of success, independence, autonomies and self-efficacy. Along with these feelings of success and efficacy likely developed abroad, the career explorations activities function as a motivational element. 
Studies underline the relevance of the explorations activities within the identity formation (Grotevant \& Cooper 1986; Schmitt-Rodermund \& Vondracek 1999). According to these investigations findings, impacts of explorations activities on identity achievement have been reported (Schmitt-Rodermund \& Vondracek 1999). Their study results determine the exploration activities as a strong precursor for identity achievement development. In conjunction with Bluestein's (1989) conceptualization, Schmitt-Rodermund and Vondracek (1999) perceived that exploration is a process that is motivated inside the students' minds (intrinsically). Exploration, as has been previously shown, plays a central role in students' career and vocational development. This study also pointed out the function that self-efficacy has within career exploration. There are some assumptions from Grotevant (1987) and Schmitt-Rodermund and Vondracek (1999) that individuals with more confidence in their own abilities are inclined to engage in more career exploration. It seems to be that self-confidence might have an important contribution into students' vocational career development.

This could be similar to the theory of career exploration by Lent et al. (1994). According to these researchers, students develop a perception of self-efficacy based on diverse activities that reinforce their abilities (e.g. study abroad and interacting with international students). These activities, as per Schmitt-Rodermund and Vondracek (1999), are learned "based on their history of observational learning, as well as engagement in a variety of activities in which they receive reinforcement from others" (p. 300). Hereby, the reinforcement of others (especially interacting in an international setting and with international students) comes into play in student's self-perception which plays an essential role in their career exploration sense whereas they gain an affirmative selfefficacy. Thus, in addition to the self-efficacy factor, Lent et al. (1994) see two other factors that support the career exploration process, and sustain vocational behavior, namely the outcome expectation and personal goals.

The outcome expectations in life planning activities such as career choice development are highly regarded within the socio-cognitive career theories (Lent, Brown \& Hackett 1994). As an important fact of cognitive perspective, the outcome expectation also serves to develop motivational interest. This type of motivation is essential here. As for McInerney and McInerney (2006), with respect to cognitive perspective understanding, point out the importance of intrinsic motivation. In the framework of study abroad experience, students 
are somehow intrinsically motivated, and this is manifested through personal goals. The intrinsic motivation, according to McInerney and McInerney's (2006) understandings, this could be defined as a "motive that keeps an individual at a task" (p. 208), going abroad to discover and learning about other cultures, are major indicators of the students' intrinsic motivation.

The value of setting goals in one's career planning embrace a broad set of socio-cultural factors that at the same time regulate one's motivational behavior and the subsequent subgoals (Brickman \& Miller 2001). Additionally, these authors underline the importance of a well attained knowledge of one's abilities by the accomplishments of future goals. They express that "further experience and more elaborate knowledge help to further define what future goals are possible for the self to accomplish and the proximal subgoals and immediate goals that are necessary to accomplish more distant future goals" (Brickman \& Miller p. 120). The knowledge that students gain through their study abroad experience, supports the student's future personal career goals, and esteems their possible accomplishment. The role of a self-concept of ability (Brickman \& Miller 2001) or selfefficacy (Bandura 1997) plays a central role in students' career goals.

\subsubsection{Summary}

In Summary, the social cognitive elements (perceived self-efficacy, personal goal and outcomes satisfactions) within students' career development are evident. They are also factors (e.g. career path definition, high concentration in one self, increasing a sense of self-efficacy, acceleration of one's reflection of future goals) that contribute to, and mediate vocational identity development, especially while students are in a foreign sociocultural environment.

This literature provides researchers with a fundamental theoretical base that students, within their career and vocational developmental process, tend to search for environments, activities and roles, which make them, feel a greater coherence, and congruent sense of personal satisfaction in terms of professional abilities and skills. After this literature review, we may conclude that the meaning of vocational identity is beyond a simple career choice and occupation, and it is much more than aptitudes and interest in their chosen career. The vocational choice, in this case, is to achieve a well assured self-identification 
with the career, occupation or profession that the students feel, that they not only are identified with, but at the same time are content and comfortable to perform for a long period of time.

\subsection{Study abroad programs in the United States}

In order to see the objectives, goals and effects of study abroad programs, it is necessary to comprehend what universities and colleges' offer for students during their career development to achieve international standards and global awareness.

The following Chapter will address the relevant relationship between the trends and demands of the $21^{\text {st }}$ Century, on student's career development, and furthermore the function of study abroad programs in the student's career and vocational developmental process. There will also be examples of the implementations of study abroad programs into college and universities.

\subsubsection{Promotion of study abroad programs in the US academic institutions}

With the emergence of globalization in the $21^{\text {st }}$ century highlighting a global society, many international educators and business people are awakening to the growing need to better equip students with an international perspective and global understanding (NAFSA 2008; Gardner \& Witherell 2008). Dervarics (2008), in conjunction with the Open Doors report (2007), attributes the increasing numbers of students studying abroad to the improvement of marketing at minority-serving institutions.

There are colleges and universities that have to deal with global forces, which challenge them, and at the same time they must create new reforms towards global integrated programs which could fit into their global movement of market and labor (Bloom 2005). Globalization represents a need for higher education, and a type of challenge for the colleges and their communities (Bloom 2005; Scott 2005; Egron-Polak 2005; Leliūgienè \& Baršauskienè 2007; Brustein 2007). Bridges and McLaughlin (2007) argue that, with the globalization, a new era of social transformation and new identity formations have been generated; such as "the identity of discipline or subject and of the student with such a subject or discipline" (p. 5). 
Study abroad programs have been promoted and developed world wide, especially in the US College and university systems. Even though only $10 \%$ of 4 year colleges require international courses, there are still a plenty of universities that are responding satisfactorily by increasing the number of study abroad or exchange programs, and this is due to the perceived global need as well as the academic, cultural, personal and professional benefits for students. Based on the impressive numbers of students studying abroad, "study abroad" has become an innovation at universities in the US (Spiering \& Erickson 2006). Still with the exceptional total of participating students studying abroad, there are more that choose not to go. Among students' reasons (for not participating in study abroad) are mainly lack of financial aid opportunities and appropriate (sometimes limited) study abroad program information; furthermore, they hesitate participating because of personal fears of unknown places and a high sense of interdependence and comfort within the family.

Current data proves that more and more college and universities are looking at study abroad in new ways, such as positive strategic aspects for international education, global awareness and, furthermore, as an optimal option to acquire appropriate skills for the economy (national safety purposes) and the global society. In the hope of creating better programs (international courses, more education abroad, etc.) to equip students to face global education, Bok (2006) argues that many colleges are still lacking "a thoughtful, comprehensive plan to combine these opportunities into well-integrated programs that can be fitted with all the legitimate aims of a rounded undergraduate education" (p. 240). The positive trend of including an international experience, such as a curriculum challenge, seems to be already at the doorstep of plenty of institutions (Robinson by AIFS $^{2}$ ). As per Irwin (2004), based on results released by the American Association of Community Colleges (AACC), stated that " $80 \%$ of responding colleges have integrated international components into coursework and an $83 \%$ percent sponsor activities to promote global awareness" (Para. 3).

Numerous universities have initiated the study abroad learning experience as a required core course, as a part of a degree plan. As follows, are some examples of institutions inside the US that are considering study abroad as an "add on" curriculum:

\footnotetext{
${ }^{2}$ http://www.aifs.com/aifsfoundation/robin.htm
} 
- Brown University- Provides a student oriented CORE curriculum, where if the students wish to complete a study abroad program (usually in their junior year) it satisfies some of their CORE curriculum courses.

- Tufts University- Nearly 40 percent of Tufts juniors spend at least one semester studying in a foreign country during their college careers ${ }^{3}$.

- Duke University- Offers Cross Cultural Inquiry (CCI) that may involve study abroad as a general requirement to graduate, regardless of major ${ }^{4}$.

- Montana University- Offers study abroad programs, which satisfy Core requirements ${ }^{5}$.

- Grand Valley State University (GVSG) - The academic departments of this university have been successful at incorporating study abroad programs as course and degree requirement, and are also investing substantially in its curriculum. (Robinson 2003).

- Pennsylvania State University- Study abroad is a program requirement for its landscape architecture program (Myers, Hill \& Harwood 2005). Faculties are challenged to include service learning activities components as a part of the study abroad programs.

- Michigan State University- Possess an excellent project, which, in conjunction with the office of study abroad, is called the "curriculum integration project." This project attempts to closely integrate study abroad options into the undergraduate experiences and curricula for all students in all majors ${ }^{6}$.

In Texas, there are some universities that are implementing the inclusion of gaining experience abroad, in some cases, it is required, not mandatory, for students to participate in a study abroad or exchange program.

- St. Mary's University -Through a program of Academic Advising Plan (AAP), study abroad experience is required for students to combine a language major with a minor or major in another field, and also students majoring in other areas are encouraged to consider adding a major or minor in a language ${ }^{7}$. Study abroad is not only offered to

\footnotetext{
http://education-portal.com/videos/Tufts University in Medford Somerville MA Video Review.html

${ }^{4} \mathrm{http} / / /$ www.aas.duke.edu/admin/council/agendas/documents/ReviewoftheCrossCulturalInquiryModeofInquiryREV.pdf

${ }^{5}$ http://www.montana.edu/wwwcat/requirements/reqs4.html

${ }_{7}^{6}$ http://studyabroad.msu.edu/currintegration/project.html

7 http://www.stmarytx.edu/advising/?go=plan
} 
students but also to faculties who's interest falls within their visions and goals for internationalization, ${ }^{8}$

- Texas A\&M University at College Station- Offers a bachelor degree in International Studies that requires experience abroad. The International Studies (INTS) degree provides an interdisciplinary curriculum that captures the broad range of social, political, cultural and economic forces at play in an increasingly interdependent world. Students take courses in a number of different departments. These courses are linked by language, topic and region. INTS majors must meet the International Experience requirement. Minimum 14 weeks abroad (3 credit hrs.). ${ }^{9}$

- Baylor University- This University offers a bachelor degree in International studies and International Business. It is required to incorporate study abroad as an internship abroad as a part of these degree programs. ${ }^{10}$

- The University of Texas-Pan American- The office of International Programs at UTPA, in addition to administrative and special events within the institution, has offered, for more than 16 years, a wide variety of international exchange and study abroad programs to students and faculties. Included in the programs and events organized by the OIP are the following: International Exchange and visiting (one or two week) programs; International special events and delegations; Advisory Committees on International Studies and LatinAmerican Studies; International scholarship; External Advisory and Funding Committees $^{11}$.

Based on the significant effects long-term programs have on personal and professional growth, and in particular on the self-awareness and vocational interest of students, longterm individual study abroad programs were selected for this research study.

\subsubsection{Goals, functions and effects of study abroad programs}

Even though the movements of market labor and the knowledge economy are the main aspects of globalization (e.g. Natarajan 2005), Bloom (2005) assured that there is a

\footnotetext{
${ }_{9}^{8} \mathrm{http} / / / \mathrm{www}$. acenet.edu/AM/Template.cfm?Section=Home $\&$ Template=/CM/HTMLDisplay.cfm $\&$ ContentID=6140

${ }^{9} \mathrm{http}: / /$ ints.tamu.edu/

${ }^{10} \mathrm{http}: / / \mathrm{www} \cdot$ baylor.edu/business/international/index.php?id=24257

${ }^{11}$ http://www.utpa.edu/dept/internationalprograms/
} 
valuable benefit in education abroad (study abroad) for acquiring knowledge, "Students, too, can benefit from a period of study abroad, and society can benefit from the new skills they acquire" (p. 25). There is evidence that education abroad can produce significant attitudinal changes in personal development (e.g. Patterson 2006; Sajiki 2006; Williams 2006; Emert 2008). About $85 \%$ of US universities provide some form of study abroad (Bok 2006; Gardner \& Witherell 2007), as an alternative way to gain students global awareness and intercultural competence. In Europe, especially in Germany during the last 11 years, the number of Germans in study abroad participation increased $226 \%$, over the last 70 years; study abroad has obtained a considerable importance and power ${ }^{12}$.

The increasing motivation to study abroad has meaningful connections to the college movement of internationalization demands. According to Gardner and Witherell (2008), based on their survey data released by the Institute of International Education (IIE) in November 2007, two common reasons for US students studying abroad were that they were "eager to learn about different countries and cultures and acquire global skills" (1). In addition to Sheppard (2004), Bok (2006) and Gardner and Witherell (2008) are of the opinion that the growth of interest in international education in today's global society has increased, not only by national leaders, but also by colleges and universities. Aside from these strong visions and tendencies, this research study focuses on international education visions at the micro level, namely personal and vocational developmental success. Sheppard (2004) empathizes that, within international education, success should be seen as a "human face" element. He states: "The human face of international education is reflected in stories, in the power of a moment to change the person's life" (p. 34).

According to the statistic data given by Gardner and Witherell (2008) in the Open Doors 2007 report, over the last 10 years, the participation of US students has increased up to $150 \%$. Only during the academic year 2005-2006, a total of 241,791 students went abroad. In other words, an $8 \%$ increase in comparison from the previous year when only 205,983 went abroad. The annual 2008 report given by Open Doors shows the increase of favorite destinations places for the students to go abroad: China, Argentina, South Africa, Ecuador and India (Gardner \& Witherell 2008).

This includes a variety of types of education abroad programs such as exchange programs, international internships, semester-summer program, and goodwill expeditions (to less

\footnotetext{
${ }^{12}$ Source: The local: Germany's news in English. Published 09.17.2008
} 
privileged locales for civic purposes), sponsored by universities. In terms of marketing promotion, Spiering and Erickson (2006) consider that study abroad offices promote study abroad by demonstrating what the students, in general, will gain from the experience.

Study abroad programs have provided college students with unique opportunities for cross-cultural contact and exchange of ideas through which they may come to appreciate the social and academic values, and experiences (Graban 2007). Beyond those benefits, some authors such as Carlson, Burn Useem and Yachimowicz (1990) and Bok (2006) agree that living in another country and culture support the gain of self-confidence, independency, and the development of special abilities to work in multifaceted environments. The effects of study abroad programs on students' vocational development will be discussed in the next section.

\subsubsection{Effects of study abroad experience on vocational identity development}

In fact, there are numerous examples of empirical research studies that have targeted the effect and outcomes of study abroad programs developed within the students' international personal development. Some impacts of long-term study abroad programs, are on psychological development (Herman 1996; Lathrop 1999), on self-awareness through others (Williams 2006), on personal and cognitive development (Thomas 2005; Graban 2007), on the intercultural sensitivity, awareness, empathy, and communication development (Herman 1996; Patterson 2006; Sajiki 2006; Meyer-Lee \& Warfield 2006; Domville-Roach 2007) and on intercultural and global competences (Patterson 2006; Fernandez 2006; Emert 2008).

For instance, students, in general, are encountering different cultural complexities and challenges that somehow drive them to develop new forms of personal identity formation. In other words, cultural challenges and complexities often differ from the local culture of the immediate family and community. The personal and career identity formation can take place anywhere, and in any social interaction, especially in multi-culturally developed countries; for example, students in the United States a multicultural country, are already more receptive to global perspective than any other students in countries with less multicultural exposure. 
For Furrow and Wagner (2003), the identity formation is closely related to diverse areas such as: civics, morals, culture and religion. Nevertheless, they still attribute the identity formation to a kind of transcendence process, where they use the term transcendence as "a process of extension of the concept of selfhood beyond the autonomous individual to that of an interconnected self" (p. 116). Regarding the idea of transcendence of one's identity, this research attempts to incorporate the terminus of transcendence within the vocational development. Vocational development is closely related to a career choice (Walker 1987) and to the self-concept (Super 1957; Goff 1994). Chickering and Reisser (1993) underline the difficulty regarding the process to find one's vocation.

"Finding our vocation is more than just securing a job. Vocations can include paid work, unpaid work, or both. We discover our vocation by discovering what we love to do, what energize and fulfills us, what uses our talents and challenges us to develop new ones, what actualizes our potential for excellence (pp. 50 and 212). Ideally these vocational plans flow from deepening interest, and in turn, lend momentum to further aspiration that has meaning and value" (p. 50).

It has been empirically approved that, in order to achieve vocational goals, explorations activities along with self-awareness programs, such as long-term study abroad programs, may serve as a positive precursor in developing a higher level of vocational behavior and self-definition. Schmitt-Rodermund and Vondracek (1999) define that "exploration is known to be a precursor of identity achievement and thus a healthy transition to adulthood" (p. 298). With that said, it is indispensable to increment exploration activities, not only within identity development, but furthermore in vocational oriented-activities.

During the vocational development, adolescents look for what matters to them as personal and professional values; they search for voices that require them to consider vocational commitments which preserves their own self. Duffy and Sedlacek (2007) underline more the role of career values on the selection of work and occupation. They point out four types of values: intrinsic, extrinsic, social and prestige (p. 359). They assume that career choice depends on the value they place on an occupation. According to their theory, the students make a long-term career choice according to their values regarding an occupation. 
Study abroad experience, as a multicultural exposure and discovering activity, might also serve as a self-definition opportunity. Beyond a self-definition process in terms of vocational interests, this process is a constant search to find those intrinsic voices to which individuals need to feel interconnected to a certain field and occupational area of interest, indeed to preserve their vocational identity.

The nature of study abroad programs makes the experience less stressful and enjoyable, which benefits and improves their vocational and professional visualization. Lindsay (2004) based her research study on social work values; she found that the students' study abroad experience of comparing two countries helps them to "more fully understand and identify with the ...profession" (p. 243).

As per Curran (2007), students are looking for multiple aspirations, nevertheless the "career advantage that education abroad will give them, is still in the back of their mind" (p. 48). While students are studying abroad, they are gaining new perspectives on academic subjects and real-world issues, achieving proficiency in a foreign language, experiencing personal growth, and developing valuable career skills. The findings of this research study provide significant insights in regards to self-perception and vocational satisfactions.

In fact, any experience abroad influences student learning and personal development (Kuh 1999), increases global competence and perspective, world mindedness and cross-cultural awareness (Bok 2006); being out of their own country may also help students to appreciate their own culture and identity (Williams 2006). With that said, study abroad programs experience seems to be a unique experiential event, which inevitably increases the knowledge of students' abilities, interests, and competencies to develop new coping strategies. These particular study abroad characteristics may function as a potential setting for personal growth initiative enhancement, which also serves as a predictor for exploration and vocational identity (e.g. Robitschek \& Cook 2002).

Beyond the usual socio-cultural competences gained during the study abroad experience, the students are in a constant physical and mental interaction with the foreign sociocultural environment. Consequently, the students develop personal competences that make them capable of better intercultural outcomes such as intercultural communication. Williams (n. d.) stated: "I believed, though, that in addition to developing skills which are 
directly related to one specific other culture, that participants develop certain personal skills such as sensitivity, perseverance, and adaptability that transcend success in a single culture to success in a variety of intercultural situations. These skill sets can be identified as intercultural communication skills or the ability to effectively interact with people of different cultures" (p. 4).

The impact of study abroad programs experience, along with its increasing popularity among US universities is leading us to rethink pedagogical initiatives, and to reflect on students' (e.g. cross-cultural and career-oriented) experience outcomes. An increasing need for an enhanced pedagogical approach in career development and cross-cultural learning experiences is required in order for students to gain new insights into a variety of cultural systems, values, alternative professional methods, as well as their personal identity and career aspirations (Myers, Hill \& Harwood 2005). There is a reason to believe that "an interdisciplinary service-learning environment embedded in a study abroad program can provide opportunities for cross-cultural learning and students transformations" (p. 173). In a world of social and environmental needs, college institutions have the potential to adjust study abroad programs academically into a more sustainable method which also could provide more service based-learning related to their major. Applying this idea into academic efforts and curricula could be worthwhile for every institution, and furthermore for students' career and vocational development.

It is apparent that, for a better international understanding, researchers need to include international learning activities in each curriculum. This is in regards to pedagogical recommendations (Praetzel 1999; Robinson 2003; Myers, Hill \& Harwood 2005). In other words, in reference to all majors with the exception of business, one should involve courses of different fields, and for an advanced international understanding, include practice and work abroad. This could prove to be difficult for any faculty member. Praetzel (1999) strongly promotes study abroad as a comprehensive approach as well as an integrated learning experience to encourage and campaign for international understanding, and for the curricular integration. He advises educators and administrators of study abroad programs to relate study abroad to career majors such as economics, history, politics, culture, language (p. 141). In addition to the study abroad programs' benefits, Bloom (2005), underlines the teaching exchange abroad benefits. He is of the opinion that teacher 
exchanges abroad could benefit their own institution and country by learning new teaching methods and expanding their knowledge.

Even though short-term study abroad programs have demonstrated a higher preference by US students and faculties, long-term programs undoubtedly have a better effect on personal and vocational development. Studies have documented the effect of longer study abroad programs experience (e.g. Toncar \& Cudmore 2000; Orahood, Kruze \& Pearson 2004; Thomas 2006), unfortunately with little pedagogical attention concerning vocational identity development outcomes.

Additional literature suggests and affirms that, through study abroad program, students have the opportunity to improve their curricular (course content) perspectives. In order to be able to interact with any kind of international and cultural issues, they gain proficiency in a foreign language, personal growth, career skills, and professional values (Lindsey 2005; O'Callaghan 2006; Graban 2007). Furthermore, each of these programs represents a unique form of experiential and cross-cultural learning which also is intended to broaden the students' self-experience such as career education, psychosocial development, personal, professional, cultural or intercultural identity beyond a classroom (Patterson 1994; Lathrop 1999; Myers 2005; Spiering \& Erickson 2006).

Experience abroad should be considered as an alternative to promote self-knowledge and awareness within professional career development (Williams 2006). According to Graban's (2007) study, study abroad programs are not only the best academic alternative for curricular achievement, but also the most valuable innovation for international education, for educators and students who want to meet the global challenge of this century. Graban (2007) focuses his study on the self-perceptions of students regarding the value of their experience abroad. Results are evidently significant towards one's professional career development. Also, according to Graban (2007), those activities abroad are more likely to be a considerable potential environment for personal and intellectual growth.

Other studies have demonstrated that oversees study brings life and identity changes upon completion of a degree. One study focused on the self perception of Japanese women upon their return home (i.e. the re-enter process). Their gender and professional identities experienced modifications during their return into their socioeconomic culture. This study 
supports the premise that researchers should look deeper into the individual's life, in order to have an overview of individuals' identity adjustments (Mimura 2007).

According to the latest projections issued by the US Department of Labor (1977), Brown (2003) stated: "the occupations growing the fastest are those that require the highest educational level, and the specific vocational preparation for these jobs requires a solid educational foundation" (Brown 2003, p. 72).

In the field of career developmental theories, Brown (2003) summarized 17 foundational skills needed by students entering the work force in the $21^{\text {st }}$ Century:

- Basic skills: reading, writing, mathematics, speaking, listening.

- Cognitive skills: creative thinking, problem solving, decision making, visualization.

- Interpersonal relationship skills: communication, negotiation, leadership, ability to work as a team member, ability to function effectively in a multicultural setting.

- Personal qualities: self-esteem, self-management, responsibility.

The nature of study abroad programs offer students a unique experience and opportunity to potentially enhance their basic skills, furthermore, cognitive, interpersonal, and personal qualities skills that are necessary for a life-long vocational identity.

The purpose of this study is not to judge, assess or evaluate career development programs at colleges and universities, but rather to outline the consideration of study abroad program experience as a beneficial tool and as an alternative setting for vocational behavior development such as self-directed exploration, as well as to facilitate a closer approach to the vocational identity development. These alternatives could also provide career and self awareness activities, exploration of interests, values, goals, and decisions.

In reference to a better career guidance program, this research study put emphasis on an experiential learning element (Hopkins 1999) which study abroad contains, in contrast to some of the computerized career programs such as DISCOVER published by the American Testing Programs (Walker-Staggs 2000). Study abroad environments provide interactive and practical self-explorative activities that accelerate discovering and knowledge of students' own abilities, interest and efficacies that serve as fundamental bases for a self-definition and a current vocational identity. 
The realities of the job market and its future trends, such as practical, accurate information about careers, are main components of career development services (e.g. Griff 1987; Brown 2003). In other words, these aspects could be identified, addressed and planned according to the students needs before they leave the country. With that said, it is an interdisciplinary collaboration of administrators, educators and international advisors with a shared objective, the achievement of students' satisfaction and vocational goals.

The concept of vocation identity in this research study is based on Haußer's (1995) psychological understanding. His reflections regard that identity formations are based on career-oriented satisfaction as a fundamental base to achieve a vocational identity. This is attained through self-exploration events as well as the resulting effects on one's personal and vocational identity, i.e. when one has a sense of vocational satisfaction in one's career, occupation or professional choice.

\subsubsection{Self-exploration and vocational development by studying abroad}

Since identity formation plays a central role in adolescence, especially during the career choice development and achievement process (Rangel-Lopez 2000), the adolescent is challenged to make a career decision, and at the same time, take into consideration his or her interest, wishes and skills, which is an exploration process, perhaps, not yet completed. Naturally, this requires a certain degree of self-esteem, self-knowledge and awareness. Super (1957) considers adolescence as a period of cultural adaptation and as the emergence of self-concept. The principal idea behind this study is to uncover whether or not study abroad experiences give the students the tools they need in order to progress their identity and vocational development.

Empirical studies have served as a theoretical framework to develop new avenues, especially in the international educational setting. In the college environment and under diverse perspective, the identity (personal development) has been the focus of research (e.g. Erwin 1982; Chickering \& Reisser 1993; Pascarella \& Terenzini 2005).

Among all of the several developmental students' tasks during their career development, it is important to underline that the adolescent is primarily striving for his or her independence, detachment from his or her parents, deciding for a career or an occupation, 
achieving a heterosexual role adjustment, and moreover an adequate integration of the personality (Gomberoff 1992, pp. 119-123). However, youths, despite all outside and internal restrictions to which they are subjected, are still being considered "interpreter, creator and designer of their own development" (Ewert 1986, p. 119). Students are constantly constructing their personal and career identity through social interaction (e.g. experience study abroad) acquiring new knowledge that helps them to grow by shaping and modifying their personality as well.

Chickering and Reisser (1993) inspired by Erikson's and Marcia's works pointed out that the formation of identity occurs during a discovery process which is directed throughout seven vectors: developing competence, managing emotions, moving through autonomy toward interdependence, developing mature relationship, establishing identity, developing purpose and developing integrity. These vectors were used to assess psycho-social development of students abroad (Lathrop 1999), unfortunately, findings related to vocational development elements were limited.

As per Haußer's (1995) conceptions of exploration, he describes it as "Bewusste Erkundung von Umwelt und Handlungsmoeglichkeiten aufgrund von Neugier und Interesse" (p. 6), in English, "it is the conscious reconnaissance of the environment, and the opportunity of action on the basis of interest and curiosity" (Translated by Author). Through experiences abroad (example group activities in and out of classroom), the students are gaining a better self-knowledge of their own skills and abilities. As college students develop and move from one position to another, they are inevitably constructing new knowledge about themselves. Especially, just by being motivated to study abroad, students are making a new commitment to the self-development that may change their self-perception over the time as they gain additional information. Being in a different environment, such as abroad, the students are in a constant development, creating new coping strategies when they see their problems as a challenge and commitment. Pascarella and Terenzini (2005) suggested that "position is by definition statics and development is by definition movement" (p. 36).

The significance of the role of exploration activities such as experiential learning, and the challenging aspect of a new environment, make the study abroad experience a substantial setting to increase self-efficacy, career preparedness (Teranishi 2007) and to develop further the vocational identity. As per Hopkins (1999), study abroad programs experience 
is a form of liberal education. As a benefit to the students' development, Hopkins states that "study abroad programs take many forms, but all share the characteristics that, by their nature, provide students with a healthy dose of experiential learning" (p. 1). Furthermore, along with diverse types of experiential learning such as field experience, internships and study abroad programs, there is an added relevant factor which is selfknowledge. In reference to this, Hopkins (1999) demonstrates that, through study abroad, the students "inevitably find themselves looking inward as well as outward" (p. 1). Throughout that process, the students could also develop a very positive sense of discovering vocational interests along with their career constructed knowledge throughout their experiential learning activities with themselves.

Study abroad programs that are designed and based on students personal and career interest and motivation, as well as a more meaningful identity and career learning experience, will provide the students with a greater sense of success within their vocational identity definition.

Lack of information, socio-cultural influences about the career profiles and selfknowledge could guide the students into vocational identity confusion. Damron (2006) attributes to the study abroad experience a valuable sense of educational experience. Encountering any kind of career self-knowledge activities during their study abroad program experience grants the students a powerful effect on their vocational learning outcomes. These constructive influences of study abroad experiences on identity formation will be positively exposed in the following Chapters of this research study. 


\section{Chapter 3}

\section{Methodology}

This study was developed with the support of the Office of International Programs (OIP) at a university in the Southern United States. According to the university fact-book created by the Office of Institutional Research and Effectiveness, the student population for the fall of 2007 approached 17,400 of which almost 85\% was Hispanic. The OIP was established in 1994 with the main focus of developing new opportunities for cross-cultural experience for the students and faculty. The OIP offers a variety of exchange programs, as well as study abroad programs to its students and faculty. Individual, customized or faculty led programs are offered to the students within the study abroad programs. Individual-customized programs are those in which the students study abroad on an individual basis for one or two semester at any of the OIP partner or affiliated universities. Faculty-led programs are specially designed for students who are going to study abroad and are accompanied by a faculty member. These programs are modified according to the academic summer calendar and last 2 to 4 weeks.

\subsection{Participants}

The research participants were selected from a university with a predominant Hispanic population, which is located in the United States along the border of Mexico. These students reside in the US, and come from a variety of Hispanic backgrounds (i.e. MexicanAmerican, Mexican Nationals and Colombian-American). The participants were students, with diverse ages, classifications and majors, who enrolled in an individual study abroad program during the spring semester of 2008. This selected group represents one of the characteristics of qualitative sampling strategies which is referred to as "purposive sampling," which according to Gay, Mills and Airasian (2009), identify research participants that are believed to be representative of a given population (pp. 134 and 136). The clear criteria that distinguish this selected group of participants were any student regardless of his or her major and enrollment in a semester (individual) study abroad program during the spring semester of 2008. Variables of each study abroad program 
design (i.e. areas of study/major, the additional challenge of a foreign language, and educational systems abroad) were not measured in this study. These issues may possibly regulate the transferability of research results. A discussion regarding this matter will be presented in Chapter \# 6.

After a thorough review of the research design, consent was given by the Institutional Research Board (IRB) at the University for conducting this research study. The approval for the consent letter was received December 2007. The Office of International Programs reported a total of 15 students enrolled in the study abroad program for Spring 2008. The 15 students, 10 females and 5 males, were contacted for an interview before and after their study abroad program. This was the first time participating in a semester-long-term study abroad program for all of the research students: majoring in different areas, from different classifications in regards to accumulated credit hours (e. g. freshman, sophomore, junior, senior and graduate) and academic levels. Table 3.1 below presents the sum of research students by gender and country of study abroad program.

Table 3.1 Research participants

\begin{tabular}{|l|c|c|c|}
\hline $\begin{array}{c}\text { Study abroad } \\
\text { program }\end{array}$ & $\begin{array}{c}\text { Females } \\
(\mathbf{N}=\mathbf{1 0})\end{array}$ & $\begin{array}{c}\text { Males } \\
(\mathbf{N}=\mathbf{5})\end{array}$ & $\begin{array}{c}\text { Total } \\
(\mathbf{N}=\mathbf{1 5})\end{array}$ \\
\hline France & 4 & 2 & 6 \\
\hline Spain & 4 & 2 & 6 \\
\hline Argentina & 1 & & 1 \\
\hline Germany & & 1 & 1 \\
\hline Italy & 1 & & 1 \\
\hline
\end{tabular}

Due to logistical components involved in the traveling arrangements before going abroad (e.g. finalizing travel documentations, financial issues and home addresses changes), the total of the research students interviewed, before study abroad experience, was 12 . After study abroad experience a total of 14 were interviewed, taking into account the challenges presented due to the fact that research students returned home on different dates and from different destinations. 
The study abroad program experience (dependent variable) includes a semester-long (four or five months) stay in a foreign country within the context of a university or academic setting. The independent variables in this study were the self-concept characterizations, vocational assessments, career choice clarity and vocational identity development. However, no evaluations or assessments were made in regards to their housing circumstances, course instruction language, or degree of integration with host-country nationals.

It is important to note that, to protect the research students' identities, they received a code with the first letter of the country where they were going and their names were changed. The main characteristics of the five main study abroad program groups are as follows:

Research students from the individual program in Bordeaux, France (F1, F2, F3, F4, F5, and F6): This group of participants was fortunate enough to be part of a well established exchange program between both universities. It is important to mention that this group was unified in relation to study abroad program motives and expectations. They all shared a common motivation, which was to speak and understand the French language and culture. In fact, French language professors from each university, as part of the exchange program, provided students with previously arranged accommodations, study abroad program preparation sessions and monitoring before, during, and after their study abroad program. In addition, the research students were familiar with each other, were wellguided, prepared and informed.

Research students from the individual program in Salamanca, Spain (S8, S9, S10, S11, S12 and S13): This group of research participants, quite unlike the France group, had substantially diverse characteristics: they were not familiar with each other because they were individually advised and prepared. Unlike the French group, these students received less preparation sessions and academic support they seemed to demonstrate self-developed interests and motivation. This group had various vocational (e.g. career choice) issues to be resolved, and they had the responsibility of arranging their own accommodations, whereas, the France group was part of an already existing and established exchange program and had a defined goal of learning the French language. This group consisted of students with diverse individual programs abroad which were designed independently in line with their majors or their vocational and personal interests. 
The other three individual study abroad programs offered in Luneburg, Germany; Florence, Italy; and Buenos Aires, Argentina, were composed of one student each.

Florence, Italy (I17): a female student majoring in Art. This student went to Florence and enrolled in a non-partner university. She decided to study abroad to become more acquainted with Italian art. This student planned, organized, and arranged her own study abroad program in Florence. As an important note, this student was not registered on the list of participants in study abroad programs for the Spring 2008, provided by the office of international programs. Due to this unfortunate circumstance, it was not possible to interview her prior to departure.

Buenos Aires, Argentina (A14): a female student whose studies were in the field of medicine. She chose to go to a non-partner and private university in Buenos Aires (B.A.) because of personal motives (e.g. friends in B.A.). Her motives included enrolling herself in basics classes towards her degree in biology, which is a requirement for medical school.

Luneburg, Germany (G15): a male student who went to a well established exchange program with a business school university in Germany and was majoring in economics. He clearly selected this university in Germany due to his major. These three research students, as well as the group going to Spain, received less faculty supervision and preparation.

\subsection{Research Design}

This research study is longitudinal and has been designed utilizing a qualitative approach, as described by Gay, Mills and Airasian (2009). Qualitative research "seeks to probe deeply into the research setting to obtain in-depth understanding about the way things are, why they are that way, and how the participants in the context perceive them" (p. 12). The research design used in this study is considered longitudinal due to the fact that the data was collected two times before and after study abroad experience (Gay et al.).

By using a mixed method design, it was possible to obtain more evidence regarding potential data sources concerning students' cognitive and emotional aspects of vocational identity. The objective of this type of method design is, as per Gay et al. (2009), "to build 
on the synergy and strength that exist between the QUAN and QUAL research methods to understand a phenomenon more fully than is possible using either one of each alone" (p. 462). As documented, this type of combined research method has previously been observed and applied in varies study abroad research studies (e.g. Graban 2007; Williams 2006).

In this study, the qualitative data collected was more heavily weighted than the quantitative data. In other words, the quantitative instruments will be used, first to see and compare results before and after study abroad experience using independent variables (e.g. career choice clearness, identity status, vocational assessment, self-concept characterization and vocational identity), and second, to look at the relationships and links to the qualitative material. Based on the research questions and the purpose of this study, the analysis and interpretation is, in particular, qualitative.

This combined method research utilized questionnaires, surveys and interviews. The main benefit of this method is optimal for qualitative studies within social sciences research because it provides trustfulness through data comparison and management (Bortz \& Döring 1995, p. 342). The main characteristics of qualitative research are its inductive approach, research students' perspectives, describing and understanding relationships, emerging questions and purposive sampling (Gay et al. 2009).

The quantitative and qualitative data sources were first separately evaluated and analyzed. Comparison results, before and after the experience abroad, will be provided. This comparison contains data from 11 students who participated in the two data collections. In view of the fact that the number of subjects is small, and that the research design of this study is qualitative, there was no statistical significance done. The triangulation method analysis and interpretation were applied for the descriptive results comparisons (section 4.4) of four cases (Sara, Gabriela, Lorena and Marc). The triangulation method is recognized as one of the best strategies that ensures the validity of qualitative information. Gay et al. (2009) describe triangulation as "the process of using multiple methods, data collection strategies, and data sources to obtain a more complete picture of what is being studied and to cross-check information" (pp. 377 and 408). Meticulously documented records (in a data base) of research students' assessments and perceptions, established a trustworthiness criteria for a qualitative research as presented by Bortz and Döring (1995). 
The instruments that were used, to understand research students' perception and possible influences in their vocational choice and identities, were the following:

a. Demographic survey: "The vocational career development of college students"

b. Self-concept inventory "Frankfurter Selbstkonzept Skala" (FSKN) (Deusinger 1986)

c. Holland's “Self-Directed-Search” Inventory (1994)

d. Semi-structured interview

A copy of the research participants consent letter, and all four instruments that were employed and administered to each individual student, are attached as Appendices 1, 2, 3, 4 and 5. The four instruments were administered to each student in person on the same occasion. They were utilized before and after the study abroad term.

\subsection{Quantitative instruments}

The students enrolled in an individual study abroad program during the spring semester were selected for this study, as opposed to the fall semester due to the fact that a higher number of students were enrolled in diverse majors and disciplines and represented various age levels. Below are the instruments that were selected for this mixed-method study.

\subsubsection{Survey "The vocational career development of college students"}

One of the research questions is, "What are the effects of study abroad experience on vocational and career satisfaction?" This survey attempts to embrace data associated to the career decision status as well as its influence and effect from internal or environmental aspects. Furthermore, the data extracted provides relevant factorial sources which, from an internal frame of reference, contribute to the research students' career definitions, meanings and ideas.

This survey was also employed to complement and support research students' personal background information that relates to their career choice status. Additionally, it was used to gather data regarding their career choice and advisement support and to see how they 
develop information acquired for their career choice status (clear and decided, unclear and undecided and without idea). This survey was developed utilizing qualitative insights collected from a longitudinal project (Rangel-Lopez 2000), whose main focus was to assess the "vocational orientation and career choice status" of 224 high school research participants from a university in Monterrey, Mexico.

This survey includes six main areas of personal and professional development: 1) career choice support and advisement; 2) career choice status and its (environmental or personal) contributions; 3) self-reported identity status for professional occupation; 4) values within the professional career plan; 5) expectations of study abroad experience in vocational career development, and the last, 6) preferences in their lifespan.

The relevant questions that were found appropriate for analysis to answer the present research questions were question 2, 3 and 5. With question 2, the research participants were asked about their career status, if their career choice was clear and decided, not clear and undecided, or without idea. As supplementary information to question 2, they were also asked to rate using a percentage the contribution of others or other factors, for example personal, family and environmental, to their current career choice status.

Question 3 refers to a self-evaluation regarding identity status and professional occupation. The research participants were asked to reflect upon themselves and their professional identities. According to a self-evaluation, the research participants had to place themselves in the status in which they believe they belonged by marking a box with an " $\mathrm{X}$ ". For example, they had to rate, from high to low, their time and effort invested in their vocational identity status: e.g. achievement, foreclosure, diffuse or moratorium. Question 5 was included to see how the research participants rate expectations of their study abroad experience regarding their vocational career development. To ensure research credibility, this data material was evaluated and interpreted using a qualitative method, e.g. contextualizing data with the literature or connecting findings with other data sources.

\subsubsection{The Frankfurter Selbstkonzept Skala (FSKN)}

This Frankfurter Self-Concept Scale (FSKN) is a German tool used to assess research participants' self-perceptions. Ensuring its reliability, this instrument was first translated into Spanish and applied in a research project involving 224 research participants (Rangel 
Lopez 2000). Posteriori, the instruments were carefully translated and revised twice to ensure their accuracy for the appropriate English contextual terminology. The FSKN inventory consists of a 10-dimensional Scale (See Diagram below) for determining the respective image or self-concept that an individual has developed in important areas of his or her self.

The FSKN Scale differentiates the fact that self-concepts are the individual and multidimensional structure of the self in key parts. This kind of self-description with the help of the FSKN Scale may also provide clues to the mental health or the disturbance of the subjects. In reference to the reliability, the internal consistency of the 10 scales may prove with $\alpha=.93$ to $\alpha=.97$ as a very satisfactory $(\mathrm{N}=1,794)$. A particularly high reliability coefficient was obtained from scales FSSW, FSST, FSAL and FSAP. The RetestReliability is (after 4 to 5 months) at $r=.82$.

The self-concept domains that were assessed were 10 in total. The first three domains, FSAL FSAP and FSVE, correspond to the concepts of self that are related to the area of efficiency, productivity, and achievement. The FSSW relates to the general sector of selfworth and self-esteem. The FSEG "sensitivity and overall mood" falls under the sector of mood and sensitivity. The domains 6 through 10 correspond to the social aspects of selfconcept.

Diagram 3.1 Frankfurter Self-Concept Scale domains.

\begin{tabular}{|ll|ll|}
\hline 1. & FSAL & $\bullet$ & Efficiency \\
\hline 2. & FSAP & $\bullet$ & Problem Coping \\
\hline 3. & FSVE & $\bullet$ & Conduct and decision' assurance \\
\hline 4. & FSSW & $\bullet$ & Self-esteem \\
\hline 5. & FSEG & $\bullet$ & Sensitivity and overall mood \\
\hline 6. & FSST & $\bullet$ & Stability \\
\hline 7. & FSKU & $\bullet$ & Social Contact and dealings skills \\
\hline 8. & FSWA & $\bullet$ & Regard, Appreciation or esteem by others \\
\hline 9. & FSIA & $\bullet$ & Irritation through others \\
\hline 10. & FSGA & $\bullet$ & (Emotion and Relationships \\
\hline
\end{tabular}

1. FSAL (Efficacy): this domain considers all attitudes of the person regarding his/her self-efficacy. These are considered cognitive thoughts: perceptions, reelections, judgments, assessments, feelings and actions that the person relates to his/her capacity of achievement (could be related to success or failure). 
2. FSAP (Problem coping): This domain corresponds to the attitudes of the person regarding his/her ability to resolve daily problems or difficulties independently; it is the person's assessment of his or her own perseverance in difficult situations, in addition to the person's expectative in regards to her or his own future.

3. FSVE (Conduct and decision assurance): This domain considers all attitudes of a person regarding feelings of personal confidence, i.e. feelings of being safe or unsafe. This also refers to conduct assessment as well as a feeling of being secure in situations of individual decisions, by certain self-assessment of everyday decisions or by given alternatives.

4. FSSW (Self-esteem): This domain represents the attitudes towards the self, such as self-esteem or self-respect that refers to feelings of satisfaction or dissatisfaction with one's own self, thus in comparison to one's peers, and to the feeling of usefulness.

5. FSEG (Sensitivity and overall mod): This domain considers the cognition and emotions of the person which embrace the level of sensitivity, sensibility, vulnerability and mood (e.g. a positive person considers him or herself happier than a person who is vulnerable and less sensitive).

6. FSST (Stability): This domain is one of five scales that look closely at determining the self-concept within the psycho-social area in particular, e.g. the attitudes towards social situations, conduct in different social connections within his or her environment. All the cognitions and attitudes of each person are hereby described, which are more predominant in the social debate and discussion with others, as well as with authorities. This area covers the ability to express and to carry out his/her own opinions, ideas, and viewpoints.

7. FSKU (Social contact and dealing skills): This domain attempts to grasp the selfconcept abilities of the person within the psycho-social area. The attitudes described or expressed are predominately those cognitions and emotions related to the aspect of ability and confidence in approaching people, in terms of starting and following a conversation, or self-introduction in the social environment (e.g. a positive or optimal self-perception: skillful, clever, secure and natural; and a negative self-perception would be shy, timid and insecure).

8. FSWA (Regard, appreciation or esteem by others): This domain is another of the five psycho-social dimensions in the Self-Concept Scale. In this domain lies the cognition and emotions of the person in regards to his/her self-appreciation by other people (i.e. peers, friends, family etc). 
9. FSIA (Irritation through others): This domain is the fourth of the five psycho-social dimensions of the Self-Concept Scale. Hereby, all attitudes of tolerance, and acceptance towards others are included, e.g. all that a person perceives as an influence on his or her own self, as well as the influence that others exert on the person's ideas, emotions and behavior.

10. FSGA (Emotions and relationships): This domain is the fifth psycho-social dimension of the Self-Concept Scale. The FSGA assesses the attitudes that a person describes concerning his or her cognition, ideas, reflections and emotions with regard to his or her social environment (translated by the author, according to Deusinger 1986, pp. 32-39).

This quantitative component was utilized to assess the level of students' "self-concept" characterization before and after their experience abroad. The data extracted from the Frankfurter Selbstkonzept Skala (FSKN) was evaluated using the Liker's method. Each of the FSKN test statements were summarized and evaluated with the Liker's method as well. A Liker scale requires an individual to respond to a series of statements by indicating if he or she strongly agrees (1) or strongly disagrees (6) demonstrating their degree of agreement or disagreement. For each statement, there were six options to select. See example below.

Mark with an $\mathrm{X}$ the little box with the number that coincides with your answers.

$1=$ is very accurate

$2=$ is accurate

$3=$ is a bit accurate

Example:

I like to eat chocolate.

$$
\begin{aligned}
& 4=\text { is less accurate } \\
& 5=\text { is not accurate } \\
& 6=\text { is not at all accurate }
\end{aligned}
$$

\subsubsection{Holland's Self-Directed-Search Inventory}

Professional (vocational) identity issues have been a focal point in vocational behavior literature dealing with the person-environment fit. The widely accepted theory regarding person-environment fit is Holland's (1985) typological theory. Holland's (1994) SelfDirected-Search (SDS) assessment, the third quantitative instrument used in this study, was developed by Holland in 1970 and revised with the $4^{\text {rd }}$ edition in 1994 . The reliability of this instrument is well documented (Holland, Johnston, Hughey \& Asama 1991; Holland, Johnston, Asama \& Polys 1993). In regards to vocational personality, 
occupational interest and environment, the application of the Self Directed Search (SDS) from Holland (1994) was deemed the most appropriate for the analysis.

Holland's (1994) SDS assessment was used to collect data regarding vocational interests. The SDS is a self-administered, self-scored, and self-interpreted vocational counseling tool. A person obtains a three-letter occupational code, which is used to correspond with suitable occupations. Scores are totaled for activities, competencies, occupations, and selfestimates. This self-administrated tool assesses vocational activities, competencies and occupations, which these research students feel they are capable of performing; also it assesses how they estimate their vocational abilities and skills. The scores obtained are totaled for activities, competencies, occupations, and self-estimates.

These scores are subsequently totaled and yield a summary code of Holland's (1985) personality types; R-(Realistic) indicates a conforming, materialistic, practical, modest, stable person which corresponds to outdoor and blue-collar work: the I-(Investigative) is the personality type that is precise, and refers to a rational person which corresponds to investigation and research; the A-(Artistic) refers to the type of person that is emotional, imaginative, impulsive, independent and nonconforming person, which corresponds to artistic creation and freedom; the S-(Social) type of personality is a cooperative, friendly, helpful, kind, and understanding person which corresponds to teaching and counseling; the E-(Enterprising) refers to the type of personality that is attention-getting, ambitious, selfconfident, and popular person which corresponds to business and political activities; and the $\mathrm{C}$-(Conventional) personality type is a conforming, conservative, inhibited, obedient, self-controlled, and efficient person, which corresponds to clerical and office procedures.

\subsection{Qualitative instrument}

\subsubsection{Semi structured interview}

The qualitative instrument used for the purpose of this study is a semi-structured interview. The semi-structured interview was designed with the objective of gaining an enhanced approach to the research students' expectations, motives, goals and outcomes, that in one way or another inspired them to make the decision to study abroad. The SocioCognitive-Theories from Bandura (1986) and their function within the career 
development, as well as the theories from Lent, Brown and Hackett (1996), reveal the strong relationships between the sense of a high level of self-efficacy and the student's expectations and goals in their vocational career development.

Therefore, as a central part of this research study, the interview attempts to extract the students' personal resources (self-efficacy) before and after their study abroad experience. Priorities for this study were all resources that are attributed to the cognitive element of personal development which are strongly related to self-knowledge and vocational development. The qualitative data analyses were made possible with the support of the NVIVO 7.0 Software, which helped mainly in the evaluation and organization of categories for data frequency. It was expected to enrich qualitatively the quantitative components, providing substantial and additional insights into the qualitative data analysis, e.g. how the study abroad experience would impact students' self-concept characterizations and also their expectation on identity development regarding vocational interest and career definitions outcomes. Below are the questions that were included in the interview before and after study abroad experience.

\section{Before study abroad experience:}

What is / was your motivation for studying abroad?

What do you expect from your study abroad experience?

In reference to your career choice, how do you expect your experience abroad to contribute to your career?

Do you think that study abroad will strengthen your vocational choice? Why and how?

What are your weaknesses and strengths for studying abroad?

How do you describe yourself?

What are your strengths and weaknesses in regard to your career choice?

How do you visualize yourself in the future?

Is there anything that you want to share?

\section{After study abroad experience:}

How do you describe your study abroad experience?

Do you think that study abroad reinforced your vocational choice (the career that you had wanted to fulfill)?

What motivated you most during your study abroad program? 
What was the most important thing you learned and experienced in your study abroad program?

What was the greatest contribution (persons, event or activity) to your career choice?

Did your study abroad strengthen or weaken your career choice? Why and how?

Can you mention, the changes that you encountered in yourself?

Are those changes supporting you in your vocational career development?

How do you describe yourself now after your study abroad experience?

How do you visualize yourself in the future?

\subsection{Procedures for data collection}

\section{Before study abroad experience}

The contact information of the 15 research students enrolled in the Spring of 2008 study abroad programs was provided by the Office of International Programs from the university. All 15 research students enrolled in a semester study abroad program during the Spring of 2008 were contacted via e-mail in the month of December to explain the purpose of this research study. Posteriori, they were also contacted by phone with the intention of setting an appointment for an interview. Fortunately, all students willingly accepted the invitation to participate in this study. An unfortunate limitation was the fact that there was a timeframe of only one month (e.g. the France and Spain group) to carry out the interviews before their departure.

The interviews were conducted in person and in accordance with the students' time available before departures. The short period of time and the further accommodations to arrange for living out of the country proved to be a considerable challenge and limitation for the data collection.

The two groups (France and Spain) were interviewed between the $3^{\text {rd }}$ and the $7^{\text {th }}$ of January 2008. The three research participants going on individual programs (Argentina, Germany and Italy) were contacted and interviewed during the months of February and March 2008. All 15 research participants were contacted and accepted the invitation to participate in the survey; nevertheless, three students were not able to find an available place and or time to be interviewed before departure. Some of their home addresses were on the other side of the border in the country of Mexico. The scheduled interview characteristics were as follows: 
1. The interviews were conducted individually, in a friendly, quiet and peaceful atmosphere, mostly in private rooms, classrooms, or the library on campus.

2. A Consent Letter (see Appendix No.1) to be signed was provided to each student, explaining the purpose and the importance of this research study. Their participation in either one of the sessions (before or after) was not obligated. Also, and not of less importance, is the fact that their participation responses were anonymous.

3. Since the focus of this methodological approach was qualitative, during every interview, the research students were given the liberty to answer the interview questions, in the language (English or Spanish) in which they felt more comfortable expressing themselves. Also, they had the opportunity to ask questions at anytime if something was not understood. For qualitative data reported in Spanish, a translation by the researcher will be provided. Originals texts in Spanish from sources will translate attached as Appendix No. 7.

4. After signing the "Consent letter," using pencil and paper, each student started answering Survey I "vocational career development of college students," (see Appendix No. 2.) which took approximately 15 minutes to complete.

5. After a short break (if needed), they started answering the "Frankfurter Selbstkonzept Skala" (FSKN), which lasted approximately 20 minutes. A copy of the FSKN Scale in German and English is attached as Appendix No. 3.

6. After a short break (if needed), they received a self-administered questionnaire that assessed their vocational interest, which is Holland's "Self-Directed-Search," which took approximately 10 minutes. A copy of Holland's SDS instrument is attached as Appendix No. 4.

7. Last but not least and of utmost importance for this study, the students took part in a semi-structured interview during which the research students were asked about their expectations of and the experience after their study abroad experience, once again expressing themselves in the preferred language they felt more comfortable (English or Spanish). A copy of the semi-structured interview guideline is attached as Appendix No. 6. To administer and organize all data after each interview, the quantitative instruments were immediately evaluated, scored and entered into an access database file.

The qualitative information, which was voice recorded, was subsequently transcribed into a Word document version 2003 and revised twice posteriori. 


\section{After study abroad experience}

The second data collection, as far as the interviews and surveys, was carried out applying the same method and sequence as previously used before the research students' study abroad experience. In some ways, the data collection the second time around appeared easier than before study abroad experience (e.g. well known instruments, accurate data and personal openness). All 15 research students were contacted prior to their arrival. The interviews were scheduled during June $12^{\text {th }}$ through September $24^{\text {th }} 2008$. In comparison to the first interview setting, two considerable challenges for the second data collection were the different return flight dates and the unexpected changes of home addresses and phone numbers.

Fortunately, in comparison to the before study abroad experience survey study, two more research students made themselves available for the interviews. Only one research participant (S 13) could not be reached. Finally, 14 of 15 research students were successfully found, contacted and interviewed after their study abroad experience. The data collecting sequence (Survey II, Frankfurter Self-concept inventory, Holland's SelfDirected-Search and interview) remained the same as was used before study abroad experience.

The voice recorded interviews were transcribed utilizing a Word document, and revised twice for accuracy. After all this, the depth data analysis and interpretation began.

\subsection{Procedures for data analysis}

\subsubsection{Quantitative data analysis}

Immediately after completing each interview, the instruments were evaluated, scored and entered into a general access database document to be evaluated and analyzed. The data were organized using diverse Excel databases.

For example, Surveys I and II were evaluated by simple results comparisons, and in some cases of importance, a percentage value was extracted. Questions 2, 3 and 5 from each survey were extracted and entered into a new database to be compared with results from before and after study abroad experience. The Frankfurter Self-concept inventory and the SDS were, after being summarized and evaluated, converted into mean groups to appreciate impacted changes in terms of self-assessments domains and the dominant 
control variables as a group. An optimal visual picture of impacted variables and a student's profile (compiling all three quantitative data analysis results), was created with the purpose of gaining a greater visual inspection and comparison of results before and after.

The quantitative data analysis of all sources was evaluated using results comparison and the mean measures by variables. The mean provides the value that is obtained by totaling the students' responses and subsequently dividing their sum by the number of research students. The mean extracted from the FSKN domains provided excellent insights into the group's major effects concerning cognitive, emotional and social aspects of selfcharacterization before and after study abroad experience. Also, the mean analysis for the Self-Directed-Search provided the dominant groups characteristics between the types of occupational environments and personal domains. In the next Chapter, a descriptive results presentation is provided.

The group's mean is provided regarding vocational activities, competencies, occupations and self-estimates in relation to the six types of occupational environments (realistic, investigative, artistic, social, entrepreneur and conservative). For a trustworthy understanding and reliability of the students' vocational preferences impacts and changes (before and after), an in-depth interpretation with group and individual mean, before and after study abroad, was extracted (see next section 4.4 descriptive results comparison before and after study abroad experience of four individual cases).

Table 3.2 is an example of a (SDS) self-administrated summary which was reported by a student (F6) before study broad experience. The summary code "SRC" represents the type of vocational environment that are dominant by the student's preferences.

Table 3.2 Example of Holland's Self-Directed-Search summary

\begin{tabular}{|l|c|c|c|c|c|c|}
\hline & R & I & A & S & E & C \\
\hline ACTIVITES & 6 & 5 & 10 & 9 & 6 & 10 \\
\hline COMPETENCIES & 7 & 0 & 3 & 4 & 1 & 8 \\
\hline OCCUPATIONS & 10 & 7 & 9 & 13 & 7 & 8 \\
\hline SELF-ESTIMATES & 12 & 6 & 9 & 13 & 9 & 6 \\
\hline TOTAL & 35 & 18 & 31 & 39 & 23 & 32 \\
\hline
\end{tabular}

Student's score (before study abroad experience): SOCIAL-REALISTIC-CONSERVATIVE = SRC 
The sum was executed by either the research participants or the researcher. The left column shows the four vocational domains of assessment before and after the studying abroad experience. The domain of self-estimates, in terms of skills and abilities, is a selfassessment domain (low score $=2$; average score $=8$; high score $=17$ ). The occupations domain corresponds to different types of work or professions in all six areas of the research students' disclosed preferences. The competencies domain reveals those activities (out of 11 questions per type of environment) where the research students feel they perform well or competently. The Activities domain assesses the type of vocational activity (out of 11 activities) that the research students "like" or "dislike" doing.

The data analysis and interpretation has been carried out and divided in two sections. The presentation comes first with a descriptive results interpretation for the entire research group (e.g. sections 4.1, 4.2 and 4.3) and then comes a detailed descriptive comparisons analysis and interpretation of four research students. Further details regarding the four descriptive cases data analysis will be presented in the next section 4.4.

Four research students (F1, S8, A14, and G15) who studied abroad in four different countries were randomly selected as representative evidence of the impact of selfregulative experience abroad on the students' career and vocational development. Displayed below is the qualitative method of analysis (triangulation) in which results comparisons of four cases were carried out and the instruments used for their interpretation to answer phenomenological changes.

\section{Diagram 3.2 Qualitative data analysis}

Study abroad programs experience impacts (before) and effects (after) in terms of:

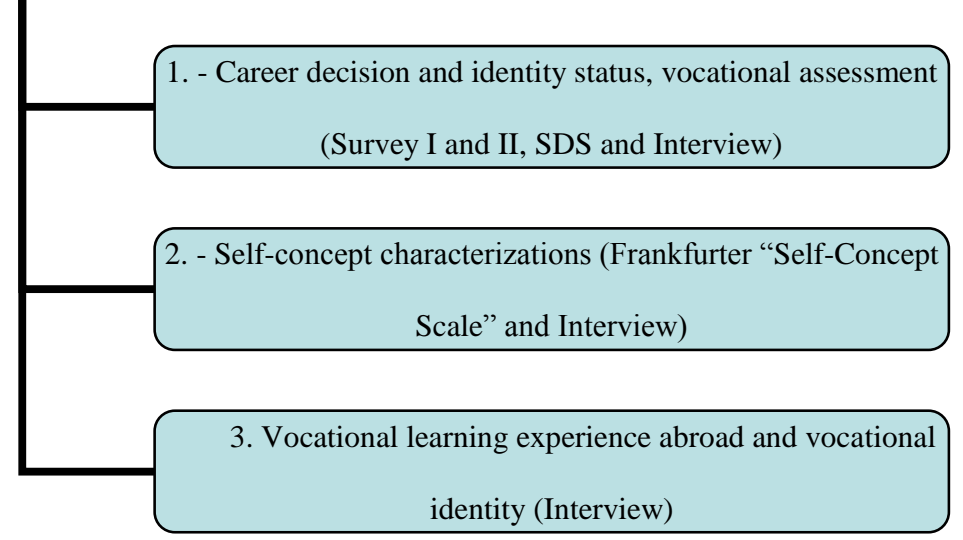


The data information of QUAL and QUAN instruments were qualitatively used to analyze and interpret student's perceptions regarding independent variables of vocational identity (career choice, vocational assessment, self-concept characterization and vocational learning experience).

\subsubsection{Qualitative data analysis}

The first stage of the qualitative data analysis followed steps as described by Gay, Mills and Airasian (2009), and the second stage involved a profound text analysis as described by Mayring (2000).

To maximize the reliability of this research study purpose, such as the impact of study abroad experience on research students' self-perceptions and their vocational interest development, the qualitative data was heavily analyzed. The process for the data analysis starts first in "becoming familiar with the data and identifying potential themes to understand the research students; second, by examining the data in depth and providing detailed descriptions of the students (e.g. describing); and third, categorizing and coding pieces of data and grouping them into themes (e.g. classifying)" (p. 449). See more details in the next section of qualitative data analysis.

The software N-VIVO 7.0 was used in order to make the data analysis meaningful and understandable. This N-VIVO 7.0 software, in accordance with Mayring's (2000) procedures of qualitative content analysis, facilitated the organization of meaningful bits extracted from textual data by making it available to code and categorize the material. The process of data organization and interpretation was made possible by using this qualitative data analysis NVIVO 7.0 software.

A transcriber was employed to transcribe the interviews. Once the interviews were transcribed, they were reformatted into a Word processor 2003-2007 document, in order to analyze them using N-VIVO 7.0. Once all interviews were transferred into NVIVO 7.0, the rereading commenced. The interviews were read and reread several times to get even more familiar with the material and furthermore to gain a closer approach to the students' cognitive reflection on study abroad motives and goals, strengths and weaknesses, selfperception, vocational identity satisfaction and career plans for the future. During the 
reading process, short phrases were written in the margins (or into the text itself) highlighting patterns of communications, adjustments, and identity within their statements. In order to code the collected data and understand vocational behavior and maturity within career development, personal determinants were identified that contribute to a student's vocational career development (Lent, Brown, \& Hackett 1994). Going away to study abroad requires a series of motivational factors that inspire the students to go abroad, and experience something new that is beyond their familiar environment and comfort zone. Just making the decision to study in another country and encountering another culture and traditions abroad implies a lot of courage, effort and personal investment, which at the same time, leads them to their (individual) goals. Students, by going abroad, are actively engaged in vocational career activities that move them closer to their vocational identity. In other words, students engaged in a long-term program abroad have a specific target and objective that will have an effect on their career development, which at the same time, will contribute to their personal growth and vocational career maturity. These internal forces are referred to as vocational interest.

This research study is essentially looking at what impact their semester study abroad experience might have on their vocational development and furthermore, on their interests and skills regarding their future professional and career goals. For instance, there were themes that emerged out of the interviews that helped to understand this phenomenon from three main dimensions (Motivation, Resources and Goals):

- What types of motivational factors attract research students to go abroad and how those factors are oriented towards their personal or vocational career plan before they go abroad and after they return. How intercultural experiences abroad benefit research students' personal and vocational development.

- What sort of personal resources (social, personal, intercultural or financial) are research students equipped with and how these personal resources might be affected or impacted by study abroad and furthermore, how these resources may shape and facilitate their vocational career interests and choices after studying abroad? 
- What types of goals research students have by participating in study abroad programs, as well as how these goals are valued by them and applied or utilized for their vocational career development?

\subsubsection{Procedures}

The research questions are directed to examine the research students' expectations of their approaching study abroad experience and their outcomes after their study abroad experience.

To maintain reliability and confidentiality in the data analysis and interpretation, the basic ideas of Mayring's (2000) content analysis were applied. This facilitated a profound data analysis of all 15 students and, in particular, the four cases mentioned in section 4.4.

Those basic ideas led the researcher to take advantage of a more qualitative text interpretation. Mayring (2000) proposed four steps to execute the data analysis and maintain reliability.

Step 1: Reading the material: The material needs to be integrated into a model of communication. There should be a determination as to which part of the communication inferences shall be made to the aspect of the communicator (experiences, opinions, feelings).

For a trustworthy qualitative analysis, it was necessary to become familiar with all data sources collected though the interviews. The interviews were read several times to get a comprehensive idea of each student's articulations. Units of content emerged such as motivation, resources and goals. A notebook with relevant notes was created to profoundly appreciate student's reflective information. These notes were discussed and reviewed along with two other research assistants' students to concur with student's main themes. For Gay, Mills and Airasian (2009), this point encompasses three steps (reading, describing and classifying) into qualitative data analysis. According to them, these steps could be repeated as needed.

STEP 2: Rules of analysis: The material is to be analyzed step by step, following rules of procedure, devising the material into content analytical units. The first units that emerged 
during the first analysis were: motivations, resources and goals. These dimensions were categorized into new specific units: personal, intercultural and vocational development.

STEP 3: Category building: Categories need to be structured as a focal point of the analysis, e.g. the aspects of text interpretation. With the support of the research questions which were organized into categories. These categories were then carefully extracted and revised within the process of analysis (feedback loops). For better reliability, this was revised twice and discussed with two other research students.

STEP 4: Criteria of reliability and validity: The procedures have the pretension to be inter-subjectively and comprehensible, to compare the results (e.g. from interview) with other (e.g. FSKN, Surveys and SDS for relationship among data sources) results in the sense of triangulation (pp. 2 and 3). The data content analysis has been based on the deductive category development. The main idea of this analysis method is that this application requires providing explicit definitions, examples and coding rules for each deductive category, deciding exactly under which circumstances a text passage can be coded with a category (pp. 4 and 5).

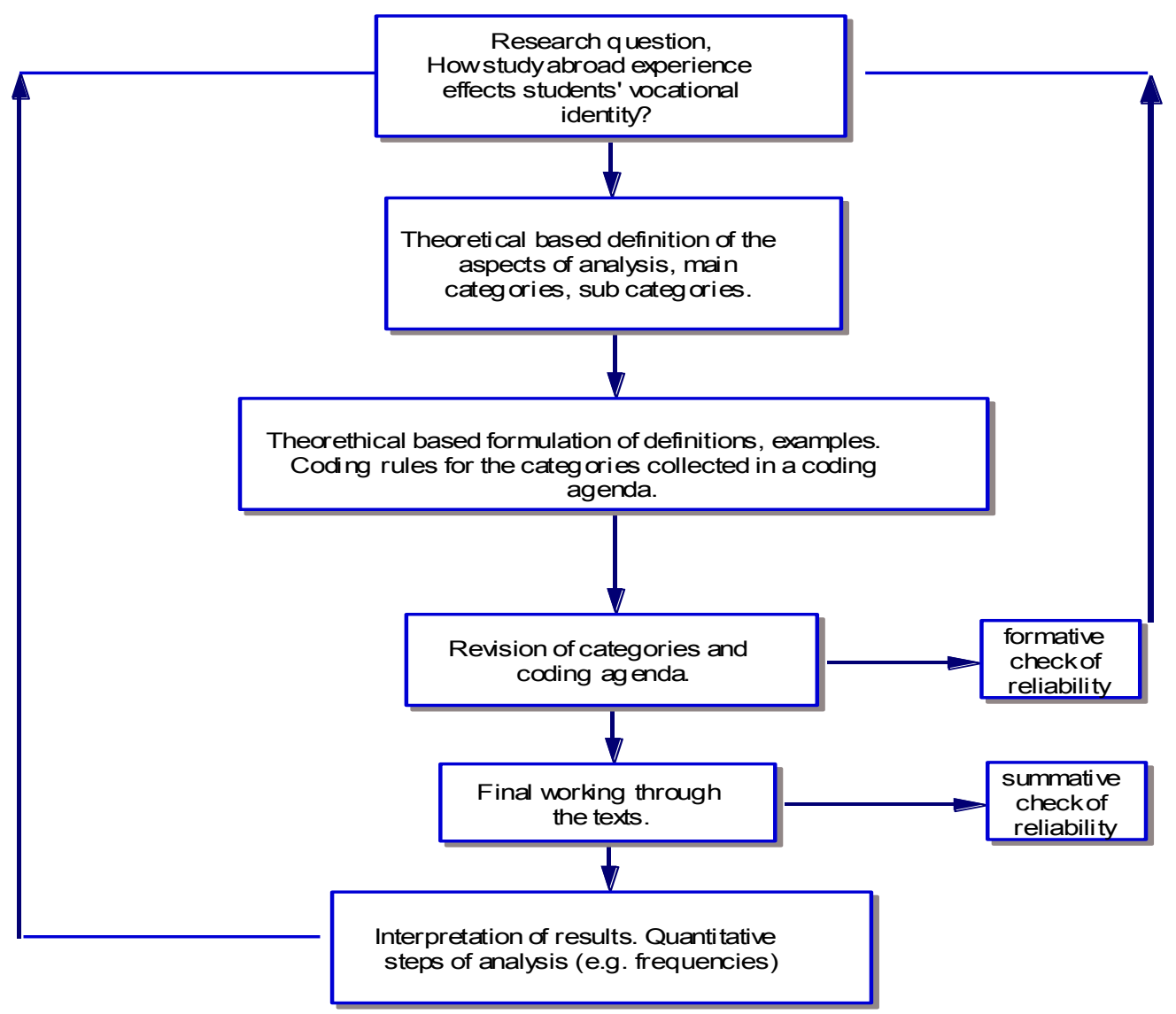

Diagram 3.3 Step model of deductive category application (Mayring 2000) 
After reviewing the theoretical literature regarding vocational behavior and identity development (e.g. career-choice status, self-perception, self-efficacy, motivation and goals) and following Mayring's step-model, the aspect of category building for the data analysis commenced. The case study analyses looked at how a study abroad experience might impact a student's vocational career choice and identity development. To understand this phenomenon, it was necessary to analyze what motivational forces move research students towards a goal, what types of resources they count on, and finally, what are the actual goals they have which motivate them to participate in a semester study abroad experience.

By reviewing the interviews, as a whole, the dimensions (motives, resources and goals) evolved. Once the qualitative data was coded into each dimension, new categories (e.g. personal, intercultural and social values) emerged as the transcripts were read and coded. This process was helpful in identifying clustered comments made by various research students with references to these new categories. After the coded statements were reviewed once more, the transcripts were read a second time to verify the initial coding data and update codes to reflect whether they had been expanded or consolidated. Any response that was related to any one category was coded to the corresponding category, considering that each statement was coded no more than once.

1. Motivation: The units of motivation were analyzed in depth, and embrace all research students' statements that primarily reflect (emotive expressions) a sense of enthusiasm, inspiration or a reason to be attracted to participate in a study abroad program (experience). In other words, the set of reasons that determines students' engagement in a particular activity falls under this dimension, which may be expressed in an implicit or explicit manner. Motivation can be represented by statements about skills (in forms of steps) that research students know they possess or plan to develop further. By the statements' analysis, the question "why" has been of relevant assistance to find the corresponding information that would fall under this dimension. There were three subcategories extracted from these dimensions: intercultural development, personal development and social factors. 
Although it was never excluded for further analysis, it is significant to mention, for the purpose of this study and the role of motivation within the vocational development, that during the posteriori text analysis, this dimension ("motivation") became relatively difficult to identify. Questions were applied to maintain the meaning of the dimension motivation (e.g. the implicit or explicit reasons why the research students remained, or not, engaged in a specific and individual task).

While this domain encountered concrete statements during the first data analysis, during the second data analysis, the students' statements emerged (e.g. encountered) more in the direction of motivational conditions that somehow kept them motivated and attached to a certain personal task.

2. Resources: This dimension compiles all students' statements, where students verbalize how they describe their person, regarding skills and abilities, vocational preference and career choice, as well as their financial, social and values as resources. This dimension of resources can be represented by the student's statements, not limited to reflections and acquired skills, abilities, career choice status and values regarding their personal or social circumstances, which are linked to or somehow associated with their cognitive representation of their current self-concept.

3. Goals: This dimension embraces statements that address a well and firm plan, or work plan to achieve a certain task. It is an objective that the student carefully plans or intends to achieve. The objective of this dimension was to include real plans, not desires or dreams. This dimension emerged during the data analysis; on the whole, this dimension was difficult to identify from the students statements due to their level of career maturity. By coding data from this dimension and also by delimiting it from the dimension of "motivation," key questions served as excellent resource tools (e.g. what is the purpose of her/his action). In the next section, the three dimensions, along with their categories and subcategories will be presented. Each dimension description and meaning, as well as the (sub) categories, will be exposed with a more detailed description.

The Diagram below illustrates the themes found during the qualitative data analysis, as well as the order in which they will be displayed in this section. Note that an example of coded statements by dimension, categories and subcategories will be provided. 
Diagram 3.4 Dimensions and categories emerged from the qualitative data analysis

\begin{tabular}{|c|c|c|}
\hline Dimension & Categories & Subcategories \\
\hline 1. Motivation & $\begin{array}{l}\text { 1. Intercultural Development } \\
\text { 2. Personal Development } \\
\text { 3. Social factors }\end{array}$ & $\begin{array}{l}\text { 1.1 Learning } \\
\text { 1.2 Language } \\
\text { 1.3 Academic and Institutional } \\
\text { 2.1 Vocational } \\
\text { 2.2 Self-growth } \\
\text { 2.3 Self-knowledge } \\
\text { 3.1Family }\end{array}$ \\
\hline 2. Resources & $\begin{array}{l}\text { 1. Cognitive } \\
\text { 2. Vocational career } \\
\text { 3. Social } \\
\text { 4. Others issues } \\
\text { 5. Programs values }\end{array}$ & $\begin{array}{l}\text { 1.1 Strengths } \\
\text { 1.2 Weaknesses } \\
\text { 1.3 Self-concept } \\
\text { 1.4 Challenges } \\
\text { 3.1 Family } \\
\text { 3.2 Peers }\end{array}$ \\
\hline 3. Goals & $\begin{array}{l}\text { 1. Vocation and career develop } \\
\text { 2. Intercultural experience } \\
\text { 3. Personal development }\end{array}$ & $\begin{array}{l}\text { 1.1 Vocational vision } \\
\text { 2.1Traveling } \\
\text { 2.2 Academic experience } \\
\text { 2.3 Language } \\
\text { 2.4 Intercultural learning } \\
\text { 3.1 Communication skills } \\
\text { 3.2 Maturity } \\
\text { 3.3 Self-identification } \\
\text { 3.4 Independency and autonomy } \\
\text { 3.5 Self-confidence }\end{array}$ \\
\hline
\end{tabular}




\subsubsection{Dimension I "Motivation"}

Diagram 3.5 presents an overview of the dimensions and the categories that were obtained from the dimension of "Motivation", which were analyzed and categorized before and after study abroad experience. Hereby, it consists of informational data that declares the reasons and intentions that keep the students working on a task which toke place before, during, or after study abroad experience.

Diagram 3.5 Dimension I "Motivation"

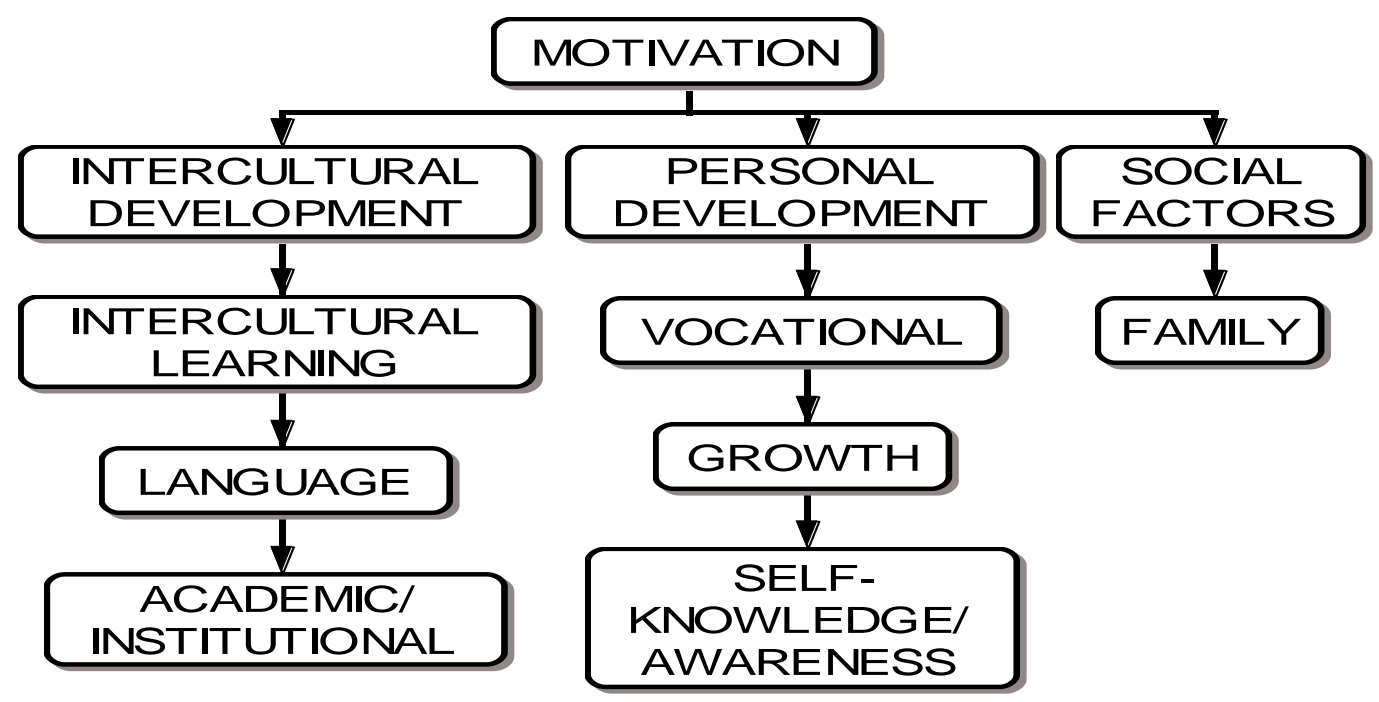

\section{Intercultural development}

This category represents related statements that are specifically directed to any kind of declarations that characterize wishes, thoughts or reflections within an international and educational learning setting.

\subsection{Intercultural learning}

Classified in this subcategory are all the intercultural statements represented by the desires of gaining intercultural experience and awareness.

\subsection{Language}

This subcategory embraces declarations that are closely associated to any student's incentive in improving a (mother) language in some way but also included is any interest in the acquisition and proficiency of a foreign language. 


\subsection{Academic and institutional}

In this subcategory fall all informational statements that are specifically referred to as intercultural motives and purposes that relate to a student's intercultural motivation within the instructional and academic framework, namely that which relates to his/her academic environment (professors, advisor, staff and classmates) and institutional (such as systems) environment.

As follows, an example of intercultural category and its subcategories before and after study abroad experience is presented.

\begin{tabular}{|l|l|l|}
\hline $\begin{array}{l}\text { 1.Intercultural } \\
\text { development }\end{array}$ & \multicolumn{1}{|c|}{ Before SA } & \multicolumn{1}{c|}{ After SA } \\
\hline $\begin{array}{l}\text { 1.1 Intercultural } \\
\text { learning }\end{array}$ & $\begin{array}{l}\text { I think study abroad is a pretty } \\
\text { important opportunity, to get to go to } \\
\text { another continent, another country, } \\
\text { and immerse yourself into different } \\
\text { cultures and an international } \\
\text { environment... (Juan, Para. 1). }\end{array}$ & $\begin{array}{l}\text { My experience abroad taught me about } \\
\text { other people and about my world } \\
\text { perspectives, and almost the world view } \\
\text { changed. You realize, how little you } \\
\text { know, and how much there is abroad to } \\
\text { know... and you also learn about } \\
\text { yourself (Miguel, Para. 1). }\end{array}$ \\
\hline 1.2 Language & $\begin{array}{l}\text { Here in the US, I don't think, I will } \\
\text { have the ability to be practicing the } \\
\text { [French] language as fluently as in } \\
\text { France... (Darian, Para., 5) }\end{array}$ & $\begin{array}{l}\text { Now, I would go anywhere that they } \\
\text { would let me... somewhere in Asia just } \\
\text { because they are different, that would be } \\
\text { even harder, because of the language } \\
\text { there... (Sara, Para. 29). }\end{array}$ \\
\hline $\begin{array}{l}\text { 1.3 Institutional } \\
\text { and academic }\end{array}$ & $\begin{array}{l}\text { Well, I expect from my experience } \\
\text { abroad to learn about the French } \\
\text { teachers because first of all, I heard } \\
\text { [in France] there are Hispanic } \\
\text { professors that are teaching French, } \\
\text { so I want to learn about them } \\
\text { (Darian, Para.,1) }\end{array}$ & $\begin{array}{l}\text { For me, I learned more, I developed } \\
\text { intellectually more from the people that I } \\
\text { met over there than from my classes, it's } \\
\text { just something about the educational } \\
\text { system over there that I didn't like (Juan, } \\
\text { Para., 17). }\end{array}$ \\
\hline
\end{tabular}

\section{$\underline{\text { 2. Personal development }}$}

Statements attributed to the students' "Self" in terms of vocational and career development, awareness and personal growth are classified in this category.

\subsection{Vocational development}

This subcategory represents each and every statement that reflects an explicit form of students' vocational interest to develop career skills for their desired future profession. Also in this category are any types (emotional or cognitive) of expressions that somehow represent students' vocational career identification. This subcategory also correlates to 
"career development" and encloses all motivational factors that are expected most likely to shape their career or vocational identity development.

\subsection{Personal growth}

This subcategory includes all of the research students' expressions that represent a profound interest to grow (development) as individuals, persons or citizens.

\subsection{Self-knowledge and awareness}

This subcategory classified all motivational statements that represent, implicitly, a student's appeal for her/his study abroad experience such as gaining a better sense of selfknowledge. Some examples of self-awareness, personal career and vocational development, and personal growth" will be presented in the following Table.

\begin{tabular}{|l|l|l|}
\hline $\begin{array}{l}\text { 2. Personal } \\
\text { development }\end{array}$ & \multicolumn{1}{|c|}{ Before SA } & \multicolumn{1}{|c|}{ After SA } \\
\hline $\begin{array}{l}\text { 2.1Vocational } \\
\text { development }\end{array}$ & $\begin{array}{l}\text { So going abroad is going definitely to } \\
\text { help my vocational career, but I don't } \\
\text { think, if it is going to motivate me to } \\
\text { change it... it might reinforce it a little } \\
\text { bit... it might just make me feel like, } \\
\text { yea! That it is [my career], definitely. } \\
\text { (Alberto, Para.,6) }\end{array}$ & $\begin{array}{l}\text { Study abroad reinforced my career } \\
\text { choice, because I think, it'll look good } \\
\text { in my resume that I've studied in }\end{array}$ \\
$\begin{array}{l}\text { France for a semester... I speak three } \\
\text { languages; I think it'll be pretty good } \\
\text { (Sara, Para. 10). }\end{array}$ \\
\hline 2.2 Growth & $\begin{array}{l}\text { I also think part of the thing that } \\
\text { makes this experience exciting is not } \\
\text { being too informed. I kind of want to } \\
\text { get there, and not know, not be like } \\
\text { you're going to do this, like I just } \\
\text { want to... like... experience it, let it } \\
\text { come to me and whatever } \\
\text { happens...because I kind of just } \\
\text { wanted to get there, and the first } \\
\text { person I see that walks, start talking to } \\
\text { them and see where that leads me to. I } \\
\text { mean ...I kind of just want to let the } \\
\text { experience hit me rather than me } \\
\text { guided through the experience (Juan, } \\
\text { Para. 13). }\end{array}$ & $\begin{array}{l}\text { No, I would never have this experience } \\
\text { here. I think I would be the same, as I } \\
\text { used to be. I don't know why, because } \\
\text { over there, in Germany, I was } \\
\text { independent, I was like if I was going } \\
\text { to do anything [by myself], there was } \\
\text { no one to tell me, I couldn't do it or I } \\
\text { wasn't going to do it, but it makes me } \\
\text { more mature (Marc, Para., 34). }\end{array}$ \\
\hline $\begin{array}{l}\text { Yes! ...study abroad is going to help } \\
\text { me to identify myself. (Sara, Para. 8). }\end{array}$ & $\begin{array}{l}\text { 2.3 Self-knowledge } \\
\text { and awareness }\end{array}$ & $\begin{array}{l}\text { Into another country, basically } \\
\text { knowing nothing; it taught me a lot } \\
\text { about myself. (Miguel, Para. 1) }\end{array}$ \\
\hline
\end{tabular}




\section{Social factors}

Statements considered in this category are related to students' motivational reasons that are expressed and attributed to at least one of the following social groups outside of the academic environment: family and peer groups.

\begin{tabular}{|l|l|l|}
\hline 3. Social factors & \multicolumn{1}{|c|}{ Before SA } & \multicolumn{1}{c|}{ After SA } \\
\hline 3.1 Family & $\begin{array}{l}\text { What motivates me to go study } \\
\text { abroad is my family. My family; } \\
\text { it's a goal for me to go there... I } \\
\text { want my parents to be proud of me. } \\
\text { (Adriana, Para. 1,2,3) }\end{array}$ & $\begin{array}{l}\text { Well, I always wanted to go on my own, } \\
\text { my parents were always a little scared of } \\
\text { letting me go by myself, but I always } \\
\text { wanted to have that experience, I guess } \\
\text { they did motivate me in some ways. } \\
\text { (Sofia, Para. 18). }\end{array}$ \\
\hline
\end{tabular}

\subsubsection{Dimension II "Resources"}

The dimension "resources" was created and established to encompass all data information that represents diverse sources and assets that research students felt were necessary. This dimension is something that the research students already possessed or had adopted from their experience abroad.

It is pertinent to underline that, during their experience abroad, the research students were immersed into an active intercultural process, so that statements concerning personal resources were classified as such, only if they were closely expressed and linked to the present (time).

In this dimension, the types of resources that were found in students' statements were: cognitive, social resources (i.e. peers, family etc.); vocational career resources, and programs values. 


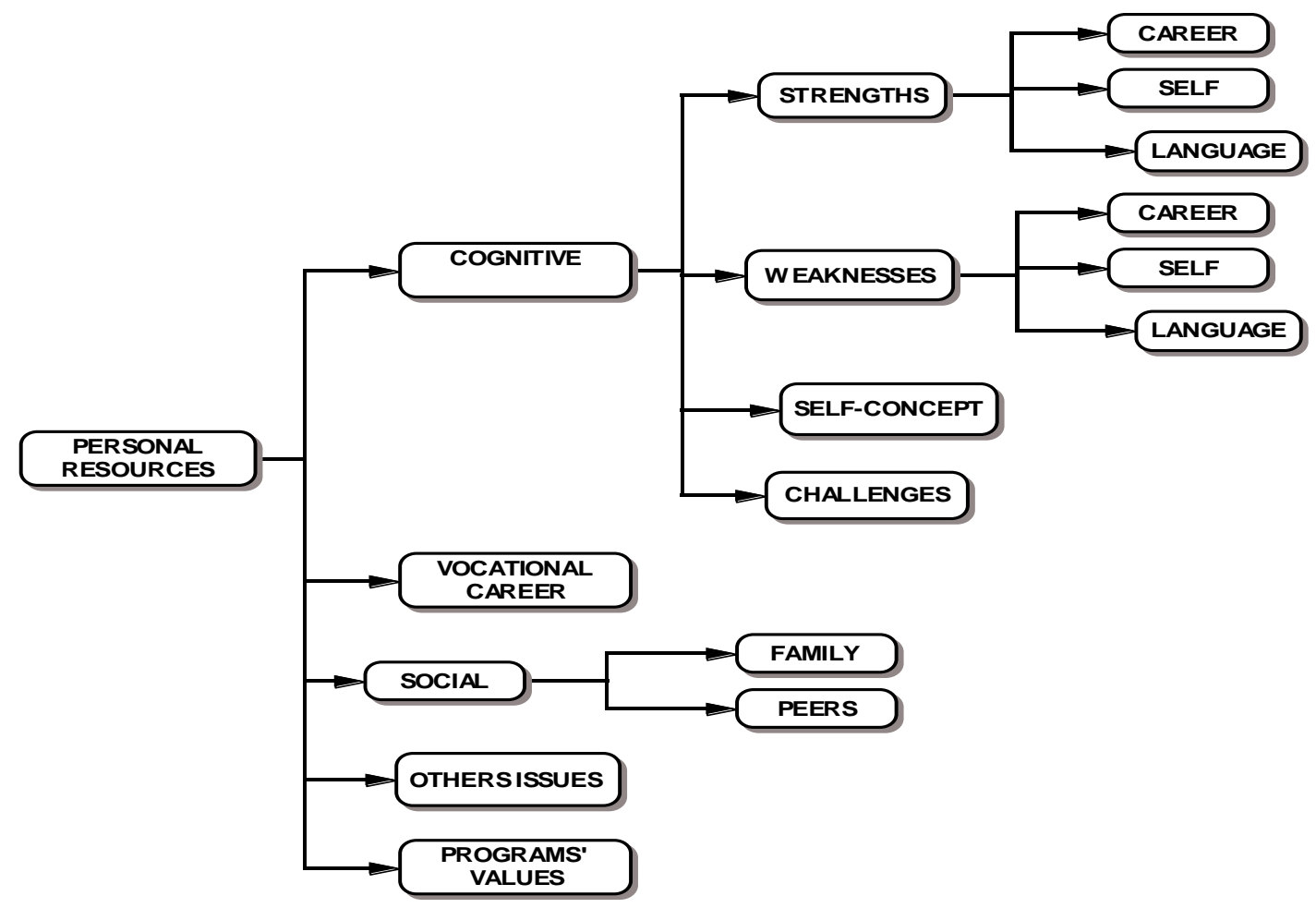

\section{Cognitive development}

All the informational data attributed to their cognitive and personal abilities was placed in this category, namely the self-concept and its beliefs in their own capabilities, which provides a good sense of assured skills and abilities to perform. The cognitive category includes students' statements that represent students' reflections about themselves, personal strengths and weaknesses that are either linked to their experience abroad or their career, before and after study abroad experience.

\subsection{Strengths}

This category represents, in contrast to weaknesses, everything the research students perceive to be an asset and a strong component, namely a positive pivot of self-efficacy. This informational data characterized students' personal acknowledgment in terms of being capable of performing a task well.

\subsection{Weaknesses}

This category represents, in the words of Bandura (1997), the most relevant domain of "self-efficacy" in personal agency. This domain includes all perceptions that are valued as a weakness for the research students (e.g. loss of control, where students either do or do 
not believe that they are capable, good enough, or believe that they do not have control). This informational data provides an in-depth analysis into the sense of dearth, ambiguity, vulnerability, ineffectiveness and sometimes failure.

The category of weaknesses, as well as the previous category of "strength," was found to have been strongly related to the three main areas of development: self, career and language. This could also be called self-efficacy in relation to the self, self-efficacy in relations to career and self-efficacy in relation to language.

\subsection{Self-concept}

Enclosed in this subcategory are all statements that the students used to describe themselves and, furthermore, all accounts that expressed beliefs about self in physical, social and academic domains (McInerney \& McInerney 2006). In particular, students' responses are included here to the interview question, "How do they describe themselves before and after their experience?"

\subsection{Challenges}

This category represents explicit declarations where the students perceived and emphasized a certain developmental circumstance as a difficult task and, also, where they felt like they were being challenged and were faced to create coping strategies.

Examples of the cognitive development before and after study abroad:

\begin{tabular}{|l|l|l|}
\hline $\begin{array}{l}\text { 1. Cognitive } \\
\text { development }\end{array}$ & \multicolumn{1}{|c|}{ Before SA } & \multicolumn{1}{c|}{ After SA } \\
\hline $\begin{array}{l}\text { 1.1 } \\
\text { Strengths }\end{array}$ & $\begin{array}{l}\text { My personal strength... I am... I'm very } \\
\text { committed if I set a goal, I am very } \\
\text { committed to reaching that goal. I can } \\
\text { communicate with people, and I can ask } \\
\text { around, and see what it is that } \\
\text { everybody is looking for, that's not hard } \\
\text { for me... (Sara, Para. 6-7) }\end{array}$ & $\begin{array}{l}\text { As far as my strengths, I think there were } \\
\text { skills that I was already beginning to } \\
\text { develop before I went, but they really } \\
\text { solidified abroad, they really came into } \\
\text { being clearer, they were stronger, more } \\
\text { developed skills....(Juan, Para., 24) }\end{array}$ \\
\hline $\begin{array}{l}\text { Weaknesses } \\
\text { Weake }\end{array}$ & $\begin{array}{l}\text { The weakness to my career choice, well, } \\
\text { I think that my career choice is still a } \\
\text { little hazy and undecided. On the other } \\
\text { side, towards my study abroad program } \\
\text { is that sometimes, I tend to have too } \\
\text { much fun and sometimes it gets in the } \\
\text { way of your school work... (Juan, Para. } \\
\text { 7-8). }\end{array}$ & $\begin{array}{l}\text { Now, I can't pin point it to exactly what } \\
\text { career I want to have. To me the idea of a } \\
\text { career winds down to what you are going to } \\
\text { be doing because it has already been set by } \\
\text { other people... I think... And so I kind of } \\
\text { want to break out of that and I see a } \\
\text { possibility of having a career where I am in } \\
\text { control of what I want to do and where I } \\
\text { want to go... Juan Para, 9). }\end{array}$ \\
\hline
\end{tabular}




\begin{tabular}{|c|c|c|}
\hline $\begin{array}{l}1.3 \text { Self- } \\
\text { concept }\end{array}$ & $\begin{array}{l}\text { I think, I consider myself a responsible } \\
\text { person, I help a lot people. I am always } \\
\text { trying to be there for everyone, for my } \\
\text { family, my friends, and I never make } \\
\text { myself go down with any problem that I } \\
\text { have, I always try to solve or confront } \\
\text { them ... So I think like a responsible } \\
\text { person, I am always trying to be to have } \\
\text { success in my career... pass all my } \\
\text { classes never let down by anyone, so I } \\
\text { think that is how I consider myself } \\
\text { being a responsible caring person. } \\
\text { (Darian, Para., 10) }\end{array}$ & $\begin{array}{l}\text { I would have to say that through my } \\
\text { experience abroad, I learned to be more } \\
\text { independent in solving my own problems, } \\
\text { because before I've always been around } \\
\text { family and friends that had help, but this } \\
\text { was in a whole, different in other country. } \\
\text { I had to do things myself. For example, } \\
\text { when I wanted to go travel I had to plan } \\
\text { my own trip, and it just made me more } \\
\text { kind of independent and yeah, it's just } \\
\text { character building... (Diana, Para. 11) }\end{array}$ \\
\hline $\begin{array}{l}1.4 \\
\text { Challenges }\end{array}$ & & $\begin{array}{l}\text { Yeah... definitely I spent more time with } \\
\text { myself. Six months is a long time and in } \\
\text { those six months there are good times and } \\
\text { there are bad times and yes in the bad } \\
\text { crucial critical moments, there were } \\
\text { definitely times that I had to reflect and } \\
\text { introspect, and figure things out on my } \\
\text { own, and yes, definitely, I was outside my } \\
\text { comfort zone, so I had to get over that, and } \\
\text {... I did (Juan, Para., 3) }\end{array}$ \\
\hline
\end{tabular}

\section{Vocational career}

The informational data that lead students' to their vocational career status or decision is defined in this category. In contrast to the previous category of "vocational career" under motivation, this is a personal resource that applies to the student's current decided career choice or any other affirmation of information related to his/her vocational interest, preference and identity.

\begin{tabular}{|l|l|l|}
\hline 2. Vocational career & \multicolumn{1}{|c|}{ Before SA } & \multicolumn{1}{c|}{ After SA } \\
\hline $\begin{array}{l}\text { 2.1 Vocational } \\
\text { career status }\end{array}$ & $\begin{array}{l}\text { I am not hesitating about my } \\
\text { vocational career, but I need to } \\
\text { know more about the career that I } \\
\text { choose, what it is that I'm } \\
\text { interested in... (Cecilia, Para., 4) }\end{array}$ & $\begin{array}{l}\text { I think definitely, my career choice } \\
\text { wasn't so clear before I went study } \\
\text { abroad, but now, I enjoy } \\
\text { economics. There is a difference } \\
\text { between just having an idea as } \\
\text { your career path and then getting } \\
\text { submerged in the subject, and now } \\
\text { actually enjoying it, I don't know, } \\
\text { if a lot of people are blessed to } \\
\text { have this opportunity, but yeah } \\
\text { going abroad it did reinforce it. } \\
\text { (Lorena, Para., 4) }\end{array}$ \\
\hline
\end{tabular}




\section{Social}

Students' assertions are in this category, in terms of social resources (family member, peers and others) which they counted on before, during or after their study abroad experience and which is also considered part of the student's behavioral engagement.

\begin{tabular}{|l|l|l|}
\hline 3. Social & \multicolumn{1}{|c|}{ Before SA } & \multicolumn{1}{c|}{ After SA } \\
\hline 3.1 Family and Peers & $\begin{array}{l}\text { I think, my strengths are all the } \\
\text { support that my parents have } \\
\text { given me to go study abroad" } \\
\text { (Darian, Para., 6) }\end{array}$ & $\begin{array}{l}\text { There is a girl that I've been } \\
\text { exchanging emails. She's coming here } \\
\text { to Texas and ... still keep in touch } \\
\text { with her. We're planning trips... (Sara, } \\
\text { Para., 21) }\end{array}$ \\
\hline
\end{tabular}

\section{Others}

This category contains all students' statements that somehow do not fall into any of the above mentioned categories and, also, all accounts which were not relevant for the purpose of this research.

\section{Programs' values}

Found in this category are the appreciation (high or low) or regard of diverse issues that somehow they felt they had adopted or learned from their study abroad experience. Ideas positively accepted in their values hierarchy for personal development.

\begin{tabular}{|l|l|l|}
\hline 5. Programs' values & \multicolumn{1}{|c|}{ Before SA } & \multicolumn{1}{c|}{ After SA } \\
\hline $\begin{array}{l}\text { 5.1 Programs' } \\
\text { values }\end{array}$ & $\begin{array}{l}\text { I want to say my study abroad } \\
\text { program in Spain it's going to be } \\
\text { an experience, because the Spanish } \\
\text { that we speak here in the area is } \\
\text { not the same that probably they } \\
\text { speak over there ... (Lorena, Para., } \\
\text { 2). }\end{array}$ & $\begin{array}{l}\text { Ok, the study abroad program takes you } \\
\text { out of your comfort zone, you're out of } \\
\text { your environment, and you don't know } \\
\text { what is going to happen. So hanging in } \\
\text { there, getting through it and coming out } \\
\text { of the other end, makes you an } \\
\text { incredibly stronger person, I think that is } \\
\text { one of the main things (Lorena, Para. } \\
\text { 15). }\end{array}$ \\
\hline
\end{tabular}

\subsubsection{Dimension III "Goals"}

This dimension was one of most difficult to identify during the data analysis. In contrast to the dimension of "motivation," the dimension of goals, gathers students "declarations that 
are expressed in terms of a, sound and valid, work plan. This dimension is also an expressed objective that the students carefully plan or intends to achieve. This dimension represents a concrete and unwavering intention on a specific goal.

Diagram 3.7 Dimension III “Goals”.

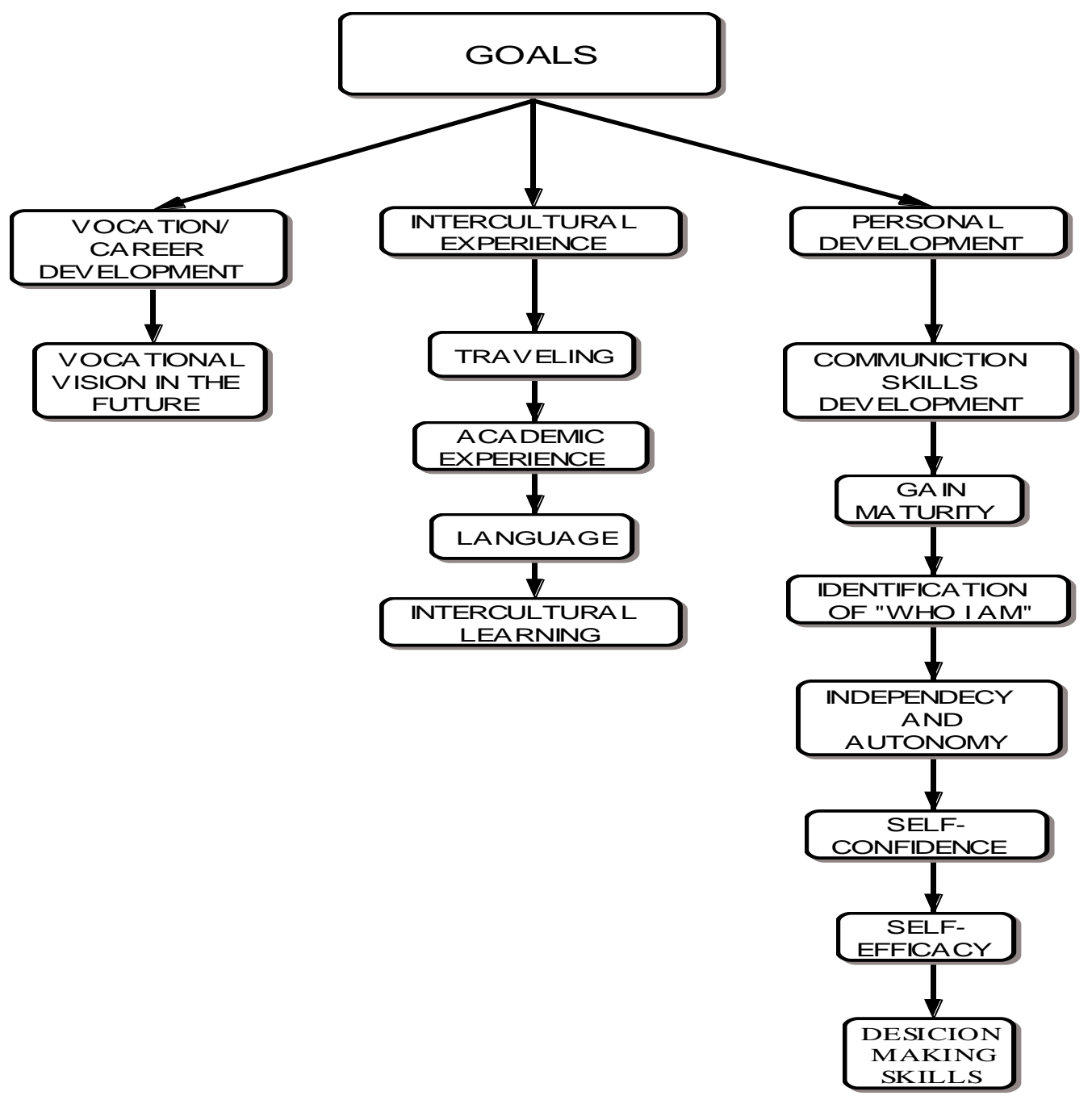

\section{Career and vocational development}

Contemplated in this category is each and every one of the informational statements that reflect a specific-task plan in regards to students' vocational behavior, such as achieving career skills for their desired future profession.

\subsection{Vocational career}

This category contains statements that somehow represent a strategy for the students' vocational identification development regarding their career related plan. 


\begin{tabular}{|l|l|}
\hline $\begin{array}{l}\text { 1. Career and } \\
\text { vocational development }\end{array}$ & \multicolumn{1}{c|}{ Before SA } \\
\hline 1.1 Vocational career & $\begin{array}{l}\text { I feel that by going to France, and learning French that would even } \\
\text { expand my borders even more, and ...that's really what I'm looking } \\
\text { forward to. So, I know that learning the language doesn't come over } \\
\text { night, and I'm planning on learning more even in the future, so I see that } \\
\text { if I learn one right now maybe another one in a year, two by the time I'm } \\
\text { old thirty, forty, fifty, I'm going to, hopefully, be speaking a few more so } \\
\text { then I'll be able to do my own part in my [doctor career] own way and } \\
\text { help out people... (Alberto, Para. 9). }\end{array}$ \\
\hline
\end{tabular}

\subsection{Vocational vision}

In this subcategory, students' vocational career visions are in representing plans, as well as the congruence and constancy of the students' vocational career and identity development. Included in this subcategory are all students' statements that refer to how they visualize themselves in the future with regards to their career and professional plans. The Table presents some examples of (long-term) goals' declarations before and after their study abroad.

\begin{tabular}{|l|l|l|}
\hline $\begin{array}{l}\text { 1.2 Vocational } \\
\text { career vision }\end{array}$ & \multicolumn{1}{|c|}{ Before SA } & \multicolumn{1}{c|}{ After SA } \\
\hline & $\begin{array}{l}\text { How do I visualize myself in the } \\
\text { future? Definitely having my own } \\
\text { business. Maybe I start with } \\
\text { something small but I definitely } \\
\text { having my own business, this is } \\
\text { going to provide me with the level... } \\
\text { that I am contributing in my own } \\
\text { way to society... (Lorena, Para. 10). }\end{array}$ & $\begin{array}{l}\text { Five years from now, I will be definitely } \\
\text { getting a Masters in the European Union } \\
\text { Studies and working maybe in some } \\
\text { governmental agency where I can use } \\
\text { this knowledge and... trying to advise... } \\
\text { (Lorena, Para. 8) }\end{array}$ \\
\hline
\end{tabular}

\section{$\underline{\text { 2. Intercultural development }}$}

The intercultural development category manifests students' declared goals that are linked to a type of international experience that is focused on acquiring a better global knowledge and experience. From this data, four related subcategories emerged. In reference to this domain, the subcategories are geared towards gaining experience in traveling, academic experience, language and intercultural learning. 


\subsection{Traveling}

This subcategory embraces students' plans in general that are closely related to the experience of traveling (experiential cultural interactions), namely studying abroad just to travel for fun and recreation. Example:

\begin{tabular}{|l|l|}
\hline 2. Intercultural experience & \multicolumn{1}{c|}{ After SA } \\
\hline 2.1 Traveling & $\begin{array}{l}\text { I think, if I were to go back abroad, it would be more in the way } \\
\text { of learning by traveling...it would be to get to know more } \\
\text { cities... I missed getting to know a lot of cities... (Darian, Para. } \\
25 ; \text { original text in Spanish in Appendix No.7, p. 261 ) }\end{array}$ \\
\hline
\end{tabular}

\subsection{International academic experience}

This category, in contrast to the categories of "traveling and language," contains all of the students' specific plans that are focused on acquiring more academic oriented knowledge from their exchange experience within an international education system, degree plan or teaching performance in their visiting country. An overview will be presented in the next Table.

\subsection{Language}

This category includes all students' declarations that led them to consider the study abroad experience as an opportunity to gain language oriented knowledge, specifically to learn and to improve a (foreign) language and furthermore to gain proficiency. An example of this category appears below.

\begin{tabular}{|l|l|}
\hline 2. International experience & \multicolumn{1}{|c|}{ Before SA } \\
\hline 2.2 Academic experience & $\begin{array}{l}\text { I also expect from my abroad experience,... I think, to be in a } \\
\text { different university system in a totally different country in a } \\
\text { different continent. It is a different experience as being here in the } \\
\text { United States (Juan, Para., 2). }\end{array}$ \\
\hline 2.3 Language & $\begin{array}{l}\text { I want to learn more about the French language because I want to } \\
\text { have a better pronunciation of the language. I think that being over } \\
\text { there, all this five months, this [spring] semester will help me to } \\
\text { increase the pronunciation, and to have better perspective of the } \\
\text { language itself... (Darian, Para. 1 and 5). }\end{array}$ \\
\hline
\end{tabular}




\section{Personal development}

This category of personal development, in terms of goals contains all students' intentions that are strictly directed and focused on having an effect on the personal "Self-growth." This could be denoted as all declarations on the subject of task-specific goals that are directed to gain and acquire certain personal skills for their self-concept: like selfconfidence, self-identity, self-maturity, independence and autonomy, self-efficacy, decision making and communications skills.

\begin{tabular}{|c|c|c|}
\hline $\begin{array}{l}\text { 3. Personal } \\
\text { development }\end{array}$ & Before SA & After SA \\
\hline $\begin{array}{l}\text { 3.1 Decision- } \\
\text { making skills }\end{array}$ & $\begin{array}{l}\text {...this trip will help me make better } \\
\text { decisions... (Darian, Para. 3) }\end{array}$ & \\
\hline 3.2 Self-efficacy & $\begin{array}{l}\text { I will be able to market any product with } \\
\text { people who speak Spanish, English or } \\
\text { French (Sara, Para. 3). }\end{array}$ & $\begin{array}{l}\text { Now, I am feeling more capable to } \\
\text { say things. I'll say something } \\
\text { because, I feel like I can, you know } \\
\text { when I was over there I traveled to a } \\
\text { different country... myself and you } \\
\text { know, alone, so now I feel like, I } \\
\text { don't know how to explain it, just I } \\
\text { am not shy (Sara, Para. 3). }\end{array}$ \\
\hline 3 Self-confidence & $\begin{array}{l}\text { I expect to have more like... } \\
\text { confidence...confidence about myself... } \\
\text { (Adriana, Para. 5). }\end{array}$ & $\begin{array}{l}\text { Now, after my experience... I'm } \\
\text { just more... I take advantage of my } \\
\text { opportunities... like I'm not afraid } \\
\text { to raise my hand in class because } \\
\text { I'm scared someone is going to } \\
\text { think something about me... (Sara, } \\
\text { Para. 2). }\end{array}$ \\
\hline $\begin{array}{l}\text { 3.4 Autonomy } \\
\text { and } \\
\text { independency }\end{array}$ & $\begin{array}{l}\text { To become more independent is what I } \\
\text { hope for from this trip. Well... my } \\
\text { objective is to see what it is like to live on } \\
\text { my own and solve my problems... not } \\
\text { count on my mom or with my parents and } \\
\text { also to see what life is like without } \\
\text { them... (Gabriela, Para. } 2 \text { and } 7 \text {; original } \\
\text { text in Spanish, see p. 261). }\end{array}$ & $\begin{array}{l}\text { Over there, you have to speak up for } \\
\text { yourself to go do things by yourself } \\
\text { in a different language and not } \\
\text { having someone there all the time, } \\
\text { like your mom and dad comforting } \\
\text { you...(Sara, Para. 2). }\end{array}$ \\
\hline $\begin{array}{l}3.5 \text { Identification } \\
\text { with who am I }\end{array}$ & $\begin{array}{l}\text { My goal is to gain some... like... } \\
\text { satisfaction with myself and hopefully } \\
\text { know myself, to have a better picture of, } \\
\text { who I am by the end of this trip... } \\
\text { (Mariana, Para. 2). }\end{array}$ & $\begin{array}{l}\text { Yes, study abroad helped me to } \\
\text { identify myself more. It kind of } \\
\text { helped me realize that I want to } \\
\text { expand the things that I'm learning } \\
\text { about myself; I want to go study } \\
\text { abroad again... (Sara, Para. 4). }\end{array}$ \\
\hline $\begin{array}{l}\text { 3.6 Gaining } \\
\text { maturity }\end{array}$ & $\begin{array}{l}\text { I expect from my experience abroad is to } \\
\text { be more like, mature... (Adriana, Para. } \\
\text { 5). }\end{array}$ & $\begin{array}{l}\text { Being abroad is really different, I } \\
\text { think it makes you grow up, it } \\
\text { makes you more open... (Sara, } \\
\text { Para. 2). }\end{array}$ \\
\hline
\end{tabular}




\begin{tabular}{|l|l|l|}
\hline $\begin{array}{l}\text { 3.7 Develop } \\
\text { communications' } \\
\text { skills }\end{array}$ & $\begin{array}{l}\text { My goal is, getting out there talking to } \\
\text { people, and if I can learn to speak to } \\
\text { people... (Sara, Para. 5). }\end{array}$ & $\begin{array}{l}\text { Now here in the classroom, my } \\
\text { experience abroad helped me very } \\
\text { much in communicating... (Sara, } \\
\text { Para. 3). }\end{array}$ \\
\hline
\end{tabular}

After a careful data analysis of all notes, observations, interviews and survey results, the descriptive data interpretation ensued and will be presented in the next section.

\subsection{Summary}

This longitudinal research study utilized a mixed-method design to analyze how the study abroad experience impacts students' vocational identity. This research seeks to profoundly understand the students' perceptions (expectations and outcomes) regarding their study abroad experience. The total number of research students was 15: 10 females and 5 males. This research was carried out as an exploratory mixed-method design, also known as a QUAL-QUAN model (Gay, Mills \& Airasian 2009), where all data sources are qualitative and are heavily analyzed to create an enhanced depiction of cognitive and emotional aspects of vocational identity.

The QUAN instruments which were employed to answer research questions were as follows:

- Survey I and II served primarily to analyze the career choice status of students before and after their experience and how this career status was either supported or influenced (family, self or other environments). Also, these surveys revealed how students assess their identity status in so far as the level of effort and commitment to find a vocational identity. Additionally, the surveys assessed how students range their study abroad experience expectations in their endeavors to find a vocational identity.

- Holland's Self-Directed-Search (a vocational self-evaluation) was employed to see how students assess their personality type with their vocational skills and abilities and how their assessed vocational identity coincides with their statements during interviews before and after study abroad experience. 
- The Frankfurter Self-Concept Scale was utilized to see how students' characterizations of self-concept reflect and agree with their statements before and after study abroad experience.

- The principal qualitative research instrument, the face to face semi-structured interview, was employed to obtain important data that may complement their vocational career choice expectations and outcomes from a study abroad experience. The purpose was to obtain data material that was not accessible with the other instruments and to corroborate or deny relationships among all data sources.

The quantitative data results were interpreted separately, and posteriori (See section 4.4) correlated with the qualitative data analysis, which was developed utilizing Mayring's procedures model and accomplished by using the computer software NVivo 7.0. For greater validity, the qualitative data analysis was correlated with and enhanced by the quantitative results. The results analysis was carried out by applying the triangulation method, which facilitated finding relationships and comparisons among qualitative data with quantitative results. Using this type of method design enriched data sources substantiation regarding cognitive and emotional aspects of vocational identity. 


\section{Chapter 4}

\section{Results}

The following chapter will present descriptive results of the quantitative and qualitative data analyses as revealed by the four instruments (Surveys; Frankfurter Self-Concept Scale; Holland's (1994) Self-Directed-Search and Interviews). The results are presented in two ways: one for the whole group of participants and the other for each of the four individual cases. The first presentation starts with a descriptive data result of each (quantitative and qualitative) instrument before study abroad experience. The second segment displays the students' descriptive results after their study abroad experience, and finally a thorough group results comparison before and after study abroad experience. The individual results presentation (4.4.) attempts to offer a profound data analysis of the four cases to truly appreciate students' career and vocational impacts. The intention of section 4.4 is to understand, in depth, the impacts of study abroad experience on vocational identity with respect to the four research participants (F1, S8, A14 and G15).

\subsection{Descriptive results before study abroad experience}

\subsubsection{Survey I "Vocational career development of college students"}

Table 4.1 displays students' profiles including each assigned code (utilizing the first letter of the country of study abroad), fictitious names, age, gender, grade point average (GPA) and their study abroad programs (by country).

Table 4.2 presents the students' career decision status (decided, undecided or not clear ), and current major, as well as the percentage (see fourth and fifth column) that students believed have attributed to their reported career decision, and the development of career information and meanings, e.g. by themselves $(\mathrm{S})$, by their family environment $(\mathrm{F})$, or by other reasons $(\mathrm{O})$. The last column of Table 4.2 represents the students' self-reported identity status in relation to the level of commitment in their decision and the level of exploration efforts and commitments in regards to their effort in finding a vocational 
identity. The percentage of students $(\mathrm{n}=12)$ with a (reported) decided major corresponds to $66 \%$, while the other $33 \%$ reported not having a professional career (major) decided.

In reference to one of the questions regarding "vocational identity status," the students were asked where they would place themselves as far as their level of investment in career exploration, and level of commitment in making a career decision. Of the students' responses, $58.3 \%$ of them reported an achieved vocational identity status, $33.3 \%$ declared being still in the foreclosure stage, while reporting that they have a "decided" major, yet are still looking for more exploration activities (might be following simple tradition). There was only one student (S9), who self-reported being in the moratorium status. In accordance with his answer, Antonio (S9) revealed not having a clear career choice of professional occupation due to diverse (unexplored) vocational career interests.

Table 4.3 represents relevant information for this study, which advocates what the students are pursuing personally and vocationally. The students were asked to rate statements from 1 to 5 in relation to their expectations of study abroad experience regarding their vocational identity development.

The respondents chose from a scale from 1 to $5(1=$ not at all, $2=$ a little, $3=$ somewhat, $4=$ a lot, and 5= totally). According to the responses from Survey I, the students before their study abroad experience were expecting to foster and promote their vocational interest through their study abroad program experience; inclusively; they reported the highest mean score of 4.08 which corresponds to the status of "a lot" $(=4)$. Even though the gain of self-knowledge is not the students' greatest and main purpose of their experience abroad, nevertheless, they reported a mean score of 3.42 corresponding to a considerable desire by the students. In terms of acquiring greater competencies and gaining clear ideas about their professional identity, the students were looking forward to their experience abroad, and rated it rather significantly. 
Table 4.1 Characteristics of research participants $(n=15)$

\begin{tabular}{|c|c|c|c|c|c|}
\hline Code & Name & Age & Gender & GPA & $\begin{array}{c}\text { Study abroad } \\
\text { program }\end{array}$ \\
\hline F1 & Sara & 21 & F & 3.6 & France \\
\hline F2 & Darian & 21 & F & 3.1 & France \\
\hline F3 & Alberto & 19 & M & 2.7 & France \\
\hline F4 & Miguel & 19 & M & 2.8 & France \\
\hline F5 & Adriana & 24 & F & 3.1 & France \\
\hline F6 & Diana & 20 & F & N/A & France \\
\hline I7 & Sofia & 21 & F & 2.7 & Italy \\
\hline S8 & Lorena & 24 & F & 3.6 & Spain \\
\hline S9 & Antonio & 23 & M & 2.5 & Spain \\
\hline S10 & Juan & 21 & M & 2.9 & Spain \\
\hline S11 & Mariana & 20 & F & 2.8 & Spain \\
\hline S12 & Cecilia & 21 & F & 2.4 & Spain \\
\hline S13 & Alejandra & 19 & F & 2.9 & Spain \\
\hline A14 & Gabriela & 20 & F & 3 & Argentina \\
\hline G15 & Marc & 23 & M & 2.4 & Germany \\
\hline
\end{tabular}

Note: the GPA as per the college American systems is based on a scale from $100=4.0$

Table 4.2 Students' career decision and vocational identity status before $S A(n=12)$

\begin{tabular}{|c|c|c|c|c|c|}
\hline Student & $\begin{array}{l}\text { Career } \\
\text { choice }\end{array}$ & Major & $\begin{array}{r}\text { Influence on st } \\
\text { information a } \\
\text { development: Sel } \\
\text { reas }\end{array}$ & $\begin{array}{l}\text { dents' career } \\
\text { d meanings } \\
\text { family or other } \\
\text { ns. }\end{array}$ & $\begin{array}{l}\text { Self-reported } \\
\text { vocational } \\
\text { Identity status }\end{array}$ \\
\hline Sara & Decided & Marketing & $50 \% \mathrm{~F}$ & $50 \% \mathrm{~S}$ & Foreclosure \\
\hline Darian & Decided & Spanish & $90 \% \mathrm{~F}$ & $10 \% \mathrm{~S}$ & Achievement \\
\hline Alberto & Decided & $\begin{array}{c}\text { Biology (Pre- } \\
\text { Med) }\end{array}$ & $50 \% \mathrm{~F}$ & $\begin{array}{l}30 \% \mathrm{O} \\
20 \% \mathrm{~S} \\
\end{array}$ & Achievement \\
\hline Miguel & Failed & Failed & Failed & Failed & Failed \\
\hline Adriana & Decided & Spanish & $80 \% \mathrm{~S}$ & $20 \% \mathrm{~F}$ & Foreclosure \\
\hline Diana & Failed & Failed & Failed & Failed & Failed \\
\hline Sofia & Failed & Art & Failed & Failed & Failed \\
\hline Lorena & Not clear & None & $51 \%$ Relocation & $39 \%$ not clear idea & Achievement \\
\hline Antonio & Not clear & None & $\begin{array}{c}\text { interest in other } \\
\text { fields }\end{array}$ & & Moratorium \\
\hline Juan & Not clear & None & $\begin{array}{l}\text { No specific } \\
\text { occupation }\end{array}$ & & Foreclosure \\
\hline Mariana & Decided & Architecture & $60 \% \mathrm{~S}$ & $40 \% \mathrm{~F}$ & Achievement \\
\hline Cecilia & Not clear & None & $\begin{array}{c}\text { No clear idea about } \\
\text { career }\end{array}$ & & Foreclosure \\
\hline Alejandra & Decided & Marketing & $70 \% \mathrm{~S}$ & $30 \% \mathrm{~F}$ & Achievement \\
\hline Gabriela & Decided & Biology & $80 \% \mathrm{~S}$ & $10 \% \mathrm{~F}$ & Achievement \\
\hline Marc & Decided & Economics & $90 \% \mathrm{~S}$ & $10 \% \mathrm{~F}$ & Achievement \\
\hline
\end{tabular}

Note: Self (S); Family (F); Others (O). 
Table 4.3 Students' expectations of study abroad on vocational identity before $S A(n=12)$

\begin{tabular}{|c|c|c|}
\hline & $\begin{array}{c}\text { Students' expectations of study abroad experience on vocational } \\
\text { identity }\end{array}$ & $\begin{array}{l}\text { Mean } \\
(\mathbf{n}=12)\end{array}$ \\
\hline 1 & SA program will aid my vocational interest. & 4.08 \\
\hline 2 & $\begin{array}{l}\text { SA will help me in being more competent to make decisions toward } \\
\text { professional career. }\end{array}$ & 3.75 \\
\hline 3 & Through my study abroad I will discover my own interests and aptitudes. & 3.66 \\
\hline 4 & SA will help me to identify, who I am? & 3.42 \\
\hline 5 & Through my SA, I will get a clear idea about my professional identity. & 3.75 \\
\hline
\end{tabular}

Note: $1=$ not at all; $2=$ a little; $3=$ somewhat; $4=$ a lot and $5=$ totally.

\subsubsection{Frankfurter "Self-Concept Scale" (FSKN)}

Displayed in Table 4.4 are the data analysis results obtained from each of the 10 selfconcept domains before the students' experience abroad. The second column indicates the range that corresponds to a positive self-concept level. The mean scores of the participants group correspond to a positive level of self-concept taking into account Liker's assessment, the level of students' self-concept in each of the FSKN domains.

The domain with the highest mean score $(=54.91)$, as shown on the table, corresponds to the "Self-esteem" (FSSW) domain, which reveals almost five points over the media. The second most dominant is the domain of "efficiency" with a mean of 52.16. The domain FSEG "sensitivity and overall mood", and FSIA "irritation though others," reported the lowest mean scores of 25.33 and 27.25 respectively. Detailed results will be given in the next section (4.4), which offers a results' comparison of four cases before and after study abroad. 
Table 4.4 Frankfurter Self-Concept Scale results by domain before SA $(n=12)$

\begin{tabular}{|c|l|c|c|}
\hline & Frankfurter Self-Concepts' scale domains & Level (+) & $\begin{array}{c}\text { Mean } \\
(\mathbf{n = 1 2})\end{array}$ \\
\hline 1 & FSAL "Efficiency" & $40-60$ & 52.17 \\
\hline 2 & FSAP "Problem coping" & $40-60$ & 49.42 \\
\hline 3 & FSVE "Conduct/decision assurance" & $24-36$ & 28.50 \\
\hline 4 & FSSW "Self-esteem" & $40-60$ & 54.92 \\
\hline 5 & FSEG "Sensitivity and overall mood" & $24-36$ & 25.33 \\
\hline 6 & FSST "Stability" & $48-72$ & 52.25 \\
\hline 7 & FSKU "Social contact/dealings skills" & $24-36$ & 28.75 \\
\hline 8 & FSWA "Appreciation/esteem by others" & $24-36$ & 31.00 \\
\hline 9 & FSIA "Irritation through others" & $24-36$ & 27.25 \\
\hline 10 & FSGA "Emotion and relationships" & $24-36$ & 29.25 \\
\hline
\end{tabular}

\subsubsection{Students' vocational self-assessment}

The SDS inventory results are displayed as mean scores before the study abroad program experience. The vocational interest profile of the group as a whole, before their experience abroad, seems to be predominant in the vocational environments of Enterprising, Social and Conventional (ESC).

Table 4.5 presents the mean score of each of the type of vocational environments (Realistic, Investigative, Artistic, Social, Entrepreneur and Conventional) and of each of the domains (Competencies, Activities, Occupations and Self-estimates). In reference to the domain of "vocational activities", the group demonstrated a strong interest in entrepreneurial activities. According to Holland's (1985) typology of occupational environments, vocational activities in the enterprising environment are those that take place when the students have a certain control of others in order to acquire an “organizational goal and economic gain” (p. 21).

Although the group manifests strong interest in enterprising vocational activities and events, they assessed their vocational competencies, as being more social. This is being reflected in their personal strengths; more details can be seen in the descriptive qualitative data analysis (next section 4.4).

In regards to vocational occupations, the group measured compellingly in their vocational interest towards the enterprising type of environment. This type of personality, as per 
Holland (1985) is distinguished by being extroverted, dominant, adventurous, enthusiastic, power seeking and energetic (p. 22; Gysbers, Heppner \& Johnston 2003, p. 28).

The mean score of self-estimates which measures how the students value or esteem themselves in abilities and competencies in comparison to others revealed high competencies and abilities in the social and realistic environmental types.

As the leading type of personality in this group of research participants, the social environment, according to Holland (1985), encloses characteristics such as: "agreeable, friendly, understanding, sociable, persuasive and extroverted. The realistic type of personalities demonstrates being: asocial, conforming, inflexible, frank, genuine, hardheaded, materialistic and practical" (p. $19 \& 21$ ).

Table 4.5 Mean scores of vocational self-assessment results by domain before $S A(n=12)$

\begin{tabular}{|l|c|c|c|c|c|c|}
\hline $\begin{array}{l}\text { Environments } \\
\text { Domains } \downarrow\end{array}$ & Realistic & $\begin{array}{c}\text { Investi- } \\
\text { gative }\end{array}$ & Artistic & Social & $\begin{array}{c}\text { Enter- } \\
\text { prising }\end{array}$ & Conventional \\
\hline Activities & 2.69 & 4.23 & 5.30 & 5.69 & 6.46 & 4.23 \\
Competencies & 5,00 & 6.23 & 5.15 & 6.84 & 6,00 & 6.84 \\
Occupations & 3.92 & 4.15 & 7,00 & 5.53 & 8.76 & 3.38 \\
Self-Estimates & 9,00 & 8.84 & 8.07 & 9.69 & 8.15 & 8.30 \\
\hline
\end{tabular}

\subsubsection{Descriptive results of semi-structured interviews}

Table 4.6 presents the themes that came to light during the qualitative data analysis as well as the identified sources responsible for the emerging themes. This table was created with the objective of identifying students' dominant incentives to go abroad. As the results reveal, the students clearly and positively conveyed enthusiasm in discovering other cultures and meeting other people from foreign lands; thus, a professional and vocational related benefit in their study abroad experience seems to be further dominant (see Table 4.6). 
Table 4.6 Students' motivation before SA $(n=12)$

\begin{tabular}{|c|c|c|}
\hline $\begin{array}{l}\text { Dimension } \\
\text { "Motivation" }\end{array}$ & Subcategories & Sources \\
\hline $\begin{array}{l}\text { Personal } \\
\text { development }\end{array}$ & $\begin{array}{l}\text { - } \text { Career and vocation } \\
\text { - Personal growth } \\
\text { - Self-knowledge }\end{array}$ & $\begin{array}{l}\text { F1, F3, F5, S8, S9, S10, S11, S12, S13, A14, G15 } \\
\text { F2, F3, F5, S10, A14, G15 } \\
\text { F1, S12, G15 }\end{array}$ \\
\hline $\begin{array}{l}\text { Intercultural } \\
\text { development }\end{array}$ & $\begin{array}{l}\text { - Learning } \\
\text { - Language } \\
\text { - Academic experience }\end{array}$ & $\begin{array}{l}\text { F1, S8, S9, S10, S11, S12, S13 G15 } \\
\text { F1, F2, F3 } \\
\text { F2 }\end{array}$ \\
\hline Family & - Parents & F5 \\
\hline
\end{tabular}

Table 4.7 presents the themes that emerged in terms of resources. One of the key objectives of this research study was to understand the effects on students' self-concept characterization and their vocational career decision status, before and after study abroad. For that reason, the intention is to consider what type of resources (cognitive, intercultural, vocational and social) the students predominately count on or perceive as their own. In order to assess students' effects before and after their study abroad experience, it was appropriate to look closer at the type of resources the students believed to possess (table 4.7).

The cognitive resources of this group of research participants, in general, conveyed an equal number of strengths to their professional career as to themselves. The students expressed their career strengths by their resolve to help others through their professional occupations and also to gain more career knowledge through their experience abroad.

Regarding cognitive resources concerning their personal strength, the majority of the 12 students expressed social contact abilities such as: being a positive person, having the ability to make friends easily, as well as enjoying talking to people. In reference to personal strengths, a few students reported that they benefited from setting goals and being committed to achieving them.

Others recognize their parents' support as a positive strength. In this category, some students expressed self-confidence and abilities in learning a new language as a one of their strengths. They sensed that they would be challenged by learning a new language; however, the students also expressed that they did not have the fear of "messing up." As 
for perceived weaknesses, the students referred to three different themes: career, self and language. In regards to the topic of career, four research participants perceived not having a defined career choice as a weakness.

The majority expressed, as a weakness, issues related to the subcategory "Self", e.g. being away from the family. Others conveyed the fear of the challenge of a new foreign language of the host country. Only a few students perceived the factor of having too much fun and being easily distracted as a weakness.

Table 4.7 Students' resources before $S A(n=12)$

\begin{tabular}{|c|c|c|}
\hline $\begin{array}{l}\text { Dimension } \\
\text { "Resources" }\end{array}$ & Subcategories & Sources \\
\hline Cognitive & $\begin{array}{lr}\text { - Self-concept } & \\
\text { - Strengths: } & \\
& \text { Career } \\
\text { - Welf } \\
\text { Language } \\
& \text { Career } \\
\text { Self } \\
\text { Language }\end{array}$ & $\begin{array}{l}\text { F1, F2, F3, F5, S8, S9, S10, S11, S12, S13, A14, G15 } \\
\text { F1, F2, F3, F5, S8, S10, S11, S12, S13, G15 } \\
\text { F1, F3, F5, S10, S11, S12, S13, A14, G15 } \\
\text { F3, S9 } \\
\text { F2, F3, S8, S9, S10, S13, A14 } \\
\text { F1, F2, F5, S8, S10, S11, S12, S13, A14, G15 } \\
\text { F3, G15 }\end{array}$ \\
\hline Vocational & $\begin{array}{l}\text { Career status } \\
\text { /satisfaction }\end{array}$ & F2, F3, S9, S10, S11, S12, A14, G15 \\
\hline Social & Parents & F2, F3, S10, S12 \\
\hline Others & $\begin{array}{l}\text { Diverse themes } \\
\text { different from the } \\
\text { above }\end{array}$ & F2, F3, F5, S9, S12, A14 \\
\hline
\end{tabular}

Table 4.8 presents the type of dominant goals and objectives that were part of the students' study abroad plan. The dimension "goal" was the most difficult to identify and analyze from the interviews because the qualitative data information acquired is limited to the students' level of career plan explorations maturity (not leaving home, and in some cases, lack of pre-departure advisement and preparation) necessary to create a strategic plan and the (possible) lack of time spent on reflection regarding their plans abroad. Regarding students' perceived goals prior to participating in the study abroad semester program, the students expressed (see category "vocational development") themselves somewhat, alike in terms of short-term goals and future goals. Their goals in regards to their vocational development were expressed in concrete plans such as the interest to learn from other cultures during their intercultural experience, which they considered a vocational career 
advantage. It seems evident that all students (regardless of gender, age, major, or study abroad program) shared a common goal to explore and learn from other cultures which, in turn, benefits their own vocational and career plans.

As shown in Table 4.8 (See subcategory "Learning" under intercultural development), the majority of students expressed a desire to learn and gain more knowledge from experiencing the diversity of cultures. Students with a determined career goal in their future professional occupation, such as the F2 and F5, had a tangible objective of attaining more professional skills and knowledge of the French culture to enrich their occupational teaching performance as a French teacher. This will be discussed in depth in the next section "comparison of results." Noticeable, within the results of the category "personal development", was that the subcategories (e.g. independency, maturity, self-efficacy etc.) emerged rather prominently in regards to the female students. These female students revealed open strategic personal goals for their study abroad program experience which were to gain: independency and autonomy, maturity, self-efficacy, communication skills, a better self-knowledge, and the ability to make decisions.

Table 4.8 Students' goals before SA $(n=12)$

\begin{tabular}{|c|c|c|}
\hline Dimension "Goals" & Subcategories & Sources \\
\hline $\begin{array}{l}\text { Vocational } \\
\text { Development }\end{array}$ & $\begin{array}{ll}\text { - } & \text { Career and vocation } \\
\text { - } & \text { Vocational future vision }\end{array}$ & $\begin{array}{l}\text { F2, F3, F5, S8, S9, S19, S13, G15 } \\
\text { F1, F2, F5, S8, S10, S11, A14, G15 }\end{array}$ \\
\hline $\begin{array}{l}\text { Intercultural } \\
\text { Development }\end{array}$ & $\begin{array}{ll} & \text { Learning } \\
\text { - } & \text { Language } \\
\text { - } & \text { Intl. Academic Exp. } \\
\text { - } & \text { Travel }\end{array}$ & $\begin{array}{l}\text { F1, F3, F5, S9, S10, S11 } \\
\text { F2, F3, F5, S8 } \\
\text { F2, S10, S13, G15 } \\
\text { F3 }\end{array}$ \\
\hline $\begin{array}{l}\text { Personal } \\
\text { Development }\end{array}$ & $\begin{array}{ll}\text { - } & \text { Independency } \\
\text { - } & \text { Maturity } \\
\text { - } & \text { Self-efficacy } \\
\text { - } & \text { Comm. Skills } \\
\text { - } & \text { Self-knowledge } \\
\text { - } & \text { Self-confidence } \\
\text { - } & \text { Able to make decision } \\
\end{array}$ & $\begin{array}{l}\text { F2, A14 } \\
\text { F5, S11 } \\
\text { F1, F2 } \\
\text { F1 } \\
\text { S11 } \\
\text { F5 } \\
\text { F2 }\end{array}$ \\
\hline Family & - $\quad$ Parents & F1 \\
\hline
\end{tabular}

\subsubsection{Summary}

The quantitative data results revealed that four of twelve research participants, before study abroad experience, reported their career decision status as undecided and not clear in 
their professional choice. Just seven out of the twelve research participants expressed having an achieved identity status; five are still in the process of working on enhancing their sense of exploration and commitment to find their identity.

The students' expectations of their experience abroad with regards to their vocational and professional development were relatively positive $(=3)$. In reference to their vocational self-assessment, the research group exhibited a strong self-reported interest and competency in the enterprising and the social type environments.

The qualitative data results before study abroad experience revealed positive and common motives such as to gain a personal development and to become oriented predominantly in their vocation and career. Their motivational factors to participate in a program abroad led them to aim their concentration on an identity vocational definition of their chosen career throughout an intercultural environment experience. The group of students in the France program had a relatively clear idea of their study abroad experience benefits such as to enrich language skills for their (vocational) occupational career. The second group of students, going to Spain, reported diverse purposes, and demonstrated varied personal and vocational objectives. The two other students, Marc and Gabriela, participating in individual study abroad programs were virtually set in their career decisions. They shared a common aspect which was to benefit and to take advantage of the experience abroad for their self-sufficiency development.

All participants revealed diverse vocational desires, e.g. improving career skills as well as acquiring additional self-knowledge. They expected to get to know themselves better while in a foreign environment.

Indeed, the students, with the encouragement and support of their parents, were looking to improve themselves and find a greater sense of self-efficacy. Nevertheless, how the students perceived themselves varied. According to students' self-concept before going abroad, they verbalized significantly more characteristics of social self-perception as: social, open, interested in people and being a good person; also, as far as the academic self, they considered themselves as: being a hard worker, being responsible, determined, intelligent and goal oriented. 


\subsection{Descriptive results after study abroad experience}

\subsubsection{Survey II "Vocational career development of college students"}

The impacts of study abroad experience on personal career and vocational development on students will be revealed in a variety of ways (more details in section 4.4).

The career decision status, and furthermore the satisfaction of personal experience accumulated by all of the 14 students interviewed after study abroad, was much greater than before their study abroad experience and this satisfaction presented itself in diverse manners in terms of effects. Thirteen of the fourteen students declared having a clear and decided vocational career choice after study abroad experience, as shown in Table 4.9.

After their experience of study abroad, students encountered further vocational identity clarifications throughout diverse career related self-explorations. After their experience abroad, in response to the question, "Who gives the most support and advice regarding your career choice and career development?" $50 \%$ of the students reported a decrease in parental career support. This resulted in large part because the majority of the students attributed a higher percentage to the fact that they identify career information and meanings abroad by themselves (S), as shown in the fourth and fifth columns of Table 4.9. This is reflected in the increase of students' career choice status. Being in a foreign and unknown environment put them in the position to reflect and analyze their career plan and vocation more than before their experience.

The percentage of the vocational identity achievers after their study abroad experience reported a small, but nevertheless significant, improvement of $5.98 \%$. The students who reported, before study abroad experience, a status of foreclosure identity decreased from $33.3 \%$ (before SA) to $14.28 \%$. In relation to the students in the moratorium identity status, only two students (art majors), who were unable to participate in the first interview, conveyed that they were still in the middle of their career exploration.

Three of the four students, without career choice before study abroad experience, declared a cleared and decided career choice after study abroad experience. Interestingly, in the case of Mariana (S11), she reported a clear career decision status before study abroad experience; although, after her experience abroad, she seems to have had an apparent and 
significant career exploration benefit. She conveyed that she had defined her vocational interest and identity towards marketing rather than architecture as she had responded on her Survey I.

The findings (in percentage) attributed to the "self" (S) and "abroad" (A) revealed that the majority of the students gained greater career related information and meanings. As reported, one student, Juan, remained without a career decision after study abroad experience. His self-reported vocational identity status, as diffused, may indicate that he is still lacking commitment and exploration. Juan, who on his return from his international experience, returned without a clear career decision, ascribed his career decision doubts, with $20 \%$, to the fact of having a variety of different career interest ideas (either psychology or philosophy) to pursue. Four months later, he found his vocational career choice and admitted to being cleared and defined in regards to his career choice. ${ }^{1}$

Table 4.10 presents the impacts of the students experience abroad on students' career and vocational identity expectations. Before going abroad, the students rated their desires, with a mean score of 4.08 , primarily with the desire to promote their vocational interest. However, during the second survey, the students rated higher with their statements regarding their study abroad experience outcomes.

Throughout their experience abroad, the students profited, primarily, from gaining additional competencies to make better decisions regarding their professional career. For example, as the table presents, the group reported more success in reference to Statement 4 (My experience abroad helped me identifying who I am?).

With an increase of $\mathrm{M}=.86(4.28 \geq 3.42)$ this result demonstrates the fact that they had become more identified with themselves.

\footnotetext{
${ }^{1}$ In a casual interview with Juan four Months later, after the second interview in June, he enthusiastically expressed that his study abroad experience impacted his vocational identity. He realized that psychology was the career that he feels he is most interested in, and which would provide him with the necessary career skills to have a positive impact on "peoples' minds".
} 
Table 4.9 Students' career decision and vocational identity status after SA ( $n=14)$.

\begin{tabular}{|c|c|c|c|c|c|}
\hline Student & $\begin{array}{l}\text { Career } \\
\text { choice }\end{array}$ & Major & \multicolumn{2}{|c|}{$\begin{array}{l}\text { Influence on students' career } \\
\text { information and meanings } \\
\text { development: Self, family, } \\
\text { abroad and other reasons. }\end{array}$} & $\begin{array}{l}\text { Self-reported } \\
\text { vocational } \\
\text { Identity status }\end{array}$ \\
\hline Sara & Decided & Marketing & $100 \% \mathrm{~S}$ & & Achievement \\
\hline Darian & Decided & Spanish & $70 \% \quad \mathrm{~S}$ & $30 \% \mathrm{~F}$ & Achievement \\
\hline Alberto & Decided & Biology & $50 \% \mathrm{~S}$ & $25 \% \mathrm{~F} / 25 \% \mathrm{O}$ & Achievement \\
\hline Miguel & Decided & Political S. & $70 \% \mathrm{~S}$ & $30 \% \mathrm{~F}$ & Achievement \\
\hline Adriana & Decided & Spanish & $100 \% \mathrm{~S}$ & & Foreclosure \\
\hline Diana & Decided & Art & $80 \% \mathrm{~S}$ & $20 \% \mathrm{~F}$ & Moratorium \\
\hline Sofia & Decided & Architecture & $50 \% \mathrm{~S}$ & $30 \% \mathrm{~F} / 20 \% \mathrm{O}$ & Achievement \\
\hline Lorena & Decided & Economics & $40 \% \mathrm{~S}$ & $40 \% \mathrm{~A} / 20 \% \mathrm{~F}$ & Achievement \\
\hline Antonio & Decided & Management & $70 \% \mathrm{~S}$ & $30 \% \mathrm{~F}$ & Foreclosure \\
\hline Juan & Undecided & Undecided & $40 \% \mathrm{~S}$ & $40 \% \mathrm{~F} / 20 \% \mathrm{O}$ & Diffusion \\
\hline Mariana & Decided & Public Rel. & $100 \% \mathrm{~S}$ & & Achievement \\
\hline Cecilia & Decided & Marketing & $100 \% \mathrm{~S}$ & & Achievement \\
\hline Alejandra & failed & Failed & & & failed \\
\hline Gabriela & Decided & Biology & $70 \% \mathrm{~S}$ & $25 \% \mathrm{~F} / 5 \% \mathrm{~A}$ & Achievement \\
\hline Marc & Decided & Economic & $70 \% \mathrm{~S}$ & $30 \% \mathrm{~F}$ & Achievement \\
\hline
\end{tabular}

Note: Self (S); Family (F); Abroad (A); Other (O).

Table 4.10 Students' expectations of study abroad on vocational identity after $S A(n=14)$

\begin{tabular}{|c|c|c|}
\hline & Students' expectation of study abroad on vocational identity & $\begin{array}{l}\text { Mean } \\
(n=14)\end{array}$ \\
\hline 1 & $\begin{array}{l}\text { Do you think that study abroad has aided in your work for a professional or } \\
\text { vocational interest? }\end{array}$ & 4.28 \\
\hline 2 & $\begin{array}{l}\text { Do you think SA helped you in being more competent to make decisions } \\
\text { toward your professional career? }\end{array}$ & 4.35 \\
\hline 3 & Through my SA I really discovered my own interest and aptitudes. & 4,00 \\
\hline 4 & Study abroad helped me in identifying, who I am? & 4.28 \\
\hline 5 & $\begin{array}{l}\text { Through my study abroad, I have a clearer idea about my professional } \\
\text { identity. }\end{array}$ & 3.85 \\
\hline
\end{tabular}

Note: $1=$ not at all; $2=$ a little; $3=$ somewhat; $4=$ a lot and $5=$ totally. 


\subsubsection{Frankfurter "Self-Concept Scale" (FSKN)}

The effects of the study abroad experience on the self-concept of this group of participants have been found in the psycho-emotional as well as in psycho-social area. The changes of impacts were diverse and in all 10 Self-concept's domains, which are offered in table 4.11. This revealed a modest, but nevertheless, positive growth in all domains of self-concept starting from $\mathrm{M}=0.12$ (FSGA) up to $\mathrm{M}=7.17$ (FSST).

The greater impacts with a mean score of at least 1.0 and above became apparent in six different domains of Self-concept, e.g. "problem coping" (FSAP), sensitivity and overall mood (FSEG), "stability" (FSST), "social contact and dealings skills" (FSKU), "appreciation and esteem by others" (FSWA), and "irritation through others" (FSIA).

In line with these impacts, the students benefited most in the area of "stability" (FSST). The domain "Stability" (FSST) attained the highest scores. Students, after their study abroad experience, felt more self-assured and self-confident in expressing their opinions, namely by communicating what they feel and think, without hesitations of being judged or assessed by others. These gains appear with a difference in the scores of $7.17(\mathrm{M}=52.25 \leq$ 59.42) than after being exposed abroad. The domain "FSST" represents, for this research group, the greatest gain in the psycho-social area which is characterized as being stable and self-confident, e.g. students' attitudes and conducts within social debate and discussion.

This progress on psychosocial self-concept level is found, not only in some students' without a clear career choice status' (e.g. S8, S9, and S12) but also in other students with an already clear and decided career status (F1, F2, F5 and A14).

Another significantly impacted domain was the domain of "irritation through others" (FSIA), which also showed evidence of a noteworthy improvement in the mean scores of 3.17 . 
Table 4.11 Frankfurter Self-Concept Scale results by domain after SA $(n=14)$

\begin{tabular}{|c|l|c|c|}
\hline & \multicolumn{1}{|c|}{$\begin{array}{c}\text { Frankfurter Self-Concepts' scale } \\
\text { domains }\end{array}$} & Level (+) & $\begin{array}{c}\text { Mean } \\
\text { after SA }\end{array}$ \\
\hline 1 & \multicolumn{1}{|c|}{$\begin{array}{c}\text { FSAL "Efficiency" } \\
\text { Le-60 }\end{array}$} & 52.29 \\
\hline 2 & FSAP "Problem coping" & $40-60$ & 50.71 \\
\hline 3 & FSVE "Conduct/decision assurance" & $24-36$ & 28.86 \\
\hline 4 & FSSW "Self-esteem" & $40-60$ & 55.14 \\
\hline 5 & FSEG "Sensitivity and overall mood" & $24-36$ & 27.07 \\
\hline 6 & FSST "Stability" & $48-72$ & 59.43 \\
\hline 7 & FSKU "Social contact/dealings skills" & $24-36$ & 30.07 \\
\hline 8 & FSWA "Appreciation/esteem by others" & $24-36$ & 32.07 \\
\hline 9 & FSIA "Irritation through others" & $24-36$ & 30.43 \\
\hline 10 & FSGA "Emotion and relationships" & $24-36$ & 28.93 \\
\hline
\end{tabular}

\subsubsection{Students' vocational self-assessment}

The table 4.12 displayed the means of students' vocational preferences by domain (e.g. activities, competencies, occupation and self-estimates), with the type of occupational environment (Realistic, Investigative, Artistic, Social, Enterprising and Conventional). In general, after their experience abroad, the students' vocational preferences reported considerable changes in almost all vocational domains (e.g. activities, competencies and self-estimates), except in the occupation domain of social and enterprising environments as is portrayed in table 4.12 .

The vocational adjustments that the students experienced are exhibited and represented in terms of vocational environments (Realistic, Investigative, Artistic, Social, Enterprising, and Conventional). The growth increase, after the experience abroad, was confirmed in the type of enterprising environment with a mean score difference of 1.1. With that said, the group profile, in terms of vocational development, has demonstrated a consistency in their preference and interest in enterprising activities. Holland (1985) states that this enterprising environment type of personality leads to a "manipulation of others to attain organizational goals or economic gain..." (p. 21). 
Students being exposed to people and fellow students from different countries and furthermore, interacting within unknown and unfamiliar intercultural events, seem to gain considerable growth in the appreciation of further social and artistic vocational activities. With that said, the vocational improvement of the artistic environment stands out as the second highest impact $(M=1.06)$. In terms of group changes in general, this impact shows to have greatly enhanced their vocational interest in artistic activities (e.g. language, music and art appreciation). The artistic type of environment represents the kind of preference for freedom, "that entail (among others) verbal manipulation... as well as human materials to create forms or products." Those competences in artistic environments, as per Holland (1985), are manifested for example: "in problem solving, self-expression, artistic interest, such as music, language..." (p. 20-21). The majority of the students, in fact, have expressed special vocational interest to improve or learn a (new) foreign language (more information in the interviews results).

Table 4.12 Mean scores of vocational self-assessment results by domain after $S A(n=14)$

\begin{tabular}{|l|c|c|c|c|c|c|}
\hline $\begin{array}{l}\text { Environments } \\
\text { Domains } \downarrow\end{array}$ & Realistic & $\begin{array}{c}\text { Investi- } \\
\text { gative }\end{array}$ & Artistic & Social & $\begin{array}{c}\text { Enter- } \\
\text { prising }\end{array}$ & Conventional \\
\hline Activities & 3.85 & 5,00 & 7.78 & 6.92 & 8.07 & 5.78 \\
Competencies & 5.35 & 6.42 & 6,00 & 7.85 & 7.57 & 7.07 \\
Occupations & 4,00 & 4.35 & 7.42 & 5.35 & 8.35 & 3.28 \\
Self-Estimates & 9.42 & 8.92 & 8.57 & 10.85 & 9.78 & 9.14 \\
\hline
\end{tabular}

\subsubsection{Descriptive results of semi-structured interviews}

In terms of confidence in their verbal and non verbal communication, the second interview with the 14 research participants was quite different than the first interview (before studying abroad). The majority of the research students were more open and expressive to share their experience abroad. Based on the word summary extracted from N-VIVO 7.0 software reports, Sara (F1) in her $1^{\text {st }}$ interview reported 386 spoken words which, after her 
experience, she definitely surpassed, reporting, in the second interview 3,438 spoken words. A closer self-reflection and analysis, by the majority, was clearly and evidently observed. The themes that emerged from the dimension of motivation are presented in table 4.13. The study abroad learning experience, especially under a foreign educational instruction, provided intercultural and motivational tools for a self-reflection, as well as a having a positive effect on students' preparation for their career.

In regards to the motivational themes (see table 4.13) of "vocational career" after their experience, almost $87 \%(n=12)$ of the students agreed to have benefited from more motivational elements to keep them on track to follow their vocational career plans.

The students also conveyed having increased their incentives to learn more about other cultures, and furthermore, to have more appreciation for their own cultural diversity in their hometown. Some of their statements that fell under the theme of "intercultural learning" experiences outcomes were: appreciation of the educational systems differences (exams, group projects, diverse problem solving with dif. variables), the appreciation of people from different countries, the verbal communication challenges with foreign languages among classmates from different countries. Consequently, a few students expressed not feeling motivated through their experience in the classroom because they were neither familiar nor properly advised on a career degree course. Still, they recognized having learned a great deal as far as communications skills. As presented in Table 4.13 (after study abroad), only five students mentioned their parents as a motivational factor during their stay abroad.

Table 4.13 Student's motivation after SA $(n=14)$

\begin{tabular}{|l|l|l|}
\hline $\begin{array}{l}\text { Dimension } \\
\text { "Motivation" }\end{array}$ & \multicolumn{1}{|c|}{ Subcategories } & \multicolumn{1}{|c|}{ Sources } \\
\hline $\begin{array}{l}\text { Personal } \\
\text { Development }\end{array}$ & $\begin{array}{l}\bullet \text { Career and Vocation } \\
\bullet \text { Personal growth } \\
\bullet \text { Self-knowledge }\end{array}$ & $\begin{array}{l}\text { F1, F2, F3, F5, F6, I7, S8, S10, S11, S12, A14, G15 } \\
\text { F1, F2, 17, S8, S9, S10, S11, S12, A14, G15 } \\
\text { F4, F5, F6, S9, S10 }\end{array}$ \\
\hline $\begin{array}{l}\text { Intercultural } \\
\text { Development }\end{array}$ & $\begin{array}{l}\bullet \text { Intercultural learning. } \\
\bullet \text { Language } \\
\text { - Academic experience }\end{array}$ & $\begin{array}{l}\text { F1, F2, F3, F4, F5, F6, I7, S8, S9, S11, G15 } \\
\text { F1, F2, F6 F, F5, F6, I7, S8, S9, S10, S11, S12, A14, G15 }\end{array}$ \\
\hline Family & $\bullet$ Parents & F5, I7, S9, S12, G15 \\
\hline
\end{tabular}


Even more remarkable are the assets (also resources) that students acquired through their learning experience abroad. Table 4.14 illustrates the subcategories that were mentioned the most during their second interview posterior experience abroad. The majority of students, in terms of elements of Self-concept, expressed being satisfied and highly confident with their self and their psycho-social dealings skills. While students' selfconcept perceptions before the experience conveyed more reflection directed to primarily external factors such as school and people, after their experience on their own in a foreign environment and moreover dealing with issues unaided, they perceived themselves, to a large extent, to be more positive and confident.

Based on the second interviews, the primary achievements in their self-concept perceptions are in the field of independency and autonomy in their social behavior, e.g. being more independent and self-sufficient, in addition, the students conveyed a greater identification with their vocational career. Moreover, the students perceived themselves to be even more matured; somehow, their experience has taught them to be more independent. On the other hand, pretty clearly, the students stated to have gained or developed decisive strengths for their vocational career life plan and also for their own self-development (self-efficacy).

Table 4.14 presents themes that emerged as resources. Included in the "vocational" category, are all of the stated current and possessed resources correlated to students' career status, such as when students expressed a gain or accomplishment, in particular way of career and vocational satisfaction.

The dimension of strengths covers themes such as career, self, and language, although career and self were highly rated. Even though the students expressed to have gone abroad because of diverse (vocational or personal) needs, for example: career interest oriented or just simply to develop further vocational career skills for future professional occupation, they obtained a greater feeling of their career decision status than before study abroad experience. This will be apparent in the individual results comparison of four cases.

Through intercultural learning relationships and experiences, the research participants have also benefited with additional personal, social and cultural values (e.g. world news, value of time management, friendships, self-agency, nutrition, stress management etc). 
Table 4.14 Student's resources after $S A(n=14)$

\begin{tabular}{|c|c|c|}
\hline "Resources" & Subcategories & Sources \\
\hline Cognitive & \begin{tabular}{|rr} 
- Self-concept & \\
& \\
& Career \\
- Strengths & Self \\
& Language \\
& Career \\
Self \\
Language
\end{tabular} & $\begin{array}{l}\text { F1, F2, F3, F4, F5, F6, I7, S8, S9, S10, S11, S12, S13, } \\
\text { A14, G15 } \\
\text { F1, F4, F5, F6, I7, S8, S9, S10, S11, S12, } \\
\text { F1, F2, F4, F5, S10, S11, A14, G15 } \\
\text { F1, F2, F3, S12 } \\
\text { S11 } \\
\text { F2, G15 } \\
\text { F1, F5 }\end{array}$ \\
\hline Vocational & - $\begin{array}{l}\text { Career status / } \\
\text { satisfaction }\end{array}$ & $\begin{array}{l}\text { F1, F2, F3, F4, F5, F6, I7, S8, S9, S10, S11, S12, A14, } \\
\text { G15 }\end{array}$ \\
\hline Social & - Parents & F1, F3, F5, S12 \\
\hline Values & - Intercultural value & F2, F3, F4, F5, F6, I7, S8, S9, S10, S11, S12, A14, G15 \\
\hline Others & & F1, F2, F4, I7, S8, S10, S11, S12, A14, G15 \\
\hline
\end{tabular}

As Table 4.15 presents, after their study abroad programs experiences, the students' personal goals were geared more towards concrete vocational career plans. According to their future vocational development and visualization, it was observed that all research participants interviewed verbalized more determined future goals directed primarily to achieve and finish their career degree. Some of them even expressed the will to work overseas. Others even revealed wanting to pursue a Masters or a Ph.D. degree.

In general, the students see their future more encouraged and relatively more positive than before. Some students (see F1, F2, F5 and A14) expressed (confirming) further concrete goals for personal and professional development, if they were to look for another experience abroad again.

Table 4.15 Student's goals after SA $(n=14)$

\begin{tabular}{|l|l|l|}
\hline Dimension "Goals" & \multicolumn{1}{|c|}{ Subcategories } & \multicolumn{1}{c|}{ Sources } \\
\hline $\begin{array}{l}\text { Vocational } \\
\text { development }\end{array}$ & $\begin{array}{l}\text { • Career and vocation } \\
\text { • Vocational future vision }\end{array}$ & F1 F1, F2, F3, F4, F5, F6, I7, S8, S9, S10, \\
S11, ,12, A14, G15
\end{tabular}




\subsubsection{Summary}

In the second interview, the vocational development of the 14 students interviewed had a significant effect after their experience abroad. For a better representation of those changes regarding the consistency of career choice status, the comparison results of 11 students, before and after study abroad experience, refer to section 4.3.

Evidently, the students, after their experiences abroad, reported to have acquired a better sense of cognitive skills in order to process career meaning and information from their study abroad environment and being on their own (less family influences); in view of the fact that in the Survey I before study abroad, some of them admitted (with diverse percentage) having their parents as part of their career decision support.

As the Survey II data reported, it seems that the students, with their experience abroad, benefitted from getting to know themselves and being more confident with who they are. Hereby, it is to conclude that they gained a greater self-knowledge and a positive sense of self-efficacy.

The level of self-concept characterization by the students revealed significant changes in the psycho-social environment. The self-concept's domain that reported the greatest and most positive impact, after study abroad experience, was "Stability" (FSST) which describes the level of stability and confidence the student has in regards to expressing his or her own opinions, standpoints, emotions and ideas in a group. The second highest positive impact appears in the domain "Irritations through others" (FSIA). This domain represents the level of tolerance and acceptance that the students possess towards others, as well as all which the students perceive as an influence on their self, and the influences that others may exert on their opinions, ideas, and behavior.

As a group, by studying abroad, the students gained a preference for social and enterprising activities. In terms of vocational competencies, they reported greater selfestimates in the enterprising types of environments. Vocationally, the students have shaped and formed a clear idea of their future goals. Their experiences in a foreign environment provided a challenging learning process to create and develop new coping strategies to resolve daily tasks. 


\subsection{The impact of study abroad experiences on students' vocational identity: comparative presentation of data.}

For this study, 15 research participants were interviewed, 12 before and 14 after, however controllable results were extracted from 11 participants. The comparative outcomes of the study abroad experience of 11 students' vocational identity will be disclosed in this section. The students' comparison results present the modifications that students encountered upon their return. A detailed comparative presentation of the data analysis of each individual case and its impact before and after study abroad is discussed in the next segment. Four examples of four case analyses of students from different countries (France, Spain, Argentina and Germany) will be presented in depth. An overview of students' outcomes encountered after their study abroad will be presented. The findings that are pertinent for the focus, and objective of this research study, are exposed in the following tables (from 4.16 to 4.25), which were extracted from all four instrument assessments (Survey I \& II, Frankfurter Self-Concept Scale, Holland's (1994) Self-Directed -Search and the semi-structured Interview).

\subsubsection{Career decision and vocational identity status}

Table 4.16 reveals the comparison of students' outcomes regarding the clarity of career decision, and their self-reported vocational identity status, before and after their study abroad experience. Additionally, the table clearly demonstrates, by percentage, the increase of career information and meaning that they elaborated without help which is represented by a higher "S" percentage. A clear self-developed career meaning and information, after their academic and intercultural exposure, appeared to be significant for the majority of the students. 
Table 4.16 Career decision and vocational identity status before and after $S A(n=11)$

\begin{tabular}{|c|c|c|c|c|c|c|}
\hline \multirow[t]{2}{*}{ Student } & \multicolumn{2}{|c|}{$\begin{array}{l}\text { Career decision status } \\
\text { and choice }\end{array}$} & \multicolumn{2}{|c|}{$\begin{array}{c}\text { Influence on } \\
\text { students' career } \\
\text { information and } \\
\text { meanings } \\
\text { development: Self, } \\
\text { family, abroad and } \\
\text { other reasons. }\end{array}$} & \multicolumn{2}{|c|}{$\begin{array}{l}\text { Personal and vocational } \\
\text { Identity status }\end{array}$} \\
\hline & Before & After & Before & After & Before & After \\
\hline Sara & Marketing & Marketing & $\begin{array}{l}50 \% \mathrm{~S} \\
50 \% \mathrm{~F}\end{array}$ & $100 \% \mathrm{~S}$ & Foreclosure & Achievement \\
\hline Darian & Spanish & Spanish & $\begin{array}{c}90 \% \mathrm{~F} \\
10 \% \mathrm{~S}\end{array}$ & $\begin{array}{l}70 \% \mathrm{~S} \\
30 \% \mathrm{~F}\end{array}$ & Achievement & Achievement \\
\hline Alberto & Biology & Biology & $\begin{array}{l}50 \% \mathrm{~F} \\
30 \% \mathrm{O} \\
20 \% \mathrm{~S}\end{array}$ & $\begin{array}{l}50 \% \mathrm{~S} \\
25 \% \mathrm{~F} \\
25 \% \mathrm{O}\end{array}$ & Achievement & Achievement \\
\hline Adriana & Spanish & Spanish & $\begin{array}{l}80 \% \mathrm{~S} \\
20 \% \mathrm{~F}\end{array}$ & $100 \%$ & Foreclosure & Foreclosure \\
\hline Lorena & Undecided & Economics & $\begin{array}{c}51 \% \\
\text { Relocation } \\
39 \% \text { no } \\
\text { clear idea }\end{array}$ & $\begin{array}{l}40 \% \mathrm{~S} \\
40 \% \mathrm{~A} \\
20 \% \mathrm{~F}\end{array}$ & Achievement & Achievement \\
\hline Antonio & Undecided & Management & $\begin{array}{l}\text { Interest in } \\
\text { other fields }\end{array}$ & $\begin{array}{l}70 \% \mathrm{~S} \\
30 \% \mathrm{~F}\end{array}$ & Moratorium & Foreclosure \\
\hline Juan & Undecided & Undecided & $\begin{array}{l}\text { No specific } \\
\text { occupation }\end{array}$ & $\begin{array}{l}40 \% \mathrm{~S} \\
40 \% \mathrm{~F} \\
20 \% \mathrm{O}\end{array}$ & Foreclosure & Diffusion \\
\hline Mariana & Architecture & Public Rel. & $\begin{array}{l}60 \% \mathrm{~S} \\
40 \% \mathrm{~F}\end{array}$ & $100 \% \mathrm{~S}$ & Achievement & Achievement \\
\hline Cecilia & Undecided & Marketing & No clear idea & $100 \% \mathrm{~S}$ & Foreclosure & Achievement \\
\hline Gabriela & Biology & Biology & $\begin{array}{l}80 \% \mathrm{~S} \\
10 \% \mathrm{~F}\end{array}$ & $\begin{array}{l}70 \% \mathrm{~S} \\
25 \% \mathrm{~F} \\
5 \% \mathrm{~A}\end{array}$ & Achievement & Achievement \\
\hline Marc & Economic & Economic & $\begin{array}{l}90 \% \mathrm{~S} \\
10 \% \mathrm{~F}\end{array}$ & $\begin{array}{l}70 \% \mathrm{~S} \\
30 \% \mathrm{~F}\end{array}$ & Achievement & Achievement \\
\hline
\end{tabular}

Note: Self (S); Family (F); Abroad (A); Others (O) 
Table 4.17 presents the impacts and its changes represented in mean scores in respect to the students' study abroad expectation on career and vocational development. It shows that the mean of all statements increased, especially statements 2 and 4 (the sense of competency in making career decisions, and the sense of a better self-identification) reveal a great increase in the before and after interview study. After their experience abroad, the students reported having discovered themselves better e.g. their competencies, abilities, and self-efficacy. This follows Brickman and Miller's (2003) “the self-concept of ability", which also means the students believed they were more competent to make decisions towards a professional career than before this self-experience.

Table 4.17 Expectations on vocational identity before and after $S A(n=11)$

\begin{tabular}{|c|l|c|c|}
\hline & \multicolumn{1}{|c|}{ Study abroad vocational expectations } & $\begin{array}{c}\text { Mean (n=11) } \\
\text { Before }\end{array}$ & $\begin{array}{c}\text { Mean (n=11) } \\
\text { After }\end{array}$ \\
\hline $\mathbf{1}$ & $\begin{array}{l}\text { Do you think that study abroad has aided in your work for a } \\
\text { professional or vocational interest? }\end{array}$ & 4.09 & 4.45 \\
\hline $\mathbf{2}$ & $\begin{array}{l}\text { Do you think SA helped you in being more competent to } \\
\text { make decision for your professional career? }\end{array}$ & 3.73 & 4.45 \\
\hline $\mathbf{3}$ & $\begin{array}{l}\text { Through my experience abroad, I really discovered my own } \\
\text { interest and aptitudes. }\end{array}$ & 3.73 & 4.09 \\
\hline $\mathbf{4}$ & $\begin{array}{l}\text { My experience abroad helped me in identifying, who I am? } \\
\mathbf{5}\end{array}$ & $\begin{array}{l}\text { Through my experience abroad, I got a clear idea about my } \\
\text { professional identity. }\end{array}$ & 3.64 \\
\hline
\end{tabular}

Note: $1=$ not at all; $2=$ a little; $3=$ somewhat; $4=$ a lot and $5=$ totally.

\subsubsection{Frankfurter "Self-Concept Scale" (FSKN)}

Table 4.18 reveals the total self-concept scores (as per Liker method) by each domain, before (B) and after (A) study abroad experience, of the 11 students, where the impacts and effects could be measured. The self-concept level of the 11 students manifests an improvement, especially in terms of the psycho-social domains of Self-concept such as the level of "Stability" (FSST) and "Irritations though others" (FSIA). Examples of these impacts and effects will be presented in detail in the individual cases analysis and comparison. 
Table 4.18 Students' FSKN scores by domain before and after SA $(n=11)$

\begin{tabular}{|c|c|c|c|c|c|c|c|c|c|c|c|c|c|c|c|c|c|c|c|c|}
\hline & \multicolumn{2}{|c|}{ FSAL } & \multicolumn{2}{|c|}{ FSAP } & \multicolumn{2}{|c|}{ FSVE } & \multicolumn{2}{|c|}{ FSSW } & \multicolumn{2}{|c|}{ FSEG } & \multicolumn{2}{|c|}{ FSST } & \multicolumn{2}{|c|}{ FSKU } & \multicolumn{2}{|c|}{ FSWA } & \multicolumn{2}{|c|}{ FSIA } & \multicolumn{2}{|c|}{ FSGA } \\
\hline & B & $\mathbf{A}$ & B & A & B & $\mathbf{A}$ & B & $\mathbf{A}$ & B & $\mathbf{A}$ & B & $\mathbf{A}$ & B & $\mathbf{A}$ & B & $\mathbf{A}$ & B & $\mathbf{A}$ & B & $\mathbf{A}$ \\
\hline F1 & 53 & 49 & 39 & 51 & 27 & 33 & 54 & 54 & 23 & 31 & 52 & 61 & 33 & 36 & 23 & 24 & 21 & 27 & 15 & 28 \\
\hline F2 & 53 & 48 & 48 & 51 & 25 & 29 & 51 & 52 & 24 & 25 & 44 & 62 & 32 & 34 & 29 & 31 & 30 & 32 & 31 & 23 \\
\hline F3 & 46 & 50 & 50 & 49 & 31 & 28 & 55 & 54 & 28 & 17 & 67 & 65 & 25 & 27 & 31 & 33 & 31 & 30 & 27 & 33 \\
\hline F5 & 54 & 55 & 54 & 55 & 31 & 31 & 57 & 52 & 31 & 31 & 50 & 56 & 27 & 31 & 31 & 30 & 28 & 32 & 29 & 30 \\
\hline S8 & 55 & 57 & 54 & 55 & 27 & 31 & 58 & 60 & 28 & 30 & 42 & 66 & 24 & 27 & 33 & 36 & 26 & 33 & 33 & 33 \\
\hline S9 & 47 & 48 & 47 & 49 & 31 & 28 & 51 & 52 & 25 & 31 & 43 & 53 & 30 & 31 & 26 & 31 & 27 & 28 & 31 & 27 \\
\hline S10 & 52 & 53 & 49 & 47 & 30 & 27 & 56 & 54 & 25 & 25 & 58 & 62 & 26 & 32 & 31 & 34 & 26 & 33 & 29 & 33 \\
\hline S11 & 50 & 58 & 48 & 58 & 23 & 23 & 54 & 55 & 18 & 28 & 59 & 58 & 31 & 27 & 33 & 36 & 28 & 31 & 30 & 26 \\
\hline S12 & 52 & 54 & 44 & 48 & 28 & 29 & 52 & 58 & 20 & 28 & 51 & 55 & 29 & 27 & 32 & 35 & 27 & 30 & 29 & 32 \\
\hline A14 & 55 & 54 & 52 & 51 & 30 & 29 & 56 & 60 & 28 & 28 & 48 & 51 & 32 & 33 & 36 & 36 & 31 & 31 & 32 & 31 \\
\hline G15 & 57 & 57 & 53 & 56 & 34 & 35 & 59 & 60 & 30 & 32 & 57 & 57 & 30 & 33 & 34 & 35 & 28 & 29 & 36 & 35 \\
\hline
\end{tabular}

Note: The numbers highlighted in yellow represent a neutral level in the domain of Self-Concept Scale.

Table 4.19 reveals a comparison of the FSKN Scale results by domain from the 11 students who were interviewed before and after their study abroad experience. The results are represented in mean scores. It was observable that in all 10 domains an increase occurred. The means scores, in the "after" study abroad experience, were verified by the T-test for dependable variables for possible statistical significance. From there a mixed picture resulted: the bigger differences are significant (level of $10 \%$ or also $5 \%$ ), the smaller differences insignificant. Because of the small population, it is to be expected that many differences are not significant. Due to this reason, there are no further significant means considered. If one considers each data source as "typical", which seem to be 
justified by the validation of qualitative interviews (i.e. Chapter 4.4), and by giving it a weight of 10-times, almost all differences would be significant.

This will be more comprehensively demonstrated with some exemplary comparison of case analysis in the next section. An individual Self-Concept score from all 11 students, before and after study abroad, is to be presented in Table 4.19.

Table 4.19 Impact on students' self-concept domains before and after $S A(n=11)$

\begin{tabular}{|c|l|c|c|c|}
\hline \multicolumn{2}{|c|}{ Self-Concepts Domains } & Level (+) & $\begin{array}{c}\text { Mean } \\
(\mathbf{n = 1 1}) \\
\text { Before }\end{array}$ & $\begin{array}{c}\text { Mean } \\
(\mathbf{n = 1 1}) \\
\text { After }\end{array}$ \\
\hline 1 & FSAL "Efficiency" & $40-60$ & $\mathbf{5 2 . 1 8}$ & $\mathbf{5 3 . 0 0}$ \\
\hline 2 & FSAP "Problem coping" & $40-60$ & $\mathbf{4 8 . 9 1}$ & $\mathbf{5 1 . 8 2}$ \\
\hline 3 & FSVE "Conduct/decision assurance" & $24-36$ & $\mathbf{2 8 . 8 2}$ & $\mathbf{2 9 . 3 6}$ \\
\hline 4 & FSSW "Self-esteem" & $40-60$ & $\mathbf{5 4 . 8 2}$ & $\mathbf{5 5 . 5 5}$ \\
\hline 5 & FSEG "Sensitivity and overall mood" & $24-36$ & $\mathbf{2 5 . 4 5}$ & $\mathbf{2 7 . 8 2}$ \\
\hline 6 & FSST "Stability" & $48-72$ & $\mathbf{5 1 . 9 1}$ & $\mathbf{5 8 . 7 3}$ \\
\hline 7 & FSKU "Social contact/dealings skills" & $24-36$ & $\mathbf{2 9 . 0 0}$ & $\mathbf{3 0 . 7 3}$ \\
\hline 8 & FSWA "Appreciation/esteem by others" & $24-36$ & $\mathbf{3 0 . 8 2}$ & $\mathbf{3 2 . 8 2}$ \\
\hline 9 & FSIA "Irritation through others" & $24-36$ & $\mathbf{2 7 . 5 5}$ & $\mathbf{2 9 . 2 7}$ \\
\hline 10 & FSGA "Emotion and relationships" & $24-36$ & $\mathbf{2 9 . 2 7}$ & $\mathbf{3 0 . 0 9}$ \\
\hline
\end{tabular}

\subsubsection{Students' vocational self-assessment by domain}

In order to understand more precisely how students' vocational environment and activities expanded after being in international environment, a descriptive comparison of Holland's (1994) Self-Directed-Search results for the eleven students will be offered in the following tables 4.20, 4.21, 4.22 and 4.23.

Table 4.20 gives an overview of the impacted vocational interests of the 11 students before and after their semester study abroad program. Displayed here are the six environment types, and the number of "liked" or preferred activities reported by each student in each vocational domains: vocational activities, competencies, occupations and self-estimates. This quantitative data has been used to support a qualitative analysis from the interviews within the comparison of individual cases (next segment 4.4). 
As far as students' preferences for vocational activities in the six types of environments, the three letters obtained by the group before going abroad were Enterprising-SocialArtistic (ESA) and Enterprising-Artistic-Social (EAS) after their study abroad. This confirmed that students continued to enjoy enterprising activities (i.e. persuading or directing others), and they explicitly increased their vocational preference for social activities (i.e. helping, teaching serving, counseling). In reference to the artistic activities, they still reported vocational preferences in activities that involve: reading books, writing, musical or artistic activities.

Table 4.21 offers the number of vocational competencies of each student in accordance to the six different types of occupational environments. The three letters SocialConventional-Enterprising (SCE) obtained from the group before study abroad experience remained the same after their experience abroad; however, in a different position SocialEnterprising-Conventional (SEC). The 11 students, after their semester abroad, assessed themselves greater in vocational competencies of managerial and leadership performance, and with a reduction of conventional competencies.

Table 4.22 shows the changes in terms of preferred occupational environment reported by the group before and after study abroad experience. No significant changes have been found in the domain of vocational occupations. The three letters of vocational preference towards occupations found by the group before and after study abroad experience remained the same (EAS). Nevertheless, some students (F5 and A14) have revealed a small gain in the investigative and artistic occupations which includes: exploring and understanding things and events; as well as reading and writing.

Table 4.23 presents how each of the students rated themselves on a scale from 1 to 14 ( $2=$ low; $8=$ average; $14=$ high), when compared with other persons their age, as far their abilities in each of the 6 types of occupational environments. The summary code of vocational self-estimates extracted as a group resulted as Social-Realistic-Investigative (SRI), and after their experience changed to Social-Entrepreneur-Realistic (SER), i.e. the students in general rated grater in the abilities of social environment (e.g. teaching abilities and understanding of others) after their experience abroad. After their return from a semester abroad, the group summary code Social-Entrepreneur-Realistic (see Table 4.23) 
confirmed a gain in their beliefs for more abilities in the enterprising environment, and as third place, they rated themselves more positive as far as being more skilled in the type of realistic environment.

Table 4.20 Vocational activities by personality type before and after SA $(n=11)$

\begin{tabular}{|l|c|c|c|c|c|c|c|c|c|c|c|c|}
\hline & \multicolumn{2}{|c|}{ Realistic } & \multicolumn{2}{|c|}{ Investigative } & \multicolumn{2}{c|}{ Artistic } & \multicolumn{2}{c|}{ Social } & \multicolumn{2}{c|}{ Enterprising } & \multicolumn{2}{c|}{ Conventional } \\
\hline & B & A & B & A & B & A & B & A & B & A & B & A \\
\hline F1 & 0 & $\mathbf{0}$ & 5 & $\mathbf{0}$ & 2 & $\mathbf{7}$ & 11 & $\mathbf{1 1}$ & 11 & $\mathbf{1 1}$ & 4 & $\mathbf{6}$ \\
\hline F2 & 4 & $\mathbf{5}$ & 4 & $\mathbf{7}$ & 4 & $\mathbf{9}$ & 9 & $\mathbf{1 1}$ & 10 & $\mathbf{1 1}$ & 9 & $\mathbf{1 0}$ \\
\hline F3 & 4 & $\mathbf{7}$ & 2 & $\mathbf{2}$ & 8 & $\mathbf{1 0}$ & 6 & $\mathbf{7}$ & 9 & $\mathbf{1 1}$ & 0 & $\mathbf{1}$ \\
\hline F5 & 6 & $\mathbf{6}$ & 5 & $\mathbf{5}$ & 10 & $\mathbf{1 0}$ & 9 & $\mathbf{1 0}$ & 6 & $\mathbf{8}$ & 10 & $\mathbf{1 0}$ \\
\hline S8 & 1 & $\mathbf{2}$ & 4 & $\mathbf{3}$ & 3 & $\mathbf{4}$ & 3 & $\mathbf{5}$ & 4 & $\mathbf{1 0}$ & 8 & $\mathbf{9}$ \\
\hline S9 & 3 & $\mathbf{9}$ & 6 & $\mathbf{9}$ & 4 & $\mathbf{6}$ & 6 & $\mathbf{7}$ & 5 & $\mathbf{8}$ & 3 & $\mathbf{9}$ \\
\hline S10 & 1 & $\mathbf{1}$ & 5 & $\mathbf{1 0}$ & 5 & $\mathbf{1 1}$ & 5 & $\mathbf{1 1}$ & 6 & $\mathbf{1 1}$ & 1 & $\mathbf{0}$ \\
\hline S11 & 2 & $\mathbf{0}$ & 2 & $\mathbf{2}$ & 5 & $\mathbf{1 1}$ & 6 & $\mathbf{8}$ & 7 & $\mathbf{7}$ & 2 & $\mathbf{3}$ \\
\hline S12 & 1 & $\mathbf{1}$ & 4 & $\mathbf{4}$ & 6 & $\mathbf{6}$ & 3 & $\mathbf{5}$ & 7 & $\mathbf{8}$ & 8 & $\mathbf{7}$ \\
\hline A14 & 3 & $\mathbf{6}$ & 10 & $\mathbf{1 1}$ & $\mathbf{5}$ & $\mathbf{4}$ & 4 & $\mathbf{1}$ & 1 & $\mathbf{1}$ & 0 & $\mathbf{0}$ \\
\hline G15 & 3 & $\mathbf{4}$ & 1 & $\mathbf{4}$ & 0 & $\mathbf{3}$ & 1 & $\mathbf{2}$ & 6 & $\mathbf{1 1}$ & 4 & $\mathbf{9}$ \\
\hline
\end{tabular}

Table 4.21 Vocational competencies by personality type before and after $S A(n=11)$

\begin{tabular}{|l|c|c|c|c|c|c|c|c|c|c|c|c|}
\hline & \multicolumn{2}{|c|}{ Realistic } & \multicolumn{2}{|c|}{ Investigative } & \multicolumn{2}{c|}{ Artistic } & \multicolumn{2}{c|}{ Social } & \multicolumn{3}{c|}{ Enterprising } & \multicolumn{2}{c|}{ Conventional } \\
\hline & B & A & B & A & B & A & B & A & B & A & B & A \\
\hline F1 & 1 & $\mathbf{1}$ & 4 & $\mathbf{4}$ & 5 & $\mathbf{6}$ & 8 & $\mathbf{1 0}$ & 11 & $\mathbf{1 1}$ & 11 & $\mathbf{1 1}$ \\
\hline F2 & 7 & $\mathbf{7}$ & 3 & $\mathbf{3}$ & 10 & $\mathbf{1 0}$ & 11 & $\mathbf{1 1}$ & 7 & $\mathbf{7}$ & 7 & $\mathbf{7}$ \\
\hline F3 & 8 & $\mathbf{8}$ & 5 & $\mathbf{5}$ & 4 & $\mathbf{4}$ & 7 & $\mathbf{7}$ & 7 & $\mathbf{7}$ & 8 & $\mathbf{8}$ \\
\hline F5 & 7 & $\mathbf{7}$ & 0 & $\mathbf{0}$ & 3 & $\mathbf{1 0}$ & 4 & $\mathbf{1 1}$ & 1 & $\mathbf{7}$ & 8 & $\mathbf{8}$ \\
\hline S8 & 3 & $\mathbf{3}$ & 5 & $\mathbf{5}$ & 1 & $\mathbf{1}$ & 2 & $\mathbf{6}$ & 6 & $\mathbf{8}$ & 10 & $\mathbf{1 0}$ \\
\hline S9 & 10 & $\mathbf{1 0}$ & 7 & $\mathbf{7}$ & 3 & $\mathbf{4}$ & 3 & $\mathbf{5}$ & 2 & $\mathbf{3}$ & 3 & $\mathbf{5}$ \\
\hline S10 & 0 & $\mathbf{4}$ & 11 & $\mathbf{1 1}$ & 10 & $\mathbf{1 0}$ & 11 & $\mathbf{1 1}$ & 11 & $\mathbf{1 1}$ & 4 & $\mathbf{4}$ \\
\hline S11 & 3 & $\mathbf{3}$ & 2 & $\mathbf{3}$ & 9 & $\mathbf{9}$ & 11 & $\mathbf{1 1}$ & 8 & $\mathbf{9}$ & 10 & $\mathbf{1 0}$ \\
\hline S12 & 2 & $\mathbf{2}$ & 10 & $\mathbf{1 1}$ & 5 & $\mathbf{5}$ & 6 & $\mathbf{9}$ & 5 & $\mathbf{7}$ & 11 & $\mathbf{1 1}$ \\
\hline A14 & 4 & $\mathbf{5}$ & 11 & $\mathbf{1 1}$ & 2 & $\mathbf{2}$ & 4 & $\mathbf{0}$ & 3 & $\mathbf{5}$ & 0 & $\mathbf{2}$ \\
\hline G15 & 7 & $\mathbf{7}$ & 7 & $\mathbf{7}$ & 3 & $\mathbf{3}$ & 9 & $\mathbf{9}$ & 9 & $\mathbf{9}$ & 6 & $\mathbf{6}$ \\
\hline
\end{tabular}


Table 4.22 Vocational occupations by personality type before and after $S A(n=11)$

\begin{tabular}{|l|c|c|c|c|c|c|c|c|c|c|c|c|}
\hline & \multicolumn{2}{|c|}{ Realistic } & \multicolumn{2}{c|}{ Investigative } & \multicolumn{2}{c|}{ Artistic } & \multicolumn{2}{c|}{ Social } & \multicolumn{2}{c|}{ Enterprising } & \multicolumn{2}{c|}{ Conventional } \\
\hline & $\mathbf{B}$ & $\mathbf{A}$ & $\mathbf{B}$ & $\mathbf{A}$ & $\mathbf{B}$ & $\mathbf{A}$ & $\mathbf{B}$ & $\mathbf{A}$ & $\mathbf{B}$ & $\mathbf{A}$ & $\mathbf{B}$ & $\mathbf{A}$ \\
\hline F1 & 0 & $\mathbf{1}$ & 0 & $\mathbf{0}$ & 1 & $\mathbf{1}$ & 10 & $\mathbf{1 1}$ & 11 & $\mathbf{1 1}$ & 0 & $\mathbf{0}$ \\
\hline F2 & 7 & $\mathbf{7}$ & 0 & $\mathbf{0}$ & 11 & $\mathbf{1 1}$ & 11 & $\mathbf{1 1}$ & 11 & $\mathbf{8}$ & 8 & $\mathbf{8}$ \\
\hline F3 & 10 & $\mathbf{1 0}$ & 7 & $\mathbf{7}$ & 14 & $\mathbf{1 4}$ & 1 & $\mathbf{1}$ & 13 & $\mathbf{1 3}$ & 2 & $\mathbf{2}$ \\
\hline F5 & 10 & $\mathbf{1 0}$ & 7 & $\mathbf{9}$ & 9 & $\mathbf{1 2}$ & 13 & $\mathbf{1 3}$ & 7 & $\mathbf{9}$ & 8 & $\mathbf{8}$ \\
\hline S8 & 2 & $\mathbf{2}$ & 0 & $\mathbf{0}$ & 0 & $\mathbf{0}$ & 1 & $\mathbf{2}$ & 3 & $\mathbf{4}$ & 3 & $\mathbf{4}$ \\
\hline S9 & 9 & $\mathbf{9}$ & 2 & $\mathbf{2}$ & 3 & $\mathbf{3}$ & 1 & $\mathbf{2}$ & 10 & $\mathbf{1 0}$ & 5 & $\mathbf{6}$ \\
\hline S10 & 0 & $\mathbf{0}$ & 8 & $\mathbf{8}$ & 13 & $\mathbf{1 3}$ & 14 & $\mathbf{1 4}$ & 14 & $\mathbf{1 4}$ & 0 & $\mathbf{0}$ \\
\hline S11 & 0 & $\mathbf{0}$ & 2 & $\mathbf{2}$ & 8 & $\mathbf{8}$ & 5 & $\mathbf{5}$ & 5 & $\mathbf{5}$ & 0 & $\mathbf{0}$ \\
\hline S12 & 0 & $\mathbf{0}$ & 8 & $\mathbf{7}$ & 11 & $\mathbf{1 1}$ & 10 & $\mathbf{7}$ & 12 & $\mathbf{1 3}$ & 13 & $\mathbf{1 1}$ \\
\hline A14 & 0 & $\mathbf{0}$ & 9 & $\mathbf{1 0}$ & 4 & $\mathbf{0}$ & 0 & $\mathbf{0}$ & 1 & $\mathbf{0}$ & 1 & $\mathbf{0}$ \\
\hline G15 & $\mathbf{0}$ & $\mathbf{1}$ & $\mathbf{0}$ & $\mathbf{0}$ & $\mathbf{0}$ & $\mathbf{1}$ & $\mathbf{0}$ & $\mathbf{0}$ & $\mathbf{1 3}$ & $\mathbf{1 3}$ & $\mathbf{1}$ & $\mathbf{4}$ \\
\hline
\end{tabular}

Table 4.23 Vocational self-estimates by personality type before and after SA $(n=11)$

\begin{tabular}{|l|c|c|c|c|c|c|c|c|c|c|c|c|}
\hline & \multicolumn{2}{|c|}{ Realistic } & \multicolumn{2}{l}{ Investigative } & \multicolumn{2}{c|}{ Artistic } & \multicolumn{2}{c|}{ Social } & \multicolumn{2}{l|}{ Enterprising } & \multicolumn{2}{l|}{ Conventional } \\
\hline & B & A & B & A & B & A & B & A & B & A & B & A \\
\hline F1 & 4 & $\mathbf{4}$ & 4 & $\mathbf{4}$ & 5 & $\mathbf{5}$ & 12 & $\mathbf{1 2}$ & 13 & $\mathbf{1 3}$ & 11 & $\mathbf{1 1}$ \\
\hline F2 & 12 & $\mathbf{1 2}$ & 8 & $\mathbf{8}$ & 14 & $\mathbf{1 4}$ & 12 & $\mathbf{1 2}$ & 11 & $\mathbf{1 1}$ & 10 & $\mathbf{1 0}$ \\
\hline F3 & 10 & $\mathbf{8}$ & 7 & $\mathbf{5}$ & 7 & $\mathbf{5}$ & 12 & $\mathbf{1 0}$ & 12 & $\mathbf{1 0}$ & 12 & $\mathbf{1 0}$ \\
\hline F5 & 12 & $\mathbf{1 2}$ & 6 & $\mathbf{6}$ & 9 & $\mathbf{9}$ & 13 & $\mathbf{1 3}$ & 9 & $\mathbf{9}$ & 6 & $\mathbf{6}$ \\
\hline S8 & 3 & $\mathbf{4}$ & 8 & $\mathbf{8}$ & 2 & $\mathbf{2}$ & 6 & $\mathbf{1 1}$ & 6 & $\mathbf{1 0}$ & 11 & $\mathbf{1 4}$ \\
\hline S9 & 12 & $\mathbf{1 1}$ & 12 & $\mathbf{1 2}$ & 3 & $\mathbf{5}$ & 6 & $\mathbf{9}$ & 5 & $\mathbf{9}$ & 5 & $\mathbf{8}$ \\
\hline S10 & 6 & $\mathbf{8}$ & 11 & $\mathbf{1 2}$ & 10 & $\mathbf{1 2}$ & 11 & $\mathbf{1 3}$ & 10 & $\mathbf{1 2}$ & 7 & $\mathbf{7}$ \\
\hline S11 & 9 & $\mathbf{1 0}$ & 9 & $\mathbf{9}$ & 12 & $\mathbf{1 2}$ & 10 & $\mathbf{1 2}$ & 5 & $\mathbf{6}$ & 10 & $\mathbf{1 2}$ \\
\hline S12 & 12 & $\mathbf{1 3}$ & 9 & $\mathbf{1 0}$ & 11 & $\mathbf{1 1}$ & 12 & $\mathbf{1 2}$ & 9 & $\mathbf{1 3}$ & 11 & $\mathbf{1 1}$ \\
\hline A14 & 8 & $\mathbf{9}$ & 10 & $\mathbf{1 2}$ & 8 & $\mathbf{8}$ & 6 & $\mathbf{4}$ & 4 & $\mathbf{4}$ & 6 & $\mathbf{4}$ \\
\hline G15 & 9 & $\mathbf{1 1}$ & 7 & $\mathbf{1 0}$ & 4 & $\mathbf{4}$ & 6 & $\mathbf{1 0}$ & 8 & $\mathbf{1 4}$ & 4 & $\mathbf{1 1}$ \\
\hline
\end{tabular}

Table 4.24 illustrates the relationship between the self-reported identity status extracted from the Surveys I and II $(n=11)$, and the three-letter code of vocational preferences obtained from Holland's (1994) SDS inventory before and after experience abroad. The last column presents the status of congruency (achieved, still in process, or close to their 
vocational self-assessment) between the students' vocational self-assessment summary code with the interpretation of occupational codes extracted from the dictionary of Gottfredson and Holland's (1989) occupational codes.

Table 4.24 Identity status, vocational codes before and after SA, and the status of congruency $(n=11)$

\begin{tabular}{|l|c|c|c|c|c|}
\hline Student & $\begin{array}{c}\text { Identity } \\
\text { status }\end{array}$ & $\begin{array}{c}\text { Identity } \\
\text { status }\end{array}$ & $\begin{array}{c}\text { Vocational } \\
\text { codes }\end{array}$ & $\begin{array}{c}\text { Vocational } \\
\text { codes }\end{array}$ & $\begin{array}{c}\text { Congruency status } \\
\text { After occupational } \\
\text { dictionary }\end{array}$ \\
\hline Sara & Foreclosure & Achievement & ESC & ESC & Achieved \\
\hline Darian & Achievement & Achievement & SAE & SAE & Achieved \\
\hline Alberto & Achievement & Achievement & IAR & IAR & Still in process (IRA) \\
\hline Adriana & Foreclosure & Foreclosure & SRC & SAR & Achieved \\
\hline Lorena & Achievement & Achievement & CEI & CES & Achieved \\
\hline Antonio & Moratorium & Foreclosure & RIE & RIE & Achieved \\
\hline Juan & Foreclosure & Diffusion & SEA & SEA & Still in process \\
\hline Mariana & Achievement & Achievement & ASE & ASE & Close (EAS) \\
\hline Cecilia & Foreclosure & Achievement & CAE & ECA & Close \\
\hline Gabriela & Achievement & Achievement & IAR & IRA & Achieved \\
\hline Marc & Achievement & Achievement & ERS & ECR & Still in process (IAS) \\
\hline
\end{tabular}

\subsubsection{Summary}

The results reveal that the students' study abroad experience appeared as an excellent resource-scenario for self-exploration challenges that equip students with potential means for vocational development and maturity such as a greater sense of self-knowledge and self-awareness that somehow either cleared up or defined a vocational interest for a chosen career. Also in the majority of students, a positive impact of this experience abroad provided them a greater sense of confidence in their level of stability as far as their conducts and opinions are concerned. Six of the students (F1, F2, F5, S8, S9 and A14), according to Gottfredson and Holland's (1989) directory of occupational codes, and the three letters obtained from Holland's (1994) SDS inventory in regards to students' vocational preferences, showed more clearness and achievement for a greater congruency between their occupational code, and their chosen career major, which they reported after their experience abroad. Some examples of these results are presented in the next section. 


\subsection{Analysis and interpretation of four cases before and after their study abroad experience}

The purpose of this section is to portray in depth the effects of study abroad program experience on individual vocational identity in four different cases. This results comparison presentation focuses on providing effects of study abroad experience on three broad areas of vocational identity development: 1) Career choice, self-reported identity status and vocational self-assessment; 2) Self-concepts' characterization; and 3) The effects of learning experiences abroad on vocational identity development.

Four cases (Sara, Lorena, Gabriela and Marc) that studied in different countries (France, Spain, Argentina and Germany) were randomly selected as significant evidence of the impact of study abroad experience on students' career and vocational development. Using the triangulation method for a qualitative data analysis and interpretation, the results analysis comparison of each student follows the diagram previously presented (Diagram 3.3 , p. 73). The presentation of comparative results analysis, of each case, before and after study abroad experience, will be offered in the following order:

- A brief depiction of students' personal information (age, major, parents' occupations, study abroad program, and grade point average).

- Career choice and identity status before and after study abroad experience

This section presents the students career choice and major, including the type of support that they perceive as dominant before and after their experience abroad. In addition, their self-reported identity status (e.g. achieved, foreclosure, diffuse or moratorium) as well as students' statements regarding their vocational status will be displayed.

Students' vocational self-assessment.

This section reveals how students evaluate their vocational interest in terms of activities, competencies and occupations as well as, how they rate themselves in terms of vocational skills and abilities before and after their impact of study abroad experience. 
Students' self-concept characterizations.

In this section are the students' Self-Concept Scale (FSKN) results as well as their respective modifications after their experience abroad. Also, relevant relationships between the students' statements during the interview and their FSKN domains results are found here.

Vocational identity development.

In this section, three relevant points are analyzed and interpreted which finally shaped students' vocational identity: first, the types of motivational factors and goals that were dominant before and after their experience abroad; second, the type of resources (e.g. perceived strengths \& weaknesses) students possessed before, or gained after their experience, and as third, the types of contextual learning experiences that students perceived or have contributed to an enjoyable career decision and vocational identity satisfaction. 


\subsubsection{SARA}

\section{Personal information}

Sara (F1) spent one semester in Bordeaux, France. She, as well as five other students, participated in an exchange French language program. She is 20 years old, with a Hispanic (Mexican-American) background. Her father is a business man. Inspired professionally by her family environment, Sara reported majoring in business, namely marketing with a minor in French. As far as her academic achievement, she possessed an excellent grade point average of 3.6 (=96 in a scale of 100), which is one of the highest scores of all research participants.

\section{- Career choice and identity status}

\section{Before SA:}

A very interesting occurrence took place, when Sara was filling out Survey I. When she approached the question, "Do you already have clear in your mind the professional occupation that you will fulfill?" Sara first underlined the answer "undecided" then, moments later, changed it to "decided." This issue is relevant in terms of vocational and self-definition adjustments aspects because it exhibits a deficiency in career definition status. This aspect (unclear vocational definition) became apparent and corroborated, later on in the second interview after study abroad experience.

Apparently, Sara's career decidedness status, in marketing, had been partially developed within her family environment because of the fact that her father owns his own business. This became transparent when she was asked the question, who gives her the most career advisement and support. Regarding her minor in French, she expressed an interest in the language because of an experience with a French speaking nanny during her childhood.

When she reflected about her time and effort dedicated to seek her vocational identity development, her self- reported identify status, was "foreclosure." These aspects, career decision influence (family environment and support) and her self-reflective identity status, clearly convey the level of commitment that she had invested in finding her vocational identity. According to Marcia (1980), individuals, in the foreclosure identity status, have 
apparently not experienced any crisis yet. Other authors, in reference to the occupational identity, express that students in the status of foreclosure, have not yet explored adequately, and are, furthermore, following family traditions (Rodermund \& Vodracek 1999). Her reported level of "foreclosure" regarding identity exploration and her vocational exploration needs became evident, when she declared general career values (such as communication, responsibility and organization) as the most important values in her professional career plan. Sara declared that she expected to gain a better sense of vocational choice by becoming more acquainted with the French language, which would enrich her career in marketing based on her experience in intercultural communications skills; she said, "well, marketing is definitely all about communication; if I speak three different languages, then I will be able to market any product with people who speak English, Spanish and French.”

With that said, in terms of vocational explorations activities, Sara was in the loop to search for explorations activities that could provide her with a greater sense of vocational identity definition.

\section{After SA}

The experience abroad supplied Sara's career decision status with a sense of stability and consistency. In addition to her career choice consistency, she admitted to have had undergone a type of career clarification period which was deliberated by her vocational self-exploration events when she said:

"I wanted to steer in a different direction. Like, I really liked history, I really liked...It kind of made me want to (not study business) but instead study something a little bit more open, like sociology... this situation it kind of got me confused for a while, and I'm kind of at the point, where, I have to decide, what I want to do then? I was kind of steering towards sociology. I wanted to study people, and I wanted to study everybody's different cultures, and why everybody is the way they are..."

Instead of considering these vocational explorations adjustments as a strong point, Sara perceived them as a weakness after her experience abroad. In the end, she ended up 
defining her choice in business when she expressed her final career decidedness satisfaction. "Yes, I am satisfied with my career choice; business, kind of makes the world go around." With that said, her career value in communications represents a relevant asset within her vocational career in marketing. Through the congruent defining process of career interest identification, self-differentiation and self-explorative vocational interest, she acquired a better sense of an achieved vocational identity for marketing. In terms of Holland's (1985) theories, this refers first, to the process of differentiation, which "helps one refine or modify predictions of vocational behavior" (also cited by Gysbers, Heppner \& Johnson 2003, p. 30), and second, to the process of consistency in the career choice. Throughout these reflections about career and vocational identity adjustments, Sara's career choice status of maturity is more likely to predict satisfaction in a future occupational choice (Gati \& Meir 1982).

Regarding her career decision support, before going abroad, Sara attributed her reliance on her family with a high percentage; however, after her experience abroad, she declared that her reliance on family support decreased considerably. After study abroad experience, she felt that she developed further career information and meanings that contribute directly to her career decidedness status in marketing on her own.

Sara's exposure to an unfamiliar environment without family support, increased her level of exploration in the search for her vocational identity, and this is reflected in her selfreported identity status as "achieved". Sara's study abroad expectations, regarding her vocational career development, were documented in Survey I and II. She chose the answer "totally," when asked, if she thought that, through her study abroad experience, she discovered her own interests and aptitudes. Repeating the same response with, "totally," Sara reported that study abroad experience supported her in the process of finding her vocational identity.

\section{Vocational self-assessment}

\section{Before SA:}

During Sara's first interview, she perceived her program abroad as a complement for her vocational exploratory behavior, in particular through seeking out opportunities to 
demonstrate her mastery (Jordan 1963). This motivational factor is reflected in statements that express developing communication skills, not only in English but in French as well, which would enrich her career. This is confirmed when she stated, "getting out there talking to people, and if I can learn to speak in French to people, which I'm not very fluent with their language, then, it will make me feel like I can communicate with anybody and market any product."

The three letters for the summary code of vocational self-assessment that Sara obtained before her study abroad program were entrepreneur-social-conventional (ESC).

\section{After SA:}

Sara's vocational interest and competencies were partially impacted by her intercultural environment and experience. Diagram 4.1 demonstrates Holland's (1994) Self-DirectedSearch results of Sara's vocational self-assessment, as well as presenting the changes and impacts that she encountered after her study abroad program in France. Her vocational environments, especially the artistic and social type, were mostly influenced and developed abroad.

After being exposed to diverse cultures and people from different countries, she reported her competency, in the social environment type, which turned out to be more favorable than before her study abroad experience and she expressed herself by confirming the following statement: "I find it easy to talk with all kind of people".

Her vocational interest in social activities increased as well, such as for example, playing an instrument, working as a sculptor, writer or a guitarist playing in a musical group. Her Self-Directed-Search summary code, before and after her study abroad experience program, did not present any change which remained ESC (Entrepreneur-SocialConventional). According to Holland (1985), this combination of personality patterns ES (also C) demonstrates a high level of consistency (p. 28). Consistency predicts positive engagement in further vocational career explorations. If there is a close relationship between the personalities types and work environment like Sara's, according to Holland's (1985) hexagonal model, a positive grade of congruency appears, which predicts that one's career choice could be consistent (see also Gysbers, Heppner \& Johnston 2003, p. 
29). In this case, Sara's chosen type of vocational personality, might predict a satisfactory identification with her career choice in the long-term.

Diagram 4.1 Sara's vocational self-assessment before and after SA.

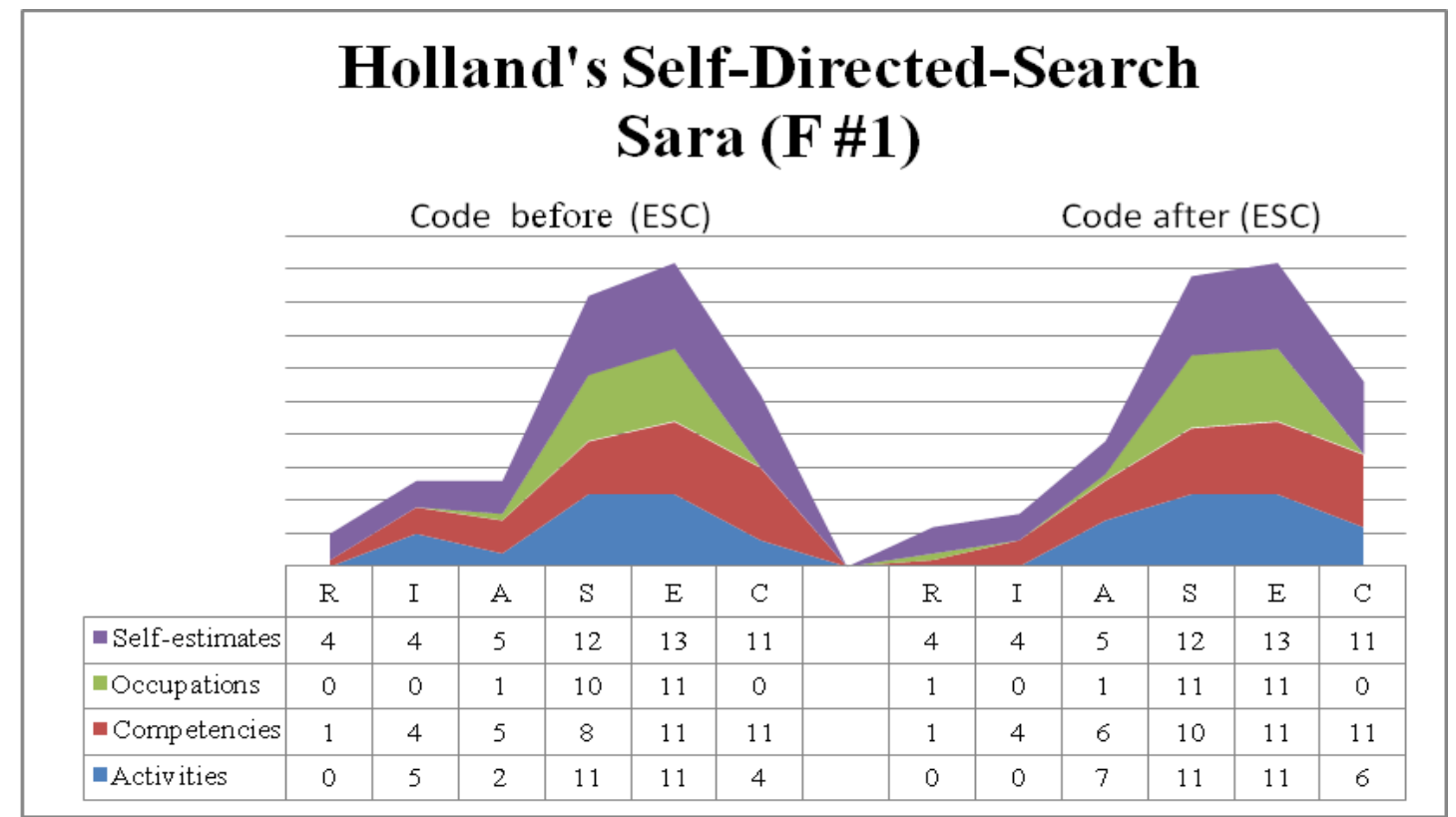

\section{Self-concept characterization}

How is Sara's self-concept characterized before and after study abroad experience, and how does this reflect in her self-assessment? What are the domains that she improved in the most?

\section{Before SA:}

Sara's self-concept perception, before her experience abroad, appeared as "goal oriented and determined" and also with a certain confidence of success in the future. She definitely expressed to have fairly high expectations of her experience abroad, e.g. getting more indentified with herself. Sara seemed to look further in achieving personal needs, and she expressed herself like this "I definitely expect to become a better well rounded and more responsible person." 
Despite Sara's self-assurance during her Interview before study abroad experience, surprisingly, Sara's self-concept assessment (FSKN) demonstrated a neutral level rather than a positive. She assessed herself at a neutral level in five different domains of selfconcept. Significant relationships were found between her neutral scored domains and statements during the first interviews.

The five domains, where her self-assessment demonstrated a neutral level, were: "Emotion and Relationship" (FSGA); "Problem solving" (FSAP), "Sensitivity and overall mood" (FSEG), "Regard and esteem by others (FSWA), "Irritation through others" (FSIA).

Significant effects and its relationship with her vocational identity development were clearly reflected, in her second interview. It is really interesting that, despite having a career choice set and decided, her self-concept level was still unclear. On a par with the majority of other students, Sara's intrinsic goal was inclined to increase her level of exploration and self-knowledge.

As Diagram 4.2 presents, her positive improvement of $11.53 \%=54$ points more than before going to France. This seems to point more to an intrinsic aspiration for a self-and vocational identification.

Diagram 4.2 Sara's Self-Concept assessment before and after SA.

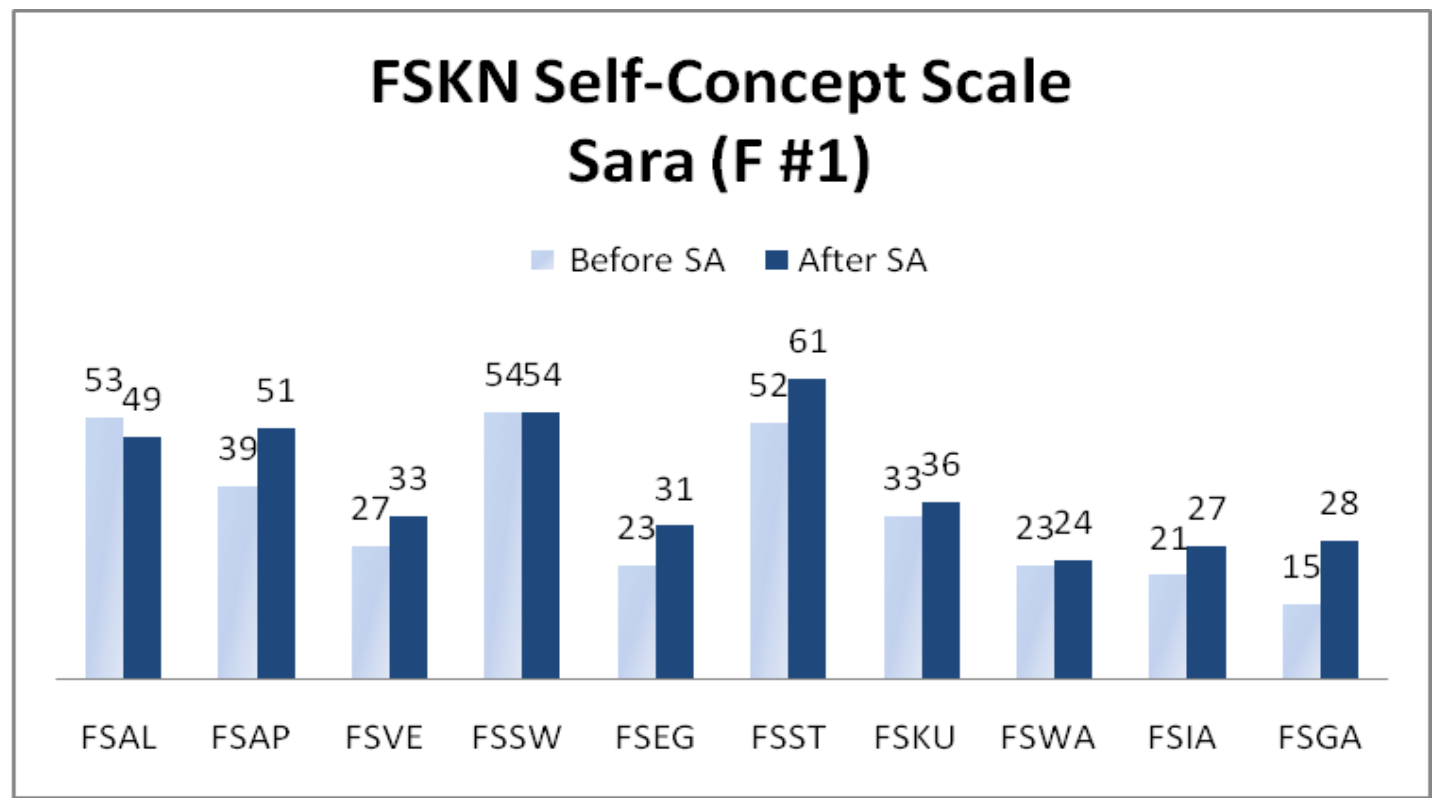


The most significant relationships that have been found between Sara's statements and her impacted domains of Self-Concept are described as follows. As far her FSKN results, she reported ( 1 to 13 points of difference) positive effects in eight of ten domains (FSAP, FSEG, FSWA, FSIA, FSVE, FSGA and FSST), and in the domain of "self-esteem" she did not appear to be impacted, although, during the second interview, she openly conveyed her greater sense of self-esteem. Only in one domain e.g. "Efficiency" (FSAL), she decreased four points less than before study abroad experience. In relation to these deficits, there were no (negative statements) associations related to this domain. Nevertheless, Sara's sense of self-efficacy enhanced significantly (see more in the last section).

\title{
Before SA:
}

Before her program in France, Sara described herself as "goal oriented and determined," which manifests a certain firm career goal commitment. One of the deficit aspects that she accepted was her psycho-social development of being impatient, she described it like this:

\begin{abstract}
“One of my weaknesses is that I'm pretty... I'm very impatient, and I'd rather run than walk slow... I think that might hurt me a little bit.... I'm very committed if I set a goal, I am very committed to reaching that goal..."
\end{abstract}

\section{$\underline{\text { After SA: }}$}

After study abroad experience, her emotional management within relationships (FSGA) improved significantly; this actually reports the highest change of improvement with a 13 point increase. Even though Sara did not report a change in her FSKN self-esteem domain, she openly expressed being impacted by self-explorative learning activities and interaction with other people of different cultures; she increased her self-worth, attributing to her selfacceptance.

"Yes! I don't know why, but, I feel like my self-esteem is different. I have no idea why, but, I definitely feel like... it was a transitional period when I was there, but yes I feel my self-esteem is better, I don't know if it's because I'm more accepting about other people, so I might be more accepting about myself as well, something like that". 
In her study abroad experience expectations, Sara seemed pretty much assured. She expected that, through her experience in a foreign country, she would find and be more identified with herself. In fact, this will be made more apparent later in the last section.

Actually, Sara's Self-concept level, as a whole, had an increase of $11.53 \%$ more than before her study program experience in France. The greater impacts are mainly reflected in six domains e.g. "Irritation through others" (FSGA) and the "problem solving" (FSAP), followed by "Stability" (FSST), "Sensitivity and overall mood" (FSEG), "Irritation through others" (FSIA) and "Conduct and decision assurance" (FSVE).

\section{The positive effects in the domains of the FSKN that coincide with Sara's statements extracted from her interview.}

(FSGA) "Emotion and relationship" scores comparison before SA $15>28$ after SA, Sara feels more comfortable accepting other people as they are.

"All the people over in France were their own person, they all had their different style they all... they disagreed, but they didn't argue, they spoke about it, somebody had pink hair and no one would stare, and it made them happy so, if it makes you happy just go with it ..."

(FSAP) "Problem solving", scored before $39>51$ after study abroad experience: Sara gained a good sense of self-efficacy in problem solving, and she demonstrated it during her second interview; after study abroad experience, Sara developed a considerable sense of self-confidence living on her own, especially in abilities to solve problems (FSAP). This is revealed by her FSKN scores; she reported an increase of 12 points more than before study abroad experience. She perceives herself more capable to manage, deal and cope with personal problems. This is reflected in her second interview after study abroad experience, as:

"Now, I feel like you can solve problems. Like before going abroad, I was like... I would get mad and frustrated, if something didn't go my way, or if 
I thought I couldn't solve something, but now it's like I have growth as an adult"

(FSEG) "Sensitivity and overall mood", in comparison before 23>31 after, she gained a better sense of self-confidence, now she feels that she can express herself how she wants to be, without concern of how others would perceive her.

"The most important thing that I have learned through my study abroad experience program, it sounds corny but don't be afraid to be yourself. I really don't mind other people's opinion's to a certain extent, just be yourself and be happy..."

Sara's clarification of vocational interest in marketing is identified also through a higher level of "Stability" (before SA $52>61$ after) in her self-concept assessment which she revealed as a positive effect regarding her socio-psychological areas:

"My study abroad experience made me more, not more outspoken, but less shy, because over there you have to speak up for yourself to go do things by yourself in a different language and not having someone there all the time... I'm not afraid to raise my hand in class because I'm scared that someone is going to think something wrong about me and because you know, being by yourself abroad is really different... I feel like I'm not afraid..."

In terms of "Irritation through others" (FSIA), scores obtained before and after $(21>27)$ study abroad experience, Sara's self-assessment appears to have developed significantly, and raised six points more than before her study abroad experience. She appears to be more acceptable to herself, as she expressed previously. Being within an intercultural environment, she started to appreciate cultural diversity and accepting that people are different as well,

"I'm more accepting about other people, so I might be more accepting about myself as well..." 
With six points higher than before going abroad, her behavioral self-confidence improved positively. The positive effect $(27>33)$ is reflected in her scores regarding the domain of "conduct and decision assurance" (FSVE). Sara's "achieved" vocational identity status is actually conveyed with her statements in being more capable to make important decisions without help. After her experience abroad, she realized that she comes first, namely making herself a priority.

"I was afraid to move away from my family... I have a really close knit family so I kind of put my needs and my happiness and my education on the side... before I went to France I felt like I would put everything... my happiness and goals to make everybody happy, and now I realize that you don't have to put your life on hold, your family is going to be happy with whatever you do"

Throughout her experience of being in an unfamiliar environment, Sara conveyed, during the second interview, to have discovered and obtained a better sense of self-efficacy. Now, she believes more in herself and in her personal abilities to perform and pursue things, e.g. moving out to Houston. The way Sara perceives her abilities appears differently than before study abroad experience:

"before, I was afraid to move away from my family, I'm from Houston but my whole family moved down to the valley, and I was afraid to move to Houston again by myself, because I have a really close knit family so I kind of put my needs, my happiness, and my education on the side to stay here in the valley to stay with my family... I'm not the same as before going to France... how can I put this? I realize that I'm capable of doing more stuff than I thought, but if you don't believe that you can do something, you're not going to do it, but once you're abroad in a new environment, without your family, and you know that you can do this, and then... I can do that, you kind of push yourself to do stuff..."

On a par with the majority of other students, beside her acquired confidence in her abilities (positive self-efficacy), Sara admitted having gained a better sense of independency and autonomy, which predicts a greater sense of self-sufficiency. She declared this by saying: 
"Now, after my experience, I take advantage and value the things that I have here ... now, like over there it was my first time living on my own... go do things by yourself in a different language and not having someone there all the time, like your mom and dad comforting you, and now I'm just more independent, I take advantage and value my opportunities."

As far as her self-characterization in relation to her family, Sara's experience was quite significant. After study abroad experience, Sara's self-characterization revealed a higher priority than before her experience abroad regarding her personal development. After study abroad experience, she stated, "before I went to France, I felt like, I would put everything, my happiness and goals to make everybody happy, and now I realize that you don't have to put your life on hold, your family is going to be happy with whatever you do".

\section{Vocational identity development}

How did study abroad experiences affect Sara's vocational identity? What type of personal or social factors impacted her vocational career and identity?

In contrast with other students enrolled in Spain, the students in the French language program had already counted on a specific objective regarding career related skills. Sara, like the others, was aware of the potential study abroad program's benefits regarding her personal career development. Sara's lack of exploration and high-level of commitment in the search of her vocational identity (e.g. "foreclosure" identity status before study abroad experience), provided her with a rather high personal motivation to participate in this study abroad program. Improving communications skills, especially foreign languages, became evident as a primary vocational value in her personal career goals, e.g. future professional or occupational performance.

\section{Motivation and goals}

What type of motivational objectives and goals did Sara have within her career development plans before her study abroad experience? 
Sara's primary motivational factor to participate in this study abroad program was to explore herself through the fact that she was going to experience different environments and cultures. This study abroad program served Sara's career in marketing as a constructive channel (instrumentality) for self-explorative activities and career development. Especially in the college years, career development involves selfexplorations and occupational activities (Holland 1985). In addition, Sara wanted to undergo an intercultural learning experience, due to her focus on her future goals which included learning a third language. Definitely, Sara's keen awareness of required professional career competencies, for instance the advantage of speaking a third language, would make her more marketable in the workforce.

Sara's personal accomplishments seemed to be obtained through her associative learning motivation. She obtained a positive sense of self and a greater cultural awareness. It was clear from Sara's interview statements that, throughout the profit of a higher sense of selfefficacy, she gained valor for personal benefits and future goals. The table below demonstrates how Sara's motives and goals before and after her study abroad experience were not only impacted but even expanded.

\begin{tabular}{|c|c|c|}
\hline & Before SA & After SA \\
\hline $\begin{array}{l}\text { Motiv } \\
\text { ation }\end{array}$ & $\begin{array}{l}\text { Intercultural learning: } \\
\text { My motivation was definitely to discover and } \\
\text { learn about different cultures and meeting } \\
\text { different people... } \\
\text { Personal growth and career development: } \\
\text { Well, marketing is definitely all about } \\
\text { communication. So, if I speak three different } \\
\text { languages, then I will be able to market any } \\
\text { product with people who speak Spanish, English } \\
\text { or French.... }\end{array}$ & $\begin{array}{l}\text { Intercultural learning: } \\
\text { My study abroad was amazing! It was what I } \\
\text { expected, and more. It changed me, and the } \\
\text { way I view things and people in general... } \\
\text { Personal growth and career development: } \\
\text { The people that I met... were people that } \\
\text { spoke five different languages, it motivated } \\
\text { me! They knew a lot of different languages. } \\
\text { It motivated me to try harder and try to do } \\
\text { better in school and to learn the language as } \\
\text { well... }\end{array}$ \\
\hline Goals & $\begin{array}{l}\text { Intercultural learning: } \\
\text { Well, I definitely expect to learn from others } \\
\text { cultures and get a better idea of everybody else } \\
\text { around me, and what different cultures are like, } \\
\text { and to just become a better well rounded... } \\
\text { Personal and career goal: } \\
\text { I think study abroad would help me in intensify } \\
\text { my career choice in marketing, because a lot of } \\
\text { marketing is communication...then it will make } \\
\text { me feel like I can communicate with anybody and } \\
\text { market any product.... }\end{array}$ & $\begin{array}{l}\text { Intercultural learning: } \\
\text { I just feel I'm more open to different cultures } \\
\text { and people. } \\
\text { Personal and career goals: } \\
\text { Yes, It kind of helped me realize that I want } \\
\text { to expand the things that I'm learning. It's } \\
\text { helped me realize that I shouldn't limit } \\
\text { myself, shouldn't limit my goals... I think I } \\
\text { should set my goals higher than what they } \\
\text { were... }\end{array}$ \\
\hline
\end{tabular}




\section{Resources: strengths and weaknesses}

How does Sara perceive her strengths and weaknesses regarding her personal and career development within a foreign environment before and after study abroad experience? The role of perceived abilities to perform diverse tasks is relevant for the "Self" and for future or present goals. Sara perceived herself significantly greater after her study abroad experience. She considers herself stronger in her social performance skills; furthermore, she feels even more committed to continue working on her search for her vocational identity development. Her interest in intercultural awareness and knowledge is greater than before. Her current communication skills in Spanish and English proficiency give her self-confidence to learn another foreign language such as French. She confided the fact that she had to work more on her emotions management in social activities and events, as well as her intolerance in certain career related issues (e.g. working slowly: taking her time). The relevant impact on her vocational identity clarification is that she recognized that being abroad helped her to consider other areas of interest such as sociology and history. Despite this, she seems to have achieved a clear vocational identity.

\begin{tabular}{|l|l|l|}
\hline \multicolumn{1}{|c|}{ Before SA } & \multicolumn{1}{|c|}{ After SA } \\
\hline Strengths & $\begin{array}{l}\text { Study abroad: } \\
\text { My strength for my study abroad } \\
\text { programs is that I can basically make } \\
\text { friends with anybody, and I'm very } \\
\text { committed, if I set a goal I am very } \\
\text { committed to reaching that goal... }\end{array}$ & $\begin{array}{l}\text { Study abroad: } \\
\text { Study abroad experience made me more, not } \\
\text { more outspoken, but less shy because over there } \\
\text { you have to speak up for yourself to go, do } \\
\text { things by yourself in a different language ... I } \\
\text { just feel I'm more open to different cultures and } \\
\text { people... }\end{array}$ \\
$\begin{array}{ll}\text { Career in marketing: } \\
\text { Well my strength is that I can } \\
\text { communicate with people and I can } \\
\text { ask around and see what it is that } \\
\text { everybody is looking for, that's not } \\
\text { hard for me... }\end{array}$ & $\begin{array}{l}\text { Career in marketing: } \\
\text { Study abroad strength my career choice because } \\
\text { I speak Spanish and English, and a little bit of } \\
\text { French....and I think for the career part, it } \\
\text { would help me there... }\end{array}$ \\
\hline $\begin{array}{l}\text { Study abroad: } \\
\text { My weakness is that I'm very } \\
\text { impatient and I'd rather run than walk } \\
\text { slow, I think that might hurt me a little } \\
\text { bit... }\end{array}$ & $\begin{array}{l}\text { Study abroad: } \\
\text { I was not prepared. I was kind of in a weak state } \\
\text { of mind, I didn't know what to expect from SA, } \\
\text { and I had never been abroad, I had never done } \\
\text { something like that, I wasn't prepared at all... }\end{array}$ \\
$\begin{array}{l}\text { Career in marketing: } \\
\begin{array}{l}\text { I would say again that my weakness is } \\
\text { that I am very impatient and I don't } \\
\text { like to work slow and I know that } \\
\text { sometimes where you're marketing } \\
\text { things are slow, it's not as fast paced } \\
\text { as I would like it to be... }\end{array}\end{array}$ & $\begin{array}{l}\text { Career development: } \\
\text { I feel it [study abroad] strengthened it but I also } \\
\text { feel it weakened it as well, because it kind of } \\
\text { made me want to do something different... } \\
\text { made me want to steer in a different direction, it } \\
\text { kind of got me confused for a while... }\end{array}$ \\
\hline
\end{tabular}




\section{Contextual learning's experiences that shaped Sara's vocational identity}

What kind of contextual learning experiences did Sara encounter through her study abroad experience programs that somehow contributed to her vocational identity development?

Being out of her family and cultural environment (comfort zone), she explored and discovered her level of self-efficacy; in other words, she acquired stronger beliefs in her capabilities and abilities to perform efficiently. As with the rest of the other research participants, she increased her self-knowledge and acceptance which supports her selfreported identity status (achieved) and vocational choice.

Through the acquisition of a foreign language as an instrumental (professional tool) learning experience: Sara's objective to participate in this program abroad, especially in the French language program, was very specific for her personal and career development. The acquisition of a third language represents a professional value within her occupational skills support for marketing. Sara highly valued a competency in the French language along with international experience which will both definitely support her future professional performance in marketing.

In reference to Sara's vocational identity adjustment and career choice clarity, the broad umbrella of cultural diversity served as a vocational education program and stimulus for her to steer to new areas of interest (as previously mentioned). She experienced a conflict in making her career decision. In other words, she experienced a vocational identity adjustment process, finding herself in a stage of confusion (for Sara this appeared as a weakness) which accelerated a deeper self-reflection regarding her vocational career choice, "marketing". She finally realized that studying the sociology components would assist in her professional vision and improve her understanding of people's behavior and communications skills which are required for her success. Study abroad experience has not only defined her vocational identity, but also expanded her vocational knowledge regarding her future occupational vision by showing consistency in her vocational career choice. She admits that acquiring knowledge in sociology will support her professional performance. 
"I decided, I would study sociology on the side, like on my own leisure time, not to go to a class, or earn a degree on it, and but I think it helps me... like marketing with international stuff so I think it'll help me understand people... I know, sociology, is going to help me a lot, because I'll know when you do business with somebody from different country.. I think it'll look good in my resume that I've studied in France for a semester, speaks three languages, I think it'll be pretty good"..

\section{Summary}

Sara's personal and vocational identities have been positively impacted by her study abroad experience in France. In particular, her career choice decidedness status in marketing, after being abroad and experiencing a conflict in career interest, she still appears consistent, clear and decided. Through self-explorative learning experience, e.g. dealing with her own problems, she acquired a greater self-knowledge (e.g. career interest and abilities; a greater sense of self-efficacy in being self-sufficient). In conjunction with her new knowledge about herself, she acknowledges that, though her self-acceptance, she was able to get to know her "real self," which is corroborated by her self-reported status of an achieved identity. Clarity of vocational identity will relate her vocational career explorations to her vocational future. 


\subsubsection{Lorena}

\section{Personal information}

Lorena (S8) is the eighth research participant on the list. She spent one semester in Salamanca, Spain. Lorena has a Hispanic (Mexican-American) background. She is the oldest research participant at twenty four years old. Her father works as an administrator in a district office, and her mother is a homemaker. Lorena completed a Bachelor's degree in accounting, a professional career decision with which she, vocationally, does not appear to be fully satisfied. Her primarily goal was to take classes in economics. As for her academic achievement, she possesses an excellent grade point average of 3.6 (=96 in a scale of 100), which is one of the two (along with Sara's) highest grade point average of all research participants.

\section{- Career choice and identity status}

\section{Before SA:}

Lorena, after having completed her degree in accounting, but not yet in the graduate program, reported, in her survey, that her professional career choice remained "unclear/undecided." Lorena expressed her interest in pursuing a career in Economics; however, she was not so sure about having chosen Accounting as her definite occupational career choice. She expressed that she was not completely satisfied with her vocational choice. In order for her to achieve a vocational identity satisfaction, she decided to explore and gain more information about her career interest in economics in which she felt a strong attraction. She openly admits the benefits that she expected regarding her vocational career plans.

"I can see benefits in studying abroad, when you explore other options or even within your same career path, either it confirms it or totally denies it, so that's how the study abroad experience can help me". 
As it was with the majority of the students, for her, it was the first time being away from her family. She considers herself very family oriented, a personal characteristic that she describes as a weakness towards studying abroad. Lorena actually reported, during her Survey I before study abroad experience, that she predominantly gets her career information support and advice from her family (parents). Lorena is one of the four research participants that reported an "undecided/unclear" career decision. Even though her career decision status was declared as "Undecided/not clear," she was very selfconfident about the potential personal benefits from study abroad experience in Spain, "Right now, I don't have really a clear choice, but I can see that, when you explore other options or even within your same career path, either it confirms it or totally denies it, so that's how the experience can help me." Regarding her career choice development before her study abroad experience, Lorena admitted to having received considerable support and advisement from her parents and counselors.

The reasons why Lorena considered herself not being clear and being undecided, as far as her professional career choice, is attributed substantially to reallocations, e.g. being away from family. In reference to her undecided vocational career status, she approvingly looks upon her family support. She expresses, "I am very family oriented, so being away from family, not having that support, can sometimes, make you feel that you're not doing the correct thing or you're not motivated enough because you are basically alone." Another reason is attributed to the lack of commitment in the effort to find a career, as well as the lack of career information regarding her desired career in business. Lorena possesses a strong will and commitment to find her real vocational career and identity. She states: "right now my strength and my career choice is that I'm open to anything."

Lorena reported an unclear career choice-decision status as she documented owing itself to a certain lack of commitment and erroneous career information. Despite the fact that her career decision status appeared ambiguous, she reflected about her time and effort dedicated to seeking her vocational identity (Marcia's framework). Lorena reported her self-assessed identity status as "achieved.” An achieved identity is, as per Marcia (1980), when one has a high level of commitment to make a decision for a specific occupation and ideology after a considerable exploration process (also Marcia 1966b, p.119). One can say 
that Lorena's goal directness was leading more towards a fulfillment of an unresolved developmental task which is establishment of a vocational identity.

Lorena's study abroad outcomes expectations (survey I) regarding her vocational career development were rated very high (i.e. with "a lot") before her study abroad experience. She considered study abroad experience to be a significant personal and cultural challenge. Her maturity in her personal and vocational developmental goals is clearly reflected.

"I am willing to take the risk and go study abroad, because if I don't take the risk, then I will be left wondering, I should've done this or that. Even if there is uncertainty, I'll try to clear that away from my path try to clear that and be persistent..."

\section{After SA}

Lorena, after completing her program and her study abroad experience in Salamanca, declared a satisfactory vocational career choice and identity. Her career decision status, after getting her desired knowledge, was confidently expressed as:

“I think, definitely my career choice wasn't so clear, but now, I enjoy doing that [economics]. There is a difference, between just having an idea about your career path, but then, getting submerged in the subject and now actually enjoying it, I don't know if a lot of people are blessed to have that but yeah going abroad it did reinforce it..."

With $40 \%$ of her career information developed abroad and another $40 \%$ developed on her own, she affirmed her career-choice satisfaction. This positive and accomplished career decision manifests satisfactory feelings in Lorena, "now I'm enjoying everything, my career path and my professional vocational career choice."

Even with her degree already completed in Accounting, she admitted having uncertainty in pursuing her career and working as an accountant. After acquiring and exploring career information regarding economics, she stated that she was intrinsically and deeply attracted to the class "The Economy in the European Union." Not only did she discover her vocational interest, but furthermore, found the interdisciplinary use of Accounting to her 
vocational advantage. Lorena stated the vocational and career benefit that she was looking for: "Now, I'm enjoying everything, my career path and my professional vocational career choice."

In reference to Lorena's self-reported identity status (Survey II), she did not report a difference in her achieved sense of identity status as before going abroad. In addition to her achieved identity, her vocational aspirations became even greater after being immersed in her desired career subject (economics). Before study abroad experience, her professional aspirations values were more in the direction of looking for a professional status rather than personal satisfaction, e.g. stability, security and flexibility. After her selfexplorations experience abroad, these values transformed into personal accomplishments and achievements: such as fulfillment, more opportunities for growth, learning something new etc.

For Lorena's study abroad expectations, her study abroad experience outcomes were a total success, as she reported by selecting ("totally") in Survey II. In other words, study abroad experience has "totally" aided her professional career and vocational interest in economy. She manifested this through study abroad experience; she "totally" became more competent to make a professional career decision, and she also feels that she "totally" discovered her own interest and aptitudes. The study abroad experience had "totally" supported her in the process of self-identification and gaining a better idea about her vocational identity.

\section{- Vocational self-assessment}

\section{Before SA:}

Although not reported in the Survey I, Lorena expressed her vocational preference in business before her study abroad experience. She also articulated her strong vocational interest in the field of economics. According to her SDS survey, she reported a summary code of CEI, which according to Gottfredson and Holland (1989), corresponds to occupations such as computer programmer or businessperson (p. 273). Lorena's future 
professional occupation appears to be quite determined, specifically having her own business, allowing her to contribute to her community. Lorena described herself like this,

"How do I visualize myself in the future? Definitely is having my own business. Maybe, I start with something small, but definitely having my own business, this is going to provide me with the level I don't want to say security but definitely that I am contributing in my own way to society ... if I have my own business, I can see, how I can contribute to the community in which I am, and work with their needs..."

According to Holland's (1994) SDS Manual "You and Your Career", students with strong conventional orientations find appealing "conventional jobs such as bookkeeper, stenographer, financial analyst, banker, cost estimator, or tax expert". This type of personality, "has clerical and arithmetic ability, but often lacks artistic abilities." (p. 3).

In this case, the primary vocational developmental goal for Lorena was absolutely appropriate. She was openly pursuing knowledge concerning her vocational interest in the field of economics, and she expressed it by saying: "I want to get acquainted with the economic system and the European Union. My major is economics, so I think it's a good place to go, and see how things work over there, and how can we apply them in the United States."

\section{After SA:}

After study abroad experience, Lorena likely defined her vocational profile after gaining vocational knowledge and experience in Salamanca. Her vocational personality code changed from CEI (before) to CES (after) from which the CE symbolizes a high level of consistency (Holland 1985, p. 28). Conventional and Enterprising personality type represents the most dominant (types) in Lorena's vocational orientation. The third code letter ("I" before and "S" after) was impacted after her experience. According to Holland and Nichols' (1964) descriptions of personality types, Lorena's vocational orientation is still impregnated with strong interest in accounting and the business fields (see p. 236). Even more significant in Lorena's case is that, throughout her gains of career knowledge and social competencies in economics, she accomplished an important progression in her 
vocational identity development. In comparison with her competencies before, after she returned, she assessed herself better regarding her social skills. She conveyed being more understanding towards others and their problems and, now for her, she finds it easier to talk to people with different backgrounds.

Her career interest consistency is also reflected in her Survey II results e.g. clear career decision and her vocational satisfactions with her chosen career in economics. When she was questioned about study abroad effects and the level of satisfaction that she encountered with her career choice, she said:

"Yes it definitely... study abroad did reinforce my vocational choice. Before I ...I think that was one of the aspects I was lacking, it wasn't so much acquiring knowledge in the academic, but also being more in contact with other people with different ideas, that made me realize, that was one of the things that I enjoyed doing, one of the things that going abroad made me realized that, there are so many things to learn but not only that, I got new ideas, fresh ideas... maybe some negative ones, but at the end, I always try to get the best out of them, so going abroad it did change, it did reinforce the career path"...

Due to the fact that she experienced people from different countries and ideas, she expressed a higher interest in social activities e.g. helping others with personal problems and interacting with educators and therapists. Now, she assesses herself better in her teaching abilities and prefers working with people.

A noteworthy observation stands out after her study abroad experience when she admitted not being fully certain with her chosen and completed career in accounting, when she stated, "Yes, before it was like... I don't really know, if that [accounting] was what I want and now, it is like... I just didn't know," by going abroad and exploring herself and enriching her vocational interest and competencies, she discovered what she actually likes, and which also complements her accounting career. This experience provided her the chance to deal with her vocational orientations and shape her vocational identity on her own, as well as providing a positive sense of her current vocational occupation in accounting. She verbalized her happiness by saying: 
"Now, the way I see it, I am happy with my Accounting career, but now, I also want to explore this other option [Economics]. At first I didn't know if...Accounting is what I wanted, but now I can use to my advantage knowing Accounting... but economics... because in the end, you can use those two things and now that I have had that experience I think Accounting is to my advantage, before I felt it like a weight, that I don't know, if I made the right choice ... before (study abroad experience) Accounting was a weight that I was carrying but now I'm using it to an advantage now, with this experience abroad, I use these two things to my advantage and develop further"...

Below, in Diagram 4.3, Lorena's acquired strengths are revealed. Her strengths were detected predominantly in the social environment which relates significantly to her achieved vocational identity (status) in economics. Only a few impacts were found regarding her vocational occupation. After her learning experience abroad, she expressed having a vocational orientation e.g. for rehabilitation counselor, airport manager and budget reviewer. Lorena rated herself above average vocationally in the social, enterprising and conventional environments which rated more favorably than before study abroad experience. This confirms her congruence with her vocational choice after her return from study abroad experience, which at the same time, as she stated, has inspired her to pursue her Master's Degree in Economics of The European Union.

Diagram 4.3 Lorena's vocational self-assessment before and after SA.

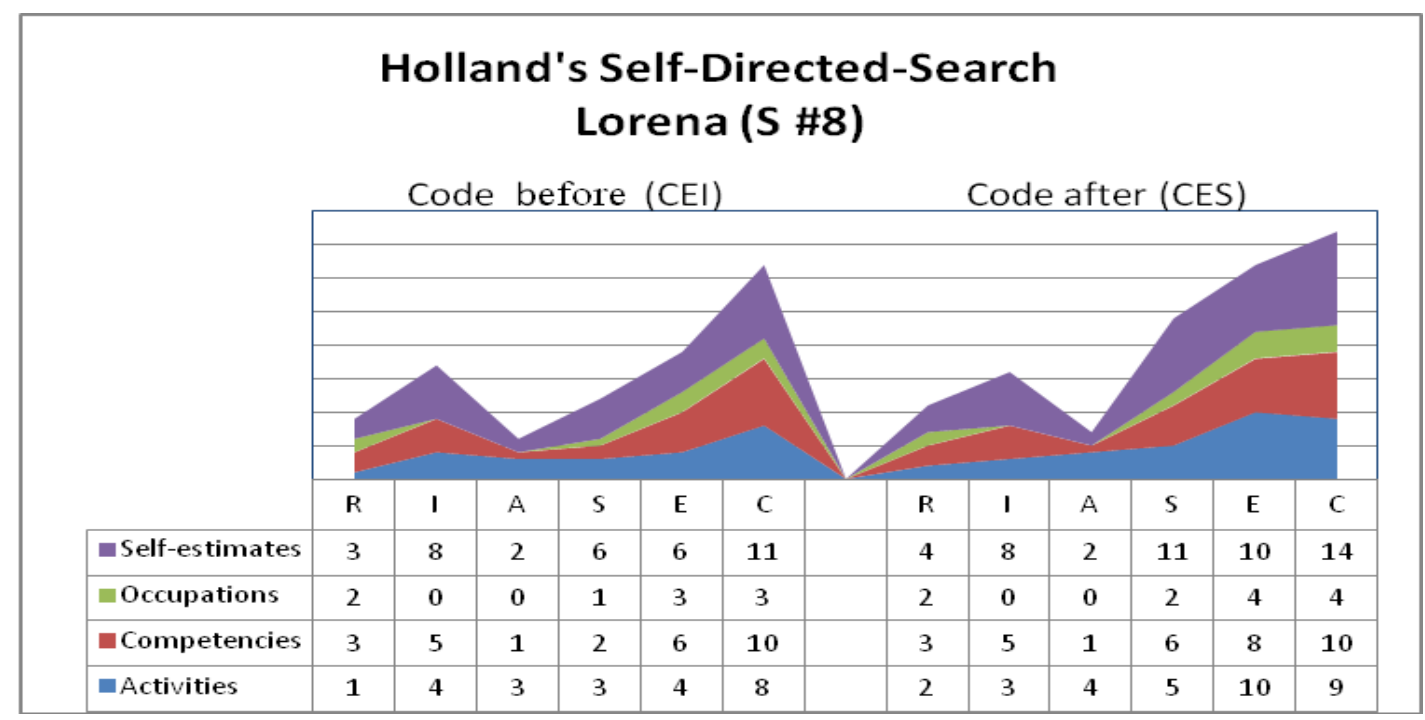




\section{Self-concept characterization}

How does Lorena characterize her self-concept before and after study abroad experience, and how does this reflect in her verbal self-knowledge?

\section{Before SA:}

Lorena perceived herself as very family oriented. This semester program abroad for her was the first time living far from her family. She demonstrated a high motivation towards personal and career plans. Regardless of her fears, she is greatly committed to take the initiative to participate in this study abroad program and discover new experiences.

To the question how she describes herself, she answered,

"I describe myself as a very motivated person and I love to start... uh... new things, I'm a person that is afraid to start new things, but I am willing to take the risk because if I don't take the risk then I will be left wondering... I should've done this or that. Even if there is uncertainty I'll try to get that away from the road try to clear that and be persistent..."

In relation to her vocational career needs which is to get familiar with field of economics, she admits being open to explore her interest and identification with the subject, "how I describe myself. I'm open to anything, because my major is in business administration with concentration in economics. But overall, I think in business, I believe that, I am very determined and I like to start new things that are one of my strengths".

This coincides with Holland's (1985) typology, because he says that "people within the conventional environment type are reinforced by traits such as persistence" (p. 40).

\section{After SA:}

Study abroad experience helped enrich Lorena's self-knowledge and strengthen her career knowledge. When she was asked how she described herself after being exposed abroad, she explicitly admitted that her self-concept developed into a positive sense of vocational identity. She attributed this to the fact that study abroad is an exceptional option to define career course and direction. In a comparative manner regarding her changes, she said, 
"I think I'm a person that has grown in knowledge...I felt like, I accomplished something, and if you're not sure of your career path, study abroad experience can either reinforce it or maybe deny it. I don't think you ever come back with the same ideas. The only way that you are going to respond this question, about you career path, is by being there. By taking that chance and if you don't take the chance you are never going to know yourself..."

In reference to her FSKN self-concept questionnaire, Lorena reported the second highest gain (Sara the highest) among all research participants. Lorena's self-concept improved positively $10.25 \%$ more than before studying abroad. Diagram 4.4 reveals the progress made in each self-concept domain after her return from her study abroad experience program in Spain.

The domain with the most significant and positive effect, after study abroad experience, was FSST "Stability" which demonstrated 24 points higher than before. This domain corresponds to the self-confidence in expressing one's opinion and standpoints, furthermore not be afraid to be oneself. Her stability is reflected in her after study abroad experience interview, when she openly expressed that interacting with people is one of the things that she enjoyed the most, e.g. when she gives and receives new ideas. Lorena expressed, "being more in contact with other people with different ideas, that made me realize, that was one of the things that I enjoyed doing... maybe here in the United States in the classroom you don't get taught those things." This particular positive gain of stability produced in her a higher sense of confidence within her social interactions, e.g. now she dares herself to speak up in a group, now when she disagrees with an acquaintance's point of view, she has the confidence to make a criticism, she does not feel ill-at-ease when somebody else has a different opinion than her, now she is able to state her opinion in a group setting, now it is not at all hard for her to represent an oppositional opinion, even more significant, now she feels self-confident because she knows that she is able to come up with good ideas just as others do.

The domain that exhibited the second highest improvement $(7+)$ is the FSIA domain "Irritation though others." In reference to the FSIA domains' improvement, which deals 
with the level of sensitivity with social acceptance, Lorena's significant effects are, for example, after study abroad experience, she perceived it to be less significant, and how others accept her opinions, e.g. taking her opinions seriously or not. Even more noteworthy is that Lorena has a greater feeling of being herself, rather than acting as others want her to be she just wants to be more likeable.

While Lorena's professional future aspirations, before study abroad experience, were not oriented towards higher leader positions, now after her experience in Salamanca, she sees herself with higher professional and vocational ambitions, even creating an international network. She said,: "In five years from now, definitely, hopefully getting that masters in the European Union Studies, and maybe in some governmental agency, where I can use this knowledge or in a corporation, where I can expand business and I can get to that market, and if not, in the governmental agency trying to advise."

Diagram 4.4 Lorena's Self-Concept assessment before and after SA.

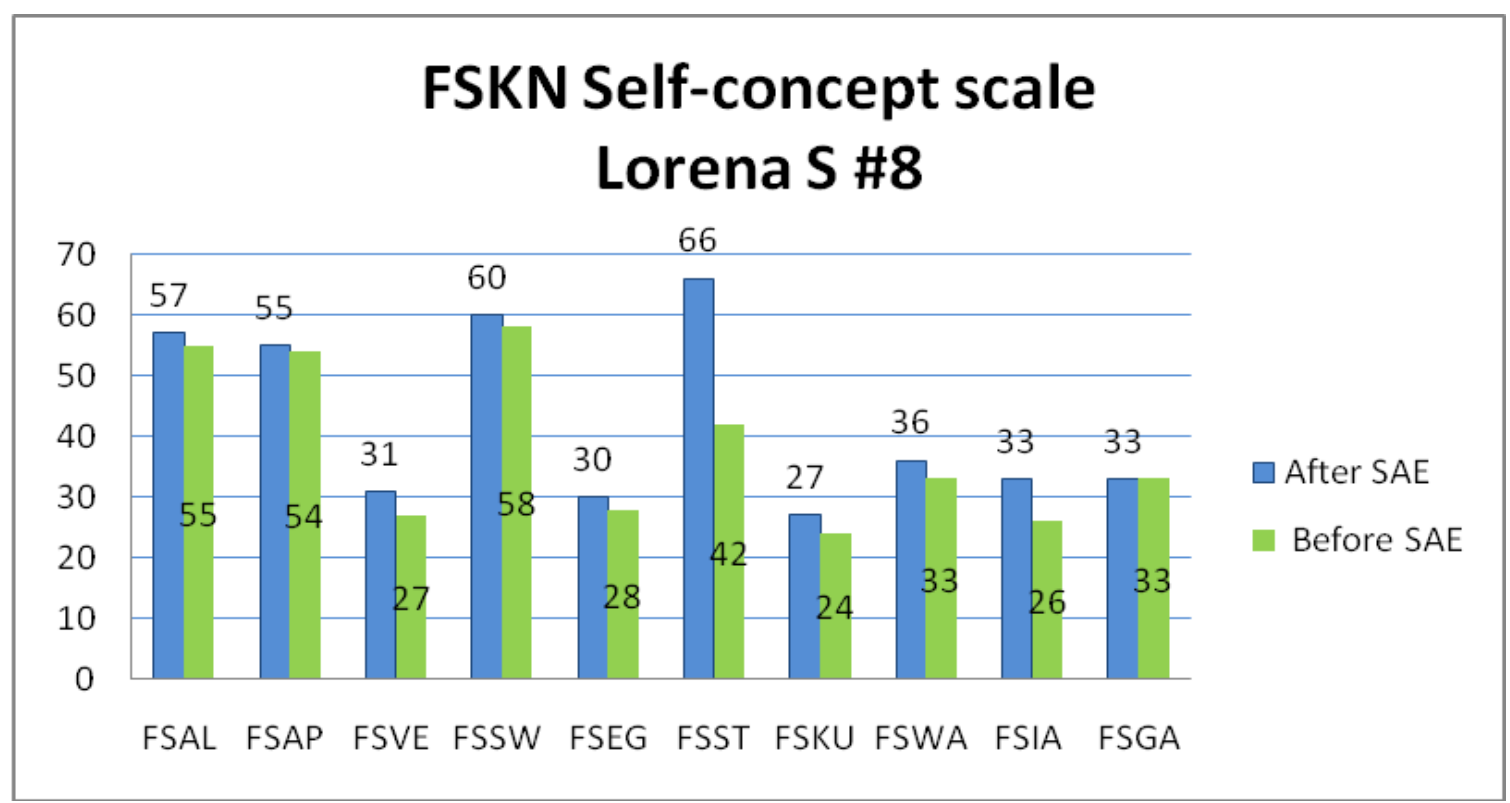

The positive effects in the domains of the FSKN that coincide with Lorena's statements extracted from her interview.

\section{After SA:}

As discussed before, the level of Lorena's self-concept domains of "Stability" (FSST) and FSIA "Irritation through others, was significantly impacted. Lorena stated, with emphasis, 
her enjoyment in taking part in group discussion, and in accepting other people's opinions and ideas. Along with a greater sense of self-confidence, she demonstrated her benefit with a positive self-knowledge and career interest awareness. She admitted accepting the diversity of individuality and cultures.

"I think that was one of the aspects that I was lacking; it was, being more in contact with other people with different ideas, that made me realize, that was one of the things that I enjoyed doing, one of the things that going abroad made me realize, that there are so many things".

\section{- Vocational identity development}

How did study abroad experiences modify Lorena's vocational identity? What type of personal or social factors impacted her vocational career and identity?

As has been illustrated and demonstrated, the self-reported status of Lorena's identity appeared satisfactory and "achieved" although she recognized that within her vocational career choice process, she lacked information and exploration. This seems to present a kind of vocational need for a self-identification with her current vocational identity.

\section{Motivation and goals}

Lorena's motivational factors and goals were pretty well oriented, namely to support her vocational career interest definition, and to minimize the discrepancy between her idea and the actual career information. These needs are reflected in her statements during her first interview before going to Spain. Her plausible engagement in and positive willingness for participation in this study abroad experience program allowed her vocational behavior to stay motivated. Her goals were associated with two main stimuli: intercultural learning and vocational development. After being abroad, she really valued the greater sense of self-sufficiency and self-efficacy that she developed while abroad. Vocationally speaking, she encountered diverse ideas by interacting with students from the same career environment, namely a sense of experiencing a collective identity (Kanan \& Baker 2006), e.g. people with the same career interest and ideas. Lorena's interaction with international 
classmates helped to reinforce her vocational motivation for her career, which she described as the most enjoyable learning activity.

\begin{tabular}{|c|c|c|}
\hline & Before SA & After SA \\
\hline Motivation & $\begin{array}{l}\text { Vocational career: } \\
\text { I think that study abroad would support } \\
\text { my vocational choice, why? I believe that } \\
\text { for a student, in any area, if you get out } \\
\text { from your circle, you might have different } \\
\text { opinions, because... when you explore } \\
\text { and go out of the circle you have a better } \\
\text { understanding, and you are open to other } \\
\text { opinions. Yes... well definitely study } \\
\text { abroad is going to contribute, like I said } \\
\text { before in economics. The economic } \\
\text { system in Europe, in Spain, in the } \\
\text { European Union over all, it is different } \\
\text { than here in the States. } \\
\text { Intercultural learning: } \\
\text { My motivation to go abroad is to first to } \\
\text { know the culture and other cultures } \\
\text { besides the one here in the United States. } \\
\text { Basically when it comes to culture, that's } \\
\text { where may be either you have to adjust or } \\
\text { you're going to have to learn from me, } \\
\text { maybe, I don't know, I'm kind of hesitant } \\
\text { right there, culture basically. }\end{array}$ & $\begin{array}{l}\text { Vocational career } \\
\text { Study abroad strengthened my vocational } \\
\text { choice, yes... it definitely did. Before, I think } \\
\text { that was one of the aspects I was lacking, } \\
\text { acquiring knowledge in the academic, and } \\
\text { also being more in contact with other people } \\
\text { with different ideas that made me realize that } \\
\text { was one of the things that I enjoyed doing. I } \\
\text { got new ideas, fresh ideas that maybe here in } \\
\text { the United States, that maybe in the } \\
\text { classroom you don't get those things. So } \\
\text { going abroad it did change, it did reinforce } \\
\text { the career path. } \\
\text { Personal growth: } \\
\text { I recommend study abroad definitely! Yes, } \\
\text { yes! If anyone has the opportunity, take that } \\
\text { chance, because we are so used to being in } \\
\text { our comfort zone and have your daily routine } \\
\text { of going to class. Once you're over there, and } \\
\text { you are going through something new, } \\
\text { because, you are on your own, you are the } \\
\text { one deciding, I think its very gratifying and } \\
\text { at the end you feel like you accomplished } \\
\text { something... }\end{array}$ \\
\hline Goals & $\begin{array}{l}\text { Vocational career: } \\
\text { I want to get acquainted with the } \\
\text { economic system and the European } \\
\text { Union. My major is economics so I think } \\
\text { it's a good place to go, and see how what } \\
\text { things work over there and how can we } \\
\text { apply that in the United States. } \\
\text { Language: } \\
\text { What I expect from studying abroad in } \\
\text { Spain, well right now is learning the } \\
\text { Spanish language, because the Spanish } \\
\text { that we speak here in this area, is not the } \\
\text { same that probably they speak in Spain, I } \\
\text { think that's one of the things... }\end{array}$ & $\begin{array}{l}\text { Vocational career: } \\
\text { In five years from now, I see myself } \\
\text { definitely, hopefully getting a masters in the } \\
\text { European Union Studies, and maybe working } \\
\text { in some governmental agency, where I can } \\
\text { use this knowledge, or working in a } \\
\text { corporation, where I can expand business } \\
\text { Now since that economy in Europe is } \\
\text { stronger than the one in the United States, so } \\
\text { I see that as a great professional opportunity. }\end{array}$ \\
\hline
\end{tabular}

\section{Resources: strengths and weaknesses}

How does Lorena perceive her strengths and weaknesses (self-efficacy) regarding her personal and career development within a foreign environment before and after study abroad experience? 
Lorena's' self-efficacy beliefs are correlated to professional performance and personal determination, such as achieving her goals. Before study abroad experience, she expressed being capable and prepared to take a change with her career plans and study abroad. She was willing to take the risk, as she previously mentioned. Her Hispanic cultural values made her reflect about her trip, because she has never been far from her family. When she was asked about her personal weakness regarding this program in Spain, she expressed the lack of self-confidence in making decisions without having family support and agreement. The effects that she experienced were felt more towards her personal growth and accomplishment, and also towards her vocational career satisfaction to pursue her career aspirations. Lorena overcame her stated personal weaknesses, and the way she expressed herself, was more in terms of strengths and challenges that she acquired throughout her program in Spain.

\begin{tabular}{|l|l|l|}
\hline Strengths & \multicolumn{1}{|c|}{ Before SA } & \multicolumn{1}{|c|}{ After SA } \\
\hline & $\begin{array}{l}\text { Career development: } \\
\text { My strengths, well I think I can contribute in } \\
\text { the academic community. But overall I think } \\
\text { in business, I believe that I am very } \\
\text { determined, and I like to start new things that } \\
\text { are one of my strengths. Another of my } \\
\text { strength is that I'm open to anything... }\end{array}$ & $\begin{array}{l}\text { Career development: } \\
\text { No, study abroad did not weaken my } \\
\text { career choice. I don't think so. No! I think } \\
\text { I spent the right amount of time, one } \\
\text { semester. I think because I met other } \\
\text { students with my ideas, I think it } \\
\text { strengthened. And so far, I think I stayed } \\
\text { there with my career choice in economics. } \\
\text { I'm going to pursue it... }\end{array}$ \\
\hline Weakness & $\begin{array}{l}\text { Self: } \\
\text {-Well my weakness right now, like I said, I } \\
\text { think, it is that I do not know the culture from } \\
\text { Spain, because I have been never far away } \\
\text { from m y family. I am very family oriented, } \\
\text { so being away from family, not having that } \\
\text { support can sometimes, can make you feel } \\
\text { that you're not doing the correct thing or } \\
\text { you're not motivated enough because you are } \\
\text { basically alone that could be one thing that } \\
\text { could be adverse to going abroad. }\end{array}$ \\
\hline
\end{tabular}

\section{Contextual learning experiences that shaped Lorena's vocational identity}

What kind of contextual learning experience did Lorena encounter during her study abroad experience programs that somehow contributed to her vocational identity development?

Lorena's vocational achievements have been defined within her academic and international experiences abroad. The social interaction and the career related ideas 
exchange were two of the successful perceived events. After being exposed to an international environment and having acquired more self-knowledge regarding her vocational interest, she reported her career path as being decided and clear.

The experience of study abroad provided her not only with trans-cultural interaction with students with a different prospective, but also with the career informational aspects that she was missing before she left, namely in the field of economics. In reference to the question, whether study abroad experience reinforced her vocational career, she responded:

"Yes it definitely did...so going abroad it did change, it did reinforce the career path ...I think definitely my career choice wasn't so clear but now, I enjoy doing that [economics].... There is a difference between just having an idea as your career path but then getting submerged and now actually enjoying it...yeah going abroad it did reinforce it..."

As far as the vocational impact of study abroad experience on her vocational interest, she experienced a type of vocational self-exploration through the role modeling of an Economics professor. She expressed that a class in Economics in the European Union has provided her with the necessary career and self-exploration that she was looking for regarding her career interest definition. She achieved a greater sense of vocational identity. She put it this way:

"When I started studying economics, I was not into... but then this class, the economics in the European Union was the one that I said, yes this is what I want, and yes I did have an excellent professor. I don't know...he had all this knowledge, and he was able to transmit that knowledge to me, and he was able to get through to me, and not a lot of professors can do that, some just go through the motions of the lecture and they don't care if you understand or not. But this professor is one of the best I have been able to know. But that professor made an impact on me, and I see in him more like a mentor towards that career path..." 
Lorena is very confident in what she has accomplished throughout her challenging experience abroad, and she expressed it when she was asked whether studying abroad weakened her career choice. She absolutely described her experience as a process of challenges in which she found her career environmental identity (Holland 1985) or a greater sense of self-identification within the appropriate socio-contextual career (economics) identity. She met other students with the same ideas and career interests as well, and she certainly valued her vocational interest and identity even more. She is decidedly convinced and has no hesitation in regards to the impact of being exposed and immersed into a new and international environment, and to the fact that it has shaped her vocational interest. Furthermore, being around students from the same career interest reinforced her vocational identity. In regards to this, she said:

"I met other students with my ideas (interest in economics) and then I think it strengthened, because I was able to go through a process (cultural challenge abroad), and at first,...it went really fast paced and towards the end, it went by slower, then I started to reflect about it and I realized that yes it did strengthen my career choice. And so far I think I stayed there and I'm going to pursue it..."

She is quite certain that she will be following her vocational interest which is pursuing a Master's degree in economics. Despite the uncertainty about her completed career in Accounting, she was inspired to gain more knowledge in economics. Currently, she obtained a job in accounting, and she expressed being satisfied, because now, she is applying economics knowledge into accounting. Her obtained knowledge is actually benefiting her occupational performance in accounting. She said:

"Now, I'm able to understand how to read a lot of contracts (in current accounting), what are the specifications there...because the contract comes from the government...now, I get my response from my economic classes because people have scarce resources. Why? Because they have to set the limits of how to manage those resources, they're connected. All this knowledge from everywhere is helping me out....Right now, I'm doing accounting, but I do employ economics because my studies aren't so deep 
about economics, but right now, I can say that going through that experience (abroad) helped me be ok with accounting, before I was uncertain but now I'm ok..."

\section{Summary}

Lorena, as the oldest of all participants, crystallized and solidified her vocational preference, as well as her vocational identity not only by attaining the necessary career information in economics, but furthermore through achieving a positive effect on her level of Self-Concept Scale results. During her career oriented learning activities abroad, she acquired a positive sense of self-efficacy and overall autonomy. In her case, her persistence in getting more knowledge about the "Economy in the European Union" supported her development in achieving a greater vocational identity because, as she stated, before her experience abroad, she was lacking on career information, and personal beliefs of a congruence of her identity and her chosen career. Now, Lorena defined her vocational career satisfaction, and she expressed herself in terms of her happiness and satisfaction with her completed career choice in accounting, by saying: "Now, I can say that going through that experience abroad in Spain helped me, be ok with accounting, before I was uncertain, but now I'm ok...." 


\subsubsection{Gabriela}

\section{Personal information}

Gabriela (A14), a 20 year old female with a Hispanic (Mexican-American) background, spent one semester in Buenos Aires, Argentina. She reported her major in biology and her minor in chemistry, which are prerequisites to enter medical school. She comes from a family with a background in business, as her father and mother have their own business. Gabriela, during the first interview, reported that she had not yet selected, the university, she wanted to attend. Based on interviews data prior to departure, Gabriela was the one student of the three individual program students that conveyed somewhat less program information and advisement prior to departure. She seemed rather determined to go to Buenos Aires to earn credits hours in basic classes that she needed. Gabriela's academic achievement before her study abroad experience is represented with a grade point average of 3.1 .

\section{- Career choice and identity status}

\section{Before SA:}

What were the effects of one semester study abroad experience program on Gabriela's vocational satisfaction and career choice?

Gabriela, before going to Argentina, reported (Survey I) her career choice status as "clear and decided" namely biology and chemistry which are prerequisites for medical school. Her career interest and decision for medical school were relatively defined. Her career choice clarity was reflected through her satisfaction, when she was asked how she rates (from 1 to 10), her career decision satisfaction, she answered with a 10.

When she was asked about her career satisfaction, she stated that she truly liked everything about her career in medicine and found the classes interesting. She admitted that without pressure she decided to study medicine, she even considered her vocational career choice as one of her "strengths" within her personal and career planning; in her own words, she said: 
"I like my career a lot, I enjoy everything about medicine and the classes are interesting, everything captures my attention. It could be that this is my strength in my career, because the truth is no one pressured me to study medicine, in other words, I alone chose it..."

She reported that she chose her career by herself. However, the reasons why she selected her career in medicine was because of career concepts and meanings developed by herself with a score of $80 \%$, family reasons $10 \%$, and because of her brother's accident $10 \%$.

Gabriela's vocational identity status was reported as achieved. She had already made a firm commitment to a specific decision. An achieved identity is as per Marcia (1980), when one has a high level of commitment to make a decision for a specific career after a considerable exploration process (see also Rodermund \& Vodracek 1999).

When she was asked about her expectation of study abroad on her career choice and development, she stated that, while she was sure about her studies leading up to medical school, she was not sure which university (medical school) she would pursue and thought that her study abroad experience would help her to seek out other options of universities abroad

"Well, I still do not know exactly which university I am going to attend after finishing with Biology and Chemistry here at the university... perhaps after Buenos Aires, one of the schools there and the degree plan, as well as its application will capture my attention..."

\section{After SA:}

The experience abroad provided Gabriela with an important element which was the definition of her vocational role and occupational aspirations. Her career decision status remains consistent, as she once again reported "clear and decided".

On the Survey II after her study abroad experience, Gabriela reported increasing her career decision clarity after her experience abroad. She attributed $5 \%$ more to career meaning and concepts developed abroad. When Gabriela was questioned about how this program contributed to her professional career development, she put emphasis on cultural 
differences between Argentina and USA. After study abroad experience, she even expressed, with enthusiasm, a stronger attraction to her career in medicine. She felt that, now, she would put more effort into her career. This is the way she expressed it: “...well, Argentina is a completely different culture. Now, I like my career even more... now I will put more effort into it..."

What Gabriela gained from her experience in Argentina was her professional and occupational image; now for her, the future is clear and it became a priority in her life. As with the other students, Gabriela's self-reflection abroad helped to further visualize her professional future goals.

\section{- Vocational self-assessment}

\section{Before SA:}

Gabriela's vocational self-assessment, represented by her Self-Directed-Search Inventory, demonstrated that the results and its impacts, before going abroad, appeared significantly positive regarding her vocational identity achievement. Her vocational summary code, before study abroad experience, revealed that she was quite interested in the InvestigativeArtistic-Realistic (IAR) environments. As previously mentioned, Gabriela loves medicine and everything related to the field, even if she does not have a concrete decision on what medical school she will attend. She is clear and decided on her vocational occupational choice, more precisely to become a medical doctor.

\section{After SA:}

After being exposed to a foreign environment on her own, Gabriela reflected positively about herself and her vocational preferences, her vocational self-assessment results appear to have a high level of consistency with her career choice in medicine. Her final summary code, taken from the Holland's (1994) SDS assessment, did not report significant changes in her three letter occupational personality type. The three letters acquired after her study abroad experience remained the same, but in a different order, before study abroad experience (IAR) Investigative-Artistic-Realistic and after study abroad experience 
Investigative-Realistic-Artistic (IRA). With that said, Gabriela equipped herself with vocational activities in the realistic environmental type. She now rated herself lower in the social environment (e.g. $5<14$ ) and higher (e.g. $20>15$ ) in realistic mechanical and technical competencies than before her experience abroad.

The highest impact reported from her Holland's (1994) SDS results was that she reported less interest in the artistic and entrepreneur types of vocational occupations (before $15>$ after 10) than before. The occupations that were less attractive to her were: to own a business (entrepreneur type), credit investigator (conventional type), artist, singer and sculptor (artistic). Regarding her interest in her vocational occupation after study abroad experience, Gabriela reported a clear and defined interest in the realistic type of occupations, such as: biologist, medical laboratory technician, and physicist. This combination (IAR) of vocational environments, according to Holland's Hexagonal model (Holland 1985, p. 29), provides a good relationship between the environments, which could predict the "ease or difficulty of one's career choice" (Gysbers, Heppner \& Johnston 2003, 27-29). For Holland (1985), the rating of consistency, regarding the IA score, relates to a high level of consistency (p. 28). Gabriela's final summary code IRA, after her experience abroad, reported an achieved and defined vocational identity that match with her vocational interest developed abroad. The summary code IRA, according to Gottfredson and Holland's (1989) occupational directory, corresponds to the type of vocational occupations that fall within the field of medicine: surgeon and veterinarian ( $\mathrm{p}$. 184).

Diagram 4.5 Gabriela's vocational self-assessment before and after SA

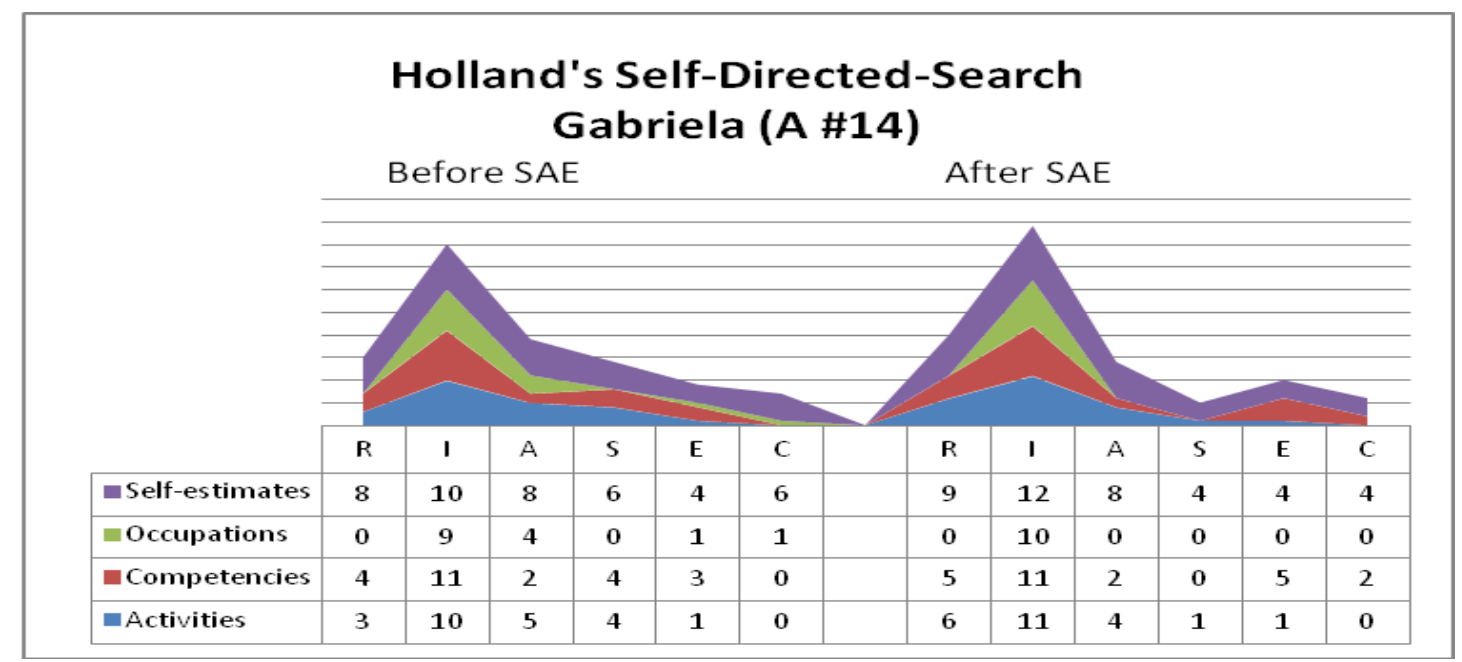




\section{Self-concept characterization}

How was Gabriela's level of self-concept characterized before and after study abroad experience, and how is this revealed in her self-assessment?

\section{Before SA:}

Before going to Argentina, Gabriela was questioned concerning her vocational career aspirations and how she sees herself in the future, and it was adequately determined by her statements that she visualize herself studying and finishing her career in medicine.

In regards to her academic self-concept, Gabriela described herself as a responsible person. As far as her social self-concept, she adapts very easily to people but she can be timid at times. She sees herself as being a little shy, especially when it comes to meeting new people. Nevertheless, Gabriela also optimistically expressed that she is in the process of working on overcoming her shyness. She stated:

"Towards school, I consider myself a responsible person... socially, I adapt easily to people and have conversation and so forth... I can be very timid sometimes... when I meet a person, yes it intimidates me...I can be very timid but I am already overcoming it..."

Gabriela's primarily expectation of her study abroad experience, concerning her selfdevelopment, was largely to acquire a better sense of living on her own e.g. dealing with her own issues alone.

\section{After SA:}

After her experience in Buenos Aires, being without family support for one semester she expressed, on several occasions, that the primary benefits of her experience were more within the personal development and growth categories, especially in gaining a positive sense of independency, than in the academic achievements aspects.

When Gabriela was asked about the most successful changes and impacts that she experienced, after her study abroad. She responded, with a fair amount of stability, she expressed that she felt like she was more independent. Before study abroad experience, 
she would always call on her mother for assistance, and now, after her experience, she increased her sense of self-confidence in her social conduct and the ability to deal with her problems on her own. She revealed in her second interview that the most important personal achievements, she learned, were how to live on her own, and gaining a better sense of independency.

"I feel that I am a much more independent person, before I called my mom for everything, and now, after my experience abroad it is different, I have to do everything by myself. I know how to deal with my own problems by myself... being independent...is the most important thing that I learned during my stay in Argentina..."

The self-concept characterizations, extracted from her FSKN results (diagram 4.6), confirm the changes that Gabriela reported before and after her study abroad experience program in Argentina. A small but significant improvement of $0.85 \%$ appeared in her level of self-concept; this impact was revealed in two domains: self-esteem (FSSW) and "Stability" (FSST). She gained a higher sense of self-esteem. In this case, one speaks from the principle of congruency. She acquired a better knowledge about her abilities to perform on her own, gaining also an approaching congruency between her cognitive and emotional aspect of herself.

In addition to dealing with her own problems in an unfamiliar environment, taking classes (not related to medicine)in a different educational system, and also achieving what she set out to do before she departed, study abroad experience provided her with a greater sense of emotional stability and confidence in feeling good about doing what was right for her. Her self-evaluation judgments after study abroad experience revealed a profound feeling of accomplishment towards her personal growth. 
Diagram 4.6 Gabriela's Self-Concept assessment before and after SA.

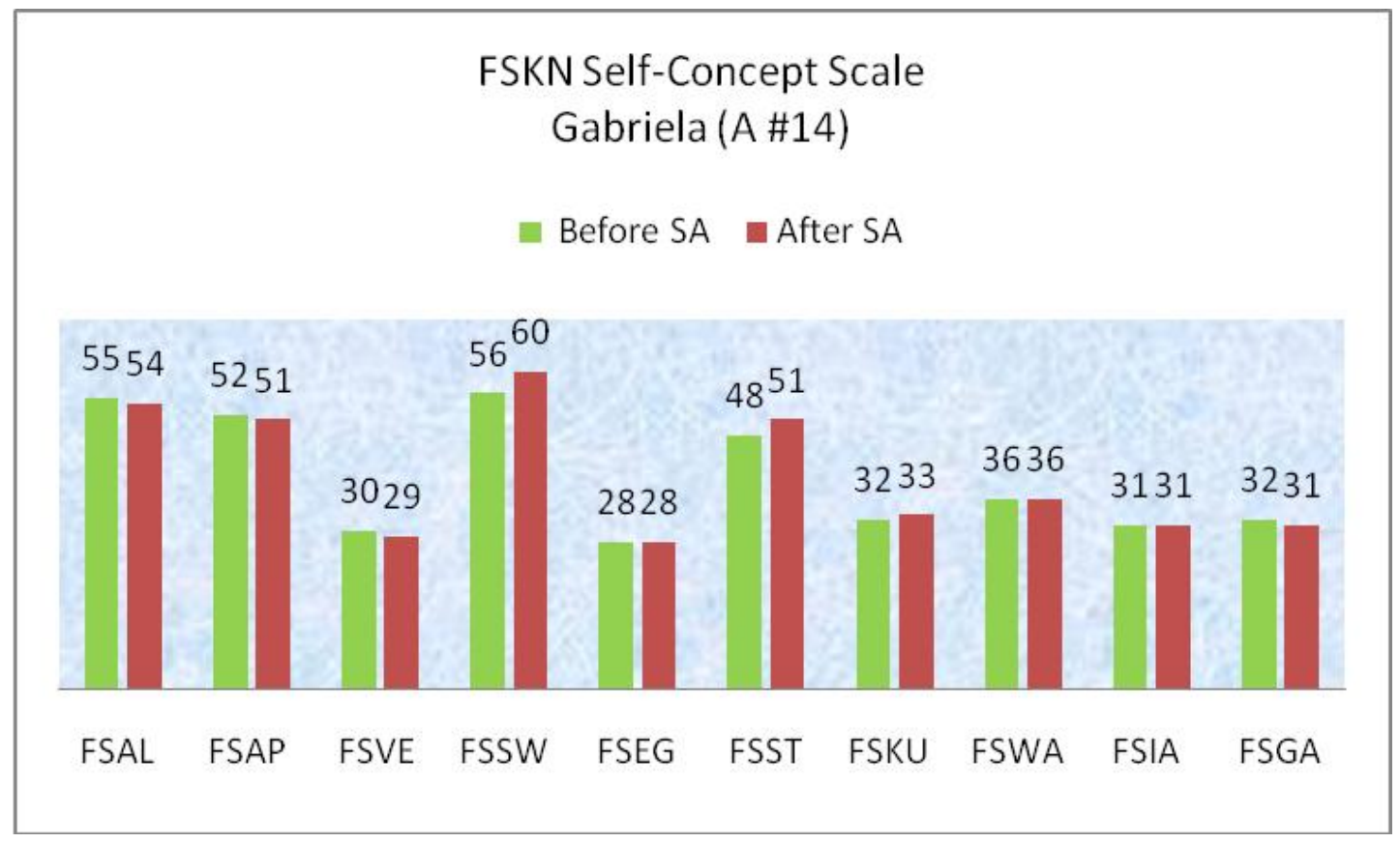

To a certain extent, Gabriela recognized that her personal needs were directed towards personal growth in her future occupational and personal plans. She noticeably acknowledged, during her second interview, the lack of opportunity of executing activities on her own, and now after her study abroad, her successful accomplishment of being independent, gave her a positive sense of self-sufficiency. Beyond her acquired sense of self-efficacy, she admitted to have benefited also in her relationship, in particular with her mother.

"Study abroad helped me a lot, in my personal development... I changed a lot in my relationship with my parents at home because... there were six months that I was not with them... where I had to go to the supermarket, clean the house, wash my own clothes. I never did that... well...it helped me a lot in my relationship that I have with my mom, it is completely different, and I don't know... but like the independency, ... I feel that I am a much more independent person..." 


\section{The positive effects in the domains of the FSKN that coincide with Gabriela's statements extracted from her interview.}

In reference to the FSST "stability" domain of Gabriela's self-concept, her scores revealed small but nevertheless important improvements.

\section{After SA:}

In regards to her improvement in the self-esteem domain (FSSW), Gabriela reported a total sum of 60 points, the highest score possible for that domain. The particular impacts reported by her "self-esteem" domain results were revealed in the following FSKN statements: “Overall, I am pretty satisfied with myself; if I compare myself with others' performance, I perform pretty well; I think I am pretty comfortable with myself; I am satisfied with myself". These aspects were reflected in her personal accomplishments. She now feels completely satisfied with a greater sense of self-sufficiency. Her gained selfefficacy in dealing with her own problems benefited her level of self-esteem. She said:

\footnotetext{
"The most important thing that I have learned from my experience abroad was that... the independency, it is something very incredible... that it is something that I have never experienced before and... for me it was something very satisfying depending on myself and not on others people..."
}

\section{- Vocational identity development}

How did study abroad experiences affect Gabriela's vocational identity? What type of personal or social factors impacted her vocational career and identity? These questions will be presented in this section.

\section{Motivation and goals}

What type of motivational objectives and goals did Gabriela have within her career development plans before her study abroad experience? 
In order to understand Gabriela's vocational identity impacts, we need to consider her main motivations and goals to participate in this study abroad experience program in Buenos Aires, Argentina. Her motivations, before going abroad, were pointing predominantly toward gaining a greater sense of independence e.g. self-sufficiency, rather than acquiring additional career related knowledge and benefits for her vocational career. Somehow, part of her motivational behavior to participate in this study abroad experience program was her outcomes expectation in achieving more independence, which was subsequently fulfilled after her experience abroad. She stated, regarding her personal development, her experience in Argentina was very different and gratifying; it really fulfilled her personal development expectations. Unfortunately as for the academic component, she firmly expressed that she did not anticipate the outcome of not being able to pass the courses in which she enrolled. As previously mentioned, she appears to have been affected by this ${ }^{2}$ particular experience. Especially relevant in this particular case is that Gabriela's goals before and after study abroad experience indicate her vocational aspects necessary for a greater sense of her vocational identity, such as a sense of independency and autonomy. This is reflected in her statements regarding her goals. Before going abroad, she was pursuing a better sense of what is involved with living on her own, which is precisely what came to pass after her experience abroad, which is a positive and motivational aspect for her future career plan achievements.

\begin{tabular}{|l|l|l|}
\hline Motivation & \multicolumn{1}{|c|}{ Before SA } & \multicolumn{1}{c|}{ After SA } \\
\hline $\begin{array}{l}\text { Vocational career: } \\
\text { M think this program will help me a lot in } \\
\text { my personal growth... I do not know but } \\
\text { I will think different, and I believe that is } \\
\text { going to reinforce my vocational } \\
\text { career... }\end{array}$ & $\begin{array}{l}\text { Vocational and academic experience: } \\
\text { In general was a very different experience, } \\
\text { very, very good. Yes, it fulfilled my goals } \\
\text { from what I expected... as far as the school, } \\
\text { not really because I failed the classes } \\
\text { although I did like them a lot, I also learned a } \\
\text { lot but it was not what I expected as far as the } \\
\text { school system...I can't explain it but... it was } \\
\text { a very, very good experience... }\end{array}$ \\
\cline { 2 - 3 } & $\begin{array}{l}\text { Personal growth: } \\
\text { This program is going to be a totally } \\
\text { new experience, meeting new people.... } \\
\text { Before getting into a full-time dedication } \\
\text { to my career ... the life alone is a total } \\
\text { different experience ... }\end{array}$ & \\
\hline
\end{tabular}

\footnotetext{
${ }^{2}$ Because it is not part of this research study to evaluate the study abroad preparation and advisements given to Gabriela, this will be discussed in the chapter 6 .
} 


\begin{tabular}{|l|l|l|}
\hline Goals & $\begin{array}{l}\text { Personal growth: } \\
\text { My goal is to get a little more independent, } \\
\text { this is what I do expect most from this } \\
\text { experience namely what is like living alone, } \\
\text { and to have to deal with all problems by } \\
\text { myself, not counting on my mom or my } \\
\text { parents... in other words, to see how life } \\
\text { will be in the future when I move out ... }\end{array}$ & $\begin{array}{l}\text { Medicine is what I really like; I am already } \\
\text { looking forward to going back to school } \\
\text { and take my chemistry and biology classes, } \\
\text { I do really miss them a lot .... In the future } \\
\text { my goal is to continue studying my } \\
\text { career..., now I like my career even } \\
\text { more... and now, I will put more effort } \\
\text { into it... }\end{array}$ \\
\hline
\end{tabular}

\section{Resources: strengths and weaknesses}

How does Gabriela perceive her strengths and weaknesses regarding her personal and career development within a foreign environment before and after study abroad experience?

When Gabriela was asked about her strengths during the first interview, she expressed that once she sets a goal, she works on it until she accomplishes it, without having any fears of not succeeding. After her experience abroad, she openly summarized again that the independence she experienced was a benefit in terms of personal strength, because she believes that this will give her the stimulus to overcome her life outside of the family environment. More precisely with her mom, Gabriela attributed her positive effects on her relationships with other people to her attained sense of self-sufficiency.

Taking into account her weakness before going abroad, she recognized that she was very easily distracted by a number of things including: e.g. friends, television etc. In a humorous and lighthearted way, she states that her only weakness after study abroad experience is becoming accustomed to traveling.

\begin{tabular}{|l|l|l|}
\hline Strengths & \multicolumn{1}{|c|}{ Before SA } & \multicolumn{1}{c|}{ After SA } \\
\hline & $\begin{array}{l}\text { Self: } \\
\text { My strengths are... when I set } \\
\text { my goals I do achieve them, and } \\
\text { I am not afraid to fail ... }\end{array}$ & $\begin{array}{l}\text { Self: } \\
\text { I think that the strength I gained was, the } \\
\text { independency, this is something unbelievable which I } \\
\text { never experience before and for me was something } \\
\text { very satisfying, just depending on myself and not on } \\
\text { other people, ok... That is true, I did not work, but it is } \\
\text { something I will do one day in my life... My } \\
\text { independency is stronger, as well as my relationship } \\
\text { that I have with other people, in particular with my } \\
\text { mom... }\end{array}$ \\
\hline
\end{tabular}




\begin{tabular}{|l|l|l|}
\hline Weakness & Self: & Self: \\
& $\begin{array}{l}\text { I get distracted easily, it could be } \\
\text { a little my weakness... I get } \\
\text { distracted by my friends, TV and } \\
\text { everything... }\end{array}$ & $\begin{array}{l}\text { One of my weaknesses after this trip, the real truth I } \\
\text { did not have any... but perhaps getting use to } \\
\text { travel... }\end{array}$ \\
\hline
\end{tabular}

In reference to the academic aspect, and as a relevant component of her study abroad experience program in Buenos Aires, Argentina, Gabriela perceived some negative experience. She selected three courses that were part of her basic classes for biology and chemistry which is part of a pre-medicine degree plan. Those courses were: Theory and Practice of Language I, (Teoría y practica de la lengua I), History of Argentina and LatinAmerica (Historia de Argentina y Latino América) and political economy (economic politics). Unfortunately, she had to cancel the last course due to the level of complexity which is equivalent to a course that is a part of a third year bachelor degree at this foreign institution.

"Well, I went there with three classes... but the one I was taking Political Economy... the first day I attended, I realized that this class was a third year class for a bachelor degree in politics, and because my career is medicine, it did have anything to do with it, they were already very advanced... I preferred to cancel that class because I did not know anything at all..."

Another aspect by which Gabriela seems to be substantially affected, is the academic grading system employed by the University in Buenos Aires, especially the grading system for exams. Gabriela's academic self-efficacy seemed to be emotionally affected through her academic achievement, in particular because the type of academic assessments and exams that she was accustomed to at her home university. According to her explanation, the types of exams at the host university encompass one mid-term and one final exam in which only five explanative questions exist, the student is required to demonstrate and explain everything that the student has learned throughout the semester. Despite this challenge, she admitted to have learned from it. She expressed herself this way: 
What I did not expected form this program in Argentina, was the school system that they have over there is completely different than here in the US. There, the system as far as the exams consist of having just one midterm exam and one final exam with 5 questions that needs to be answered explicitly. Here, I am accustomed to the multiple-choice, and it is like... they give the answer, and you do not have to write nothing, and over there you have to write everything you have learned, and it's completely different. It was hard work for me, which was the reason why I failed the classes, I put a lot of effort into it, but it did not give me the results that I wanted.... But, did I learn, I did!

\section{Contextual learning experiences that shaped Gabriela's vocational identity}

What kind of contextual learning experiences did Gabriela encounter during her study abroad experience that somehow contributed to her vocational identity development? Gabriela's learning events abroad that somehow shaped her vocational identity are identified mainly through two learning experience processes: differentiation and congruency of the vocational interest process.

As previously mentioned, the courses that Gabriela took during her study abroad experience further developed her vocational interest, e.g. by self-directed activities that revealed to her what she truly was interested in, namely Medicine.

Gabriela, throughout her experiences abroad, obtained diverse benefits, first in her level of personal growth development, such as her better sense of self-sufficiency, which has given her a closer congruency in her personal and vocational identity, as well as a higher level of self-esteem (see section 2.0, p. $6 \& 7$ ). The second was through avocational matters (See Super 1942), by taking classes in history and language in Argentina, an unfamiliar environment and educational system, helped her consider what she really takes pleasure in, which is all topics and matters related to medicine. In her statement below, she admits that, when it was time to go to her class, although they were interesting, she discovered that she really did not like them. With that said, Gabriela, with non-vocational interest 
classes (outside of her major), confirmed her love for medicine, and further intensified her vocation for medicine. She openly revealed that she enhanced her vocational interest and her eagerness for medicine. After the vocational differentiation process, she wants to start her courses in biology and chemistry, which she admitted she missed tremendously. As a matter of fact, she actually browsed the internet and other periodicals to fulfill her need to stay close to her subject. Gabriela definitely expresses and conveys her increased interest and joy for her vocational career choice.

"Yes, by taking those classes over there... well I really liked them because they were interesting, but they did not fulfill me, and well, medicine is what I really like it, I am already looking forward to going back to school and take my biology and chemistry classes, I do really miss them a lot. Yes, yes, yes, taking those classes, I did reinforced my vocational interest for my career in medicine, by the way whenever I got tired of it, I went online to read something about biology and I brought some notebooks from my past biology classes in order for me to not forget it... because I do like it a lot. By the way, there is a newspaper named "Clarin" and just when I arrived, every Wednesday, they were giving away a brochure called the "Atlas of the human body", I was always anxious for it to arrive, I even set the alarm on my cell-phone to not forget it. Well... I already knew that medicine was what I liked... but this situation it really served to prove that medicine was my vocation..."

Self-knowledge: Going through a process of seclusion, she was allowed the time to reflect and think more about herself and her future. These two vocational developmental task processes, self-exploration and vocational knowledge in other areas of content, made her differentiate between what she wants and that which she feels more attracted to. Furthermore, her interest and engagement to go back home and begin her classes in Biology towards her degree in medicine was expressed openly and with enthusiasm.

"Yes, well...many times I was alone in my apartment, if did not have any homework or anything like that, I went out for a walk to the parks of 
Buenos Aires, and I read... and the truth is yes it helped me a lot to really think about myself and my future..."

\section{Summary}

Gabriela is a female Hispanic who comes from a family oriented environment. Before her study abroad experience, she was accustomed to always having someone available to help, attend, and care for her. Going abroad seemed to serve as a different and exciting opportunity to demonstrate herself that she is able to live unaided, and become selfsufficient. In addition, she acquired an enhanced interest in regards to her career interest definition through avocational activities (Super 1942) such as studying subjects outside the field of medicine, while in a foreign environment.

In terms of personal and vocational improvements and achievements, Gabriela's study abroad experience provided her with the kind of encounter that she was seeking, e.g. learning how to be independent. She wanted to experience what it would be like in a foreign country, being on her own and not having anyone else taking care of her. As previously illustrated with the Self-Directed-Search results (See Diagram 4.5), and in accordance to Gottfredson and Holland's (1989) Dictionary of Occupational Codes, after this rewarding experience abroad, Gabriela achieved the type of vocational letters codes of environments matching her vocational interest with her career choice in medicine. Gaining a positive sense of self-efficacy in the self-sufficiency category, as well as acquiring clarity in regards to one's vocational interest, and increasing ones vocational career choice satisfaction might be considered a good predictor for a stable vocational identity. Only by being far away from one's interests, customs, comfort, social life with family and friends, one is able to analyze and reflect about what is important for one in one's career life plan. 


\subsubsection{Marc}

\section{Personal background}

Marc (G15) is 22 years old, and like the rest of the research participants, of Hispanic (Mexican-American) background. His personal milieu is a business oriented vocational environment. His father is a businessman, and his mother works in real estate. Marc is the one and only student who embarked on an individual study abroad experience program in Luneburg, Germany. Marc's major is in economics. As far as his academic achievement, he possesses a grade point average of $2.4(=84$ in a scale of 100), which is one of the two lowest grade point average of all research participants.

\section{- Career choice and identity status}

\section{Before SA:}

When Marc was asked, on Survey I (before SA), whether his career decision was clear towards a professional occupation, he answered the question with a confident response, "decided and clear." He also reported his major in Economics. The percentage that Marc attributed to the development of his career concepts and meanings, before going abroad, is very interesting. He reported that $90 \%$ of his career meanings and concepts were developed by himself and only 10\% developed within the family environment. Regarding his career choice status, his expectations of study abroad for his vocational choice were rather high. He said, "Yes, I'm pretty sure" that studying abroad will strengthen my vocational choice.

When he was asked to reflect about his vocational identity development, namely the time and effort invested in seeking his vocational identity towards his professional occupation, he answered, with an "achieved status". This aspect clearly conveyed his perceptions in terms of the level of exploration and commitment that he has invested in finding his vocational identity. His expectations of study abroad on his vocational identity development, in general, were reported with a relatively high score of 5, "totally". 


\section{After SA:}

After his study abroad experience, Marc's career decision remained consistent with a "clear and decided" status. During the second interview, when he was asked if his career in economics remained the same, he stated, "Yes, the same [career choice] it is right now." Furthermore after his study abroad experience, his vocational choice was reinforced, as he stated, "Actually I'm learning in my classes, I understand better, I pay more attention, it's much better." These statements confirm that his vocational interest in economics remained stable and his overall learning experience was enriched.

In answering Survey II, Marc credited 30\% (20\% more than more than before study abroad experience) to the family environment in supporting his career concepts and meaning development. With that said, according to his interviews, he reported that regarding his career decision status his family supported him significantly during his stay in Germany. He, beyond a doubt, acknowledges that his family was the one thing that kept him motivated during his study abroad experience. "My family was the one, who motivated me, because the first three weeks were very difficult to me...they told me, hey you are already over there. That is your dream, accomplish it. After that, I was like it is true, very, very true. I was there for six months, and it was very good". The consistency in his career choice status was also revealed in his future vocational aspirations.

Marc stated that his study abroad experience in Germany enriched and further helped to develop his vocational career in economics. He recognizes that, before going abroad, he was kind of insecure about economics as his major.

However, after study abroad experience, he became even more focused and satisfied with his vocational decision, he stated:

"Before, I was like... ok, I'm going to study economics, but I was like, maybe...I can just major in economics...But now after my study abroad program, I have more focus on my career, because the school that I went to in Germany, is pretty much oriented on economic majors and they taught me... and I learned from them [Germans] a lot." 
Marc's study abroad experience in Germany helped him learn more about his career from a different point of view. In addition, it helped him become even more attracted to the field of Economics than he was before his study abroad experience. With a gain in his career knowledge, his vocational interest seemed to be enriched. With that said, through his academic experience abroad, Marc found a better sense of congruency between his vocational choice and interest.

After study abroad experience, Marc endowed his career decision with more interest and further future expectations, with even more commitment and determination than before study abroad experience. In regards to the question, how he sees his career in the future, he responded with a determined and firm answer, "I see my vocational career in the future, better. I'm going to finish it and that it will be a total success. Much, much better, I want to finish in a year".

\section{- Vocational self-assessment}

\section{Before SA:}

Even though Marc's career decision in Economics remained consistent after study abroad experience, he indicated a sign of vocational uncertainty. His summary code letter, before his experience in Germany, was Enterprising-Realistic-Social. According to Holland's (1985) hexagonal model and the consistency in environmental pattern, the pattern ER attains a middle level of consistency. This is based on the distance between the two types of personality and environments.

\section{After SA:}

Marc's vocational interest inventory reported a positive vocational adjustment in his summary code (See Diagram 4.7). His summary letter code, after his experience abroad, became (Enterprising-Conventional-Realistic), maintaining his enterprising personality traits. In this case, Marc with a new personality pattern (ECR), more conventional than social, gained a better level of consistency in his personality. This new vocational code (Holland 1985; Gysbers, Heppner \& Johnston 2003), predicts for Marc to engage easier in 
more career explorations activities in economics than before. Marc reaffirms his preference to enterprising activities, and also corroborates his self-concept of ability higher in the personality type of enterprising environment. According to Holland's (1985) hexagonal model for defining psychological resemblances among types and environments and their interactions, this final summary code (ECR) after study abroad experience, assumes a positive degree of congruence and consistency in Marc's vocational personality in the direction of the enterprising environment. Marc expressed that he was happier and satisfied with his vocational choice. However according to Gottfredson and Holland's (1989) occupational codes, interestingly enough his vocational identity profile was not achieved, because according to them a well defined profile for an economist is IAS, not ECR which he reported after study abroad experience.

After study abroad experience, Marc's vocational self-assessment increased primarily in his vocational interest in the enterprising and conventional environments. As the Diagram 4.7 shows, the most significant changes are mainly in the enterprising (business and administrative) and conventional areas (accounting and commercial areas). In the domain of vocational competencies, Marc did not report any change. He also evaluated his vocational competencies with a higher score in the social and enterprising environment. Now, he presents even more interest in other types of occupations in the realistic environments (e.g. technical and mechanical), as well as in the artistic (e.g. actor) and conventional (e.g. bank teller, financial analyst). The most significant impact on Marc's vocational development resulted successfully in his self-estimates scores. As far as his skills and abilities in comparison with others, he rated himself 22 points higher than before his experience in Germany. As a matter of fact, he assessed himself highly competent in all types of environments, especially in business and managerial skills and abilities, as well as in the personality type of conventional environment. These positive aspects of personal and vocational ratings support Marc's vocational development, engaging him in more exploratory activities that predict a satisfactory vocational congruency in his career path with his vocational beliefs. 
Diagram 4.7 Marc's vocational self-assessment before and after SA.

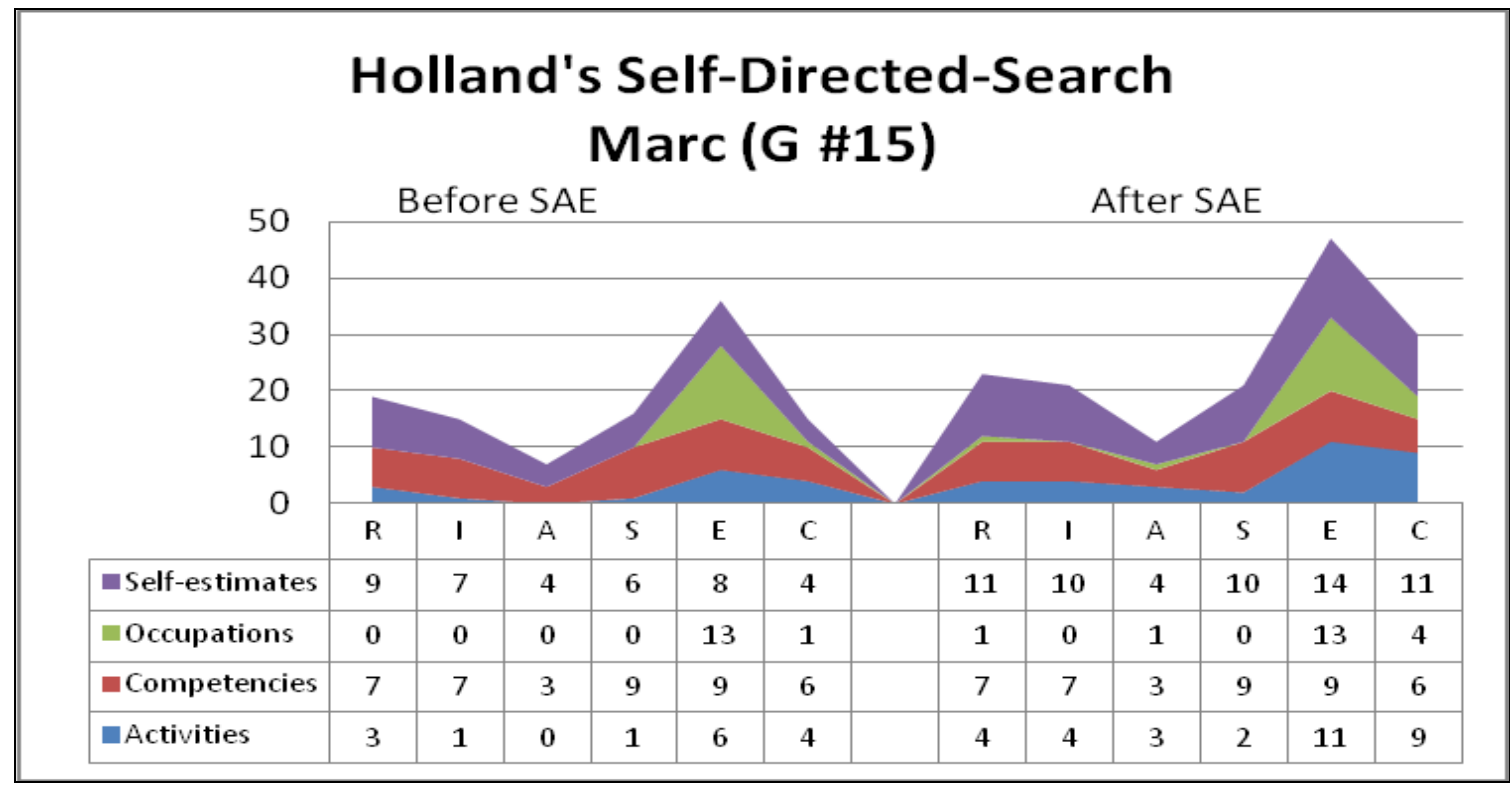

\section{Self-concept characterization}

How is Marc's self-concept characterized before and after study abroad experience, and how does this reflect in his self-assessment? In which domains did he improve the most?

\section{Before SA:}

During the first interview, Marc reacted astonishingly when he was questioned about how he describes himself smiling, he answered: "I don't know, no! How would I describe myself? That's a good question." Interestingly by this question, he seemed to appear somewhat surprised, and taken aback. After a brief silence of self- reflection, he described himself more in the social environment which reflects his community leadership (entrepreneur type of personality): I'm a hard worker; I work really hard. I'm in a fraternity organization "Phi Kappa Theta." I'm treasurer right now, so I'm the guy, who is in charge of managing the money pretty much. I want to be the president next semester, when I come back from Germany I want to be the president and what else can I say, I have a good sense of humor, I believe, and that is it." 


\section{After SA:}

The impacts of study abroad experience on Marc's self-concept characterization are absolutely positive. During the second interview, when Marc was asked to describe how he felt about himself after this experience abroad, he said: "Good, very good! It was amazing, it was a good experience!" In reference to his self-perceptions he responded with a proud voice, "Yes, I feel that I'm more independent now, I don't depend on my parents now... What stands out is how he describes himself after study abroad experience, his greater sense of self-esteem; he strongly believes that his learning experience abroad impacted, with certainty, his self-identity, in his words he said: "I lost a lot of weight, because I was walking all the time and riding my bike, I didn't get sick over there, I never got sick, it was very cold, but I was in perfect condition, I lived by myself." Additionally his sense of self-efficacy, concerning his personal ability to control his career and destiny, improved positively. Marc expressed himself by saying:

"I feel like I'm better now, I can do more things now. Yes, because, I set my goals now, well my first goal was to go to Germany and I accomplished that one already and I have three more so, step by step I will accomplish them...."

His vocational and occupational aspirations for the future, after his program in Germany, illuminate his gained self-confidence. Now, he feels more self-confident to work in an international setting, out of his hometown. Marc expresses this by stating:

"My professional aspiration before going to Germany, were not really like that, I was thinking to stay and work here (in Texas), but now, I want to go somewhere else. Now, I see myself working hard and anywhere, I don't care where, I can go anywhere, I can work here or in Germany or Japan, my doors are open..."

As far as the level of self-concept characterization, Marc's FSKN "self-concept" results reveal changes and impacts (See Diagram 4. 8). After his experience abroad, he reported small but nevertheless positive improvements in seven FSKN domains. Actually, in both interviews before and after study abroad experience, he got the highest point summary of 
all participants (before 418 \& after 429). Marc's Self-Concept Scale summary report illustrates a stable and positive level of self-concept; he perceived the impact of study abroad experience in Germany as positive, especially in the psycho-emotional domain of "self-esteem" (FSSW). The contextual learning activities that he encountered abroad changed his sense of self and self-image which in the end had a positive effect on his selfesteem as well. Primary impacts that become visible in Marc's self-concept after study abroad experience were that he achieved a better sense of self-knowledge, self-efficacy and problem solving. These aspects emerged as a common effect on the self-concept among other research participants in their statements in this research study. The improvements that were found in his self-concept summary correspond to an increase of 11 points from which seven points were attributed to increasing a better sense of problem solving, greater confidence in conduct and assurance by doing what is right for him, and furthermore, his sense of a gained higher self-esteem are all significantly visible. This will be made more evident in the next section, with some examples of positive impacts and relationship found between his FSKN results and interviews statements.

Diagram 4.8 Marc's Self-Concept assessment before and after SA.

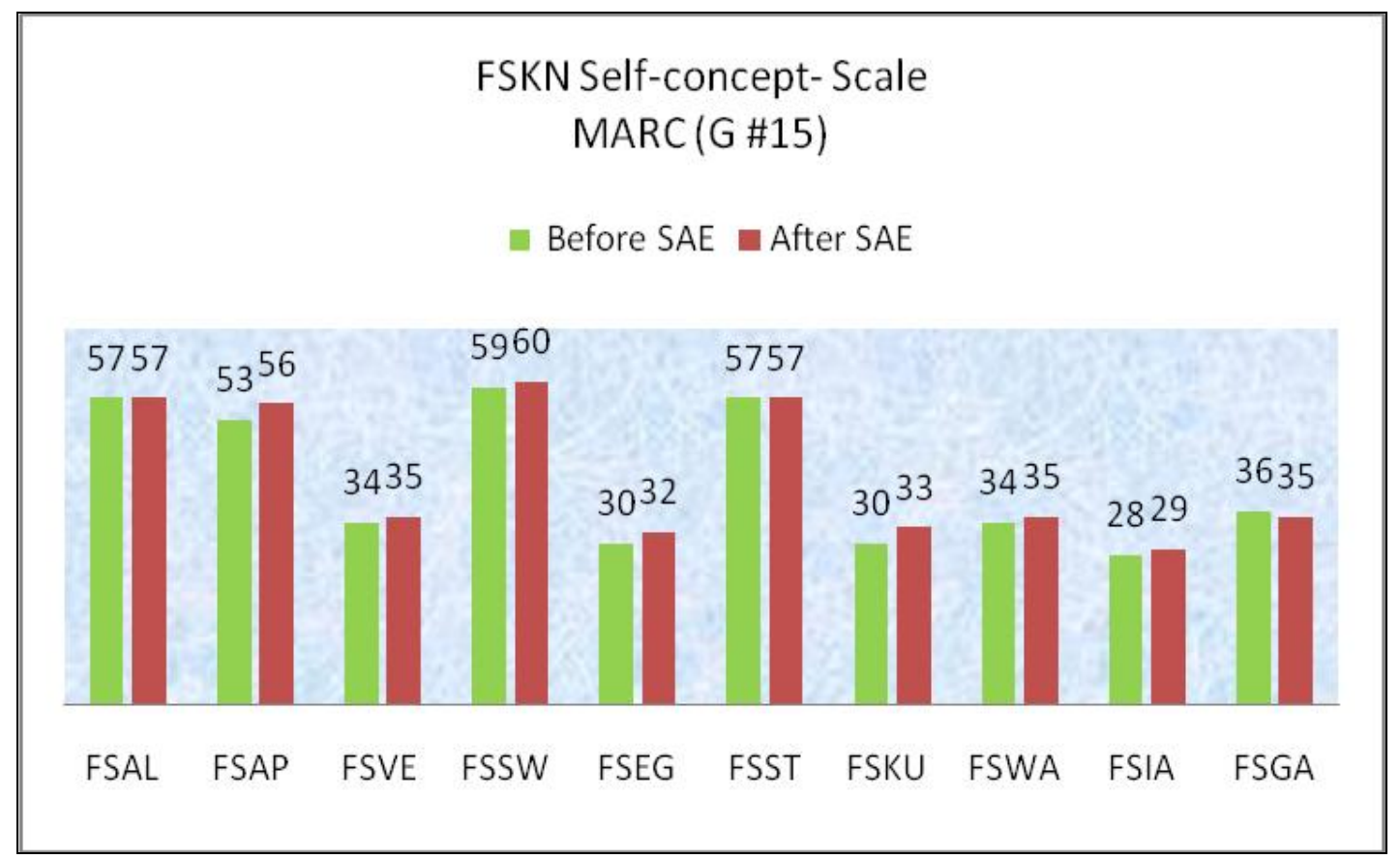


In reference to his professional career expectations, when he was asked how he visualizes himself in the future, he again demonstrated his community leadership goals: "I want to be the president of my country, pretty much. I want to work in the government. I want to start as a "Major" pretty much, that's my goal in 15 years."

Some relationships in research findings (FSAP, FSVE, FSSW) between the Self-Concept Scale (FSKN) and the interviews before and after study abroad experience will be illustrated with the following examples:

\section{The positive effects in the domains of the FSKN that coincide with Marc's statements extracted from his interview.}

\section{After SA:}

As far as the psycho-emotional domains scores, the "problem solving" domain increased 3 more points $(56>53)$ than before, the "conduct and assurance" decreased one point (35> $34)$, the "self-esteem" domain decreased one point $(60>59)$, and the domain "sensitivity and overall mood" decreased two points $(32>30)$. Marc conveyed and encountered positive effects on his physical self-concept (image) about himself. As far as his ability in "problem solving" (FSAP) and "conduct and assurance" (FSVE), Marc, now believes that he is able to master things more fluently than before, also he expresses confidence in his gained ability to do more than, what he thought he was able to do, and achieve his goals greater than before. Marc expresses and reflects this in his statement:

"My self-esteem is higher, now yes, it used to be normal, but now, after my experience, it is higher. I feel like, I can do a lot of things that I would usually say no, or just not say anything and now I can speak out my mind and say anything and not have any worries or anything. I feel that I can do more things now. I can focus more on specific things, I developed the way that I learned over there [in Germany] to study, and understand other people, I feel like I'm better now, I can do more things now..."

In the domain of "social contact and dealing skills" (FSKU), he scored 33 points compared to 30 points before, this is a small, yet significant, improvement within this domain. He feels less shy and more secure in social contact: "I develop the way that I learned over 
there to understand other people." He considers himself more socially kind and polite, as far as getting in social contact with other people, more secured and accepted as he is. The effects of international experience, on Marc's point of view, is stated as follows: "Yes, I think by watching, learning everything seeing different cultures, and I think all of that changed my mind, my point of view, it was very good."

\section{Vocational identity development}

How did study abroad experiences modify Marc's vocational identity? What type of personal and or social factors impacted his vocational career and identity?

\section{Motivation and goals}

According to Holland's (1985) personality types of vocational environments and personality traits, Marc's personality could be identified as enterprising: ambitious, selfconfident, social, and agreeable. The conventional personality's traits are: careful, efficient, methodical, orderly (p. 21-23). With this in mind, it is simple to understand that Marc's self-perceptions seem to appear congruent with his vocational choice. In order to comprehend in depth Marc's personal and career plans, his motivations and goals before study abroad experience will be presented.

Apparently, Marc experienced very specific types of exploratory behaviors. Developing personal skills and growth were primarily motivational factors to participate in a study abroad program for Marc. For Marc as well as all the other participants, this was the first time spending a semester in an unfamiliar and foreign environment away from his family. Rather determined, he conveyed his goals in choosing Germany for an economics program. Apparently, he seems to have had previously researched the program. For him, acquiring more knowledge in the economic career system in Germany appears most important. In addition, Marc's goal was to gain more knowledge in business and the opportunity to obtain a cross-cultural economics learning experience (See table below). 


\begin{tabular}{|c|c|c|}
\hline & Before SA & After SA \\
\hline Motivation & $\begin{array}{l}\text { Vocational career / personal growth: } \\
\text { I want to develop my skills, to be a better } \\
\text { person and help people...Yes, I'm pretty } \\
\text { sure that my study abroad program will } \\
\text { strengthen my vocational choice.... I } \\
\text { want to learn the same thing economics, I } \\
\text { want to learn a lot I don't know, how to } \\
\text { explain it, it's going to help me... } \\
\text { Intercultural learning: } \\
\text { I chose the program of business in } \\
\text { Germany, because Germany's a first } \\
\text { power right now, it's good country, they } \\
\text { are very smart and they know what } \\
\text { they're doing, pretty much" }\end{array}$ & $\begin{array}{l}\text { Vocational career / personal growth: } \\
\text {...No, I would never experience the same here } \\
\text { in my hometown. I think, I would be the same } \\
\text { as I used to be, because over there, in } \\
\text { Germany, I was independent, I was like, if I } \\
\text { was going to do anything by myself, there was } \\
\text { no one to tell me, I couldn't do it or I wasn't } \\
\text { going to do it, but it makes me more mature... } \\
\text { Intercultural learning: } \\
\text { My experience abroad was very nice. I learned } \\
\text { a lot of culture and of other people. I learned } \\
\text { that Germans are very strict when you are } \\
\text { talking about time, that you have to be } \\
\text { punctual. Germany is very different, people are } \\
\text { colder, but nice, and overall it was a very good } \\
\text { experience, a total success. I learned that } \\
\text { everything is on the schedule all the time, } \\
\text { that's what I like about the Germans. They do } \\
\text { everything step by step on regular... }\end{array}$ \\
\hline Goals & $\begin{array}{l}\text { Vocational career development: } \\
\text { My major is economics, so I can analyze } \\
\text { economic situation in Germany, so I can } \\
\text { bring back here, and work with in a } \\
\text { governmental department...Yes, I'm } \\
\text { planning to see, how the business field is } \\
\text { over there... my major is in economics, } \\
\text { so I'm going to try to expand... my } \\
\text { knowledge, so I can learn a lot from the } \\
\text { Germans". }\end{array}$ & $\begin{array}{l}\text { Vocational career development: } \\
\text { Yes, now I feel that have more control about } \\
\text { myself, because I set my goals now, well my } \\
\text { first goal was to go to Germany, and I } \\
\text { accomplished that one already and I have three } \\
\text { more so, step by step I will accomplish them. }\end{array}$ \\
\hline
\end{tabular}

\section{Resources: strengths and weaknesses}

How does Marc perceive his strengths and weaknesses regarding his personal and career development within a foreign environment before and after study abroad experience?

The role of perceived abilities to perform diverse tasks is relevant for one's motivation as well as for present and future goals. As we have discussed, it is important to consider the role of self-efficacy within the career development. This reveals itself, to a considerable extent, in one's abilities to adapt easily to the social and professional world. Marc, in the interviews before and after, seemed to appear coherent as far as his limitations and aptitudes are concerned. He possesses a strong sense of self-concept of ability (Brickman \& Miller 2003) regarding his career choice and study abroad program. He seems to be 
aware that the acquiring of knowledge (in any area) implies setting personal goals for achievement. The effects on Marc's career goals appear to be pretty well set and firm. Through his personal accomplishments by studying abroad and being consistent in economics, his motivation to continue with his major in Economics developed a special sense of self-efficacy and self-esteem. How does Marc perceive his strengths and weaknesses (self-efficacy) towards his personal and career development before and after study abroad experience? (See table below.)

\begin{tabular}{|l|l|l|}
\hline $\begin{array}{l}\text { Weakness and } \\
\text { strengths }\end{array}$ & \multicolumn{1}{|c|}{ Before SA } & \multicolumn{1}{c|}{ After SA } \\
\cline { 2 - 3 } & $\begin{array}{l}\text { Career choice: } \\
\text { In regards to my career, I don't know, I } \\
\text { don't know what is my weakness, I think } \\
\text { maybe mathematics but no!, I don't know... } \\
\text { math it's something I can learn very easily, } \\
\text { so I can study hard and I study a lot and } \\
\text { read a lot so I can be prepared for any tests } \\
\text { or something. Also, I know what I'm going } \\
\text { to do pretty much. And I don't know what } \\
\text { my weakness is... everybody has weakness } \\
\text { but I don't know mine right now... }\end{array}$ & $\begin{array}{l}\text { Career choice: } \\
\text { Study abroad strengthened my career } \\
\text { like I said, I learned more about my } \\
\text { major, and now, I want to have better } \\
\text { grades, finish school with a good }\end{array}$ \\
$\begin{array}{ll}\text { GPA, and be a good economics } \\
\text { major... No, I don't think study } \\
\text { abroad weakened my development, } \\
\text { because I was over there by myself, I } \\
\text { Iidn't know anybody but after that it } \\
\text { got better each day, it motivated me a }\end{array}$ \\
& $\begin{array}{l}\text { My weakness is the language, I speak just a } \\
\text { lot, I feel like my self esteem is } \\
\text { higher. }\end{array}$ \\
$\begin{array}{ll}\text { little German just the basic stuff, I took a } \\
\text { course the beginning German I, ... I do } \\
\text { know I think my weakness is the language } \\
\text { but I think it's not a weakness because I am } \\
\text { going to learn that's why I'm going over } \\
\text { there so it's not problem and then I have my } \\
\text { knowledge I do know, I know! }\end{array}$ & $\begin{array}{l}\text { Well...I need to study more the } \\
\text { language of the place that I'm going } \\
\text { to and prepare everything with time, } \\
\text { two months before at least, because } \\
\text { that was my problem I didn't prepare } \\
\text { myself a lot, and I missed a lot of } \\
\text { things... }\end{array}$ \\
\hline
\end{tabular}

\section{Contextual learning experience that shaped Marc's vocational identity}

What kind of contextual learning experience did Marc encounter during his study abroad experience that somehow contributed to his vocational identity development?

He reportedly gained a special benefit from his study abroad experience in his self-image and self-confidence more precisely from the style of life that he experienced in Germany. He acknowledges the value of time that he had to explore, and to get to know himself better. Beyond that, he discovered his self-efficacy and ability to achieve his goals. 
"I lost a lot of weight because I was walking all the time and riding my bike, I didn't get sick over there, I never got sick, it was very cold but I was in perfect condition. I lived by myself and I saw completely different people, from other countries too. It was like spending time alone made me think more and really appreciate more what I was doing and what my parents were doing for me and when I was by myself I kept thinking that I could do better every single time..."

The Germany university academic system, e.g. assessments, was a definite contextual learning experience that impacted Marc's attitudes towards academic evaluation.

"The academic system is very, very different. You can choose classes which ones you want and which ones you don't. They have only one final exam, and they make you start studying two months before the final to be prepared and be ready. Well the first exam, it was one question and you had to fill it out everything and then the other one it was multiple choice questions, true/false and then short answer..."

One of the most important academic values he has learned is: "How the economy runs, and the way they teach over there is totally different. The academic system is very good!" In reference to the class contents and assignments in the host country, he openly expressed that he was truly motivated in his vocational career by learning how the economics system works in Germany.

"Well, the money is very interesting, trying to work and make money, and another activity well researching on the internet, how everything works and I was looking at the euro and the dollar. Regarding the classes, it is not that complicated. You have only one final exam, no midterm, and you need to learn everything because it's the only one you have for the entire semester..."

The experience abroad, in general, contributed to his career, with his appraisal of $100 \%$. After study abroad experience, he has increased his motivation, not only in his interest for 
the subject, but also in his enthusiasm, understanding and attention given to the subject right now as well as the classes in which he is currently enrolled:

"A year ago, I was like I want to do everything maybe tomorrow; it was always later, later, later! When I went over there...I said, you were going to do it today, not tomorrow, you were going to finish it today.... Being in studying abroad helped in my career, yes, $100 \%$, because when I went everything was different, and like I said, I want to do everything right now, today, I want to study more, it changed me a lot. Better, that I'm going to finish it and that it will be a total success. Much, much better, I want to finish in a year...."

\section{Summary}

The type of motivational factors Marc' experienced were more specific which define a clear objective, such as developing his personal career skills and learning more about the economics system in Germany. Marc's greatest benefits and accomplishments are reflected in a positive self-evaluation, and in a higher sense of self-esteem, as well as an excellent self-confidence to maintain his commitment to learning. In reference to his vocational career, his motivation increased substantially. Study abroad experience, as an educational scenario for self-definition, served as a potential instrument for a selfexplorative challenging activity that opened new areas of interest which consequently provided a development of vocational adjustment and identity definition.

\subsubsection{Overview of the four cases}

The impact of study abroad experiences on the vocational identities of these four research participants were revealed in differentiated modes and forms.

In case 1, Sara, was impacted in two broad areas personal identity and communication skills development. In other words, the experience abroad presented an optimal setting for 
a vocational identity definition process of Sara's vocational career interest, as well as in developing further her communications career skills such as the acquisition of a foreign language to perform in the international market. The type of vocational exploration she experienced was driven mainly by extrinsic orientations, because her primary goal was to achieve a subsequent benefit (e.g. acquisition of a third foreign language) for her vocational career and professional performance.

Case 2, Lorena, the oldest and the only graduate research participant, had her vocational identity impacted in three areas. First, the satisfaction in her current vocational and professional identity accounting and second, study abroad experience served to appreciate satisfactorily the utility of her knowledge in accounting on her future vocational path in economics. The third was the fact that her career choice status became clear and decided, especially due to the academic and international interactions learning experiences with her classmates that, incidentally, shared the same vocational interests and ideas; she clearly defined her vocational career interest for economics. Her type of vocational exploration was fairly inquisitive. Her motivational tasks were based simply on a search-oriented response to her indecisiveness regarding her vocational choice by acquiring more knowledge in her vocational preferences for economics.

In case 3, Gabriela's (A14) vocational identity was positively impacted, in two areas: her definition of vocational identity through avocational activities and vocational interest consistency of her choice in medicine, e.g. the fact that she enrolled in classes outside the area of medicine, increased her vocational self-exploration and her vocational interest in the field of medicine. While abroad, her vocational career preferences were reflected in her continuing search for articles in health-magazines, newspapers, or online material related to the field of medicine. Lastly, the impact of study abroad is manifested in her achieved personal identity status, e.g. gaining a greater sense of self-efficacy and independency. Her mode of vocational exploration was directed more by a personaldevelopmental quest, e.g. experimenting roles of autonomy and self-sufficiency (i.e. independency).

In case 4, Marc's (G15) study abroad experience impacted mainly his vocational preference for his career choice in economics; furthermore, the life abroad changed his 
self-image and self-esteem. Study abroad experience kept him vocationally motivated through the experience of the German educational system and lifestyle. In Marc and Gabriela, their gain in the emotional area of self-esteem served positively in their enhanced sense of personal identity. Marc's vocational exploration was very specific; he had a clear objective of building up his personal and vocational competencies and skills.

The effects of exploratory learning activities experienced abroad which other participants had in common, were that, through a dynamic process of self-reflection and interest definition, the students benefited with an enhanced clarity of vocational interest, and a higher self-motivation for further career and vocational engagement. A positive advantage in all cases was that the nature of the study abroad setting was an excellent environment to provide students with personal agency development. All research students, during their study abroad experience, found themselves in challenging situations that presented them the opportunity to discover their answers through others or themselves that, in some way, complemented their personal and vocational identity needs.

A greater sense of vocational congruency (see principle of congruency, p. 16-17) between their current vocational visualization (real "I" and real "me"), and their future vocational visualization (ideal "I" and ideal "me"), were positively stimulated. By a cognitive deliberation of vocational and avocational events the students revealed a positive reinforcement of vocational career choice. Observed in the majority of the research students, regardless of study abroad program, was the fact that their learning experiences abroad increased their vocational career exploration, and developed (across borders) their vocational goals into future career plans. The qualitative analysis results have revealed that study abroad experience provided the students with the opportunity to live in an environment free of family and (hometown) cultural factors that, in a lot of ways, facilitated, not only the personal identity, but also their vocational development by increasing a positive sense of self-efficacy, confidence and independency. 


\section{Chapter 5}

\section{Discussion}

The intention of this research study was merely heuristic, and had three major objectives. The first was to examine the impact of long-term study abroad experiences on students' development of vocational career choice status and satisfaction, as well as how students assessed themselves in relation to their vocational preferences and competencies. The second was to analyze how the students' self-concept was characterized and manifested before and after a study abroad experience. The third objective was to analyze how a long term experience abroad impacted students' vocational identity.

\section{Career choice and vocational satisfaction}

To answer the first research question, how a semester study abroad experience impacts students' career choice status and vocational satisfaction, a combined research method proved to be effectual.

Previous research has shown that developmental tasks (resolved or unresolved crisis), such as the achievement of emotional independence, the preparation for a career linked to vocational development, the gain of self-knowledge and the development of future perspectives are undoubtedly crucial to students' developmental responsibilities for the identity formation process. How students cope with these tasks and the type of strategies used is a determinant. It seems to be that, nowadays, college students take advantage of study abroad programs offered by universities, in order for them to resolve personal issues associated with developmental crises. Also important is the way and how students feel and perceive themselves as far as their competencies and abilities to perform and achieve vocational goals.

Researchers agree that developmental tasks and the way in which they are coped with play a central role within one's personal success and life's career plan and vocational satisfaction (e.g. Havighurst 1972; Erikson 1968, 1974, 1980; Fend 1991; Chickering \& Reisser 1993; Bohleber 1996), and furthermore in one's vocational adjustment process 
(Super 1942, 1957, 1965; Holland 1985). The results of this study clearly report a strong motivation by the students to resolve personal and career issues.

Most career development theories (e.g. Zunker 1998; Brown 2003; Gysbers, Heppner \& Johnston 2003) utilize Super's (1953) stage model of vocational development, selfconcept and vocational choice, as well as Holland's (1985) typology of vocational environments and its relationship with personality type. Even if the career choice process might appear as a simple life event, in reality, it is one of the most crucial and important decisions that could define one's career path for the rest of one's professional and occupational life. Vocational career development and education is an essential event that is influenced by many personal or environmental factors (Krumboltz, Mitchell \& Gelatt 1975), including some international and intercultural factors such as study abroad programs as a learning experience (Orahood, Kruze \& Pearson 2007; Brustein 2007), which could be employed as a form of instrumental or associative learning experience.

The findings, in general, indicate that the students career choice status, after their study abroad experience, gained a clear and defined status, especially by the 4 students whose career decision status was reported as "undecided and unclear" before study abroad. A consistent career choice status was observed in 6 of the 11 research participants, measured before and after study abroad. Just one female student, Mariana (S11), after her experience in Spain clarified her career interest, by changing her major from Architecture to Public Relations. The results obtained from the surveys and semi-structured interviews provided noteworthy findings regarding students' career information development attributed to their experience abroad. All research participants reported an increase in self-reflection activity with regards to their development of career meaning and concepts.

Career choice status and students' vocational satisfaction were found to be closely related to their vocational career definitions, meanings and concepts developed through selfexploration abroad. Even though, vocational career choice support and development were not the primary and central goals before their study abroad program, the students admitted that their experience abroad was one of certain high-quality growth in self-sufficiency and greater career interest in their chosen major.

The Holland's "Self-Directed-Search" tool and Surveys I and II provided substantial data regarding the correlation between the students' career status decision and their vocational 
personality type, before and after their study abroad experience. The employment of these assessment tools were useful for this particular research group, due to the fact that all participants were from diverse majors of study and enrolled in different programs abroad. The findings regarding their vocational development and career choice status showed significant differences within career status decisions of the group. For example, some students corroborated, denied or changed their career decision, whereas many others expanded their career and vocational aspirations. The students' career choice status and vocational choice satisfaction were directly evaluated with these two instruments. Specifically the level of congruency of students chosen career was assessed with the three letter codes before and after study abroad, and compared using the Dictionary of Holland's occupational code created by Gottfredson and Holland (1989).

Holland's (1985) theory frames vocational identity by personality types, using a clear classification of types of occupational environments. His classification provided (vocational) occupational types based on environments such as Realistic, Investigative, Artistic, Social, Enterprising and Conventional. For Holland, the process of congruency and stability are important key concepts within vocational development. While the process of congruency determines whether a personality type matches a students' vocational preference or not, the consistency indicates the level of relationship between the (two letter code) pair of vocational environments.

The Holland's "Self-Directed-Search" instrument provided excellent data sources regarding student's vocational personality types and its congruency with their vocational choice and interest. It is reasonable to claim necessary an even more detailed analysis of a separation of students' vocational personality, e.g. how students' vocational identity develops and how it is impacted by the cultural aspects of where the study program took place. Although such analysis would reveal more detailed and valid impacts by each country, the number of research participants and the number of countries with study abroad programs in this study was clearly insufficient to formulate a meaningful comparison.

A combined design of qualitative and quantitative research methods was beneficial to assess students' vocational career effects before and after their experience abroad. The combined methods are recognized as forms of different epistemological traditions that, when they were combined, added new perspectives to the phenomenon under examination 
(e.g. Foss \& Ellefsen 2002). The instruments that proved to be useful in this research study to assess student's career choice status and vocational self-assessment were: the Surveys I \& II "Vocational identity development by college students" and Holland's (1994) "SelfDirected-Search" (SDS) which investigated the students' status of career choice (clear/decided; unclear/undecided; no idea at all) and their vocational identity formation.

A qualitative analysis and interpretation was employed with the objective of finding strong relationships among the data sources. This method of analysis helped to compare and correlate the quantitative results regarding the status of students' career choice consistency with their qualitative data information in regards to their status of career choice decidedness status and satisfactions before and after study abroad experience. Although this method did not prove to live up to expectations (e.g. an in depth qualitative reasoning) during the analysis, the statistical trend of students' career decidedness after their experience abroad represented a significant indicator of self-verification progress for students' vocational identity.

The results observed by the Holland's' (1994) SDS inventory indicate that students, through diverse self-explorative activities during their semester study abroad, developed an increased vocational interest in the artistic (e.g. appreciation for artistic and innovative activities) and enterprising (e.g. appreciation for self-confidence and leadership) environments. Concerning vocational competencies and self-assessments, the majority of the research students reported a significant increase essentially in types of enterprising and social personality. The students vocational competencies, abilities and self-estimates, in the enterprising and social environments types, developed further after their experience abroad. According to Holland's theory of personality types, persons with a strong enterprising personality type are believed to be good at "talking and using words to persuade, influence, and manage for organizational or economic goals," (Holland, 1985; cited also in Gysbers, Heppner \& Johnston, 2003, p. 293).

These social personality types, according to Holland (1985), recognize that people with social competencies are oriented not only to the social problems of people but to the growth of people and the interpersonal relationships as well (Gysbers et al.). On the whole, this group of research participants consisting of students with Hispanic background, e.g. Mexican-Americans, Mexican-Nationals and one Columbian-American, regardless of their major or career choice, benefited positively from a long term study abroad experience. 
With that said, explorative activities in a foreign country allow students, from all cultural backgrounds and genders, to interact easily within an international and intercultural social setting. In other words, study abroad participants may get an earlier jump, not only on learning the skills of leadership and social attitudes, but also goal setting, decision-making skills, and aptitudes toward their professional career plan. In summary, the majority of students revealed an increased confidence in setting expanded aspirations for future career plans.

Even though some of the students, during the second interviews, had limited time to reflect upon their experiences after their return, they still reported the effects of their experience on vocational career interest and decision from everything that they had lived and experienced abroad. Four students, who reported unclear professional and vocational career choice before study abroad, after their exposure declared a significant impact on their vocational choice and vocational interest development satisfaction. Study abroad programs utilized as self-awareness learning activity seem to equip and furnish a greater sense of students' vocational choice satisfaction and also, without a doubt, facilitate their career determination process.

Studies concur on the positive impact of study abroad experience, in particular, on education (Toncar \& Cudmore 2000; Teranishi 2007), on the development of professional values in social work students (Lindsay 2005), on cross-cultural learning for students of architecture (Myers, Hill \& Harwood 2005), on international internships for undergraduate in political science (Damron 2006), and on business careers (Praetzel, 1996, 1999; Brustein 2007; Orahood, Kruze \& Pearson 2007, Sindt 2007).

In conclusion, the employment of the Surveys (I and II), the semi-structured interview, and the Holland's (1994) vocational self-assessment (SDS) were of great utility as far as the chosen major and the students' vocational similarity to the type of vocational environment before and after study abroad. Holland's (1994) "Self-Directed-Search" tool facilitated the interpretation of individual interest scores, and served as a predictor of whether vocational occupation types were congruent or not with the students' reported or expressed career interest. The advantage was to identify the students whose personality requires the need for vocational career support and advice. It can be concluded that college students participating within a semester study abroad program experience may have, at their disposal, greater opportunities with a high potential for vocational self-explorative 
scenarios of reflection and practice than those students who are devoid of challenging situations of self-discovery and self-reflection and are immersed in an entirely routine ambiance of socio-factorial influences (family, college, and work environments). How students during their experience abroad developed a new career choice status, and furthermore, how they changed, or what precisely caused them modify their vocational self-assessment toward their chosen career, still remains unclear. The employment of a semi-structured interview served to identify, in depth, not only students' constancy of career choice status, but furthermore helped to distinguish the level of intensity in their career choice constancy satisfactions. However, exactly how students developed their career choice consistency during their stay abroad remains still unclear and should be highly considered for future studies.

\section{Self-concept and self-characterization}

The second research question of this study corresponds to how students assess their selfconcept and how they perceive and describe themselves before and after their experience abroad. Also assessed were what kind of strengths they gained abroad, and furthermore, how do students perceive themselves in terms of competencies, abilities and self-esteem.

Adolescence represents a crucial stage for the identity formation and for the success and achievements of personal developmental tasks, such as the search for a vocational career choice and enhanced self-knowledge. A current self-concept represents a major element within the formation of vocational identity. There are theoretical agreements that present the self-concept and the identity formation as cognitive and evaluative processes that occur in the person, wherein personal experiences are also incorporated, interpreted and evaluated by the person (e.g. Fend 1991; Haußer 1995; Keupp, Ahbe, Gmür, Höfer, Mitzscherlich, Kraus \& Strauss 2006). These experiences, as Bandura (2003) expresses, might include self-evaluations which comes from significant others (p.10-11).

Self-concept and self-awareness are milestones within vocational and identity development (e.g. Frey and Haußer 1987; Blos 1989; Fend 1991; Haußer 1995; Bohleber 1996; Krause, Wiesmann \& Hannich 2004) and within career counseling and advisement programs. 
Super (1957, 1963a) believes that throughout the explorative period, which includes vocational developmental stages and the gathering of new knowledge for their vocational self-concept, students will achieve a vocational maturity. With that in mind, the study abroad experienced served research participants as an explorative activity that expanded, cultivated, and updated perceived self-concepts. Therefore, it is to be assumed that study abroad experiences influence the students' self-verification and self-perception development in relation to one's professional picture, as well as enhancing one's maturity toward adjustments of vocational identity development. Relevant studies (e.g. WallaceBroscious, Serafica and Osipow 1994; Zunker 1998; Brown 2003; Gysbers et al. 2003; Tomas \& Oliver 2004) have employed Super's theory of self-concept within career development. Super's (1957) theory on vocational development suggests that one selects an occupation based upon one's concept of oneself, where one can say: I am this and that kind of person. On the other hand, Holland (1985) suggests that a vocational identity is achieved with an estimate of clarity and stability in personal identity within a vocational environment.

The employed mixed-method design enhanced the contribution of the study by investigating quantitatively significant relationships between the Frankfurter Self-Concept Scale (FSKN) results, and students' qualitative information extracted from a face to face semi-structured interview.

In order to facilitate the examination of students' self-characterization, before and after study abroad experience, two research instruments were employed, the Frankfurter "SelfConcept Scale" (FSKN) and the face to face semi-structured interview. These instruments were utilized with the following objectives:

- To identify the level of the student's self-confidence on a quantitative scale, the accurate self-presentation in a qualitative setting, and furthermore to compare the outcomes before and after their study abroad program.

- To identify the multidimensional components of students' self-concept characterizations, and its effects after their experience abroad.

- Correlate partially quantitative variances within the self-concepts domains (efficiency, psycho-emotional and psycho-social) with the students' statements during the interview. 
The FSKN Scale results have provided significant impacts (means) in two psycho-social areas, such as the FSST (Stability) and FSIA (Irritation through others), with mean differences of 7.17 for the FSST and 3.17 for the FSIA before going abroad. After study abroad, the psychosocial self-concept of students presented more improvements than the psycho-emotional area and their level of efficiency. These FSKN results have provided important insights into the psychosocial impact of study abroad on students' self-concept domains, thus a qualitative analysis on an individual level, is highly reliable.

Qualitatively, the students' self-characterization statements after studying abroad were significantly more explanative after their experience abroad. Due to the situation of being alone and in an unfamiliar environment, the investment in self-knowledge through purposeful and vicarious learning allowed the opportunity for introspection and deep reflection about themselves and their career plan.

Due to the fact that the impact of international experience is a multifactorial dynamic, this research study was mainly focused on the qualitative level of the impacts, which is on the micro level (personal level). No one person starts at the same level of self-perception, selfbeliefs, self-motivation, and self-efficacy etc., or finishes with the same outcome. The impact differs for each individual; therefore, group differences among the five groups were not considered in this study. This suggests further research and its effects of the country in which they studied.

The students, during the after interview, demonstrated a considerable amount of adjustment in the area of problem solving skills, self-sufficiency (verbalized as independency), and a greater self-efficacy.

The FSKN results found that the mean of all domains contained a relatively positive level of self-concept. The results reported by the FSKN domain of self-esteem before and after study abroad reported no significant changes and impacts as predicted. In contrast to those qualitative results, during the interview, the students seemed to be more satisfied with themselves after their experience abroad; in other words, they conveyed a greater sense of self-worth.

This research study attempted to fill qualitatively the gap of knowledge regarding the relationship between the students' vocational career development and the self- 
characterization; unfortunately due to the lack of data there were no significant findings. It is necessary to conduct additional research studies utilizing a group focus-interview (instead of a semi-structured interview) specifically on the subject of self-concept (FSKN) and vocational identity development (Vocational Identity Scale).

Before these results are further discussed, some limitations of this study need to be mentioned. Qualitative analysis results regarding students' self-characterization, before going abroad, were not substantially explicit by some of the younger students, as had been expected. During the first interview, it was observed that all research participants seemed to be less reflective about their own self-concept and much more enthusiastic and excited about a new adventurous experience, namely far from home.

As is typical for adolescents, the search for independence and self-sufficiency (Blos 1989; Fend 1991, 1994; Zimmerman \& Cleary 2006) are main factors in one's personal development. Developing a good sense of self-esteem and self-efficacy stimulate an accurate self-concept.

Coincidentally, in this study, all participants came from Hispanic backgrounds, e.g. Mexican-American, Mexican-National and Colombian-American. Based on observations obtained, in particular during the interviews, the students' self-reflection thoughts were not as explicit before as they were after their study abroad experience. This might be attributed to the student's culture and his or her family bonds. In line with these observations and their culture, these research participants have never lived far from home. This circumstance might present a constraint for growth and maturity to resolve ones personal developmental tasks. Therefore this opportunity such as studying in a foreign country, has represented for them a potential opportunity to enhance a self-reflection, consequently to experience a real independence and self-sufficiency. The findings in this research study, e.g. improvement of self-reflection regarding self-concept of abilities and interests, as well as a gain of self-confidence and self-esteem, could provide relevant aspects for comprehensive methods and techniques of counseling and career advisement programs with students from Hispanic backgrounds: Mexican-American, Mexican-National, Colombian-American, or any other Latin-American country.

Career awareness counseling programs for minorities in multicultural settings (Craig, Contreras \& Peterson 2000) suggest that career counseling programs need to support the 
enhancement of self-concept, improving self-confidence and self-esteem. Others such as Zunker (1998) suggest counseling programs for students with Hispanic-American background should include: learning goal-setting, problem-solving skills, and improving financial management of resources (p.436-437). The participants, despite studying in different countries and with different career perspectives, still developed significant personal and career development skills, such as a considerable sense of goal setting and determination in their goal achievements, self-worth, a greater sense of independence, and self-sufficiency. These findings of students who achieved self-confidence and independence are not much different from other research studies (e.g. Bok 2006).

Students, that stayed for at least one semester abroad, not only gained a better cultural understanding and improved attitudes for international affairs and cooperation, also noteworthy is the fact that they returned with superior levels of personal identity e.g. emotional and cognitive aspects (Carlson, Burn, Useem \& Yachimowicz 1990; Pitts 2005; Thomas 2005; Graban 2007) and professional aspirations (Myers, Hill \& Harwood 2005), which will likely lead to a vocational identity development.

Since the purpose of this study was to examine the impacts on vocational personality development, rather than gender differences among participants, some small but nevertheless interesting differences were observed. These differences were in the emotional-cognitive aspect. While the females were impacted more in the field of independence and self-sufficiency in dealing with their own decisions, goals and money, the males appeared to be more impacted in the feeling of higher self-esteem, accomplishment and determination in achieving tasks.

\section{Adriana after study abroad in France:}

"I changed a lot, before I went to France, I was a person who always looked around, and as... last looked at me. Now after my experience, first I look at what is the best for me and my future, the rest is irrelevant. In reference to that I changed a lot. Before going abroad, I was a person that looked around me and then after ... in the end, it was me. Now, I think about myself, I come first, that which suits my future, and the rest is left over, I am first, in that, I changed a lot...you teach yourself to be more independent and you learn from that, you learn to live making your own decisions. You learn to 
live with your decisions...think about them before doing them. You mature more in general. It contributed a lot because you feel like you are more mature... you already know what you want" (Original text in Spanish, Appendix 7).

\section{Darian after study abroad in France:}

"This is true, I matured more. I helped myself mature more and to save more money. Yes, I learned a lot how to manage money and to know how to resolve problems, to have... to keep up with your classes. I think that before I was a person that did not have an open mind to other things, I closed myself a lot. Yes, the truth is before I was different, I left my matters on the side to be with my family and now not anymore. Yes, I am still with them but now I try to give more time to my life, and that was what I needed, a little push to get ahead..."(Original text in Spanish Appendix 7).

\section{Diana after study abroad in France:}

"Study abroad helped me, I would have to say... in being more independent, in solving my own problems, by myself, because I have always been around family and friends and had help, but study abroad was in a whole different... other country, I had to do things myself, and if I wanted to go travel I had to plan my own trip. It just made me more kind of independent. It was just a character building. Yes, I had more time to find myself, like really I got to know me, because here [at home] sometimes your friends, sometimes influence you or you don't really have time to look into yourself, and your either with your family or friends..."

\section{Cecilia after study abroad in Spain:}

"Well, yeah I said that I became more responsible, like more responsible, before I was less organized, but anyway my timidness did not change. I became more responsible taking care of my money and everything, and it motivated me to know that I am able to be out of the house; I can be more responsible for what I do and more organized..." 


\section{Juan after study abroad in Spain:}

"I see myself, after this experience, much more confident, I think. Before this experience, I was becoming a very confident person, thus there are things that I would still say, I am confident... but deep down, I knew, I was still working on it as opposed to now, I know that I am certain things rather than I'm working on it. Yes, now, I am definitely being myself. I've expanded my ability to network with people and to communicate with people. I mean, I knew that it was the path that I was on before, but studying abroad just made me better at that, like now, I am not intimidated by anyone, it definitely changed me, no one can intimidate me..."

\section{Mariana after studying abroad in Spain:}

"I think a little happier, cheerful. I already knew what it is to live on my own. I started to be more relaxed and not so repressed, in other words I used to say---I am not going to do this, I am not going to do that. Now to the contrary, I tell myself---I am going to do this, and I am going to do it. I think that is what benefitted me as a person, now I describe myself as more independent. I know the things that I have to do, because over there nobody told me anything and sometimes you get lazy, and you don't want to do it, you put on the side, and later when you return you say, now I have to do it, and I should have done it a long time ago... so I learned that the things that I have to do I have to do them when I have to do them and not leave them for the last second, I learned to take my life and organize everything then I feel smart and more prepared, more independent"...(Original text in Spanish, Appendix 7).

\section{Miguel after study abroad in France:}

"I feel a bit more accomplished, but more than anything, I feel a lot more determined. My accomplishments were not a lot over there, I was basically living a normal life but even when I started out, I started off really slacking off, and not doing what I should've done, and it made me realize that the way I was living wasn't the way that I wanted to because it won't get me to 
where I want to go, so I had to basically live my whole dream of being free, and making it out there to see that that's not what I want... and so now, I'm here back at home ready to start another path and work hard, because I knew where I want to go except now I know how to get there..."

\section{Sofia after studying abroad in Italy:}

"I think that study abroad helped me become more independent and less attached to my parents or my family and realize that I can do things on my own, by myself. I can make things work out. I think, I gained a lot of self esteem and I think that everyone that I know that went on this trip gained more self esteem about themselves, because you realize that sometimes you have to be independent in life. It helped me become more independent and mature and see my abilities in level of competition... I guess... and what I can do and my design ideas and it just helped me become a better individual...Well, study abroad definitely helped me change as a person in general, intellectually, I learned so many things and became more mature and I'm noticing that this semester, I don't want to miss my classes because now I'm actually learning. I've become more responsible. Now, I try to help more around the house, because over there I had to do everything by myself, and now that I'm back I'm trying to become a more helpful person in my environment... I think I've become a better member to my family and a better friend. I also saw... I have discovered so much inspiration from my trip, that I think I've become a more creative person..."

Due to the growing importance of the role of vocational development in the adolescent identity formation, it is important to underline the crucial role of a current "selfawareness", which is considered to be one of the foundations that facilitate the career developmental process during adolescence (e.g. Brown 2003). Study abroad programs come in different forms, but essentially their benefits include: rapid self-development, self-awareness with an increasing sense of self-efficacy, problem solving strategies and skills etc.

Therefore, study abroad experience should be considered as an out-of-classroom exploration activity as well as a valuable opportunity for students throughout their 
vocational career explorations stage. This also offers students a vital "self-verification process" (Cast \& Burke 2002), where they develop current self-perception, a greater sense of self-esteem and personal values. While the students are interacting with international students abroad, they are able to form relationships and reflect on comparisons with others. The self-verification process, along with the vocational identity formation, occurs as a function of one's activity and the activity in relation to others' activities (Cast \& Burke 2002). In line with this theory, one might consider study abroad experience as a process of vocational self-verification which consists of defining one's self in terms of vocational identity and self-visualization. Self-verification activities in an international environment have a profound effect on students' current self-perceptions as well as on motivational engagement for further career planning and aspirations.

The qualitative findings in this study show the impacts of one semester-term study abroad programs on students' vocational career choice and its identification with their current self-concept characterization. These results give some insights into students' vocational development with competencies (e.g. self-knowledge, career decision-making, communication skills, life-long career skills, etc) that are included in various career counseling programs designed for minorities groups such as Hispanics (Keller, Piotrowsky \& McLeod 1991; Craig, Contreras \& Peterson 2000).

This group of research participants, with Hispanic background, encountered an optimal scenario for self-explorative learning events which empowered them to acquire a positive current self-knowledge and self-awareness, and even greater beliefs of self-efficacy. These students enhanced their sense of a career decision-making self-efficacy.

These findings should not be generalized as applying to other students from others ethnic groups. Students from diverse backgrounds and cultures certainly possess distinct personal beliefs and expectations.

\section{Vocational identity development}

Do educators and international programs advisors really recognize the developmental tasks of college students, when they advise them to participate in a study abroad program? How much, do they really know about their students' career choice status and in 
particular, their vocational needs and desires, i.e. intrinsic calling for a professional environments and activities? How much do educators and programs advisors know about students' personal competencies regarding their career path? Are educators and international programs advisors aware of personal and career goals, or even personal expectations students have, when they plan to participate in a study abroad program? Even more, do they appreciate, measure, or interpret the kinds of vocational and personal impacts students encountered abroad?

This research study hypothesizes that a long-term studying abroad experience potentially shapes one's self and vocational identity development. A third factor considered in this research study is related to the students' vocational (or avocational) learning experience abroad. What events, activities or experiences shape students' vocational identity development?

Socio-cognitive career development theories, principally inspired by Bandura (1977, 2001), and continued by Lent, Brown and Hackett (1994), provide a theoretical foundation to understand what maintains students motivated while on their career path, namely the components of a personal agency within career development. These theories point out the relevance of cognitive motivation and personal abilities to control destiny, and how this keeps students motivated. Study abroad experiences potentially contribute to the development of the main constructs of personal agency: self-efficacy, outcomes expectation, and personal goals. While the majority of career development programs attempt to offer students basic essentials for a successful career planning and preparedness, a well-structured and supervised study abroad program experience provides students with psycho-cognitive competencies necessary for a matured vocational identity development. These research students were driven by intrinsic forces (e.g. inspiration, interest and motivation or vocation). They (consciously or unconsciously) were attracted to things, events, people, environments that are, one way or another, similar or identical to their career beliefs, interests and motivations, which endowed them with happiness and satisfaction. For the students, this experience was even more intensive and meaningful because it concerned their vocational or occupational career. Qualitative results of this study showed a strong motivation by the students to resolve personal and career issues in a foreign environment. 
These self-explorative activities for the students' vocational identity satisfaction during study abroad experience were very constructive. Students have learned to make personal and career decisions, especially in a challenging environment with limited career and study program advisements.

The identity formation stretches, through explorations' activities, over a life-span. The relevance of study abroad experience in this context played an important role in their vocational choice, aspiration and identification. By studying abroad, exploration activities and career commitments are encountered. If a certain personal conviction is achieved and diverse exploration phase is undergone, the student experiences a new type of selfidentification, which Marcia's (1980) calls "Identity Achievement". Those selfidentification activities have been found in their statements of experiential learning activities during experience of study abroad.

It is evident that the vocational identity formation is a building process where the students attempt to find a satisfactory balance between their internal (self-perception, interest, abilities and motives) and external worlds (career paths, systems and professions) (e.g. Keupp et al., 2006). In other words, the personal and vocational identity contains social, cognitive and emotional components that interact to a certain extent until one decides successfully to find a balance in both. In order to approach this, in this research a face to face interview was applied. These qualitative findings show some corresponding relationships between student's career choice satisfaction and positive self-efficacy in their performance of decision-making, concerning vocational career plans. By enhancing their self-concept, self-esteem and self-confidence the students' conveyed stronger commitments to further career explorations activities.

As Hopkins (1999) stated, "study-abroad programs take many forms, but all share the characteristic which by their nature, provide students with a healthy dose of experiential learning. Immersing oneself in another culture provides new opportunities for learning bydoing, virtually twenty-four hours a day" (p. 36). While study abroad programs may differ in varying degrees of immersion, it is assumed that spending four/five months abroad will provide satisfactory opportunity for the students to interact with people of the local culture (e.g. Thomas 2005). 
This study is an initiative to advocate study abroad programs and to include more qualitative program assessments that focus on students' personal and vocational identity. This endeavor goes beyond academic systems and policies in other countries. It is seeking for ways to work with students not only on what, but also on how, they learned abroad, as well as how they are forming their vocational identity. This can only be possible with a close supervision and monitoring.

As has been presented, vocational maturity development is relevant within vocational identity achievement, where fundamental events of stability, congruence and satisfaction are key factors for a mature vocational identity. This idea, according to the social cognitive career theory (SCCT), occurs in the development of vocational goals (planned or desired), interests and outcomes expectations. SCCT's main goals are to discover ways of defining "specific mediators from which learning experiences shape and subsequently influence career behavior" (Zunker 1998, p.77). Because vocational behavior depends, in large part, on a good sense of self-efficacy (e.g. high beliefs of one's own abilities and performance) and self-explorative activities, the sense of self-efficacy plays a central role within the motivational behavior for career identity success. Exceeding expectations after their experience abroad, the students emerged with a higher and further developed selfefficacy. The students conveyed a greater sense of self-confidence in their ability to perform. How specifically students developed their positive sense of self-efficacy and confidence during their study abroad experience remains unclear and indispensable to examine in future research studies.

Students' perceptions regarding personal motivation and goals within their career development before, during and after study abroad, should always be contemplated within international study abroad program advisement to fully understand vocational identity status and development. An objective in this research was to investigate what type of students' personal accomplishments and vicarious learning and social persuasions affected students' vocational development. Focusing on the sense of congruency, consistency, stability and identity, it was, therefore, crucial to look at the grade of satisfaction or dissatisfaction of students' career plans, as well as motives, goals, and personal selfefficacy in terms of strengths and weaknesses.

While the quantitative data did not show the types of students' motivations, interests and goals for study abroad and their career goals and plans, the qualitative interviews indicated 
that the majority of students were primarily motivated in exploring and learning from other cultures as well as the desire to improve or learn a foreign language (Bok 2006). During their second interviews, the students implicitly conveyed the desire to prove their competencies and to gain a better sense of self (e.g. self-efficiency) because they have never lived away from home unaided and on their own.

Using a qualitative assessment device (semi-structured interview) in this longitudinal investigation was absolutely an advantage in gathering qualitative information regarding students' current self-perception and vocational satisfaction status, as well as in identifying students' current vocational motives, goals and abilities, before and after their experience. However, the semi-structured interview was somewhat limited in gathering additional data regarding the types of vocational and career definitions' problems and challenges that students faced abroad. The inclusion of additional qualitative data sources, such as a daily diary, should be contemplated in further studies, particularly to gather indepth information, for example, how each event experienced abroad transpired, and the effects these events had on their vocational identity definitions while abroad.

Further follow-up-research studies are imperative to examine in depth students' vocational goals and motives, including professional and career development plans.

Longitudinal research studies of long-term study abroad experience effects on vocational identity development of diverse ethnic groups (e.g. other students with diverse Hispanic culture groups, or American, African-American, Asian-American etc.) are definitely indispensable for the design and focus of high quality study abroad programs and students' vocational identity development.

The nature of an experience abroad offer students' problem-oriented activities as well as being self-regulated nature, innovations aspects that have been discussed within vocational education and teaching evaluations (Nickolaus, Knöll \& Geschwendtner 2007, p. 22). Study abroad programs could be perceived as an educational instrumentality and mediator for self-explorations methods and future career goals. Brickman and Miller (2001) share a socio-cognitive point of view, making clear the relevance of perceptions of an instrumental event (e.g. study abroad programs) within the self-regulation process. Brickman and Miller (2001) acknowledged positively the relevance of perceived instrumentality "because such perceptions are thought to connect the value of the future 
goal to the present tasks, and thus providing incentive value for the present task" (p. 129130).

Results and findings of this study outline students' perceptions and assessments as well as the potential fundamentals for enhanced outcomes and benefits of study abroad programs on self-awareness and experiential learning to develop vocational identity competencies, such as a sense of autonomy, independence, and congruency with their career choice. Regardless of their gender, background, major, and study abroad program, all participants conveyed noteworthy insights regarding their vocational choice and satisfaction outcomes.

These results might serve as qualitative data for the design of study abroad programs within career counseling and advisements' services for a career life's project and vocational identity balance for Hispanic students. However, the development of a vocational identity satisfaction needs to remain in the loop for further research studies on study abroad program advisements services.

Despite experiencing differing (intentional or vicarious) learning experiences and embarking with different vocational needs and interest, the students' vocational identities were somehow shaped; in addition, their accomplishment satisfactions were significantly successful. For all students, no matter how small, no challenging event was insignificant. Students' identities shifted, at least a little, in two significant ways. Students became more self-aware reaching new levels of maturity and understanding of who they are as people and how they cope with challenges.

By looking back at their semester study abroad program and who they felt they were before their experience and who they became upon returning, students attained, not only a greater sense of self-knowledge, but also were given the opportunity to reflect and internalize a new aspect of their career path definition. Experiences abroad provide events and circumstances which result in a greater sense of identity developmental skills (sense of commitments and determination) for career development and future aspirations that form (definition) their personal and vocational identity. Some examples are presented here:

Antonio is one of the participants that reported a "not clear" career path decision before study abroad. He was studying engineering, but he did not know to which area of engineering he felt most attracted. He went to Spain for a semester with expectations of 
personal and professional identity development. His development regarding his personal growth, sense of self-knowledge and self-awareness, were expressed as:

"The experience in Spain, for me...helped me a lot living alone; I still did not know myself alone...so for me that was useful. It helped me a lot. Consist of taking care of yourself, washing clothes, etc. All of that...for me it was very important, I wanted to get to know myself...I did not know how I was going to react..."

Antonio suffered the consequences of miscommunication between the home and the host universities. Once he arrived, he discovered that the courses he wanted to take were off campus; however, his motivational commitment for his career choice in Manufacturing remained unchanged.

\begin{abstract}
"Well the classes (micro-economics, Spanish literature y accounting) in the program that I took in Spain did not help me a lot in my career...really...not at all. Because in a sense, I felt that I missed out on the semester. Well .....upon arriving there I had in mind to take certain engineering classes over there....but because of communication problems between the two universities it turned out that the engineering campus was in another town in reality it was almost another institution... I believe.....so then I missed the engineering classes and I got into the classes that have always interested me..”.
\end{abstract}

Regarding his vocational choice, he expressed that, through the experience abroad, he reinforced and confirmed his career choice:

"Yes...I reinforced my career choice. Well I was working in Madrid ....so I got little bit closer to the industry. Before going...yes I liked engineering but I started to lose interest, because I did not have the opportunity to work....besides... here since the United States is not my country, it is not so easy to get closer to an industry and work. On the other hand in Spain I could and I liked it... and now I know a country better... made friends...I don't know ...it helped me to have new ideas with respect to the future...new professional plans. Yes...sure my career interest ...even 
though I did not study engineering over there...continues to be engineering. I was in doubt, in what area to specialize in manufacturing or mechanical...but now I have come back enthusiastically to continue studying what I was studying manufacturing..."

Juan, another male participant that reported an "undecided" status before study abroad, he did not have a clear idea about what career path he wanted to follow, when went to Spain and realized that two of the things he learned from his vicarious learning experience abroad were self-awareness and confidence from which he developed his motivation for his vocational career plan:

"I have learned that the only thing that stops you from getting what you want is yourself. I have reinforced my vocational choice, I'm very aware about it. There are times, when you are sort of scared, where you don't want to do it, but I have discovered it's all about motivation, when you get in the state of motivation, there is nothing that can stop you. In other words, it's when you get out of the state of motivation that you start doubting yourself. It's a practice of continuing being in the right state of mind and that is going to take you to where you want to go..."

Through his experience, Juan definitely acquired a clear picture about what career he wanted to pursue studying. After study abroad experience and after having lived and interacted with peers that had similar career initiatives abroad, he returned satisfied with his career choice which he acquired by collective professional identity.

"Yes, my experience did definitely reinforced my vocational interest, because I would say that it just gave me the confidence in what I want to do and it reinforced the idea that what I want to do is a good idea and that there is other people who think that it's a good idea and who back it up and yea, basically that is it. It's easy to say the cliché, I came back and it changed my life but it really did, in a lot of different levels. It was very intense. Before the trip, I was on track and the trip didn't change the track it just intensified it..." 
Adriana's vocational identity emerged favorably. Her vocational choice remained the same, but after her experience in France, she admitted gaining more knowledge related to her vocational identity as a teacher, and she wants to continue learning about the French language and culture.

"My career interests continue onward, but now I was there in France...I am interested to know more about the French culture. I am interested in choosing a second career (major) in French. I would like to learn more not only focusing on that but to learn about the culture and teach. My career remains the same but with a little bit more knowledge...in other words with enthusiasm and interest to know more. Now, my interest is in a double major (Spanish and French). Leave my career how it is, but I want to focus more on France..."

Adriana's vocational and personal aspirations changed positively. The personal interaction with people from other cultures helped to realize her self-efficacy to learn. After study abroad experience, she felt even more committed to herself. Her level of exploration gave her a good sense of personal improvement.

"Yes, to be abroad, helps you to not be a conformist...to want to look for more. When you go over there, you meet very professional people, you realize all that you can learn, and well if you want to be somebody, do not hold yourself back from achieving it. My vocational interests were reinforced. You learn a lot and...my interests are reinforced because you change, for the good. Now I want a better future. Now that I have returned from my trip my overall achievement is first, and after comes that (family). Now I set goals and I continue until they are finished..."

As revealed, the effects and the impacts of study abroad experience on students' vocational identity are manifested in both areas of personal development: cognitive and emotional, and vocational clarification of their self and their career interest.

The forgoing discussion regarding students effects can be summarize as follows. Observed in the majority of the research students, regardless of study abroad program, was the fact that their learning experiences abroad increased their career decision-making self-efficacy, 
values of engagement as well as determination for their intended vocational career plans and developed (across borders) their vocational goals into future career plans. A satisfied sense of vocational congruency between their current vocational (real "I" and real "me"), and their future vocational visualization (ideal "I" and ideal "me"), were positively motivated. Cognitive deliberations of vocational and avocational events were observed in the majority of students. Overall students revealed positive reinforcements of their intended vocational career choice and satisfaction.

This research study differentiates itself from others (e.g. Pitts 2005; Williams 2006; Graban 2007) by its main purpose and objectives which is the individual effects on students' cognitive perspectives regarding vocational identity development and its impacts on participants studying in five different countries.

Finally the variables chosen here in this study may have not been measured in the familiar way other researchers have in the past. The selection and measurements of the variables seemed to be quite reasonable. These findings have revealed potential factors for students' vocational satisfactions while studying abroad, which can also be considered in future research studies and advisements services regarding study abroad programs. 


\section{Chapter 6}

\subsection{Implications for further research studies}

This research study attempted to answer questions regarding effects of semester study abroad programs on students' career choice status and their vocational identity. The results have a theoretical implication for models of career development and study abroad programs advisement. In fact, this study represents a small assertion in the wide umbrella that covers students' identity, career and vocational development while having their study abroad experience.

Furthermore, the type of qualitative approach and assessments is indeed essential for students' international programs, advisements, and counseling services. It is fair to conclude, that, the longer study abroad learning experience the greater the effects will be on the clarity of vocational preferences and self-definitions.

The findings of qualitative data sources indicated higher levels of self-efficacy and selfconfidence are related to students' vocational identity satisfaction. Studies on this matter have identified the potential role of a career related self-efficacy in career development for Latino students (Gushue, Clarke, Pantzer \& Scanlan 2006).

There are certainly many more gaps to explore and more limitations to consider for ancillary research studies regarding vocational identity development. This longitudinal research study was from a single institution and no control group; all students were from different age groups and vocational maturity, the research instruments employed (Survey I \& II, Frankfurter Self-Concept-Scale, Holland's SDS and a semi-structured Interview) may not have provided decisive and conclusive information to assess students' vocational identity status outcomes from study abroad. Despite these limitations, this study provides a stepping stone for theoretical discussions regarding the effects of experience abroad on vocational identity development.

Single institution study: The data was collected exclusively from students at a large university located in the south most area of the United States, in which the Hispanic population corresponds to $85 \%$ of the student population ${ }^{1}$. This may limit the

\footnotetext{
${ }^{1}$ Academic Planning Statistics Report-Spring 2008, extracted on the January, 15, 2009
} 
transferability of the findings, because the student population here is close to the border of Mexico and may differ from other student populations in different regions of the USA. Another distinction of the findings transferability would be among American students (non-Hispanic).

Future studies should include additional variables that can control for possible group differences (e.g. such as a comparative research study across borders, students from USA, Mexico and Germany).

Population size and student differences: Conducting experimental research studies on the effects of long-term study abroad programs is ideal, because it will produce more evidence concerning cause-effect relationships. This type of research design method involves manipulation and control of variables and treatments. Taking into account that experimental research design involves a comparison of two or three groups including controls groups, this experimental approach allows researchers to identify students' vocational identity statuses and effects. Increasing the sampling of research participants, and the inclusion of diverse (minorities) ethnic groups will produce diverse variables in the effects of study abroad experience on students' vocational identity development needs and outcomes. For example, some differences might result if researchers were to compare the following: Hispanic (Mexican-American) students who decided to study abroad vs. those who do not; or even multicultural, Hispanic (Mexican-Nationals) students who immigrated into the US vs. those who were born and raised in the US; or American (Non-Hispanic) students compared to African-American and Hispanic students.

No specific study abroad program differences: It is possible that students who choose to study abroad in a country where a foreign language is spoken are fundamentally different (as far as personality, vocational needs, motivations and goals) than others who choose to study in a country that speaks the same language as they speak, or those who decided to go as a group or an individual study abroad program. 


\subsection{Implications for counseling and advisement services}

Studies indicate that the acquisition of personal and social competencies of achievement and accomplishments depends mainly on education level and quality (e.g. Behringer 1998).

A critical goal of advisors and counselors in higher education is the facilitation of career and life development programs. Moreover, international studies programs often fail to give appropriate attention to the crucial steps and elements necessary for an adequate career development program (e.g. Brustein 2007). In a time of limited resources, study abroad programs serve as a pedagogical avenue (e.g. Orahood, Kruze \& Pearson 2007; Brustein 2007) for implementing vocational career planning education and self-services programs.

Models of career development programs such as the career-information-processing model, guide counselors and advice services to accurately recognize what is involved in the career choice decision process. This includes, for example: a current self-knowledge, exploring career options, development of decision-making skills etc. According to Brown (2003), there is an ongoing effort in the improvement of the conveyance of career services in general and in particular in multicultural settings. Nowadays, with the increasing movement towards internationalization at higher institutions and the continuing need for global and international education, the career development services and educators owe it to the students to offer more alternatives for career development programs. Study abroad programs provide additional learning opportunities for students to develop not only global and intercultural skills, but also self-knowledge and career development skills that enhance their vocational identity. Vocational choice and personality development are, in this case, the responsibility and educational challenge for institutions of higher education.

The results of this study demonstrate the importance of acknowledging the identityshaping potential of international socio-contextual influences that occur in college students' career plan development during a semester study abroad experience, as well as the possible differences within the level of self-awareness, sense of independence and self-efficacy, before and after a semester abroad. 
For students enrolled in any semester study abroad and exchange program, there should be more flexible study abroad programs available as additional alternative which includes an elective course option. This option may support and reinforce further individual needs concerning the career choice making process (e.g. self-concept of ability, career information, exploration of career roles and profiles, career skills and competencies, differentiation and identifications process). A study abroad program experience for a semester may not only enhance and develop personal career skills and competencies, but could also definitely serve as instrumentality for future career aspirations and values. It is necessary for international offices and universities to be more sensitive towards students' vocational development issues (exploration, consistency, congruency and identity) namely creating study abroad programs (with or without credit transfer) that support students' personal and vocational developmental issues.

All educators, faculty members or administrators involved in the planning, organizing and designing of study programs abroad exchange, are strongly recommended to have experienced or embark on an international experience in studying or teaching abroad. Setting up a curricular objective in study abroad programs that helps students to reflect and achieve personal vocational needs which maximize the international objectives of universities.

$>$ Establishing a strategic planning committee with the objective of creating a strong network among faculty members, academic advisors, counselors and professional career counselors, which increase students' academic, personal and pedagogical outcomes, especially in regards to their mental health. This predicts favorable life-long professional and vocational career competencies, including sustainable self-confidence and selfefficacy satisfaction.

\subsection{Implications for college and universities}

Colleges can improve their benefits of study abroad programs by promoting and supporting students' vocational development.

This research study is particular because its main focus is on students' cognitive and emotional perceptions concerning their vocational and career success which is in contrast 
to some academic institutions that focus primarily on increasing the quantity of study abroad programs. As educators, it is time to take responsibility in identifying career developmental tasks, as well as adopting them as an invariable educational challenge. According to highly regarded theoretical views on education, the decision for a vocational future should be always contemplated in academic priorities (e.g. Remmers 1962; Berg 1969; Dreher \& Oerter 1985; Dreher \& Dreher 1985; Chickering \& Reisser 1993). In order for students to be successful and fully satisfied in their career choice during college years, universities and colleges should constantly develop new alternatives of career development programs and services which provide them with a broad self-educational environment that leads them to self-knowledge (i.e. skills, competences, attitudes, goals, expectations, and values) and higher achievements.

Study abroad programs ought to be designed with a broadened learning and pedagogical perspective and objective. International offices at universities and colleges need to focus, qualitatively, more on designing programs that respond to the students' personal and career development requests (psychosocial and pedagogical) rather than focusing on the eagerness to increase the number of programs and student enrollment. The inclusion of more qualitative and program assessment devices to gain an in depth perception of study abroad program offerings is strongly recommended and relevant for colleges and universities, especially for international offices. This will improve the quality of international program advisements services and international exchange programs offered.

Another challenge that arises for all academic institutions is the complexity of the degree and the systems of transfer of credits for students who participated in study abroad programs in partner and non-partner universities, which is occurring more and more with the current international mobility across countries (e.g. Tonkin 2008; McKenna 2003).

Globalization is tending to demand, from universities and colleges, a more international competency in their student's development; at the same time, it is developing hybrid identities as declared by Dixon (2006), as result of a confused or hybrid vocational identity. This refers to the diversity of degree plans (core and career courses), occupational profile requirements, established by each political and education system. Therefore, more college and universities in United States should be part of an academic network with the Bologna Process to continue analyzing degree programs in diverse areas. According to an article by the German Academic Exchange Service (DAAD) 
online news, retrieved April, 2009, the universities of Utah, Indiana and Minnesota were already in the process of applying to the Bologna process for Higher Education.

According to Ron Moffatt president of (NAFSA) the National Association of International Educators, he pointed out on the NAFSA Report (2008) that despite institutional efforts, there are still some issues that come up with the increase of enrollment, and certain study abroad program practices are making news, "the issue raised - the existence of potentially questionable financial arrangements between institutions and program providers and questionable credit-transfer policies, among others - will prove, the task force believes, to be limited in scope. But these issues do focus our attention on the rapid growth of study abroad, the increasing diversity of student needs, the challenge of integrating study abroad into all aspects of an institution, and the unique risk-management and quality-control issues inherent in study abroad" (NAFSA's Report 2008, p. 2). Due to the research purpose of this study, these issues (risk-management \& quality-control) were not opened and investigated.

The offices of international studies of each college and university need to ensure what types of course programs are offered. While studying abroad, students face course schedule problems. Those academic conflicts might affect students' psychological development, academic self-concept and ultimately their sense of self-efficacy. These tendencies are challenging the US universities' and colleges' international offices and systems regarding the credit and course transferring process. The increasing eagerness of some universities and colleges in seeking ways to promote for study abroad programs are surpassing the professional competencies and administrative-management control.

In light of this longitudinal research study in the realm of student vocational identity development, many questions remain:

$>$ How might educators and international programs advisors develop study abroad programs that build on personal satisfaction, greater self-concept development, selfefficacy, career oriented achievement and happiness in order to nourish their vocational identity? How can educators and international programs advisors be responsive to the students' career oriented needs and develop vocational study abroad programs that might provide an appropriate preparation for students which increases the likelihood of vocational identity satisfaction? 
How do students from diverse background and ethnic groups differ vocationally before and after being abroad? What are the vocational relationships and differences between students participating abroad in diverse types of experiential components: research, internships, co-ops, or community services?

There certainly is a need for additional longitudinal research regarding study abroad program effects and gender differences in the shaping of vocational identity, as well as gathering additional knowledge about long-term study abroad events, experiences, and relationships faced by students. In the meantime, while international groups and organizations, such as Institute of International of Education (IIE), National Association of International Educators (NAFSA), The German Academic Exchange Service (DAAD), and Bologna Process etc., are fervently working on their endeavors, they are advised to continue to seek out new methods of facilitating international exchange and study abroad program management's satisfaction. For college and universities the challenge remains to keep surveying and researching at the micro level (e.g. career developmental student's level) for the most favorable program components that involve beneficial vocational identity developments.

\subsection{Summary}

The focus of this research study was to analyze the impact of the study abroad experience on vocational identity development. It is pertinent to point out that the study abroad experience in general may well be considered a success for students' selfdevelopment, self-knowledge, and self-definition in terms of vocational aspirations for a professional career. The results found in this research study, notwithstanding limitations, presented relevant insights into the relationships between study abroad experience, selfawareness (knowledge and identification) and vocational identity. Specifically, this research suggests that long-term study abroad programs shape student's self-awareness and the vocational identity development. From these results, further hypothesis may be drawn. Additional studies can begin examining the specific effects of long-terms study abroad programs on vocational (career specific) identity development, and supplementary experiments studies can be designed to examine the direction of the relationship. 
It would be effective if educators considered their students and their potentiality in vocational identity development while studying abroad which derives from new values, cognitive and emotional growth.

These results can be used as guide to design academic and pedagogical interventions and career counseling/advice services that could be beneficial to students who are either planning or are already enrolled in a semester study abroad program. This also applies to students who find themselves in the career choice and professional identification process, as well as in the stage of self-knowledge during vocational career development.

This research study also yielded other unexpected results, such as the degree of impact on the educational systems in each host country (Argentina, France, Germany, Italy and Spain), and the development of personal and cultural values that may have an effect on vocational identity development. Future research could explain additional factors which might relate to changes in career choice and vocational identity development. Such research could provide a greater understanding of the relationship between study abroad experience and vocational development outcomes.

The focus of this research was evocative regarding the vocational adjustment process and clarification of vocational interest improvement and its utility and application during the study abroad experience. These results could prove to be useful for international educators, faculties and study abroad program advisors. Those who design, in particular long-term programs abroad, will be able to incorporate a professional and vocational prospective, that could foster the development of positive identity and career development in participating students.

Faculty could also benefit from this study and its educational outcomes in supporting student's vocational career development and their students' vocational interest by advising them according to their vocational needs, and guiding them into an international self-awareness encounter such as a study abroad program experience. In addition to encouraging study abroad experience, academic institutions and public organizations should find ways to promote this invaluable tool with a global and integral perspective that attract students, in particular, to clarify and define their vocational and personal interest. Adequate pedagogical resources are always an issue and require involvement of a diverse group of people, faculties and academic offices with a positive network aiming 
for global education, and an overall plan for a sustainable students' personal and vocational development.

A study abroad experience, as depicted below, serves as a motivational scenario that potentially contributes to self-exploration and self-knowledge which consolidates one's self-awareness, and further engagement in vocational activities which ultimately shapes one's vocational identity.

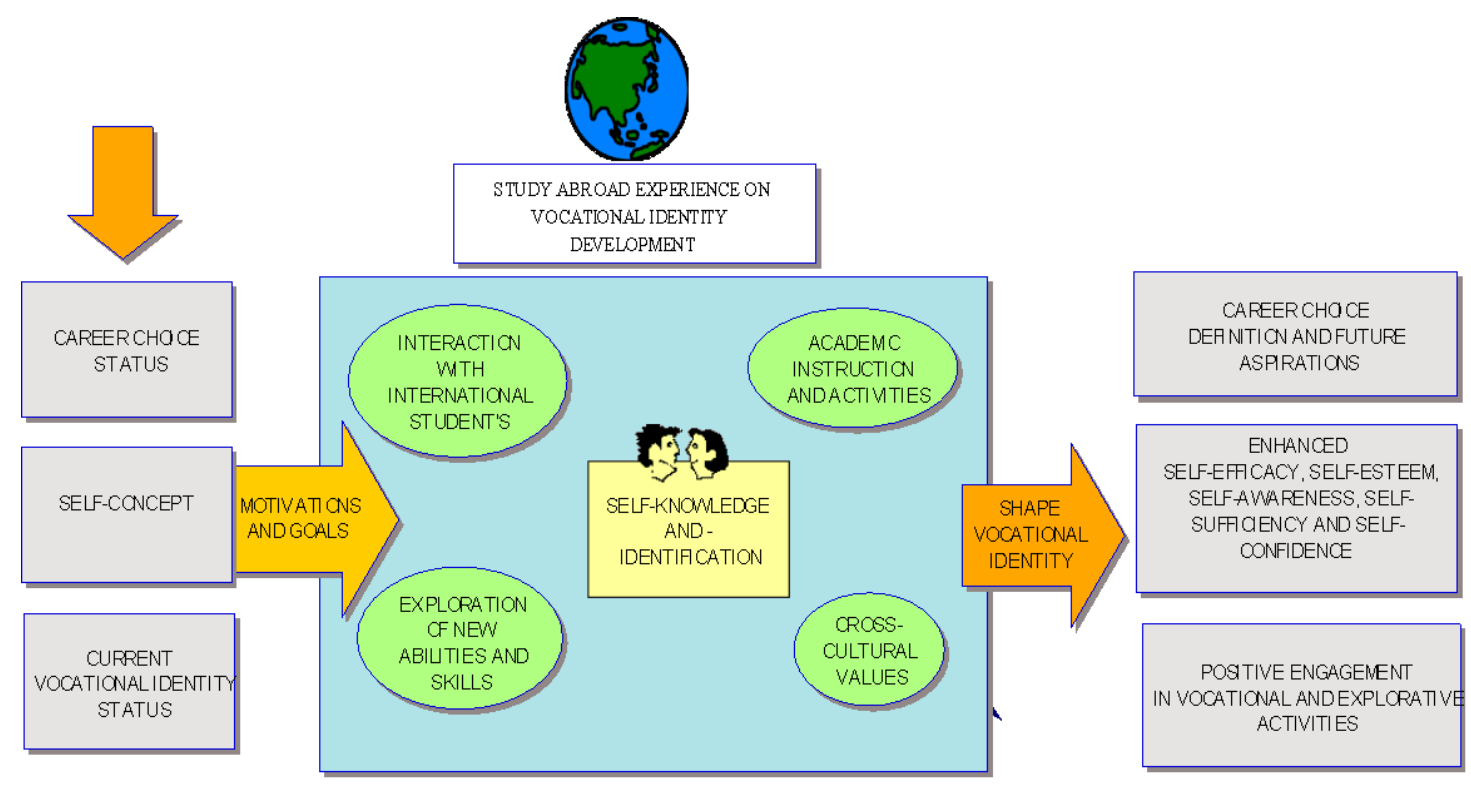

"We discover our vocation by discovering what we love to do, what energizes and fulfills us, what uses our talents and challenges us to develop new ones, and what actualizes our potentials for excellence” (Chickering \& Reisser 1993, p.212). 


\section{References}

Achtenhagen, F. \& Grubb, W. N. (2001). Vocational and occupational education. Pedagogical Complexity, Institutional Diversity. In V. Richardson (Ed.), Handbook of research of teaching (pp 604-635). Washington: AERA.

Astin, A. (1977). Four critical years: Effects on college on beliefs, attitudes and knowledge. San Francisco: Jossey-Bass.

Astin, A. (1998). The changing American college student: Thirty years trends, 1966-1996. Review of Higher Education, 21(2), 115-135.

Bandura, A. (1977). Social learning theory. Morristown, N.J.: General Learning Press.

Bandura, A. (1986). Social foundation of thought and action: A social cognitive theory. Englewood Cliffs, N.J.: Prentice-Hall.

Bandura, A. (1997). Self-efficacy: The exercise of control. New York: Freeman.

Bandura, A. (2001). Social cognitive theory: An agentic perspective. Annual Review of Psychology, 52, 1-26.

Bauer, H. G. (2001). Erlebnis- und Abentuererpädagogik. Eine Entwicklungsskizze. München: Rainer Hampp Verlag.

Behringer, L. (1998). Lebensführung als Identitätsarbeit:Der Mensch im Chaos des modernen Alltags. Frankfurt-New York: Campus.

Berzonsky, M. D. (1990). Self-construction over the life-span: A process perspective on identity formation. Advances in Personal Construct Psychology, 1, 155-186.

Berzonsky, M. D. (1993). A constructivist view of identity development: People as postpositivist self-theorists. In J. Kroger (Ed.), Discussions on ego identity (pp. 169-183). Hillsdale, N.J.: Erlbaum.

Berzonsky, M. D. (2003). Identity style and well-being: Does commitment matter? Identity: An International Journal of Theory and Research, 3(2), 131-142.

Bloom, D. E. (2005). Raising the pressure: Globalization and the need for higher education reform. In G. A. Jones, P. L. McCarney \& M. L. Skolnik (Eds.), Creating knowledge, strengthening nations: The changing role of higher education (pp. 21-42). Toronto, ON: University of Toronto Press.

Blos, P. (1989). Adoleszenz: Eine psychoanalitische Interpretation (4th ed.). Stuttgart: Klett-Cotta.

Bluestein, D. L. (1989). The role of goal instability and career self-efficacy in the career exploration process. Journal of Vocational Behavior, 35(2), 194-203.

Bohleber, W. (1996). Adoleszenz und Identität. Stuttgart: Verlag Internationale Psychoanalyse. 
Bok, D. C. (2006). Our underachieving colleges: A candid look at how much students learn and why they should be learning more. Princeton: Princeton University Press.

Bortz, J., \& Döring, N. (1995). Forschungsmethoden und Evaluation (2nd. ed.). BerlinHeidelberg- New York: Springer-Verlag.

Brickman, S. J., \& Miller, R. B. (2001). The impact of socio-cultural context on future goals and self-regulation. In D. M. McInerney, \& S. Van Etten (Eds.), Research on sociocultural influences on motivation and learning (pp. 119-137). Greenwich, CT: Information Age Publishing.

Bridges, D., \& McLaughlin, T. H. (2007). Introduction. In D. Bridges, P. Juceviciene, T.H. Mclaughlin \& J. Stankeviciute (Eds.), Higher education and national development: Universities and Societies in Transition (pp. 1 -10). London - New York: Routledge Taylor/ Francis Group.

Brown, D. (2003). Career information, career counseling, and career development (8th ed.). Boston-New York-San Francisco: A \& B.

Brustein, W. (2007). The global campus: Challenges and opportunities for higher education in North America. Journal of Studies in International Education, 11(3-4), 382-391.

Burris, A. P. (2006). Institutional effectiveness in internationalization: A case study of internationalization at three higher education institutions (Doctoral dissertation, George Washington University, 2006). Dissertation Abstract, AAT 3199633.

Caplan, R. D., Naidu, R. K., \& Tripathi, R. C. (1984). Coping and defense: Constellations vs. components. Journal of Health and Social Behavior, 25, 303-320.

Carlson, J. S., Burn, B. B., Useem, J., \& Yachimowicz, D. (1990). Study abroad: The experience of American undergraduate. New York: Greenwood Press.

Cast, A., \& Burke, P. (2002). A theory of self-esteem. Social Forces, 80(3), 1041-1068.

Cerulo, K. (1993). The many faces of social identity: Implications for political psychology. Sociological Forum, 8(2) 243-271.

Cerulo, K. (1997). Identity construction: New issues, new directions. Annual Review of Sociology, 23, 385-409.

Chickering, A. W., \& Reisser L. (1993). Education and identity (2nd ed.). San Francisco: Jossey-Bass Publishers.

Craig, M. P., Contreras, M., \& Peterson, N. (2000). Multicultural career exploration with adolescent females. In N. Peterson \& R. Cortez-Gonzalez (Eds.), Career counseling models for diverse population: Hands-on applications by practitioners (pp. 22-35). Canada: Wadsworth/Brooks Cole.

Crites, J. O. (1969). Vocational psychology: The study of vocational behavior and development. New York: McGraw-Hill. 
Curran, S. J. (2007). The career value of education abroad. Retrieved January 14, 2008, from http://www.nafsa.org/_File/_educationabroadinted_2007.11.pdf.

Damron, D. (2006). Paper presented at the annual meeting of the APSA Teaching and Learning Conference, Renaissance Hotel, Washington, DC, February 18, 2006. Retrieved August 30, 2008 from http://www.allacademic.com/meta/p101386_index.html

Dervarics, Ch. (2008). Study abroad programs show growth, increased diversity. Retrieved August 30, 2008 from http://diverseeducation.com/artman/publish/article_11974.shtml.

Deusinger, I. M. (1986). Die Frankfurter Selbstkonzeptskalen. Göttingen: Hogrefe.

Dik, B. J., Sargent, A. M., \& Steger, M. F. (2008). Career development strivings: Assessing goals and motivation in career decision-making and planning. Journal of Career Development, 35, 23-41.

Dirkx, J., Anger, D. G., Brender, J. E., Gwekwerere, J. R., \& Smith, R. O. (2006). Beyond culture shock. The meaning of affect and emotions in international educational experience. Retrieved January 25, 2008, from http://www.umsl.edu/continuinged/education/mwr2p06/pdfs/B/Dirkx_et_al_Beyond\%20 Culture\%20Shock.pdf.

Dixon, M. (2006). Globalization and international higher education: Contested positioning. Journal of Studies in International Education, 10(4), 319-333.

Domville-Roach, E. (2007). A comparative study of intercultural and American study abroad students' expectations and experiences with host countries (Doctoral dissertation, East Tennessee State University, 2007). Dissertation Abstract, AAT 3256787.

Dreher, E., \& Dreher, M. (1985). Wahrnehmung und Bewältigung von Entwicklungsaufgaben im Jugendalter: Fragen, Ergebnisse und Hypothesen zum Konzept einer Entwicklungs- und Pädagogischen Psychologie des Jugendalters. In R. Oerter (Ed.), Lebensbewältigung im Jugendalter (pp. 30-61). Weinheim: Edition Psychologie/VCH.

Dreher, M. (1985). Planung im Jugendalter.Konzepte der Handlungsorganisation. In R. Oerter (Ed.), Lebensbewältigung im Jugendalter (pp. 62-68). Weinheim: Edition Psychologie/VCH.

Dreher, E., \& Oerter, R. (1985). Children's and adolescents conception of adulthood: The changing view of crucial developmental task. In R. K. Silbereisen \& K. Eyferth, et al. (Eds.), Development as action in context (pp.109-120). Berlin: Springer.

Duffy, R. D., \& Sedlacek, W. E. (2007). The work of values of first-year college students: Exploring group differences. The Career Development Quarterly, 55(4), 359-364.

Duke, Ch. (2000). Study abroad learning activities: A synthesis and comparison. Journal of Marketing Education, 22(2), 155-165.

Dwyer, M. (2004). More is better? The impact of study abroad program duration. Frontiers: The Interdisciplinary Journal of Study Abroad, X, 151-164. 
Dwyer, M., \& Peters, C. (2004). The benefits of study abroad. Transitions Abroad, 27(5), 56-57.

Egron-Polak, E. (2005). Universities in the new global economy. Actors or spectators? In G. Jones, P. McCarney \& M. Skolnik (Eds.), Creating knowledge, strengthening nation: The changing role of higher education (pp. 56-67). Toronto: University of Toronto Press.

Ellis, R. A., \& Taylor, M. S. (1983). The role of self-esteem within the job search process. Journal of Applied Psychology, 68, 632-640.

Emert, H. A. (2008). Developing intercultural competence through teaching abroad with Fulbright: Personal experience and professional impact. (Doctoral dissertation, University of Minnesota, 2008). Dissertation Abstract, AAT 3308089.

Erikson, E. (1953). Wachstum und krisen der gesunden Persönlichkeit. Stuttgart: Ernst Klett-Verlag.

Erikson, E. (1965). The challenge of youth. New York: A Doubleday Anchor Book.

Erikson, E. (1968). Identity: Youth and crisis. New York: Norton.

Erikson, E. (1974). Jugend und Krise: Die Psychodynamik im sozialen Wandeln. Stuttgart: Klett-Cotta.

Erikson, E. (1980). Identität und Lebensyklus. Drei Aufsätze (6th ed.) Frankfurt: Suhrkamp.

Erikson, E. (1988). Der vollständige Lebenszyklus. Frankfurt am Main: Suhrkamp.

Erwin, T. (1982). Academic status as related to the development of identity. Journal of Psychology, 110(2) 163-169.

Ewert, O. M. (1986). Zur Identität von Jugendlichen. In H. Remschmidt, K. Allerbeck, O. M. Ewert, W. Fuchs, W. Hornstein (Eds.), Jugend und Gesellschaft (pp. 119-132). Frankfurt Main: Umwelt und Medizin Verlag.

Fend, H. (1991). Identitätsentwicklung in der Adoleszenz: Lebensentwürfe, Selbstfindung und Weltaneignung in beruflichen, familiären und politisch-weltanschaulichen Bereichen. Bern, Stuttgart: Huber.

Fend, H. (1994). Die Entdeckung des Selbst und die Verarbeitung der Pubertät (1st ed.). Bern: Hans Huber.

Fend, H. (1997). Der Umgang mit der Schule in der Adoleszenz: Aufbau und Verlust von Lernmotivation, Selbstachtung und Empathie. Bern: Hans Huber.

Fernandez, E. (2006). Developing a global perspective during a study-term abroad. (Doctoral dissertation, University of Michigan, 2006) Dissertation Abstract, AAT 3208455 .

Filipp, S. H. (1980). Entwicklung von Selbstkonzepten. Zeitschrift für Entwicklungspsychology und Pädagogische Psychology, 12(2) 105-125. 
Flores, L. Y. (2008). Introduction to special Issue: Innovative methodological advances in career development research and practice. Journal of Career Development, 35(1), 3-4.

Foss, Ch., \& Ellefsen, B. (2002). The value of combining qualitative and quantitative approaches in nursing research by means of methods triangulation. Journal of Advance Nursing, 40(2), 242-248.

Franken, R. (1994). Human motivation (3rd ed.). Pacific Grove, CA: Brooks/Cole Publishing Co.

Frey, H. P., \& Haußer, K. (1987). Entwicklungslinien sozialwissenschaftlicher Identitätsforschung. In H. P. Frey \& K. Haußer (Eds.), Identität: Entwicklungen psychologischer und soziologischer Forschung (pp.3-26). Stuttgart: Enke.

Furrow, J., \& Wagener, L. (2003). Editor's introduction: Identity and transcendence among youth: A view of the issues. Applied Developmental Science, 7(3), 116-118.

Garbrecht, L. S. (2006). Schools' influences on identity formation in a time of change. Educational Researcher, 35(9), 42-47.

Gardner, D., \& Witherell, S. (2007). American students studying abroad at record levels: up $8.5 \%$. Open Doors 2007. Retrieved November 17, 2007 from http.//opendoors.iienetwork.org/?p=113744

Gardner, D., \& Witherell, S. (2008). American students studying abroad at record levels: up $8 \%$. Open Doors 2007. Retrieved February 8, 2009 from http://www.opendoors.iienetwork.org/?p=131592

Garlichs, A., \& Leuzinger-Bohleber, M. (1999). Identität und Bindung: Die Entwicklung von Beziehung in Familie, Schule und Gesellschaft. Erziehung im Wandel 23. Weinheim - München: Juventa-Verlag.

Gati, I., \& Meir, E. I. (1982). Congruence and consistency derived from the circular and the hierarchical models as predictors of occupational choice satisfaction. Journal of Vocational Behavior, 20, 354-365.

Gay, L. R., Mills, G., \& Airasian, P. (2009). Educational research: Competencies for analysis and applications (9th ed.). New Jersey: Pearson.

Gottfredson, G. D., \& Holland, J. L. (1989). Dictionary of Holland occupational codes (2nd ed.). Odessa, FL: Psychological Assessment Resources.

Graban, J. L. (2007). The effects of study abroad experience on student cognitive and affective outcomes of college. (Doctoral dissertation, Indiana State University, 2007) Doctoral Dissertation, AAT3259531.

Grotevant, H. D. (1987). Toward a process model of identity formation. Journal of Adolescence, 2(3), 203-222.

Grotevant, H. D., Cooper, C. R., \& Kramer, K. (1986). Exploration as a predictor of congruence in adolescent's career choices. Journal of Vocational Behavior, 29(2), 201215. 
Gushue, G. V., Clarke, C. P., Pantzer, K. M., \& Scanlan, K. R. (2006). Self-efficacy, perceptions of barriers, vocational identity, and the career exploration behavior of Latino/a high school students. The Career Development Quarterly, 54, 307-317.

Gysbers, N. C., Heppner, M. J., \& Johnston, J. A. (2003). Career counseling: Process, issues, and techniques (2nd ed). Boston-New York-San Franscisco: Pearson Education, Inc.

Habermas, J. (1973). Notizen zum Begriff der Rollenkompetenz. In J. Habermas (Ed.), Kultur und Kritik (pp. 95-232). Frankfurt: Suhrkamp.

Habermas, J. (1976). Moralentwicklung und Ich-Identität. In J. Habermas (Ed.), Zur Rekosntruktion des Historischen Materialismus (pp. 3-91). Frankfurt: Suhrkamp.

Hackett, G., \& Betz, N. E. (1981). A self-efficacy approach to the career development of woman. Journal of Vocational Behavior, 24, 326-339.

Hann, N. (1977). Coping and defending: process of self-environment organization. New York: Academic Press.

Haußer, K. (1995). Identitätspsychologie. Heidelberg-Berlin: Springer.

Havighurst, R. J. (1972). Developmental task and education (3rd ed.). New York: David McKay.

Havighurst, R. J., \& Taba, H. (1956). Adolescent character and personality. New York: John Wiley \& Sons, Inc.

Herman, N. B. (1996). The impact of study abroad experience psychological development of college students. (Doctoral dissertation, Ohio University, 1996). Dissertation, AAT 9713159 .

Holland, J. L. (1985). Making vocational choice: A theory of vocational personalities and work environments ( $2^{\text {nd }}$ Ed.). Englewood Cliffs, New Jersey: Prentice-Hall.

Holland, J. L. (1991). La elección vocacional, teoría de las carreras. México: Trillas.

Holland, J. L. (1994). Self-Directed Search form $R 4^{\text {th }}$ edition. Assessment booklet: A guide to educational and career planning (4th ed.). Odessa, Fl: Psychological Assessment Resources.

Holland, J. L. (1994). Self-Directed Search: You and your career (4th ed.). Odessa, Fl: Psychological Assessment Resources.

Holland, J. L., \& Holland, J. E. (1977). Vocational indecision: More evidence and speculation. Journal of Counseling Psychology, 24(5), 404-414. Retrieved September 16, 2008, from PsycINFO database.

Holland, J. L., Johnston, J., A., Asama, N., \& Polys, S. M. (1993). Validating and using the career beliefs inventory. Journal of Career Development, 19(4), 233-244. Retrieved September 16, 2008, from PsycINFO database. 
Holland, J., Johnston, J., Hughey, K. \& Asama, N.F. (1991). Some explorations of a theory of careers: VII. A replication and some possible extensions. Journal of Career Development, 18(2), 91-100. Retrieved September 16, 2008, from PsycINFO database.

Holland, J., \& Lutz, S. (1968). The predictive value of a student's choice of vocation. Personnel \& Guidance Journal, 46(5), 428-436. Retrieved September 16, 2008, from PsycINFO database.

Holland, J., \& Nichols, R. (1964). Explorations of a theory of vocational choice: III. A longitudinal study of change in major field of study. Personnel / Guidance Journal, 43, 235-242. Retrieved September 16, 2008, from SocINDEX database.

Hopkins, J. (1999). Studying abroad as a form of experiential education. Liberal Education, 85(3), 36-41. Retrieved December 10, 2008, from ERIC database.

Howard, J. (2000) Social psychology of identities. Annual Review of Sociology, 26, 367-93. Retrieved January 15, 2008 from http://jmd.sagepub.com/cgi/content/abstract/22/2/155

Huitt, W. (2004). Self concept and self-esteem. Educational Psychology Interactive. Retrieved December 15, 2007 from http://chiron.valdosta.edy/whuitt/col/regsyst/self.html

Hurlock, E. B. (1989). Psicología de la adolescencia. (4th ed). México-Barcelona: Paidós.

Irwin, J. T. (2004). Community college: Changing individuals, meeting global needs. Open Doors 2007. Retrieved February 2, 2008 from http://opendoors.iienetwork.org/?=25126

James, W. (1890). Principles of psychology, Vol. 1. New York: Henry Holt.

Jordan, J. P. (1963). Exploratory behavior: The formation of self and occupational concept. In D. E. Super (Ed.). Career development: Self-concept theory (pp. 42-77). New York: College Entrance Examination Board.

Josselson, R. (1987). Finding herself: pathways to identity development in women. San Francisco: Jossey-Bass.

Kagan, S. L., \& Stewart, V., (2004). International education in the schools: The state of the field. Phi Delta Kappa International (PDK): The Professional Association in Education. Retrieved March 25, 2008 from http://www.pdkintl.org/kappan/k_v86/k0411ka1.htm

Keller, J., Piotrowsky, C., \& McLeod, C. (1991). The evolution of a career development program. Career Development Education, 112(3), 470-473.

Keupp, H., Ahbe, T., Gmür, W., Höfer, R., Mitzscherlich, B., Kraus, W., \& Strauss F. (2006). Identitätskonstruktionen: Das Patchwork der Identitätten in der Spätmoderne. Hamburg: Rowohlt Taschenbuch Verlag.

Krause, C. (1990). Das emotionale Grunderlebnis Schule - eine Determinante für Lern- und Lebenserfolg. In P. Richter (Ed.), Beiträge aus der Arbeit der Erziehungsberatungstelle Greifswald, 9, 14-26. 
Krause, C., Hannich, H., Stückle, C., Widmer, C., Rohde, C., \& Wiesmann, U. (2000). Selbstwert stärken - Gesundheit fördern: Unterrichtsvorschläge für das 1. and 2. Schuljahr. Donauwörth: Auer-Verlag.

Krause, C., Wiesmann, U., \& Hannich, H. (2004). Subjetktive Befindlichkeit und Selbstwertgefühl von Grundschulkindern. Lengerich, Berlin, Bremen, Miami: Pabst Science Publishers.

Krumboltz, J. D., Mitchell, A., \& Gelatt, H. G. (1975). Applications of social learning theory of career selection. Focus on Guidance, 8(3), 1-16.

Kuh, G. (1999). How are we doing? Tracking the quality of the undergraduate experience, 1960's to the present. The Review of Higher Education, 22(2) 99-119.

Labajos Alonso, J. (1998). Identidad del adolescente. In A. Aguirre Baztan (Ed.), Psicología de la Adolescencia (pp. 173-194). Bogotá: Alfomega.

Lathrop, B. J. (1999). The influence of study abroad programs states students' psychological development. (Doctoral dissertation, University of Georgia, 1999), Dissertation Abstract AAT 9949515.

Leliūgienè, I., \& Baršauskienè V. (2007). The role of the university in community development: Responding to the challenge of globalization. In D. Bridges, P. Juceviciene, T.H. Mclaughlin, \& J. Stankeviciute (Eds.), Higher education and national development: Universities and Societies in Transition (pp. 227-237). London-New York: Routledge Taylor and Francis Group.

Lent, R., Brown, S., \& Hackett, G. (1994). Toward a unifying social cognitive theory of career and academic interest, choice, and performance. Journal of Vocational Behavior, $45,79-122$.

Liepmann, D., \& Stiksrud, A. (1985). Entwicklungsaufgaben und Bewältigungsprobleme in der Adoleszenz. Göttingen-Toronto-Zürich: Verlag für Psichologie \& Dr. C. J. Hogrefe.

Lindsey, E. W. (2005). Study abroad and values development in social work students. Journal of Social Work Education, 41, 229-249.

Marcia, J. E. (1966a). Development and validation of ego identity status. Journal of Personality and Social Psychology, 3, 551-558.

Marcia, J. E. (1966b). Ego identity status: Relationship to change in self-esteem, general maladjustment, and authoritarianism. Journal of Personality, 3(1), 118-133. Retrieved September 19, 2008, from doi.10.1111/1467-6494.ep8934593.

Marcia, J. E. (1976). Identity six years after: A follow-up study. Journal of Youth and Adolescence, 5, 145-160.

Marcia, J. E. (1980). Identity in adolescence. In J. Adelson (Ed), Handbook of Adolescent Psychology (pp. 159-187). New York: Wiley. 
Marcia, J. E. (2003). Treading fearlessly: A commentary on personal persistence, identity development, and suicide. Monographs of the society for research in child development 68(2), 131-138. Retrieved September 22, 2008 from Psychology and Behavioral Sciences Collection, Ipswich.

Marin Benet, R. (1998). El acceso al trabajo en la adolescencia. In A. Aguirre Baztan (Ed.), Psicología de la adolescencia, pp. 307-337. Bogotá: Alfomega.

Mayering, P. (2000). Qualitative content analysis (28 paragraphs). Forum for Qualitative Social Research, 1(2). Retrieved 22, 2008 from http://qualitative-research.net/fqs/fqs-e/200inhalt-e.htm

McInerney, D. M., \& McInerney, V. (2006). Educational psychology: Constructive learning (4th ed.). Australia: Pearson Education Australia.

McKenna, I. (2003). Irish National Report of Implementation of the Bologna Process. Department of Education and Science at the University of Dublin. Retrieved May 25, 2008 from http://www.bologna-berlin2003.de/pdf/Irland1.pdf

Mead, G. H. (1934). Mind, self and society. The University of Chicago Press.

Meyerson, S. (1975). Adolescence and delinquency. In S. Mayerson (Ed.), Adolescence and breakdown (pp. 35 - 53). Great Britain: George Allen \& Unwin.

Mills, G., Gay, L. R., \& Airasian, P. (2009). Educational research: Competencies for analysis and applications. Columbus, Ohio: Prentice Hall.

Mimura, C. (2007). Constant struggles: The effect of overseas study on the identities of Japanese women. (Doctoral dissertation, Temple University, 2007) Dissertation Abstract, AAT 3255131.

Molla, M. (1997). La identidad del adolescente y elaboración de un test de la identidadinvestigación, 1978, 1989. In Psychology Notes - Cultural Association for Psychology Research. Retrieved September 19, 2008 from http://www.egocreanetperu.com/id1.htm

Moran, Ch. D. (2003). Nourishing and thwarting effects of contextual influences upon multiple dimensions of identity: Does gender matter? NASPA Journal, 40(3). Retrieved February 11, 2008 http://publications.naspa.org/naspajournal/vol40/iss3/art8/

Myers, D. N., Hill, M., \& Harwood, S. A. (2005). Cross-cultural learning and study abroad: transforming pedagogical outcomes. Landscape Journal 24(2), 172-184.

NAFSA, (2008). Strengthening study abroad: Recommendations for effective institutional management for presidents, senior's administrators, and study abroad professionals. Report of NAFSA's Task Force on Institutional Management of Study Abroad. Retrieved January 15, 2008 from http//:www.nafsa.org/IMSA

Naranjo Pereira, M. L. (2006). El auto concepto: un objetivo de la orientación y la educación. Revista electrónica "Actualidades investigativas en Educación”, 6(1). Retrieved January 15, 2008 from http://redalyc.uaemex.mx/redalyc/pdf/447/44760116.pdf 
Natarajan, R. (2005). The role of technical education in enabling the creation of a knowledge economy and society: The Indian experience. In G. A. Jones, P. L. McCarney \& M. L. Skolnik (Eds.), Creating knowledge, strengthening nations: The changing role of higher education (pp. 155-167). Toronto, ON: University of Toronto Press.

Nickolaus, R., Knöll, B., \& Geschwendtner, T. (2007). Innovations in vocational education and difficulties in their empirical substantiation. European Journal 40(1) 22-37. Retrieved December 15, 2008 from ERICdatabse.

Nunner-Winkler, G. (1988). Selbstkonzeptforschung und Identitätskonstrukt - Ein Vergleich zweier Ansätze aus der psychologischen und der soziologischen Sozialpsychologie. Zeitschrift für Sozialpsychologie 19, 243-254.

O'Callaghan, J. A. (2006). How a semester study abroad experience affects an undergraduate college students' identity development. (Master thesis, Montana State University, 2006).

Oerter, R. (1985). Lebnsbewältigung im Jugendalter. Weinheim: Edition Psychologie/VCH.

Oerter, R, \& Montada, L. (1987). Entwicklungspsychologie (2nd ed). München: Psychologie, Verlags-Union.

Olbrich, E. (1985). Konstruktive Auseinandersetzung im Jugendalter: Entwicklung, Förderung und Verhaltenseffekte. In R. Oerter (Ed.), Lebensbewältigung im Jugendalter. Weinheim: Edition Psychologie/VCH.

Open Doors Institute of International Education. (2007, November 13). More Americans are studying abroad at records levels up: 8.5\%. Retrieved May 13, 2008 from http.//opendoors.iienetwork.org/?p=113744

Orahood, T., Kruze, L., \& Pearson, D. E. (2004). The impacts of study abroad on business students' career goals. Frontiers: The Interdisciplinary Journal of Study Abroad, 10, 117-130.

Osipow, S. H. (1991).Teorías sobre la elección de carreras. México: Trillas.

Owens, T., Mortimer, J., \& Finch, M. (1996). Self-determination as a source of self-esteem in adolescence. Social Forces, 74(4), 1377-1404. Retrieved December 15, 2008 from http://www.jstor.org/stable/2580355

Pascarella, E., \& Terenzini P. (1991). How college affect students: Findings and insight from twenty years of research. San Francisco: Jossey-Bass.

Pascarella, E., \& Terenzini, P. (2005). How college affects students: A third decade of research (2nd ed.). San Francisco: Jossey-Bass.

Patterson, M. A. (1994). Performing the intercultural self: Culture as intertext. (Doctoral dissertation, Arizona State University, 1994). Dissertation Abstract, AAT 9514894.

Patterson, P. K. (2006). Effect of study abroad on intercultural sensitivity. (Doctoral dissertation, University of Missouri - Colombia, 2006). Dissertation Abstract, AAT 3284795 . 
Piaget, J. (1973). The child and reality: Problems of genetic psychology. New York: Grossman.

Pitts, M. J. (2005). The role of communication in cross-national adjustment and identity transitions among student sojourners. (Doctoral dissertation, Pennsylvania State University, 2005). Dissertation Abstract, AAT 3202520.

Praetzel, G. D. (1996). Making study abroad a reality for all students. Journal International Advances for Economics Research, 2(2), 174-183.

Praetzel, G. D. (1999). Pedagogical recommendations for internationalizing the undergraduate business curriculum. Journal International Advance for Economic Research, 5(1), 137-146. Retrieved December 15, 2008 from http.//www.springerlink.com/content/g7h055m424651675/fulltext.pdf

Rangel-Lopez, N. L. (2000). Self-esteem and vocational choice by Mexican adolescents. Psychology and Education, 1(26), 128-133. Switzerland: Vereinigung fuer Kinder- und Jugendpsychology SKJP.

Raskin, P.M. (1985). Identity and vocational development. In A. S. Watermann (Ed.), Identity in adolescence: Process and contents (pp. 25- 42). San Francisco: Jossey-Bass.

Reardon, R. (January 20, 2004). Holland's theory and implications for academic advising and career counseling. Retrieved September 16, 2008 from http://career.fsu.edu/documents/technical\%20reports/Technical\%20Report\%2038/Techni cal\%20Report\%2038.doc

Reese-Schäfer, W. (1999). Identität und Interesse: Der Diskurs der Identitätsforschung. Opladen: Leske \& Budrich.

Remschmidt, H. (1992). Adoleszenz: Entwicklung und Entwicklungskrisen im Jugendalter. (1st ed.). Stuttgart - New York: Thieme.

Robinson, B. (2003). The impact of study abroad on college curriculum. In M. Tillman (Ed.), Study Abroad: A 21 ${ }^{\text {st }}$ century perspective. Retrieved February 15, 2008 from http://www.aifsfoundation.org/robin.htm

Robitschek, C., \& Cook, S. W (2002). The influence of personal growth initiative and coping styles on career exploration and vocational identity. Journal of Vocational Behavior, 54(1), 127-141.

Rosenberg, M. (1965). Society and the adolescent self - image. Princeton, N.J: Princeton University Press.

Rosenberg, M. (1979). Conceiving the self. New York: Basic Books.

Ryan, R. M., \& Deci, E. I. (2000): Intrinsic and extrinsic motivation: Classic definition and new directions. Contemporary educational psychology, 25, 54-67. Retrieved February 15,2008 from http://www.psych.rochester.edu/SDT/documents/2000_RyanDeci_IntExtDefs.pdf 
Sajiki, A. (2006) Intercultural empathy as a toll as cross-cultural learning: United States students. (Doctoral dissertation, Indiana University, 2006) Dissertation Abstract, AAT 3215207.

Schmitt-Rodermund, E., \& Vondracek, F. W. (1999). Breadth of interests, exploration, and identity development in adolescence. Journal of Vocational Behavior, 55, 298-317. Retrieved April 12, 2007 from SAGE Database.

Schwalbe, M. L. (1985). Autonomy in work and self-esteem. The sociological quarterly, 26(4), 519-535. Retrieved December 15, 2008 from http://www.jstor.org/stable/4106102

Scott, P. (2005). The opportunities and threats of globalization. In G. A. Jones, P. L. McCarney \& M. L. Skolnik (Eds.), Creating knowledge, strengthening nations: The changing role of higher education (pp. 42-56). Toronto: University of Toronto Press.

Sheppard, K. (2004). Global citizenship: The human face of international education. International Education, 34(1), 34-40.

Sindt, P. E. (2007). Internationalization and higher education: Understanding the impact of short-term study abroad. (Doctoral dissertation, Arizona State University, 2007). Dissertation Abstract, AAT 3288012.

Skorikov, V. (2007). Continuity in adolescent career preparation and its effects on adjustment. Journal of Vocational Behavior, 70, 8-24.

Smart, J. C., Elton, C. F. \& McLaughlin, G. W. (1986). Person-environment congruence and job satisfaction. Journal of Vocational Behavior, 29, 216-225.

Soenens, B., Berzonsky, M. D., Vansteenkiste, M., Beyers, W. \& Goossens, L. (2005). Identity styles and causality orientations: In search of the motivational underpinnings of the identity exploration process. European Journal of Psychology, 19, 427-442.

Soenens, B., Duriez, B. \& Goossens, L. (2005). Social-psychological profiles of identity styles: Attitudinal and social-cognitive correlates in late adolescence. Journal of Adolescence, 28, 107-125.

Sullivan, T. A. (2002). A demographic portrait. In P. Cafferty, \& D. W. Engstrom, D. (Eds.), Hispanic in the United States: an agenda for the twenty-first century (pp. 1-29). New Brunswick, NJ: Transaction Books.

Spiering, K., \& Erickson, S. (2006). Study abroad as innovation: Applying the diffusion model to international education. International Education Journal, 7(3), 314-322. Retrieved May 13, 2008 from http://www.ehlt.flinders.edu.au/education/iej/articles/v7n3/Spiering/paper.pdf

Super, D. E. (1942). Avocations and vocational adjustment. Character \& personality: A quarterly for psycho diagnostic \& allied studies, 10, 51-61. Retrieved September 16, 2008 from PsycINFO database.

Super, D. E. (1953). A theory of vocational development. American Psychologist, 8, 185190. 
Super, D. E. (1957). The psychology of careers: an introduction to vocational development. New York: Harper \& Row.

Super, D. E. (1963a). Career Development: Self-concept theory. New York: College Entrance Examination Board.

Super, D. E. (1963b). Self concepts in vocational development. In D. E. Super (Ed.), Career development: Self-concept theory (pp. 1-26). New York: College Entrance Examination Board.

Super, D. E. (1965). Goal specificity in the vocational counseling of future college students. Personnel \& Guidance Journal, 43(2), 127-133. Retrieved May 29, 2009 from PsycINFO database.

Super, D. E. (1978). From information retrieval through matching to counseling and to career development. Journal of Occupational Psychology, 51(1), 19-28. Retrieved September 16, 2008, from PsycINFO database.

Super, D. E. (1980). A life-span approach to career development. Journal of Vocational Behavior, 16(2), 282-298. Retrieved September 16, 2008 from ScienceDirect database.

Super, D. E., \& Hall, D. (1978). Career development: Exploration and planning. Annual Review of Psychology, 29, 333-372. Retrieved September 16, 2008, from doi: 10.1146/annurev.ps.29.020178.002001.

Tamminen, T. (2006). How does culture promote the early development of identity? Infant Mental Health Journal, 27(6), 603-605. Retrieved January 15, 2008 from Psychology and Behavioral Sciences Collection.

Teichler, U. \& Steube, W. (1991). The logistic of study abroad programs and their impacts. Higher Education. 21(3), 325-349.

Teranishi, Ch. S. (2007). Impact of experiential learning on Latino college students' identity, relationships, and connectedness to community. Journal of Hispanic Higher Education, 6, 52 -72. Retrieved March 25, 2008 from http://jhh.sagepub.com/cgi/content/abstract/6/1/52

Thomas, A. (2005). Long-term effects of international students exchange programs. In W. Friedlmeier, P. Chakkarath, \& B. Schwarz (Eds.), Culture and human development: The importance of cross-cultural research for the social science. Part V: Acculturation, chapter 14, (pp. 303-320). Hove and New York: Psychology, Press.

Tomas, J., \& Oliver, A. (2004). Análisis psicométrico confirmatorio de una medida multidimensional del auto concepto en español. Interamerican Journal of Psychology, 38(2), 285-293. Retrieved February 21, 2008 from http://www.psicorip.org/Resumos/PerP/RIP/RIP036a0/RIP03830.pdf

Toncar, M., \& Cudmore, B. (2000). The overseas internship experience. Journal of Marketing Education, 22, 54-63. Retrieved March 25, 2008 from Sage Publications Database. 
Tonkin, H. (2008). Study, service and the self-transformed. In M. Tillman (Ed.), Study Abroad: A $21^{\text {st }}$ century perspective, volume II, the changing landscape (pp. 22-25). Stamford, CT: American Institute for Foreign Study Foundation.

Vande Berg, M. (2007). Intervening in the learning of U.S. students abroad. Journal of Studies in International Education, 11(3-4), 392-399.

Van-Dijk, D., \& Kluger, A. (2004). Feedback sign effect on motivation: Is it moderated by regulatory focus? Applied Psychology: An International Review, 53(1), 113-135. Retrieved September 26, 2008 from doi:10.1111/j.1464-0597.2004.00163.x

Walker-Staggs, J. (2000). DISCOVER: Its uses with College Students. In N. Peterson, \& R. Cortez Gonzalez (Eds.), Career counseling models for diverse populations (pp. 112121). Canada: Wadsworth/Brooks Cole.

Wallace-Broscious, A., Serafica, F., \& Osipow, S. (1994) Adolescent career development: Relationships to self-concept and identity Status. Journal of Research on Adolescence, 4(1), 127-149. Retrieved May 29, 2008 from Psychology and Behavioral Sciences Collection.

Waterman A. S. (1985). Identity in the context of adolescent psychology. In A. Waterman (Ed.), Identity in adolescence: Process and contents (pp. 5-25). San Francisco: JosseyBass.

Waterman, A.S., \& Archer, S.L. (1990). A life-span perspective on identity prevention: Development in from and process. In P. B. Baltes, D. L. Featherman, \& R. M. Lerner (Eds.), Life-span development and behavior Vol. 10 (pp. 29-57). Hillsdale, NJ: Erlbaum.

Weller, Ch. (1999). Kollektive Identitäten in der internationalen Politik. In W. ReeseSchäfer (Ed.), Identität und Interesse: Der Diskurs der Identitätsforschung (pp. 249-277). Opladen: Leske + Budrich.

William, S. (1995). Assessment of self-concept. ERIC Clearinghouse on Counseling and Students Services, Greensboro N.C: ERIC Identifier. ED389962.

Williams, A. H. (1975). Problems of adolescence. In S. Meyerson (1975). Adolescence and breakdown (pp. 11 - 24). Great Britain: George Allen \& Unwin.

Williams, B. Mc. (2006). Expanding perceptions of self and other through study abroad. (Doctoral dissertation, Ohio State University, 2006) Dissertation Abstract, AAT 3238170 .

Williams, T. (n. d.). Impact of study abroad on students' intercultural communication skills: Adaptability and sensitivity. Retrieved January 24, 2008 from http://www.aaplac.org/library/WilliamsTracy03.pdf

Zorn, C. (1996). The long-term impact on nursing students of participating in international education. Journal of professional Nursing, 12(2), 106-110.

Zunker, V.G. (1998). Theories of career development I. In V. G. Zunker (Ed.), Career counseling: Applied concepts of life planning, (pp. 22-69). Pacific Grove, California: Books/Cole. 
Zuschalg, M., \& Whiteborne, S. (1994). Psychosocial development in three generations of college students. Journal of Youth and Adolescence, 23, 567-577. 
APPENDIX No. 1 


\section{$\underline{\text { Student Consent Letter }}$}

\section{Study Title: The vocational career and vocational identity development of students during study abroad}

This research study is being conducted by Leticia Rangel Chavez, a doctoral student at the University George August of Göttingen, and supervised by Dr. Stephanie Brickman, Department Chair of Educational Psychology. This research examines the vocational identity development of Hispanic college students during a semester study abroad program. Approximately 15-20 students will participate in this study.

Participation will involve two (2), 60 minute sessions (before and after your study abroad), there are questions concerning perceptions about yourself, your career choice development, values in your lifespan, as well as your expectation on your study abroad program (sojourn) and your experience upon your return. The surveys and Interview are tentatively planned in January and June/July accordingly to the academic calendar of your international host university.

For the purposes of the study, it is important that we collect data both before study abroad and upon your return. You will be asked to participate in a follow up session upon your return from abroad. However, participation in the first session does not obligate you to participate in the second session - you are free to withdraw your participation from the study at any time.

In the before and after sessions, we will be asking you to complete the following:

1. You will be asked to complete a paper and pencil survey about "the vocational career choice development", which will last approximately 15 Minutes.

2. Then you will answer a questionnaire about "perceptions of yourself", this will last approximately 20 minutes.

3. Also, you will be asked to answer a questionnaire about your "vocational interest" that lasts approximately 10 Minutes

4. Finally, in an interview, you will be asked about your expectations on, and the experiences of your study abroad program.

Your responses may be quoted in whole or in part in publications or presentations based on this research. If your quotes are used, your real name will be replaced by a made up name (pseudonym) and any additional information that might directly identify you will be excluded.

The questionnaire and the surveys will be summarized, evaluated and interpreted, however, everything will be kept confidential by assigning a fictitious name before the interview begins, this coded name will be used through-out the questionnaire/survey and for any results used, the linking codebook will be kept under lock and key. No other identifying information will be recorded. Interview tapes will also be kept in a locked cabinet with only me, and my supervisor having access. Tapes will be destroyed at the end of the study.

Your participation is voluntary. You do not have to answer any questions you do not wish to answer, and there is no penalty should you decide not to participate or withdraw once 
you have started. There are no direct benefits to your participation; however, you may gain insight into self awareness from participation in this interview and focus group surveys.

There are virtually no risks involved in this study. However, the contact information for the university's Counseling Center is also provided below for your reference.

\section{Counseling and Psychological Services, UC 109 \\ 1201 West University Drive \\ Texas 78541-2999}

If you are in crisis, and this is after hours, please call the National Suicide Prevention Lifeline 1-800-273-TALK (8255). The office is located on the 1st floor of the University Center across from the cafeteria. Office: 956-381-2574, Fax: 292-7410

*Please note that e-mail cannot be guaranteed to be a confidential means of communication.

If you have any questions about the research, you may contact the investigator or faculty advisor (see below).

Dr. Stephanie J. Brickman, PhD, Department of Educational Psychology, Room 1.510 B, (956) 381-2901 Office (956) 381-3466.

Leticia Rangel Chavez, Primary Investigator, Graduate Student at the University of George-August in Göttingen, Germany (956) 451-8001, E-mail:

leticiarchavez@gmail.com

This research has been approved by the Institutional Review Board for the Protection of Human Subjects (IRB). If you have any questions about your rights as a participant, or if you feel that your rights have been violated, please contact the IRB at (956) 384-5004.

Signatures: By signing below, you indicate that you are voluntarily agreeing to participate in this study and that the procedures involved have been described to your satisfaction. The researcher will provide you with a copy of this form for your own reference. In order to participate, you must be at least 18 years of age. If you are under 18, please inform the researcher.

Participant's Signature

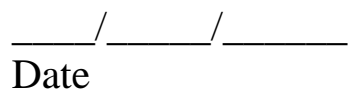

The researcher will provide you with a copy of this form for your reference. 
APPENDIX No. 2 


\section{Survey I and II \\ "Vocational career development of college students"}

Date:

Age:

Gender: Female / Male

Ethnicity:

GPA:

Study Abroad Term: Study Abroad Country:

Profession / Occupation of Father

Occupation Mother

\section{A. Regarding the carrier choice + carrier development}

Instructions: Please read carefully the following questions and answer them as sincere as possible.

1.- At this time who gives the most support / advice regarding your carrier choice a/o carrier development?

Please fill in the percentage.
a) Parents
b) Relatives
c) Friends
d) Professors
e) Counselor
f) Myself

2. - At this time (after studied abroad) do you have (already or still) clear in your mind the professional occupation that you will fulfill?
a) Clear and decided
b) Not clear / undecided
c) no idea at all

2.1 If the answer is "a" (clear and decided), what is your currently major and minor?

Major:

Minor:

From each of the following statements, what percentage contributes to your decision?

Because of concepts and meanings developed within the family environment.

Because of concepts and meanings developed and defined by my self

Others (e.g. developed abroad)

2.2 If you have answered the question \#2 with a "b" (not clear / undecided) or "c" (no idea at all), what are the reasons why do you think you are undecided? Break down in percentage.

Because of lack on information or erroneous ideologies about the career

Because of not having a clearer idea of the career, or because of lack of commitment in the effort to find it.

Other reasons (e.g. developed abroad) 
3.- Reflection about your self

If you can take a minute to reflect about your VOCATIONAL IDENTITY DEVELOPMENT (who am I, what I want to be, what am I interested in, what am I capable of and able to). Also at the same time, can you please think about the time and effort that you have invested in seeking your VOCATIONAL IDENTITY towards your PROFESSION/OCUPATION. Review the table carefully and answer the following question.

Which of the four boxes would you place yourself?

\begin{tabular}{|c|c|c|}
\hline & \multicolumn{2}{|c|}{$\begin{array}{c}\text { Level of } \\
\text { Exploration in searching }\end{array}$} \\
\hline $\begin{array}{c}\text { Commitments } \\
\text { Decision }\end{array}$ & High & Low \\
\hline High & & \\
\hline Low & & \\
\hline
\end{tabular}

4.- What are the most important values within your professional career plan? Write them in priority.

a)

c)

e)

5. - Regarding your expectation on your study abroad program and your vocational career development.

Please carefully read the following statements and circle the number that corresponds to your own perception. Note: $\mathrm{SA}=$ Study Abroad

$$
1=\text { Not at all } \quad 2=\text { a little } \quad 3=\text { somewhat } \quad 4=\text { a lot } \quad 5=\text { totally }
$$

5.1 Do you think that SA has aided in your work for

A professional carrier / vocational interest?

5.2 Do you think that SA helped you in being more competent to make decisions toward your professional career?...

5.3 Through my SA I really discovered my own interests and aptitudes?.

5.4 Study abroad helped me in identifying, who I am?

5.5 Through my study abroad I have a clearer idea about my professional identity? 1

b)

d)

f)

$\begin{array}{lllll}1 & 2 & 3 & 4 & 5 \\ 1 & 2 & 3 & 4 & 5\end{array}$

$\begin{array}{lllll}1 & 2 & 3 & 4 & 5 \\ 1 & 2 & 3 & 4 & 5\end{array}$

$\begin{array}{lllll}1 & 2 & 3 & 4 & 5\end{array}$


6.- What are your preferences in your lifespan?

a)

c)

e) b)

d)

f) 
APPENDIX No. 3 
Frankfurter "Selbstkonzept Skala"

(Translated in English by the author)

Instructions

In the following questionnaire you will read some scenarios. Read each statement very carefully and mark (X) this statement in regards to how accurate the statement is for you.

That for you have 6 different options for your answers:

$\# \mathbf{1}=$ is very accurate

$\# 2$ = is accurate

$\# 3$ = is a bit accurate
\# 4 = is less accurate

\# 5 = is not accurate

\# 6 = is not at all accurate

Mark with an X the little box with the number that coincides with your answers.

\section{Example:}

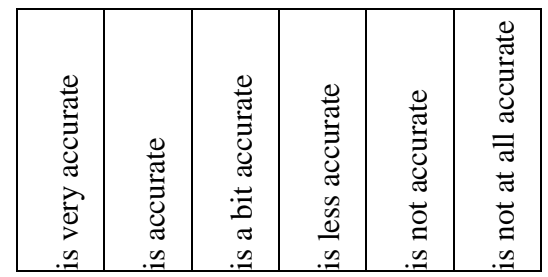

\begin{tabular}{|l|l|l|l|l|l|}
\hline 1 & 2 & 3 & 4 & 5 & 6 \\
\hline
\end{tabular}

I like to eat chocolate.

These question do not require deep thoughts, please try to answer them quickly as possible.

Code:

Age:

Ethic group:

Study Abroad Term:
Date:

Gender:

Major:

Country:

\section{Thank you for your participation and good luck in your sojourn abroad!}




\section{FSAL}

1. I am certainly as efficient and intelligent as the others

2. I feel like a loser, every time I hear of the success of an acquaintance

3. I am content with my own achievements

4. Which I planned, I can also achieve

5. If I recall, I can remember successes more easily than failures

6. On the whole I tend to regard myself as a loser

7. Whatever I plan to do I mostly have difficulties in achieving it, or I cannot achieve it at all.

8. If I can recall, I can remember failures more easily than successes

9. I believe that I am as good as everybody else

10. I often fear to fail in the crucial instant

\section{FSAP}

1. I easily lose my head

2. I can cope with my personal problems

3. I will master my problems also in the future

4. I can take care of myself in any situation

5. My personal problems are there to be solved on my own

6. I can get along as well as everybody else

7. I try to run away from my problems

8. I wished I would not give up that quickly

9. I see the future promising.

10. I do not get off track easily

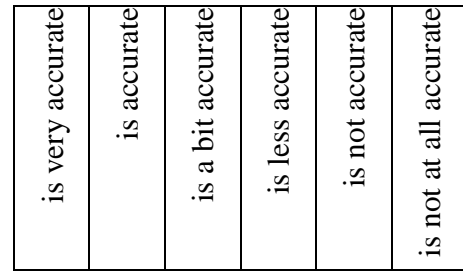

\begin{tabular}{|l|l|l|l|l|l|}
\hline 1 & 2 & 3 & 4 & 5 & 6 \\
\hline
\end{tabular}

\begin{tabular}{|l|l|l|l|l|l|}
\hline 1 & 2 & 3 & 4 & 5 & 6 \\
\hline
\end{tabular}

\begin{tabular}{|l|l|l|l|l|l|}
\hline 1 & 2 & 3 & 4 & 5 & 6 \\
\hline
\end{tabular}

\begin{tabular}{|l|l|l|l|l|l|}
\hline 1 & 2 & 3 & 4 & 5 & 6 \\
\hline
\end{tabular}

\begin{tabular}{|l|l|l|l|l|l|}
\hline 1 & 2 & 3 & 4 & 5 & 6 \\
\hline
\end{tabular}

\begin{tabular}{|l|l|l|l|l|l|}
\hline 1 & 2 & 3 & 4 & 5 & 6 \\
\hline
\end{tabular}

\begin{tabular}{|l|l|l|l|l|l|}
\hline 1 & 2 & 3 & 4 & 5 & 6 \\
\hline
\end{tabular}

\begin{tabular}{|l|l|l|l|l|l|}
\hline 1 & 2 & 3 & 4 & 5 & 6 \\
\hline
\end{tabular}

\begin{tabular}{|l|l|l|l|l|l|}
\hline 1 & 2 & 3 & 4 & 5 & 6 \\
\hline
\end{tabular}

\begin{tabular}{|l|l|l|l|l|l|}
\hline 1 & 2 & 3 & 4 & 5 & 6 \\
\hline
\end{tabular}

\begin{tabular}{|l|l|l|l|l|l|}
\hline 1 & 2 & 3 & 4 & 5 & 6 \\
\hline
\end{tabular}

\begin{tabular}{|l|l|l|l|l|l|}
\hline 1 & 2 & 3 & 4 & 5 & 6 \\
\hline
\end{tabular}

\begin{tabular}{|l|l|l|l|l|l|}
\hline 1 & 2 & 3 & 4 & 5 & 6 \\
\hline
\end{tabular}

\begin{tabular}{|l|l|l|l|l|l|}
\hline 1 & 2 & 3 & 4 & 5 & 6 \\
\hline
\end{tabular}

\begin{tabular}{|l|l|l|l|l|l|}
\hline 1 & 2 & 3 & 4 & 5 & 6 \\
\hline
\end{tabular}

\begin{tabular}{|l|l|l|l|l|l|}
\hline 1 & 2 & 3 & 4 & 5 & 6 \\
\hline
\end{tabular}

\begin{tabular}{|l|l|l|l|l|l|}
\hline 1 & 2 & 3 & 4 & 5 & 6 \\
\hline
\end{tabular}

\begin{tabular}{|l|l|l|l|l|l|}
\hline 1 & 2 & 3 & 4 & 5 & 6 \\
\hline
\end{tabular}

\begin{tabular}{|l|l|l|l|l|l|}
\hline 1 & 2 & 3 & 4 & 5 & 6 \\
\hline
\end{tabular}

\begin{tabular}{|l|l|l|l|l|l|}
\hline 1 & 2 & 3 & 4 & 5 & 6 \\
\hline
\end{tabular}




\section{FSVE}

1. I am pretty certain in evaluating my capability

2. Often I feel like making excuses for my behavior

3. In most cases, I am able to make quick and certain decision

4. I can make important decision without help

5. I believe that I can justified my conduct in most cases

6. I have difficulties in doing the right thing

\section{FSSW}

1. Sometimes, I believe that I am not good at anything

2. I am nobody

3. I devalue my self

4. Overall, I am pretty satisfied with my self

5. Sometimes, I wish, I was never born

6. I wish I had more respect for my self

7. Sometimes I fell useless

8. If I compare myself with others performance, I perform pretty well

9. I think I am pretty comfortable with my self

10. I am satisfied with my self

\section{FSEG}

1. I am a happy human being

2. I am more sensitive than what would be good for me.

3. Often I am quite awkward / clumsy

4. My feelings are hurt easily

5. I am too sensitive

6. I can tolerate accusation without losing control

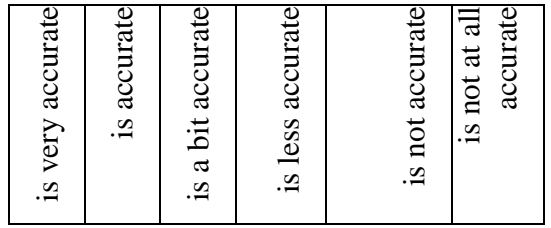

\begin{tabular}{|l|l|l|l|l|l|}
\hline 1 & 2 & 3 & 4 & 5 & 6 \\
\hline
\end{tabular}

\begin{tabular}{|c|c|c|c|c|c|}
\hline 1 & 2 & 3 & 4 & 5 & 6 \\
\hline 1 & 2 & 3 & 4 & 5 & 6 \\
\hline 1 & 2 & 3 & 4 & 5 & 6 \\
\hline 1 & 2 & 3 & 4 & 5 & 6 \\
\hline 1 & 2 & 3 & 4 & 5 & 6 \\
\hline
\end{tabular}

\begin{tabular}{|l|l|l|l|l|l|}
\hline 1 & 2 & 3 & 4 & 5 & 6 \\
\hline
\end{tabular}

\begin{tabular}{|l|l|l|l|l|l|}
\hline 1 & 2 & 3 & 4 & 5 & 6 \\
\hline 1 & 2 & 3 & 4 & 5 & 6 \\
\hline
\end{tabular}

\begin{tabular}{|l|l|l|l|l|l|}
\hline 1 & 2 & 3 & 4 & 5 & 6 \\
\hline
\end{tabular}

\begin{tabular}{|l|l|l|l|l|l|}
\hline 1 & 2 & 3 & 4 & 5 & 6 \\
\hline
\end{tabular}

\begin{tabular}{|l|l|l|l|l|l|}
\hline 1 & 2 & 3 & 4 & 5 & 6 \\
\hline
\end{tabular}

\begin{tabular}{|l|l|l|l|l|l|}
\hline 1 & 2 & 3 & 4 & 5 & 6 \\
\hline
\end{tabular}

\begin{tabular}{|l|l|l|l|l|l|}
\hline 1 & 2 & 3 & 4 & 5 & 6 \\
\hline
\end{tabular}

\begin{tabular}{|l|l|l|l|l|l|}
\hline 1 & 2 & 3 & 4 & 5 & 6 \\
\hline
\end{tabular}

\begin{tabular}{|l|l|l|l|l|l|}
\hline 1 & 2 & 3 & 4 & 5 & 6 \\
\hline
\end{tabular}

\begin{tabular}{|l|l|l|l|l|l|}
\hline 1 & 2 & 3 & 4 & 5 & 6 \\
\hline
\end{tabular}

\begin{tabular}{|l|l|l|l|l|l|}
\hline 1 & 2 & 3 & 4 & 5 & 6 \\
\hline
\end{tabular}

\begin{tabular}{|l|l|l|l|l|l|}
\hline 1 & 2 & 3 & 4 & 5 & 6 \\
\hline
\end{tabular}

\begin{tabular}{|l|l|l|l|l|l|}
\hline 1 & 2 & 3 & 4 & 5 & 6 \\
\hline
\end{tabular}

\begin{tabular}{|l|l|l|l|l|l|}
\hline 1 & 2 & 3 & 4 & 5 & 6 \\
\hline
\end{tabular}

\begin{tabular}{|l|l|l|l|l|l|}
\hline 1 & 2 & 3 & 4 & 5 & 6 \\
\hline
\end{tabular}




\section{FSST}

1. If I am in a group, I do not dare to say something.

2. I often disagree with acquaintance's views.

However, I have inhibitions to state my criticism.

3. I consistently represent my opinion in the group, even though the group does not agree with me

4. If I am of a different opinion I do not hesitate to contradict even authoritative persons

5. I am-ill-at-ease when I get the impression that somebody else is of a different opinion than me.

6. Generally I act too much in accordance with other people's opinions.

7. In order to avoid making enemies I more frequently agree with other people's perceptions and decisions even, if I in principal do not agree.

8. I have fears to be myself.

9. It is hard for me to represent my opinion in front of a bigger group.

10. I have difficulties to express my opinion in a group even if I have something important to say.

11. It is hard for me to represent an oppositional opinion in front of a group.

12. I feel uncertain in a group because others mostly come up with more ideas than myself

\section{FSKU}

1. I have a good manner in interacting with others.

2. It is easy for me to get in contact with other people.

3. I am not shy of entering a room where people are already sitting together chatting

4. I should be more polite towards other people.

5. I get pretty shy and insecure as soon as I get in contact with other people.

6. I am not afraid of encountering strangers.

\begin{tabular}{|c|c|c|c|c|}
\hline 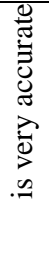 & 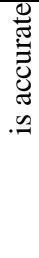 & 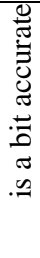 & 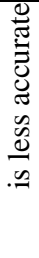 & 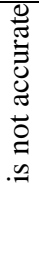 \\
\hline
\end{tabular}

\begin{tabular}{|l|l|l|l|l|l|}
\hline 1 & 2 & 3 & 4 & 5 & 6 \\
\hline 1 & 2 & 3 & 4 & 5 & 6 \\
\hline
\end{tabular}

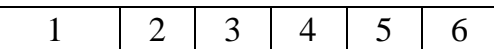

\begin{tabular}{|l|l|l|l|l|l|}
\hline 1 & 2 & 3 & 4 & 5 & 6 \\
\hline
\end{tabular}

\begin{tabular}{|c|c|c|c|c|c|}
\hline 1 & 2 & 3 & 4 & 5 & 6 \\
\hline 1 & 2 & 3 & 4 & 5 & 6 \\
\hline 1 & 2 & 3 & 4 & 5 & 6 \\
\hline
\end{tabular}

\begin{tabular}{|c|c|c|c|c|c|}
\hline 1 & 2 & 3 & 4 & 5 & 6 \\
\hline 1 & 2 & 3 & 4 & 5 & 6 \\
\hline 1 & 2 & 3 & 4 & 5 & 6 \\
\hline
\end{tabular}

\begin{tabular}{|l|l|l|l|l|l|}
\hline 1 & 2 & 3 & 4 & 5 & 6 \\
\hline 1 & 2 & 3 & 4 & 5 & 6 \\
\hline
\end{tabular}

\begin{tabular}{|l|l|l|l|l|l|}
\hline 1 & 2 & 3 & 4 & 5 & 6 \\
\hline 1 & 2 & 3 & 4 & 5 & 6 \\
\hline \multicolumn{7}{|c|}{} \\
\hline 1 & 2 & 3 & 4 & 5 & 6 \\
\hline \multicolumn{7}{|c|}{} \\
\hline 1 & 2 & 3 & 4 & 5 & 6 \\
\hline \multicolumn{7}{|c|}{} \\
\hline 1 & 2 & 3 & 4 & 5 & 6 \\
\hline & & 3 & 4 & 5 & 6 \\
\hline
\end{tabular}




\section{FSWA}

1. I have low prestige by my family.

2. There are people towards which I consider myself too unimportant that it would be worth making friends with.

3. My family does not trust me very much.

4. I feel that I am not interesting enough for other people in order to be friends with them.

5. I feel loved by my family.

6. Often I feel that strangers consider me critically.

\section{FSIA}

1. If I have the impression that somebody is smarter then me I avoid him.

2. I doubt whether my opinion is taken seriously, especially if I am not entirely sure about the matter myself.

3. It is very important for me to leave a good impression at all times.

4. I would feel more self-assured if I was not so different from everybody else.

5. In order to appear more likable I try to act more like others than truly being myself.

6. It scares me when somebody actively makes an effort for me.

\section{FSGA}

1. As a person I feel inferior to my friends.

2. As a general rule I can trust other people.

3. I have difficulties in combining sexuality and love.

4. I wish I was more trustful.

5. I am scared that many of my friends will let me down when/if I need them.

6. I have no difficulties to admit that I have done something wrong.

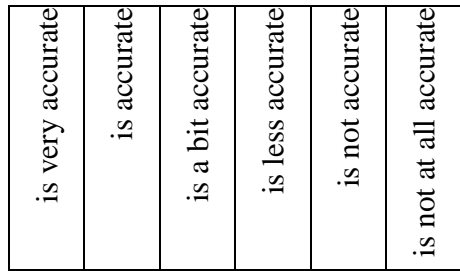

\begin{tabular}{|l|l|l|l|l|l|}
\hline 1 & 2 & 3 & 4 & 5 & 6 \\
\hline
\end{tabular}

\begin{tabular}{|l|l|l|l|l|l|}
\hline 1 & 2 & 3 & 4 & 5 & 6 \\
\hline
\end{tabular}

\begin{tabular}{|l|l|l|l|l|l|}
\hline 1 & 2 & 3 & 4 & 5 & 6 \\
\hline
\end{tabular}

\begin{tabular}{|l|l|l|l|l|l|}
\hline 1 & 2 & 3 & 4 & 5 & 6 \\
\hline
\end{tabular}

\begin{tabular}{|l|l|l|l|l|l|}
\hline 1 & 2 & 3 & 4 & 5 & 6 \\
\hline
\end{tabular}

\begin{tabular}{|l|l|l|l|l|l|}
\hline 1 & 2 & 3 & 4 & 5 & 6 \\
\hline
\end{tabular}

\begin{tabular}{|l|l|l|l|l|l|}
\hline 1 & 2 & 3 & 4 & 5 & 6 \\
\hline
\end{tabular}

\begin{tabular}{|l|l|l|l|l|l|}
\hline 1 & 2 & 3 & 4 & 5 & 6 \\
\hline
\end{tabular}

\begin{tabular}{|l|l|l|l|l|l|}
\hline 1 & 2 & 3 & 4 & 5 & 6 \\
\hline
\end{tabular}

\begin{tabular}{|l|l|l|l|l|l|}
\hline 1 & 2 & 3 & 4 & 5 & 6 \\
\hline
\end{tabular}

\begin{tabular}{|l|l|l|l|l|l|}
\hline 1 & 2 & 3 & 4 & 5 & 6 \\
\hline
\end{tabular}

\begin{tabular}{|l|l|l|l|l|l|}
\hline 1 & 2 & 3 & 4 & 5 & 6 \\
\hline
\end{tabular}

\begin{tabular}{|l|l|l|l|l|l|}
\hline 1 & 2 & 3 & 4 & 5 & 6 \\
\hline
\end{tabular}

\begin{tabular}{|l|l|l|l|l|l|}
\hline 1 & 2 & 3 & 4 & 5 & 6 \\
\hline
\end{tabular}

\begin{tabular}{|l|l|l|l|l|l|}
\hline 1 & 2 & 3 & 4 & 5 & 6 \\
\hline
\end{tabular}

\begin{tabular}{|l|l|l|l|l|l|}
\hline 1 & 2 & 3 & 4 & 5 & 6 \\
\hline
\end{tabular}

\begin{tabular}{|l|l|l|l|l|l|}
\hline 1 & 2 & 3 & 4 & 5 & 6 \\
\hline
\end{tabular}

\begin{tabular}{|l|l|l|l|l|l|}
\hline 1 & 2 & 3 & 4 & 5 & 6 \\
\hline
\end{tabular}




\title{
FSKN-GESAMTVERSION
}

\author{
FRANKFURTER SELBSTKONZEPTSKALEN
}

FSKN

Ingrid M. Deusinger

\section{Anleitung}

Im folgenden finden Sie Feststellungen zu Situationen des Altags. Bitte lesen Sie jede Aussage sorgftatig durch und entscheiden Sie, in welchem Ausmaß die Aussage auf Sie zurriftt oder nicht zutritt. Es gibt tür Sie sechs verschie.

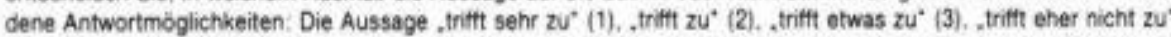
(4), Anift nicht zu' (5), triftt gar nicht zu' (6). Kreuzen Sie bitte das für Sie entsprechende Kastchen an. Bitte beantworten Sie alle Fragen.

\section{Beispiel}

Ich neige dazu, mir mit Problemen den Kopt zu zerbrechen

Wenn fur Sie fur die Aussage , Ich neige dazu. mir mit Problemen den Kopt zu zerbrechen" die Antwort ,trift $z u^{*}$ am besten past. kreuzen Sie bitte das Kastchen mit ,tritt $z u^{\prime}$ (2) an

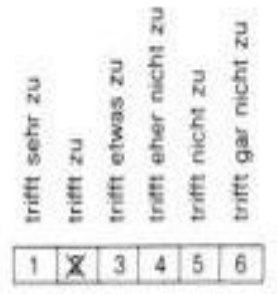

Haben Sie noch irgendweiche Fragen? Bitte antworten Sie zügig. und entscheiden Sie sich umgehend für eine Antwort. Batte beantworten Sie ale Fragen.

Name:

Vorname:

Geburtsdatum

Datum der Untersuchung.

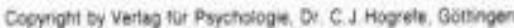

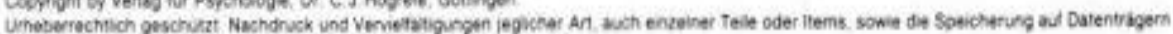
oder die Wiedergate durch optische ader akustsche Moden, verboten

Beet. Nor. 0101809 
1. Es tallt mir schwer. meine Meinung vor ener groberen Gruppe zu vertreten. . . \begin{tabular}{|l|l|l|l|l|l|}
\hline 1 & 2 & 3 & 4 & 5 & 6 \\
\hline
\end{tabular}

2. Wẹnn ich mich in einer Gruppe betinde, trave ich mich nicht, etwas zu sagen

\begin{tabular}{|l|l|l|l|l|l|}
\hline 1 & 2 & 3 & 4 & 5 & 6 \\
\hline
\end{tabular}

3. Ich bin ein trónlicher Mensch.

\begin{tabular}{|l|l|l|l|l|l|}
\hline 1 & 2 & 3 & 4 & 5 & 6 \\
\hline
\end{tabular}

4. ICh habe wenig Ansehen bei meiner Familie

\begin{tabular}{|l|l|l|l|l|l|}
\hline 1 & 2 & 3 & 4 & 5 & 6 \\
\hline
\end{tabular}

5. Ich fuhle mich als Person meinen Freunden unterlegen.

\begin{tabular}{|l|l|l|l|l|l|}
\hline 1 & 2 & 3 & 4 & 5 & 6 \\
\hline
\end{tabular}

6. Ich bin sensibler, als es fur mich gut ist

\begin{tabular}{|l|l|l|l|l|l|}
\hline 1 & 2 & 3 & 4 & 5 & 6 \\
\hline
\end{tabular}

7. Ich bin bestimmt so leistungstahig und intelligent wie andere

\begin{tabular}{|l|l|l|l|l|l|}
\hline 1 & 2 & 3 & 4 & 5 & 6 \\
\hline
\end{tabular}

6. Manchmai giaube ich, dab ich zu uberhaupt nichts gut bin.

\begin{tabular}{|l|l|l|l|l|l|}
\hline 1 & 2 & 3 & 4 & 5 & 6 \\
\hline
\end{tabular}

9. Ich tuhie mich als Versager, wenn ich von dem Erfolg eines Bekannten hore.

\begin{tabular}{|l|l|l|l|l|l|}
\hline 1 & 2 & 3 & 4 & 5 & 6 \\
\hline
\end{tabular}

10. Wenn ich den Eindruck habe. das mit jemand geistig uberlegen ist, gehe ich inm aus dem Weg.

11. Ich sehe der Zukuntt holfnungsvoll entgegen

\begin{tabular}{|l|l|l|l|l|l|}
\hline 1 & 2 & 3 & 4 & 5 & 6 \\
\hline
\end{tabular}

\begin{tabular}{|l|l|l|l|l|l|}
\hline 1 & 2 & 3 & 4 & 5 & 6 \\
\hline
\end{tabular}

12 Ich bin eir Niemand

\begin{tabular}{l|l|l|l|l|l|}
1 & 2 & 3 & 4 & 5 & 6 \\
\hline
\end{tabular}

13 lch versuche; vor meinen Problemen davonzulauten

\begin{tabular}{|l|l|l|l|l|l|}
\hline 1 & 2 & 3 & 4 & 5 & 6 \\
\hline
\end{tabular}

14. Ith kann anderen in der Regei vertrauen

\begin{tabular}{|l|l|l|l|l|l|}
\hline 1 & 2 & 3 & 4 & 5 & 6 \\
\hline
\end{tabular}

15 ich habe eine gute Art, mit anderen umzugehen.

\begin{tabular}{l|l|l|l|l|l|}
\hline 1 & 2 & 3 & 4 & 5 & 6 \\
\hline
\end{tabular}

16. Ich verliere leicht den Kopt

\begin{tabular}{l|l|l|l|l|l|}
1 & 2 & 3 & 4 & 5 & 6 \\
\hline
\end{tabular}

17 lech verachte mich

\begin{tabular}{|l|l|l|l|l|l|}
\hline 1 & 2 & 3 & 4 & 5 & 6 \\
\hline
\end{tabular}

18 ich habe Schwierigkeiten, meine Meinung in einer Gruppe zu aubern, auch wenn ich elwas Wichtiges zu sagen have

19 Es fallt mir schwer einer Gruppe gegenuber eine gegensatziche Auffassung zu vertiesen

20 Ich bin mit meinen eigenen Leistungen zutrieden

\begin{tabular}{|l|l|l|l|l|l|}
\hline 1 & 2 & 3 & 4 & 5 & 6 \\
\hline
\end{tabular}

\begin{tabular}{l|l|l|l|l|l|}
\hline 1 & 2 & 3 & 4 & 5 & 6 \\
\hline
\end{tabular}

\begin{tabular}{l|l|l|l|l|l|}
\hline 1 & 2 & 3 & 4 & 5 & 6 \\
\hline
\end{tabular}

21 Eigentich bin ich mit mir ganz zutrieden.

\begin{tabular}{|l|l|l|l|l|l|}
\hline 1 & 2 & 3 & 4 & 5 & 6 \\
\hline
\end{tabular}

22. Es gibt Menschen. gegenuber denen ich mich für zu unwichtig halte, als daß ich mich um ihre Bekanntschaft bemüen wurde

23. Ich wünschte. ich würde nicht so schnell autgeben

\begin{tabular}{ll|l|l|l|l|l|l}
\hline & 3 & 4 & 5 & 6
\end{tabular}

24 Ich zweifle, ob man meine Meinung auch ernst nimmt, vor allem, wern ich selbs: in der Sache noch nicht ganz sicher bin. .............................

25. Ich karin mit meinen persontichen Problemen gut fertig werden.

\begin{tabular}{|l|l|l|l|l|}
\hline 2 & 3 & 4 & 5 & 6 \\
\hline
\end{tabular}

\begin{tabular}{|l|l|l|l|l|l|}
\hline 1 & 2 & 3 & 4 & 5 & 6 \\
\hline
\end{tabular}

\begin{tabular}{|l|l|l|l|l|l|}
\hline 1 & 2 & 3 & 4 & 5 & 6 \\
\hline
\end{tabular}

\begin{tabular}{|l|l|l|l|l|l|}
\hline 1 & 2 & 3 & 4 & 5 & 6 \\
\hline
\end{tabular} 
27. Was ich mir vorgenommen habe, kann ich auch erreichen

28. Manchmai wünschte ich, ich ware richt geboren

29. Ich werde auch in Zukunft meine Probleme meistern.

30. Ich bin eigentlich ziemlich sicher in der Einschatzung meiner Fahigkeiten

31. Ich kann Auffassungen von Bekannten oft nicht zustimmen, habe aber Hemmun. gen, meine Kritik otten vorzubringen.

32. Wenn ich so zuruckdenke, kann ich mich an mehr Ertolge als an MiBertolge erin.

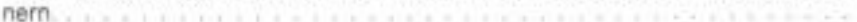

33 Es ist mir sehr wichtig. dab ich stets einen guten Eindruck mache

34 Meine Familie vertraut mir wenig

35. Ich habe das Gefuhl, daA ich für manche Menschen nicht interessant genug bin um mit innen befreundet zu sein.

36 Ich vertrete megine Meinung auch konsecuent in der Gruppe, die nicht mit mir ubereinstimm

37. Im grofen und ganzen neige ich dazu. mich für einen Versager zu haiten

38. Ich würde mich sicherer fuhlen, wonn ich nicht so verschieden von anderen ware

39. Ich hate otters das Bedurtnis, mich fur mein Verhaten zu entschuldigen.

40. Ich wollte, ich koninte mehr Achtung vor mir haben

41 ich habe Schwierigketen, Sexualtat und Liebe miteinandet zu verbinden

42. Ich kanh mich in den meisten Fallen schnell und sicher entscheiden

43. Um sympathisch zu wirken, bin ich eher so. wie mich andere haben wollen, als wie ich selbst sein mochte

44 ich schouv mich nicht, allein in einen Raum zu gehen, in dem andere Leute bereits zusammensitzen und sich unterhaiten

45. Ich kann in jeder Situation fur mich sebst sorgen

46 Wenn ich anderer Meinung bin, widerspreche ich auch Autontatspersconen

47. Was ich mir auch vornehme, stets habe ich Schwiengkeiten, es zu erreichen, meistens schatfe ich es nicht

48. ich wùnschte, ich ware vertravenswurdiger

49. ich fuhle mich von meiner Famle geliebt

50. Manchmal fühle ich mich zu nichts nùtze.

51. Ott bin ich recht linkisch. \begin{tabular}{|l|l|l|l|l|l|}
\hline 1 & 2 & 3 & 4 & 5 & 6 \\
\hline
\end{tabular}

\begin{tabular}{|l|l|l|l|l|l|}
\hline 1 & 2 & 3 & 4 & 5 & 6 \\
\hline
\end{tabular}

\begin{tabular}{|l|l|l|l|l|l|}
\hline 1 & 2 & 3 & 4 & 5 & 6 \\
\hline
\end{tabular}

\begin{tabular}{|l|l|l|l|l|l|}
\hline 1 & 2 & 3 & 4 & 5 & 6 \\
\hline
\end{tabular}

\begin{tabular}{|l|l|l|l|l|l|}
\hline 1 & 2 & 3 & 4 & 5 & 6 \\
\hline
\end{tabular}

\begin{tabular}{|l|l|l|l|l|l|}
\hline 1 & 2 & 3 & 4 & 5 & 6 \\
\hline
\end{tabular}

\begin{tabular}{|l|l|l|l|l|l|}
\hline 1 & 2 & 3 & 4 & 5 & 6 \\
\hline
\end{tabular}

\begin{tabular}{|l|l|l|l|l|l|}
\hline 1 & 2 & 3 & 4 & 5 & 6 \\
\hline
\end{tabular}

\begin{tabular}{|l|l|l|l|l|l|}
\hline 1 & 2 & 3 & 4 & 5 & 6 \\
\hline
\end{tabular}

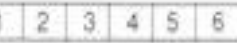

\begin{tabular}{|l|l|l|l|l|l|}
\hline 1 & 2 & 3 & 4 & 5 & 6 \\
\hline
\end{tabular}

\begin{tabular}{|l|l|l|l|l|l|}
\hline 1 & 2 & 3 & 4 & 5 & 6 \\
\hline
\end{tabular}

\begin{tabular}{|l|l|l|l|l|l|}
\hline 1 & 2 & 3 & 4 & 5 & 6 \\
\hline
\end{tabular}

\begin{tabular}{|l|l|l|l|l|l|}
\hline 1 & 2 & 3 & 4 & 5 & 6 \\
\hline
\end{tabular}

\begin{tabular}{|l|l|l|l|l|l|}
\hline+ & 2 & 3 & 4 & 5 & 6 \\
\hline
\end{tabular}

\begin{tabular}{|l|l|l|l|l|l|}
\hline 1 & 2 & 3 & 4 & 5 & 6 \\
\hline
\end{tabular}

\begin{tabular}{|l|l|l|l|l|l|}
\hline 1 & 2 & 3 & 4 & 5 & 6 \\
\hline
\end{tabular}

\begin{tabular}{|l|l|l|l|l|l|}
\hline 1 & 2 & 3 & 4 & 5 & 6 \\
\hline
\end{tabular}

\begin{tabular}{|l|l|l|l|l|l|}
\hline 1 & 2 & 3 & 4 & 5 & 6 \\
\hline
\end{tabular}

\begin{tabular}{|l|l|l|l|l|l|}
\hline 1 & 2 & 3 & 4 & 5 & 6 \\
\hline
\end{tabular}

\begin{tabular}{|l|l|l|l|l|l|}
\hline 1 & 2 & 3 & 4 & 5 & 6 \\
\hline
\end{tabular}

\begin{tabular}{|l|l|l|l|l|l|}
\hline 1 & 2 & 3 & 4 & 5 & 6 \\
\hline
\end{tabular}

\begin{tabular}{|l|l|l|l|l|l|}
\hline 1 & 2 & 3 & 4 & 5 & 6 \\
\hline
\end{tabular}

\begin{tabular}{|l|l|l|l|l|l|}
\hline 1 & 2 & 3 & 4 & 5 & 6 \\
\hline
\end{tabular}

\begin{tabular}{|l|l|l|l|l|l|}
\hline 1 & 2 & 3 & 4 & 5 & 6 \\
\hline
\end{tabular}

\begin{tabular}{|l|l|l|l|l|l|}
\hline 1 & 2 & 3 & 4 & 5 & 6
\end{tabular} 
53. In einer Gruppe füle ich mich nicht so sicher, da den anderen mest mehr eintalit ais mir

54 Es macht mit Angst. wenn sich jemand aktiv um mich bemüht

\begin{tabular}{|l|l|l|l|l|l|}
\hline 1 & 2 & 3 & 4 & 5 & 6 \\
\hline
\end{tabular}

\begin{tabular}{|l|l|l|l|l|l|}
\hline 1 & 2 & 3 & 4 & 5 & 6 \\
\hline
\end{tabular}

55. Es beunruhigt mich, wenn ich den Eindruck erhalte. dab jemand eine andere Auttassung hat ais ich

\begin{tabular}{l|l|l|l|l|l|}
\hline 1 & 2 & 3 & 4 & 5 & 6 \\
\hline
\end{tabular}

56. Meine Getuhle sind leicht verletzbar

\begin{tabular}{|l|l|l|l|l|l|}
\hline 1 & 2 & 3 & 4 & 5 & 6 \\
\hline
\end{tabular}

57. Ich habe bei vielen Freunden Angst, daß sie mich alieine lassen, wenn ich sie brauche

\begin{tabular}{|l|l|l|l|l|}
\hline 2 & 3 & 4 & 5 & 6 \\
\hline
\end{tabular}

58. ich bin zu emptindich

\begin{tabular}{|l|l|l|l|l|l|}
\hline & 2 & 3 & 4 & 5 & 6 \\
\hline
\end{tabular}

9 ich glaube. daf ich in den meisten Falien mein Verhaten vor mit rechiffertigen kann.

\begin{tabular}{|l|l|l|l|l|l|}
\hline 1 & 2 & 3 & 4 & 5 & 6 \\
\hline
\end{tabular}

60. Meine persónlichen Probleme sind dazu da. um von mir gelóst zu werden.

\begin{tabular}{|l|l|l|l|l|l|}
\hline 1 & 2 & 3 & 4 & 5 & 6 \\
\hline
\end{tabular}

61 Ich habe Schwerigkeiten, das zu tun, was nichtig ist

\begin{tabular}{|l|l|l|l|l|l|}
\hline 1 & 2 & 3 & 4 & 5 & 6 \\
\hline
\end{tabular}

62. Ich sollie hollicher zu anderen sein

\begin{tabular}{|l|l|l|l|l|l|}
\hline 1 & 2 & 3 & 4 & 5 & 6 \\
\hline
\end{tabular}

53. Ich fichte mich in meinem Leben zu seht fach den Auttassungen anderer.

\begin{tabular}{|l|l|l|l|l|l|}
\hline 1 & 2 & 3 & 4 & 5 & 6 \\
\hline
\end{tabular}

64. Wenn ich mich mit anderen Menschen meines Alters vergleiche. schneide ich ei. gentlich ganz gut ab

65. Wenn ich so zurockderike, kanh ich mich an viel mehr MGerfolge als an Erfolge getinnern

66. Um mir keine Feinge zu schaffen, stimme ich haufiger auch Auttassungen und Entscheidungen zu die ich im Grunde nicht fur gut oder vertretbar haite. .

67. Ich habe keine Schwierigkeiten zuzugeben, das ich etwas fa'sch gemacht habe

68. Ich kann genauso gut zurechtkommen wie andere

\begin{tabular}{|l|l|l|l|l|}
\hline 2 & 3 & 4 & 5 & 6 \\
\hline
\end{tabular}

69 ich habe Furcht, ich selbst zu sein

\begin{tabular}{|l|l|l|l|l|l|}
\hline 1 & 2 & 3 & 4 & 5 & 6 \\
\hline
\end{tabular}

70 ich bin ziemlich scheu und unsicher im Kontakt mit anderen Mengchen.

\begin{tabular}{|l|l|l|l|l|l|}
\hline 1 & 2 & 3 & 4 & 5 & 6 \\
\hline
\end{tabular}

71. Ich finde mich ganz in Ordnung

\begin{tabular}{|l|l|l|l|l|l|}
\hline 1 & 2 & 3 & 4 & 5 & 6 \\
\hline
\end{tabular}

72 Es angstigt mich nicht, mit fremden Menschen zusammenzutreffen

\begin{tabular}{|l|l|l|l|l|l|}
\hline 1 & 2 & 3 & 4 & 5 & 6 \\
\hline
\end{tabular}

73 Mich wirtt $s 0$ schnel nichts aus der Bahn

\begin{tabular}{|l|l|l|l|l|l|}
\hline 1 & 2 & 3 & 4 & 5 & 6 \\
\hline
\end{tabular}

74 Ich habe oft das Getuhl, daB Fremde mich kritisch betrachten.

\begin{tabular}{l|l|l|l|l|l|}
1 & 2 & 3 & 4 & 5 & 6 \\
\hline
\end{tabular}

75. Ich bin zutrieden mit mir

\begin{tabular}{|l|l|l|l|l|l|}
\hline 1 & 2 & 3 & 4 & 5 & 6 \\
\hline
\end{tabular}

76. Ich kann Anschuldiqungen ertragen ohne gieich aus der Haut zu tahren. . . . . .

\begin{tabular}{l|l|l|l|l|l|}
1 & 2 & 3 & 4 & 5 & 6 \\
\hline
\end{tabular}

77. ich giaube, das ich genauso vel tauge wie andere.

\begin{tabular}{|l|l|l|l|l|l|}
\hline 1 & 2 & 3 & 4 & 5 & 6 \\
\hline
\end{tabular}

\begin{tabular}{|l|l|l|l|l|l|}
\hline 1 & 2 & 3 & 4 & 5 & 6 \\
\hline
\end{tabular} 
APPENDIX No. 4 


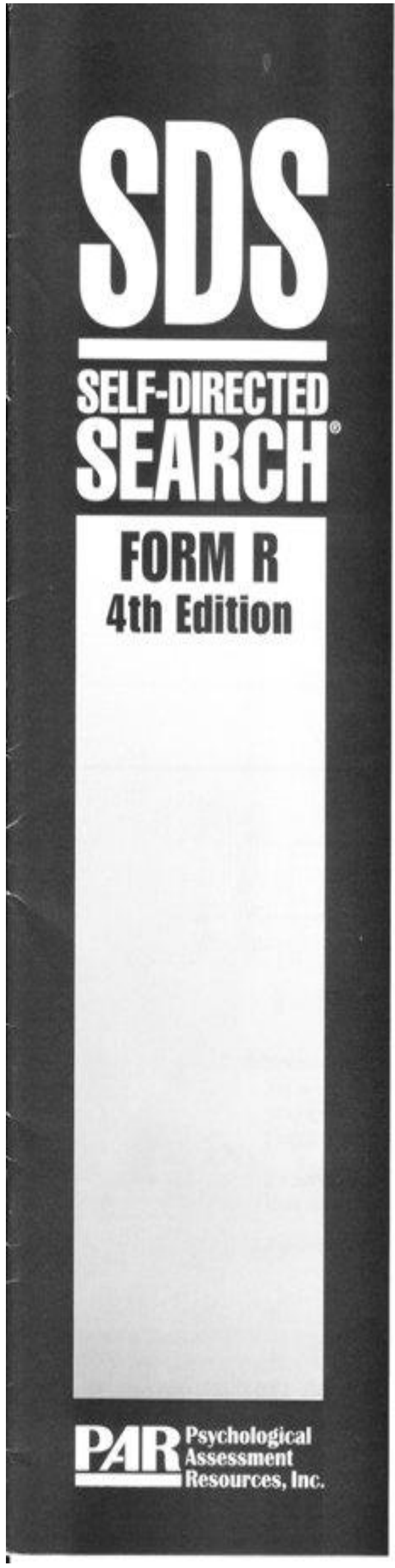

Name

\section{ASSESSMENT BOOKLET}

A Guide to Educational and Career Planning

By John L. Holland, PhD 
This booklet may help you explore what occupation to follow. If you have already made up your mind about an occupation, it may support your idea or suggest other possibilities. If you are uncertain about what occupation to follow, the booklet may help you to locate a small group of occupations for further consideration. Most people find that filling out this booklet is helpful and fun. If you follow the directions carefully, page by page, you should enjoy the experience. Do not rush; you will gain more by approaching the task thoughtfully. Use a lead pencil, so you can erase easily.

Name

Age Sex Date

Years of education completed

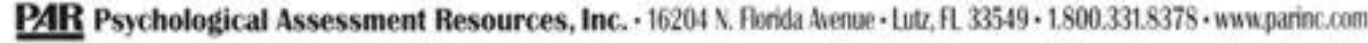

Copyright $0.1970,1977,1985,1990,1994$ by Pychological Assessment Resources, Inc. All rights resened. May not be reproduced in whols or in part in any form or by any means without written permission of Psychological Assessment Resources. Inc.

987654321

Ricorder $\#$ RO-2754

Printed in the U.S. 


\section{Occupational Daydreams}

1. List below the occupations you have considered in thinking about your future. List the careers you have daydreamed about as well as those you have discussed with others. Try to give a history of your daydreams. Put your most recent choice on Line 1 and work bachwards to the ear. lier jobs you have considered.

\section{Occupation}

Code

1.
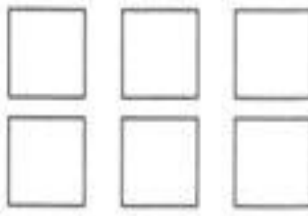

2.
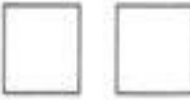

3.
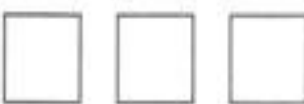

4.
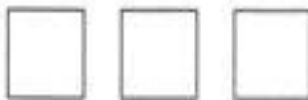

5.
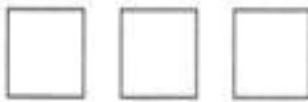

6.
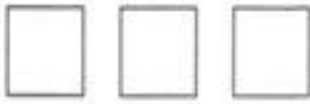

7.
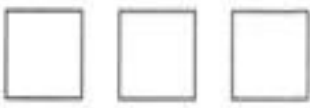

8.
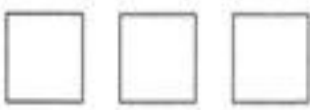

2. Now use The Occupations Finder. Locate the three-letter code for each of the occupations you just wrote down. This search for occupational codes will help you learn about the many occupations in the world. This task usually takes from 5 to 15 minutes. The Alphabetized Occupations Finder, which is available separately, may make your search easier.

If you can't find the exact occupation in The Occupations Finder, use the oxcupation that seems most like your occupational aspiration.

If you re in a hurry, do the coding after you complete this booklet. 


\section{Activities}

Blacken under $\mathbf{L}$ for those activities you would like to do. Blacken under $\mathbf{D}$ for those things you would dislike doing or would be indifferent to.

$\mathbf{R}$

Fix electrical things

Repair cars

Fix mechanical things

Build things with wood

Take a Technology Education (e.g., Industrial Arts, Shop) course

Take a Mechanical Drawing course

Take a Woodworking course

Take an Auto Mechanics course

Work with an outstanding mechanic or technician

Work outdoors

Operate motorized machines or equipment

Total No. of Ls

I

L D

Read scientific books or masazines

Work in a research office or laboratory

Work on a scientific project

Study a scientific theory

Work with chemicals

Apply mathematics to practical problems

Take a Physics course

Take a Chemistry course

Take a Mathematics course

Take a Biology course

Study scholarly or technical problems

Total No, of Is

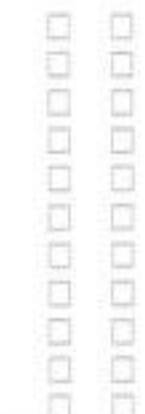




\section{S}

Meet important educators or therapists

Read sociology articles or books

Work for a charity

Help others with their personal problems

Study juvenile delinguency

Read psychology articles or bocks

Take a Human Relations course

Teach in a high school

Supervise activities for mentally ill patients

Teach adults

Work as a volunteer

Total No, of Ls

$\mathbf{E}$

L D

Learn strategies for business success

Operate my own service or business

Attend sales conferences

Take a short course on administration or leadership

Senve as an officer of any group

Supervise the work of others

Meet important executives and leaders

Lead a group in accomplishing some goal

Participate in a political campaign

Act as an organizational or business consultant

Read business magazines or articles

Total No, of Ls

C

L D

Fill out income tax forms

Add, subtract. multiply, and divide numbers in business or bookkeeping

Operate office machines

Keep detailed records of expenses

Set up a record-keeping system

Take an Accounting course

Take a Commercial Math course

Take an inventory of supplies or products

Check paperwork or products for errors or flaws

Update records or files

Work in an office

Total No, of Ls 


\section{Competencies}

Blacken under $\mathrm{Y}$ for "Yes" for those activities you can do well or competently. Blacken under $\mathbf{N}$ for "No" for those activities you have never performed or perform poorly.

$\mathbf{R}$

1 have used wood shop power tools such as a power saw, lathe, or sander I can make a scale drawing

I can change a car's oil or tire.

I have operated power tools such as a drill press, grinder, or sewing machine

I can refinish furniture or woodwork

I can make simple electrical repairs

I can repair furniture

I can use many carpentry tools

I can make simple plumbing repairs

I can build simple articles of wood

I can paint rooms of a house or an apartment

Total No. of Ys

I

Y N

I can use algebra to solve mathematical problems I can perform a scientific experiment or survey I understand the "half-life" of a radioactive element I can use logarithmic tables

I can use a computer to study a scientific problem I can describe the function of the white blood cells I can interpret simple chemical formulae I understand why man-made satellites do not fall to earth I can write a scientific report I understand the "Big Bang" theory of the universe I understand the role of DNA in genetics

Total No. of Ys

A

I can play a musical instrument

I can participate in two- or four-part choral singing

I can perform as a musical soloist

I can act in a play

I can do interpretive reading

I can do a painting, watercolor, or sculpture

I can arrange or compose music

I can design clothing. posters, or furniture

I write stories or poetry well

I can write a speech

I can take attractive photographs

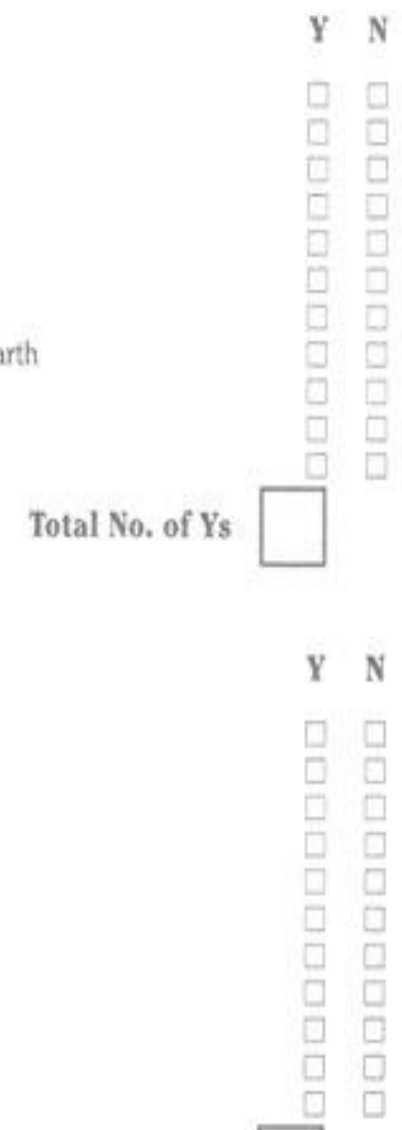

Total No. of Ys 
I find it easy to talk with all kinds of people

I am good at explaining things to others

I could work as a neighborhood organizer

People seek me out to tell me their troubles

I can teach children easily

I can teach adults easily

I am good at helping people who are upset or troubled

t have a good understanding of social relationships

I am good at teaching others

I am good at making people feel at ease

I am much better at working with people than with things or ideas

Total No, of Ys

$\mathbf{E}$

I know how to be a successful leader

I am a good public speaker

I can manage a sales campaign

I can organize the work of others

I am an ambitious and assertive person

I am good at getting people to do things my way

I am a good salesperson

I am a good debater

I can be very persuasive

I have good planning skills

I have some leadership skills

C

Total No. of Ys

I can file correspondence and other papers

I have held an office job

I can use an automated posting machine

t can do a lot of papenwork in a short time

I can use simple data processing equipment

1 can post credits and debits

I can keep accurate records of payment or sales

I can enter information at a computer terminal

I can write business letters

I can perform some routine office activities

I am a careful and orderly person

Total No. of Ys 


\section{Occupations}

This is an inventory of your feelings and attitudes about many kinds of work. Show the occupations that interest or appeal to you by blackening under $\mathbf{Y}$ for "Yes." Show the occupations that you dislike or find uninteresting by blackening under $\mathbf{N}$ for "No."

\begin{tabular}{|c|c|}
\hline & $\mathbf{Y}$ \\
\hline Airplane Mechanic & $\square$ \\
\hline Auto Mechanic & $\square$ \\
\hline Carpenter & $\square$ \\
\hline Truck Driver & $\square$ \\
\hline Sunveyor & $\square$ \\
\hline Construction Inspector & $\square$ \\
\hline Radio Mechanic & $\square$ \\
\hline Locomotive Engineer & $\square$ \\
\hline Machinist & $\square$ \\
\hline Electrician & $\square$ \\
\hline Farmer & $\square$ \\
\hline Helicopter Pilot & 맘 \\
\hline Electronic Technician & $\square$ \\
\hline Welder & a \\
\hline
\end{tabular}

Total R Ys

Career Counselor

Sociologist

High School Teacher

Substance Abuse Counselor

Juvenile Delinquency Expert

Speech Therapist

Marriage Counselor

Clinical Psychologist

Social Science Teacher

Personal Counselor

Youth Camp Director

Social Worker

Rehabilitation Counselor

Playground Director

Total $\mathbf{S}_{\mathbf{~}}$

Meteorologist

Biologist

Astronomer

Medical Laboratory Technician

Anthropologist

Chemist

Independent Research Scientist

Writer of Scientific Articles

Geologist

Botanist

Scientific Research Worker

Physicist

Social Science Researcher

Environmental Analyst

Total I Ys

Y N

Rs.

Total SYs

Buyer

Advertising Executive

Manufacturer's Representative

Business Executive

Master of Ceremonies

Salesperson

Real Estate Salesperson

Department Store Manager

Sales Manager

Public Relations Executive

TV Station Manager

Small Business Owner

Legislator

Airport Manager

Total E Ys

Poet

Musician

Novelist

Actor/Actress

Free-Lance Writer

Musical Arranger

Journalist

Artist

Singer

Composer

Sculptor/Sculptress

Playwright

Cartoonist

Entertainer

\begin{tabular}{|c|c|c|}
\hline & & \\
\hline$\square$ & $\square$ & Bookkeeper \\
\hline 문 & $\square$ & Budget Reviewer \\
\hline$\square$ & $\square$ & Certified Public Accountant \\
\hline (7) & (7) & Credit Investi反ator \\
\hline$\square$ & $\square$ & Bank Teller \\
\hline$\square$ & $\square$ & Tax Expert \\
\hline (1) & $\square$ & Inventory Controller. \\
\hline$\square$ & $\square$ & Computer Operator \\
\hline$\square$ & $\square$ & Financial Analyst \\
\hline [ & $\square$ & Cost Estimator \\
\hline$\square$ & $\square$ & Payroll Clerk \\
\hline$\square$ & $\square$ & Bank Examiner \\
\hline$\square$ & $\square$ & Accounting Clerk \\
\hline [1] & $\square$ & Audit Clerk \\
\hline
\end{tabular}

Total A Ys

Total $\mathrm{C}_{\text {Ys }}$ 
Self-Estimates

1. Rate yourself on each of the following traits as you really think you are when compared with other persons your oun age. Give the most accurate estimate of how you see yourself. Circle the appropriate number and avoid rating yourself the same in each ability.

\begin{tabular}{l|cccccc|}
\multicolumn{1}{c}{} & $\begin{array}{c}\text { Mechanical } \\
\text { Ability }\end{array}$ & $\begin{array}{c}\text { Scientific } \\
\text { Ability }\end{array}$ & $\begin{array}{c}\text { Artistic } \\
\text { Ability }\end{array}$ & $\begin{array}{c}\text { Teaching } \\
\text { Ability }\end{array}$ & $\begin{array}{c}\text { Sales } \\
\text { Ability }\end{array}$ & $\begin{array}{c}\text { Clerical } \\
\text { Ability }\end{array}$ \\
\cline { 2 - 7 } High & 7 & 7 & 7 & 7 & 7 & 7 \\
& 6 & 6 & 6 & 6 & 6 & 6 \\
Average & 5 & 5 & 5 & 5 & 5 & 5 \\
& 4 & 4 & 4 & 4 & 4 & 4 \\
& 3 & 3 & 3 & 3 & 3 & 3 \\
\multirow{4}{*}{ Low } & 2 & 2 & 2 & 2 & 2 & 2 \\
& 1 & 1 & 1 & 1 & 1 & 1 \\
\hline
\end{tabular}

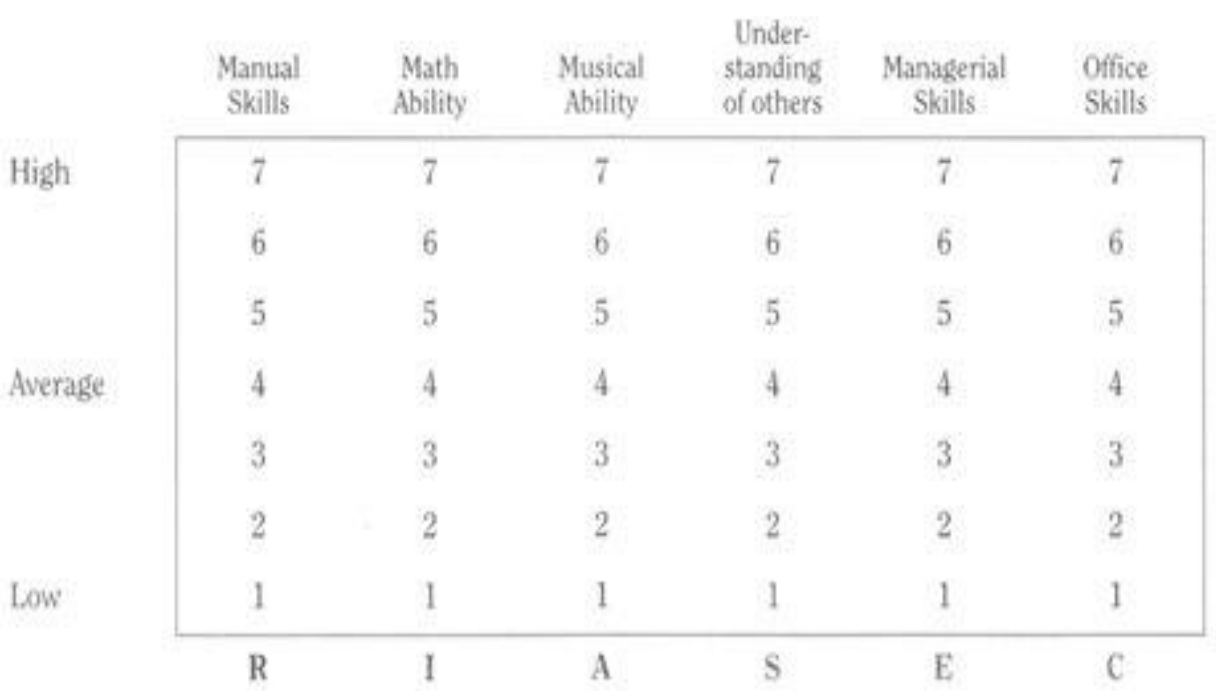




\section{How To Organize Your Answers}

Start on page 4. Count how many times you said $\mathrm{L}$ for "Like." Record the number of $\mathrm{Ls}$ or Ys for each group of Activities, Competencies, or Occupations on the lines below.

Activities (pp. 4-5)

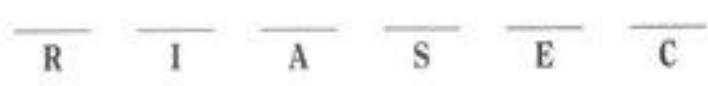

Competencies (pp, 6-7)

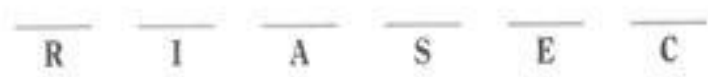

Occupations (p. 8)

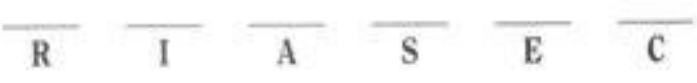

Self-Estimates (p, 9)

(What number did

you circle?

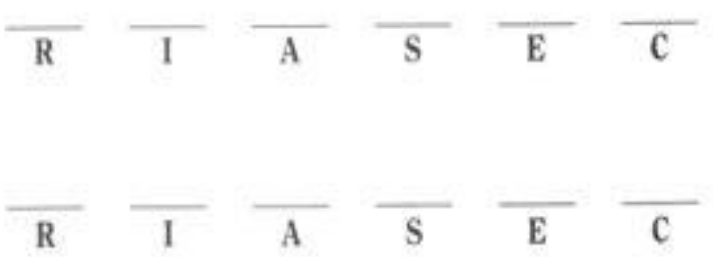

Total Scores

(Add the five R scores.

the five I scores, the

five A scores, etc.)

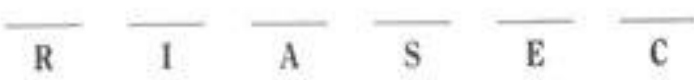

The letters with the three highest numbers indicate your Summary Code. Write your Summary Code below. (If two scores are the same or tied, put both letters in the same box.)

\section{Summary Code}

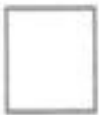

Highest

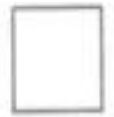

2nd

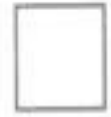

3rd 


\section{What Your Summary Code Means}

Your Summary Code is a simple way of organizing information about people and jobs. It can be used to discover how your special pattern of interests, self-estimates, and competencies resembles the patterns of interests and competencies that many occupations demand. In this way, your Summary Code locates suitable groups of occupations for you to consider.

It is vital that you search The Occupations Finder for every possible ordering of your three-letter code. For example, if you are an ESC, search for all the ESC. ECS, SEC. SCE. CES, and CSE occupations by completing Steps 1 and 2 .

Step 1. Find the occupations whose codes are identical with yours and list those occupations that are of interest to you. If your code is SEI, occupations with codes SEI are identical. Co to Step 2. whether or not you find an occupation with a code identical to yours.

Summary Code

0ccupation

Education

Occupation

Education

Step 2. Make a list of occupations whose Summary Codes nesemble yours, Search the Occupations Finder for the five arrangements of your code. For example, if your code is IRE, search for occupations with codes of IER, RIE, REI, EIR, and ERL. Start by writing down the five possible letter arrangements of your Summary Code. (If your Summany Code includes a tie such as RIEA, you must look up more letter combinations and their arrangements.)

\section{Similar Codes}

\section{Occupation Education Occupation}

Go to the Next Page 


\section{Some Next Steps}

1. The SDS is most useful when it reassures you about your vocational choice or reveals new possibilities worthy of consideration. If it fails to support a choice or an anticipated job change, don't automatically change your plans. Instead, do some investigation to make sure you understand the career you have chosen and the occupations suggested by the SDS.

2. Compare your Summary Code with the codes for your Occupational Daydreams on page 3. They should be similar, but it is not necessary that your SDS code matches your aspirational or job code-letter for letter. Occupations tolerate a variety of types. It is important that your three-letter code at least resembles the three-letter code of your faworite occupational choice. For example, your SDS code is RIE, and the occupation you aspire to is coded IRC. Other examples of strong to moderate resemblance would include occupational codes of RLA EIR. RSA. If you can see no relation between your SDS code and your aspiration, you should examine your potential satisfaction for that occupation with a counselor or a iriend.

3. Investigate the educational requirements for the occupations that interest you. Go back to The Occupations Finder and find out how much education or training is required for each occupation you listed earlier. Where could you obtain the required training? Is it financially possible? Is it reasonable in terms of your learning ability, age, family situation?

4. Consider any health or physical limitations that might affect your choice and how you can or would cope with them.

5. Seek more information about occupations from local counseling centers, school counselors, libraries, labor unions, employment services, and occupational information files (usually found in counseling offices). Talk to people employed in the occupations in which you are especially interested. Most people enjoy talking about their work. Remember, however, that they may have personal biases, so talk to several people in the same occupation. Try to obtain part-time work experience that is similar to the activities in the occupations you are considering. Read articles and books that describe occupations or attempt to explain current scientific knowledge about the choice of an occupation. Some suggestions are listed on page 13

6. Remember that your results on the SDS are affected by mary factors in your background-your sex, your age, your parents' occupations, and ethnic or racial influences. For example, because society often encourages men and women to aspire to different vocations, women receive more $\mathbf{S}$. A and $\mathbf{C}$ codes than men, while men obtain more $\mathbf{I}, \mathbf{R}$, and $\mathbf{E}$ codes. Yet we know that almost all jobs can be successfully performed by members of either sex. If your codes differ from your Occupational Daydreams, keep those influences in mind; they may account for the differences, and you may decide to stick with your Daydreams.

7. Remember, no one but you can make your vocational decision. Our knowledge of careers is too limited to provide you with a single, exact choice, but we can help you focus on some of the more likely possibilities. 


\section{Some Useful Books}

Anthony, R. J., \& Roe, G. (1991). Over 40 and looking for work: A guide for the tememployed, underomployed, and unhappily employed. Holbrook, MA: B. Adams.

Bolles, R. N. (1994). What color is your parachute? A practical mamual for jab hunters and career changers. Berkeley, CA: Ten Speed Press.

Carney, C. \& Wells, C, (1991). Disconer the career within you (3rd ed.). Pacific Grove, CA: Brooks/Cole.

Farr, J. M. (1993). The complete guide for occupational exploration. Indianapolis, IN: JST Works.

Field, S. (1992). 100 best careers for the year 2000. New York: Prentice Hall.

Figler, H. (1988). The complete job-search handbook. New York: Henry Holt and Company.

Gottiredson, G, D., \& Holland, J, L. (1989). Dictionary of Holland accupational codes (2nd ed.). Odessa, FL: Psychological Assessment Resources.

Harkavy, M. D. (1990), 101 careers: A guide to the fastest-grouing opportunities. New York: Wiley.

Holland, J. L. (1992). Making vocational choices: A theory of tocational personalities and work enrironments. Odessa, FL: Psychological Assessment Resources.

Hopke, W. E. (1993). The encyclopedia of careers and vocational guidance (9th ed.). Chicako: I. G. Ferguson Pub.

Krannich, R. L. (1993), Careering and re-careering for the 1990s (3rd ed.). Manassas Park, VA: Impact Publications.

Medley, H. A. (1992), Stueaty palms: The neglected art of being intervieured. Berkeley, CA: Ten Speed Press.

Moore, D. f., with VanderWey, S. (1994). Take charge of your oun carcer: A guide to federal employment. Odessa, FL: Psychological Assessment Resources.

Need a lift?' Educational opportunities, careers, loans, scholarships, employment. (1993). Indianapolis; The American Legion. (These inexpensive booklets are published every year and may be ordered from The American Legion, National Emblem Soles, P.0. Box 1050, Indianapolis, IN, 46206.

Petras, K. (1993). Jobs 94 . New York: Simon \& Schuster.

Savage, K. M., \& Novallo, A. (Eds.). (1992), Professional caners sourcebook (2nd ed.), Detroit, Ml: Gale Research.

Shahnasarian, M. (1993). Decision time, Odessa, FL: Psychological Assessment Resources.

Sher, B, \& Cottlieb, A. (1979). Wishcruft: How to get what you really wount. New York: Viking Press.

U.S. Department of Labor, Bureau of Labor Statistics, (1992-1993). Occupational outlook handhook. Washington, DC: U.S. Gowemment Printing Office. (This handbook is published every two years and is the best single source for information about occupations, See your counselor or librany, or order from Superintendent of Documents, U.S. Gowernment Printing Oifice, Washington. DC, 20402.)

Witt, M. A. (1992), Job strategies for people with disabilities: Enable yourself for today's job market. Princeton, N): Peterson's Guides. 


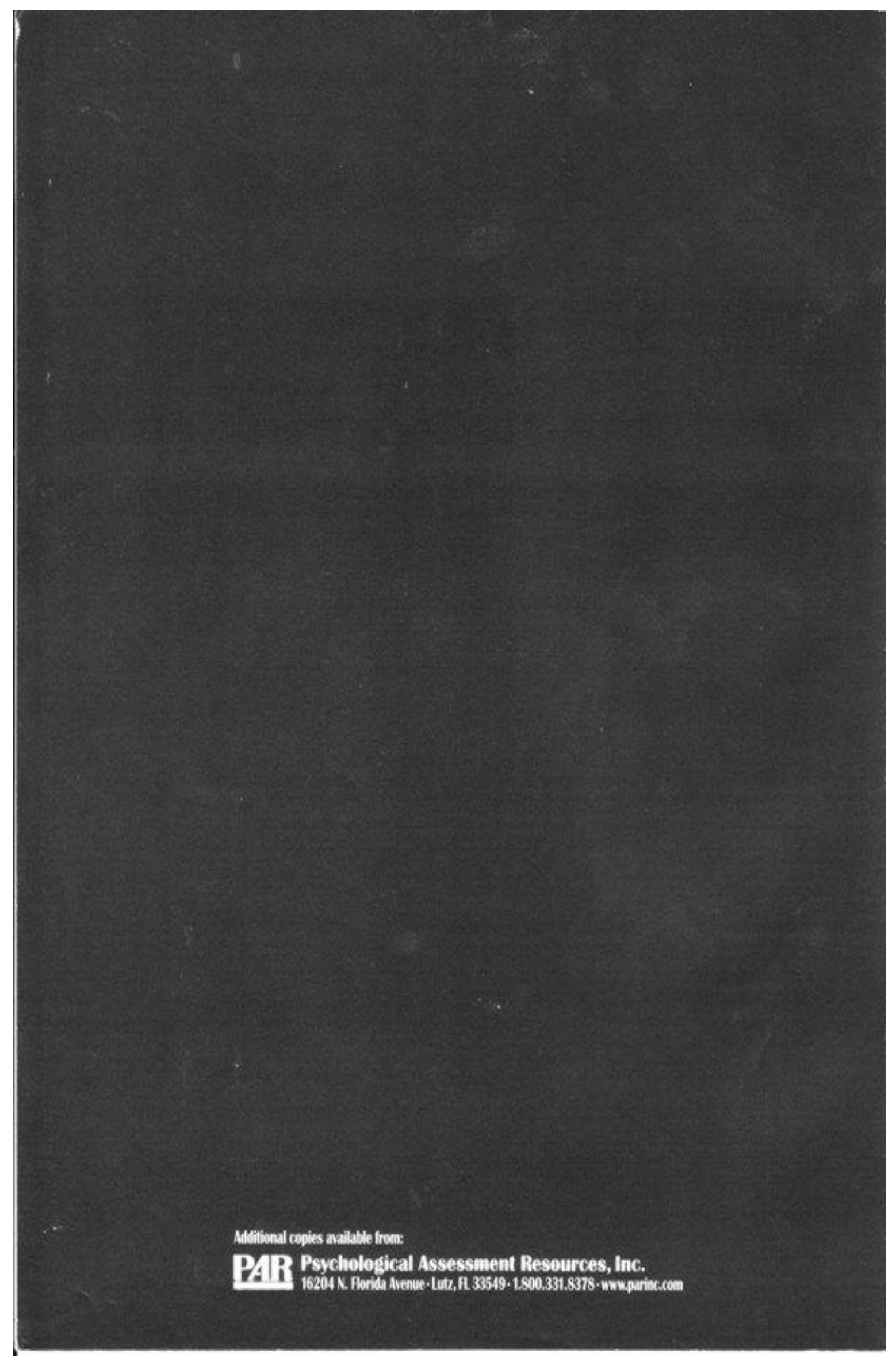


APPENDIX No. 5 


\section{Interview Guideline}

Before

1. What is / was your motivation for studying abroad?

2. What do you expect from your study abroad experience?

3. In reference to your career choice, how do you expect your experience abroad to contribute to your career?

4. Do you think that study abroad will strengthen your vocational choice? Why and how?

5. What are your weakness and strengths for studying abroad?

6. How do you describe yourself?

7. What are your strengths \& weaknesses in regard to your career choice?

8. How do you visualize yourself in the future?

9. Is there anything that you wanted to share?

After

1. How do you describe you study abroad experience?

2. Do you think that study abroad reinforced your vocational choice (career that you wanted fulfill)?

3. What motivated you most during your study abroad program?

4. What was the most important thing you learned and experienced in your study abroad program?

5. What was the greatest contribution (persons, event and/or activity) to your career choice?

6. Did your study abroad strengthen or weaken your career choice? Why and how?

7. Can you mention after your experience abroad the changes that encountered in your person?

8. Are does changes supporting you in your vocational career development?

9. How do you describe yourself now after you study abroad experience?

10. How do you visualize you self in the future? 
APPENDIX No. 6 


\section{$1^{\text {st }}$ Interview with Sara (F1)}

\begin{tabular}{|c|c|}
\hline $\begin{array}{l}\text { What is or what was your } \\
\text { motivation for studying } \\
\text { abroad? }\end{array}$ & $\begin{array}{l}\text { My motivation was definitely to discover and learn about } \\
\text { different cultures and meeting different people, from which I can } \\
\text { learn different things from. }\end{array}$ \\
\hline $\begin{array}{l}\text { What do you expect from } \\
\text { your studying abroad } \\
\text { experience? }\end{array}$ & $\begin{array}{l}\text { Well, I definitely expect to get a better idea of everybody else } \\
\text { around me, and what different cultures are like, and to just } \\
\text { become a better well rounded, more responsible person. }\end{array}$ \\
\hline $\begin{array}{l}\text { In reference to your career } \\
\text { choices, how do you expect } \\
\text { your experience abroad to } \\
\text { contribute to your career? }\end{array}$ & $\begin{array}{l}\text { Well, marketing is definitely all about communication. So, if I } \\
\text { speak three different languages, then I will be able to market any } \\
\text { product with people who speak Spanish, English or French. }\end{array}$ \\
\hline $\begin{array}{l}\text { Do you think that the study } \\
\text { abroad will strengthen your } \\
\text { vocational choice? }\end{array}$ & Definitely \\
\hline Why? & $\begin{array}{l}\text { Because I think it'll make me, it'll strengthen it because, like I } \\
\text { said, marketing is all, I think a lot of marketing, is all about } \\
\text { communication, and getting out there talking to people, and if I } \\
\text { can learn to speak to people which I'm not very fluent with their } \\
\text { language, then it will make me feel like I can communicate with } \\
\text { anybody and market any product. }\end{array}$ \\
\hline $\begin{array}{l}\text { What are your weaknesses } \\
\text { and strengths regarding } \\
\text { studying abroad? }\end{array}$ & $\begin{array}{l}\text { My weakness is that I'm pretty, and I'm very impatient, and I'd } \\
\text { rather run than walk slow. I think that might hurt me a little bit, } \\
\text { and I think my strength is, I think, I can basically make friends } \\
\text { with anybody, and I'm very committed if I set a goal, I am very } \\
\text { committed to reaching that goal. }\end{array}$ \\
\hline $\begin{array}{l}\text { Coming back to your career } \\
\text { choice, what are your } \\
\text { strengths and weaknesses in } \\
\text { regards to your career choice? }\end{array}$ & $\begin{array}{l}\text { Well, my strength is that I can communicate with people, and I } \\
\text { can ask around, and see what it is that everybody is looking for, } \\
\text { that's not hard for me, and I would say again that my weakness } \\
\text { is that I am very impatient, and I don't like to work slow, and I } \\
\text { know that sometimes, where you're marketing things are slow, } \\
\text { it's not as fast paced as I would like it to be. }\end{array}$ \\
\hline $\begin{array}{l}\text { Do you think that your study } \\
\text { abroad experience being in } \\
\text { another culture and country } \\
\text { would help you in identifying } \\
\text { yourself? }\end{array}$ & With myself, yes. \\
\hline $\begin{array}{l}\text { How? How do you describe } \\
\text { yourself? }\end{array}$ & Goal oriented. Determined. \\
\hline $\begin{array}{l}\text { How do you visualize } \\
\text { yourself in the future? }\end{array}$ & Successful! \\
\hline
\end{tabular}




\section{$2^{\text {nd }}$ Interview with Sara (F1)}

\begin{tabular}{|c|c|}
\hline $\begin{array}{l}\text { How do you } \\
\text { describe your study } \\
\text { abroad experience? }\end{array}$ & $\begin{array}{l}\text { Amazing. It was what I expected, and more. It was just sort of a culture } \\
\text { shock, at the beginning, but then I think, it changed me and the way I view } \\
\text { things and people in general. Like, now that I'm back. }\end{array}$ \\
\hline $\begin{array}{l}\text { Can you please tell } \\
\text { me in another word } \\
\text { what changes you } \\
\text { are talking about? }\end{array}$ & $\begin{array}{l}\text { I mean, I'm more open to different cultures now. I'm more understanding, } \\
\text { I take advantage of the things that I have here now, like over there it was } \\
\text { my first time living on my own, and then everything is really different, and } \\
\text { I had to do things on my own in a different culture, and there was a huge } \\
\text { language barrier so I kind of understood, how some people are here, you } \\
\text { know there is a big language barrier, and it made me more, not more } \\
\text { outspoken but less shy, because over there you have to speak up for } \\
\text { yourself to go do things by yourself in a different language and not having } \\
\text { someone there all the time, like your mom and dad comforting you, and } \\
\text { now I'm just more, I take advantage of my opportunities, like I'm not } \\
\text { afraid to raise my hand in class because I'm scared someone is going to } \\
\text { think something about me and cause you know, its really different, I think } \\
\text { it makes you grow up, it makes you more open. }\end{array}$ \\
\hline $\begin{array}{l}\text { Can you tell me } \\
\text { what differences } \\
\text { you've noticed in } \\
\text { yourself? }\end{array}$ & $\begin{array}{l}\text { Well for one in the classes I'm, well a lot of the times when they're talking } \\
\text { about different cultures I understand now, like I said I raise my hand now, } \\
\text { I'm less shy, I'll say something because I feel like I can, you know when I } \\
\text { was over there I traveled to a different country to myself and you know } \\
\text { alone so now I feel like, I don't know how to explain it, just not be shy, in } \\
\text { the classroom it helped me very much, at home it has as well because I just } \\
\text { feel like I've had the opportunity to see so many things and to share them } \\
\text { with other people, like I share my experiences with everybody and I let } \\
\text { them know that there is more to life than the valley and Texas and the } \\
\text { United States. I just feel I'm more open to different cultures and people. }\end{array}$ \\
\hline $\begin{array}{l}\text { Do you feel that } \\
\text { you are more } \\
\text { identified with } \\
\text { yourself? }\end{array}$ & $\begin{array}{l}\text { Yes, and you know what, it kind of helped me realize that I want to expand } \\
\text { the things that I'm learning, I want to go study abroad again. Just the way } \\
\text { that people teach different things, it's helped me realize that I shouldn't } \\
\text { limit myself, shouldn't limit my goals, because now I know that if I can } \\
\text { make it through France by myself without getting lost and with a huge } \\
\text { language barrier I think I should set my goals higher than what they were. }\end{array}$ \\
\hline $\begin{array}{l}\text { So now you think } \\
\text { everything is } \\
\text { possible? }\end{array}$ & Yes, trying. \\
\hline $\begin{array}{l}\text { What made you } \\
\text { different from other } \\
\text { people who haven't } \\
\text { gone study abroad? }\end{array}$ & $\begin{array}{l}\text { I think I'm more open minded than a lot of other people. Not to say that I } \\
\text { try harder, I know some people slack off at school, and take everything for } \\
\text { granted, but I think to myself you take it for granted because it's so easy } \\
\text { and everything is in English, and you can understand it, and you don't } \\
\text { have to try extra to understand the things [language]. I don't know how to } \\
\text { explain it, you know I've made friends from all over the world, I made } \\
\text { friends from Greece, India, Italy and they've taught me like a lot of things } \\
\text { as well about their culture and their history. I feel like I'm not afraid, you } \\
\text { know, here some people are afraid of saying something, like in class, } \\
\text { because here everybody is so closed minded that people are afraid of how } \\
\text { other people are going to react, and since I feel like I've been in an open } \\
\text { minded environment I don't hold myself back, I just say whatever is on my }\end{array}$ \\
\hline
\end{tabular}




\begin{tabular}{|c|c|}
\hline & mind. \\
\hline $\begin{array}{l}\text { Are you proud of } \\
\text { yourself? }\end{array}$ & $\begin{array}{l}\text { Yes, I'm very proud of myself. I'm proud because my parents are proud, } \\
\text { and that makes me proud. }\end{array}$ \\
\hline $\begin{array}{l}\text { What motivated } \\
\text { you most to go } \\
\text { study abroad, and } \\
\text { also while you } \\
\text { where there? }\end{array}$ & $\begin{array}{l}\text { Ok, to go study abroad I really just wanted something different. I really } \\
\text { didn't know what to expect, I wanted to get out of the valley to begin with, } \\
\text { and I figured, minor in French, I had the opportunity to go, and why not } \\
\text { and I just wanted something out of the ordinary something spontaneous. } \\
\text { The people that I met there [in France] at school were the people that } \\
\text { motivated me there. There was people that spoke five different languages, } \\
\text { it motivated me knowing that there was people out there that were putting } \\
\text { everything into learning a new language and traveling and some of them } \\
\text { got to travel to a lot of different countries and go to school there because } \\
\text { they knew a lot of different languages so it motivated me to try harder and } \\
\text { try to do better in school and to learn the language as well. }\end{array}$ \\
\hline $\begin{array}{l}\text { The fact that you } \\
\text { chose to go study } \\
\text { abroad, have you } \\
\text { done it for your } \\
\text { personal } \\
\text { development or } \\
\text { your career } \\
\text { development? }\end{array}$ & $\begin{array}{l}\text { I think, I did [going abroad] for both [personal and career development], } \\
\text { because I speak Spanish and English and a little bit of French and I know } \\
\text { that is going to help me a little bit. My sister's friend got a job offer in } \\
\text { Switzerland, and I think for the career part, it would help me. I wanted to } \\
\text { learn French since I was in elementary school, since, the lady that would } \\
\text { babysit me, when I was in elementary, taught me some [French], and I } \\
\text { remembered it. I never thought I was going to go to France to learn French } \\
\text { and I did it for myself, I thought, it was going to make me more open and } \\
\text { it did everything it thought it was going to make me do. }\end{array}$ \\
\hline $\begin{array}{l}\text { What was the most } \\
\text { important thing that } \\
\text { you have learned or } \\
\text { experienced in your } \\
\text { study abroad? }\end{array}$ & $\begin{array}{l}\text { It sounds corny but don't be afraid to be yourself. All the people over there } \\
\text { were their own person, they all had their different style they all, they } \\
\text { disagreed but they didn't argue, they spoke about it, somebody had pink } \\
\text { hair and no one would stare and it made them happy so if it makes you } \\
\text { happy just go with it, I really don't mind other people's opinion's to a } \\
\text { certain extent, just be yourself and be happy. }\end{array}$ \\
\hline $\begin{array}{l}\text { Do you feel that } \\
\text { your study abroad } \\
\text { experience } \\
\text { strengthened your } \\
\text { career choice? }\end{array}$ & $\begin{array}{l}\text { Well I'm majoring in business and I know that is funny but business is } \\
\text { different in any country that you go to, people's mannerisms you know } \\
\text { they way they handle and they deal with their business and I know it's } \\
\text { going to help me a lot because I'll know when you do business with him } \\
\text { you got to act this way and when you do business with this other person } \\
\text { this other way, this is rude in this culture this is not rude, etcetera, I think } \\
\text { it'll look good in my resume that I've studied in France for a semester, } \\
\text { speaks three languages, I think it'll be pretty good. }\end{array}$ \\
\hline $\begin{array}{l}\text { Now, do you feel } \\
\text { that your } \\
\text { experience } \\
\text { weakened your } \\
\text { career somehow? }\end{array}$ & $\begin{array}{l}\text { Yes, I feel it strengthened it but I also feel it weakened it as well because it } \\
\text { kind of made me want to do something different. You know, going over } \\
\text { there it kind of made me want to study not study, but it made me want to } \\
\text { steer in a different direction, I really liked history, I really liked. What else } \\
\text { was it that I really liked. It kind of made me want to not study business but } \\
\text { instead study something a little bit more open like sociology or something } \\
\text { and it kind of got me confused for a while and I'm kind of at the point } \\
\text { where I have to decide what I want to do that, and I was kind of steering } \\
\text { towards sociology, like I wanted to study people and I wanted to study } \\
\text { everybody's different cultures and why everybody is the way they are } \\
\text { because I was so amazed when I got there, you know like you hear all } \\
\text { these different stereotypes of all these different types of people and you're }\end{array}$ \\
\hline
\end{tabular}




\begin{tabular}{|c|c|}
\hline & $\begin{array}{l}\text { like no that isn't true and then you get there and you're like wow, its } \\
\text { almost like a culture shock, it is a culture shock, and I just wanted to study } \\
\text { people after seeing so many different kinds of people and I feel like that } \\
\text { weakened me in business a little bit, but I ended up sticking with business. }\end{array}$ \\
\hline $\begin{array}{l}\text { Don't you think } \\
\text { that instead of } \\
\text { seeing it as a } \\
\text { weakness you } \\
\text { could say that it } \\
\text { reinforced your } \\
\text { vocational interest? }\end{array}$ & Yes it did. \\
\hline $\begin{array}{l}\text { Do you feel that } \\
\text { something was } \\
\text { missing in the } \\
\text { program or the } \\
\text { experience? How } \\
\text { could things have } \\
\text { been different or } \\
\text { better? }\end{array}$ & $\begin{array}{l}\text { The only thing that I would want to change would be the teaching method } \\
\text { from there and here, it is very different, there is like no relationship about } \\
\text { the relationship of teacher and student. It was like I will meet with you for } \\
\text { class today and you'll have a test tomorrow. That was the only thing I } \\
\text { really didn't like. A lot of the stuff was like figure it out on your own, but I } \\
\text { kind of liked it like that because it kind of makes you go out and discover } \\
\text { where you are living and stuff but the only thing was, just one of the } \\
\text { courses, the language courses I liked them, I had the class at the university } \\
\text { and I really didn't like it. It was an American literature class and I just } \\
\text { didn't like it at all. I dreaded going to that class, I still passed it, but I } \\
\text { didn't like it at all. }\end{array}$ \\
\hline $\begin{array}{l}\text { Did you like it at } \\
\text { the language } \\
\text { institutes? }\end{array}$ & $\begin{array}{l}\text { Yes, because everybody speaks different languages, and you have to speak } \\
\text { to them in the language that you are learning, it was kind of funny } \\
\text { sometimes too because I would say the wrong thing sometimes and it was } \\
\text { a fun class because you just don't write down stuff and listen to the } \\
\text { professor, it's kind of hand on, you have to talk to everybody, it was nice } \\
\text { and the classes weren't big, it was a small class and you weren't } \\
\text { embarrassed if you messed up when you were speaking, it was nice. }\end{array}$ \\
\hline $\begin{array}{l}\text { Are you satisfied } \\
\text { with your career } \\
\text { choice right now? I } \\
\text { believe you already } \\
\text { mentioned it but } \\
\text { can you summarize } \\
\text { it. }\end{array}$ & $\begin{array}{l}\text { Yes, I am, business kind of makes the world go around. I decided I would } \\
\text { study sociology on the side, like on my own on my leisure time and not to } \\
\text { go to a class or earn a degree on it, and I think it helps me with my } \\
\text { business degree as well because you know you have to incorporate it when } \\
\text { you're doing business, like marketing with international stuff so I think it } \\
\text { helps me out like knowing that people are different and I think it'll help } \\
\text { me understand people as someone who doesn't know anything. }\end{array}$ \\
\hline $\begin{array}{l}\text { How do you see } \\
\text { yourself in the } \\
\text { future? }\end{array}$ & $\begin{array}{l}\text { Working overseas, or maybe here as I finally graduate, but eventually } \\
\text { moving over there. }\end{array}$ \\
\hline $\begin{array}{l}\text { Your visualization } \\
\text { of yourself was the } \\
\text { same before you } \\
\text { left? }\end{array}$ & $\begin{array}{l}\text { No, I was afraid to move away from my family, I'm from Houston but my } \\
\text { whole family moved down to the valley and I was afraid to move to } \\
\text { Houston again by myself because I have a really close knit family so I kind } \\
\text { of put my needs and my happiness and my education on the side to stay } \\
\text { here in the valley to stay with my family and if I move what if something } \\
\text { bad happens? And I ended up going to France and if something bad } \\
\text { happens it's going to happen whether your there or not and before I went } \\
\text { to France I feel like I would put everything my happiness and goals to } \\
\text { make everybody happy and now I realize that you don't have to put your } \\
\text { life on hold, your family is going to be happy with whatever you do. }\end{array}$ \\
\hline
\end{tabular}




\begin{tabular}{|c|c|}
\hline $\begin{array}{l}\text { Have you been } \\
\text { interacting a lot } \\
\text { with the people } \\
\text { from France? }\end{array}$ & $\begin{array}{l}\text { Yes, there is a girl here I've been exchanging emails with her and she's } \\
\text { coming here to pan am and on facebook I still keep in touch with my } \\
\text { friends and we're planning trips like oh we're going to go to Texas and } \\
\text { come visit us in Rome and all these stuff. }\end{array}$ \\
\hline $\begin{array}{l}\text { Would you } \\
\text { recommend study } \\
\text { abroad for } \\
\text { students? }\end{array}$ & $\begin{array}{l}\text { Yes! For everybody and anybody, because even if your not open minded } \\
\text { and open to other cultures you will be once your there and some things you } \\
\text { might become more close minded, but the longer you're there the more } \\
\text { open minded you will become, more accepting. }\end{array}$ \\
\hline $\begin{array}{l}\text { What about your } \\
\text { self- awareness? } \\
\text { Are you more } \\
\text { aware about } \\
\text { yourself? }\end{array}$ & $\begin{array}{l}\text { Oh definitely, I'm not as, how can I put this, I realize that I'm capable of } \\
\text { doing more stuff, but if you don't think you can do something, you're not } \\
\text { going to do it, but once you're there in a new environment without your } \\
\text { family and you know you kind of oh well if I can do this, then I can do } \\
\text { that, you kind of push yourself to do stuff. }\end{array}$ \\
\hline $\begin{array}{l}\text { Do you feel like } \\
\text { your self esteem is } \\
\text { different? }\end{array}$ & $\begin{array}{l}\text { Yeah, and I don't know why, but I feel like it is. I have no idea why but I } \\
\text { definitely feel like it was a transitional period why I was there, but yes I } \\
\text { feel its better, I don't know if it's because I'm more accepting about other } \\
\text { people, so I might be more accepting about myself as well, something like } \\
\text { that. }\end{array}$ \\
\hline $\begin{array}{l}\text { What about } \\
\text { problem solving, } \\
\text { do you feel } \\
\text { something different } \\
\text { or is it the same? }\end{array}$ & $\begin{array}{l}\text { No, no I feel like you can solve it! Like before it was like, I would get mad } \\
\text { and frustrated if something didn't go my way or if I thought I couldn't } \\
\text { solve something, but now it's kind of like more like an adult, gradual steps } \\
\text { as oppose to if I can't do it I just won't, like here you can just call your } \\
\text { advisor and ask them to do something or mom drive down the street or } \\
\text { simple as washing the clothes at your house, at the beginning it was kind } \\
\text { of fun, like oh I have to walk all the way over here to wash my clothes or I } \\
\text { have to wash my clothes by hand because I don't have money to go put it } \\
\text { in the washer and the drier and you know after a while it doesn't even } \\
\text { bother you, and you kind of get used to it and then you come back and a } \\
\text { lot of those things are not as important as they used to be. }\end{array}$ \\
\hline $\begin{array}{l}\text { Do you think that } \\
\text { you were well } \\
\text { enough prepared } \\
\text { before leaving? }\end{array}$ & $\begin{array}{l}\text { No, not at all. I wasn't prepared at all. I didn't know what to expect. } \\
\text { Financially, I wasn't, there's a lot of things that I would change, like now } \\
\text { that I go, I'll know, a budget was the biggest thing, the financial aid that } \\
\text { you get there, I didn't even apply for it, and it would've helped a lot, I } \\
\text { didn't manage my money well when I was there and if I was to go back I } \\
\text { would've changed that but I wasn't prepared. I was kind of in a weak state } \\
\text { of mind, I didn't know what to expect and I had never been, I had never } \\
\text { done something like that, I wasn't prepared at all, but I think that's what } \\
\text { makes it the experience that it is, because it's kind of bland and boring, } \\
\text { everyday, I mean everyday there was something different. Having to walk } \\
\text { back to your apartment in the rain you know just little things, the trains } \\
\text { weren't working so you had to walk all the way from the city back to your } \\
\text { house it was always something different and it was fun. }\end{array}$ \\
\hline $\begin{array}{l}\text { What kind of tips } \\
\text { would you give to } \\
\text { others? }\end{array}$ & $\begin{array}{l}\text { The biggest tip would be have a budget before you get there. Well for one } \\
\text { open an account with HSBC there because any card that you use from here } \\
\text { is going to charge you fees to convert it to Euros and there they don't and I } \\
\text { mean you go there to have fun and since you aren't working for your }\end{array}$ \\
\hline
\end{tabular}




\begin{tabular}{|c|c|}
\hline & $\begin{array}{l}\text { money somebody else is giving it to you you're like oh ok, its only ten } \\
\text { Euros, that's a lot of dollars and then it'll add you all the extra stuff and } \\
\text { now I realize how much money, it's a lot more expensive, the standard of } \\
\text { living is a lot more expensive here, specially because we are used to living } \\
\text { lavishly and washing clothes all the time and having the best soap and then } \\
\text { you go over there and everything is so expensive, so you have to know } \\
\text { what to spend, when to spend and when to say no. It's just try to stay open; } \\
\text { don't criticize like any other culture. Like at first when I got to France I } \\
\text { was like these French people are so stuck up and snobby and I didn't like } \\
\text { then and then I was like well that's their culture and they probably thing } \\
\text { we're loud and obnoxious but I'm just being myself I'm not trying to be } \\
\text { disrespectful, so definitely don't go with a close mind and don't expect } \\
\text { certain things, just let it all happen while your there. }\end{array}$ \\
\hline $\begin{array}{l}\text { If I'm offering you } \\
\text { a program, } \\
\text { everything paid, } \\
\text { where would you } \\
\text { go and how would } \\
\text { your plans look } \\
\text { like? What would } \\
\text { you do? }\end{array}$ & $\begin{array}{l}\text { I would go to, I would want to go to a country where I've never been to, } \\
\text { not like Mexico the U.S or France. First I would say, I would want to go } \\
\text { somewhere fun, like Italy or something but now I would say I would go to } \\
\text { somewhere in Asia. What was the question again? }\end{array}$ \\
\hline $\begin{array}{l}\text { What would your } \\
\text { goals be, what } \\
\text { would you do, what } \\
\text { would be your } \\
\text { motivation to go } \\
\text { there? }\end{array}$ & $\begin{array}{l}\text { Just to see a different culture and they're very like strict on their learning, I } \\
\text { would do something like that, but just because Greece seems fun. I've } \\
\text { never been there, so that was my next place to go. I think I would go } \\
\text { anywhere that they would let me know as long as it wasn't in the U.S or } \\
\text { Mexico because I've already been there, so somewhere in Asia just } \\
\text { because they are different, that would be even harder because of the } \\
\text { language there, you can't kind of pin point what they are saying. }\end{array}$ \\
\hline $\begin{array}{l}\text { Do you think that } \\
\text { all the changes that } \\
\text { you have } \\
\text { encountered in } \\
\text { yourself you'd } \\
\text { encounter them if } \\
\text { you hadn't have } \\
\text { gone? }\end{array}$ & $\begin{array}{l}\text { No, maybe like, maybe I would've encountered then when I was like } 25 \\
\text { years old or something out of college maybe like a mother but I think, not } \\
\text { that I'm putting the university down, because this is a good university, but } \\
\text { being here it doesn't really, you don't see anything different, everybody } \\
\text { has kind of the same views, not everybody but most of the people in } \\
\text { general so you aren't open to anything else. If you don't know something } \\
\text { exists you can't learn about it you don't know about it and I was able to go } \\
\text { to a different country and the thing is you don't just learn about that } \\
\text { country, you learn about everything there because everybody has a } \\
\text { different story. Like everybody that you talk to is from a different country, } \\
\text { so everybody has a different story to tell you and so you learn all these } \\
\text { different things and you start learning that all these different things exists } \\
\text { all these different views and you become more knowledgeable and I don't } \\
\text { think I would've been able to have done that just here, or I don't think so, } \\
\text { maybe yes, but I don't think so. }\end{array}$ \\
\hline
\end{tabular}


APPENDIX No. 7 


\section{Original texts from interviews in Spanish}

\section{Chapter 3}

Darian:

Yo creo que si volvería ir al extranjero, sería más en forma de conocer...seria para conocer más ciudades, me faltaron muchas ciudades por conocer... (Darian, Para. 25)

Gabriela:

Independizarme un poco es lo que más espero de este viaje... Pues ya, mi meta es ver lo que es vivir sola y tener que lidiar todos los problemas yo sola, no contar con mi mama o con mis papás y al igual y ver la vida así como va este es después de que me salga de mi casa (Gabriela, Para. 2 and 7).

\section{Chapter 4}

\subsubsection{Gabriela}

"Me gusta mucho mi carrera, me encanta todo lo de la medicina y las clases son interesantes. Todo me llama mucho la atención. A lo mejor eso es mi fuerte dentro de mi carrera, porque la verdad nadie me presionó para estudiar medicina, es decir, yo solita lo escogí...” (p. 158)

"Pues, como todavía no sé exactamente a qué universidad voy ir después de acabar con Biología y Química aquí en la universidad..., quizás y después de estar en Buenos Aires, me llaman la atención alguna de las escuelas y la manera de estudio sobre los usos de la medicina..." ( from p.158).

“...pues Argentina es una cultura completamente diferente, ahora me gusta más mi carrera... ahora así como para echarle más ganas a mi carrera...” (p. 159).

"Me considero una persona... pues en cuestión de escuela me considero responsable hacia eso, ... en cuestión de social me adapto muy fácil a las personas y tengo conversación y 
todo... puedo ser muy tímida a veces... cuando conozco una persona si me intimida... puedo ser muy tímida pero ya lo ha estado superando..." (p. 161).

"Siento que soy una persona mucho más independiente, antes para todo le hablaba a mi mama, y ahorita, después de mi experiencia es diferente, todo lo tengo que hacer sola. Ya se lidiar con mis problemas yo sola... Ser independiente es lo más importante que yo aprendí durante mi estancia en Argentina..." (p.162).

"Me ayudo mucho en mi persona... cambie muchísimo en la relación con mis padres en casa porque... son seis meses que no viví con ellos, en los que tuve que ir al supermercado, limpiar la casa, lavar mi propia ropa. Yo jamás había hecho eso, entonces... eso si me ayudo muchísimo en la relación que tengo ahora con mi mama, es completamente diferente, y no sé, pero como que la independencia, me ayudo mucho en mi persona... Siento que soy una persona mucho más independiente"... (p.162).

"Lo más importante que aprendí de mi experiencia en el extranjero fue eso, la independencia, que es algo muy increíble que es algo que yo nunca había experimentado у... para mí sí fue algo muy satisfactorio depender de mi misma y no otras personas..." (p. 163).

\section{Gabriela}

\begin{tabular}{|c|c|c|}
\hline & Before & After \\
\hline Motivation & $\begin{array}{l}\text { Vocational career: } \\
\text { Pues yo digo que este programa si me va } \\
\text { ayudar mucho en my persona. No se voy a } \\
\text { pensar ya diferente, y pues sí, yo creo que sí } \\
\text { tiene que reforzar mi carrera vocacional. } \\
\text { Personal growth: } \\
\text { Este programa va a ser todo una experiencia } \\
\text { nueva, conocer gente nueva. Antes de } \\
\text { meterme de lleno al estudio al estudio de } \\
\text { medicina... pues es una experiencia muy } \\
\text { diferente a vivir sola y así. }\end{array}$ & $\begin{array}{l}\text { Vocational and academic experience: } \\
\text { En general fue una experiencia muy } \\
\text { diferente, muy, muy buena. Si lleno mis } \\
\text { expectativas de lo que yo esperaba. Con lo } \\
\text { que respecta al tema de la escuela un poco } \\
\text { no!, porque no aprobé las materias, si me } \\
\text { gusto mucho, aprendí muchísimo me sirvió } \\
\text { pero no era lo que yo esperaba conforme al } \\
\text { sistema y todo, no lo puedo explicar pero } \\
\text { si fue una experiencia muy, muy buena... }\end{array}$ \\
\hline
\end{tabular}




\begin{tabular}{|l|l|l|}
\hline Goals & $\begin{array}{l}\text { Personal growth: } \\
\text { Mi meta es independizarme un poco es lo } \\
\text { que más espero de esta experiencia, es } \\
\text { decir, lo que es vivir sola y tener que lidiar } \\
\text { todos los problemas yo sola no contar con } \\
\text { mi mama o con mis papás y al igual y ver } \\
\text { la vida así como va este es después de que } \\
\text { me salga de mi casa." }\end{array}$ & $\begin{array}{l}\text { Mecational career: } \\
\text { ya muero de ganas por entrar a la escuela } \\
\text { acá para suir con mis clases de biología } \\
\text { yuímica que la verdad si extraño } \\
\text { muchísimo. En el futuro, seguir con mi } \\
\text { carrera, seguir estudiando, pues me gusta } \\
\text { más mi carrera, ahora así como para } \\
\text { echarle más ganas. }\end{array}$ \\
\hline
\end{tabular}

\begin{tabular}{|l|l|l|}
\hline Strengths & \multicolumn{1}{|c|}{ Before } & \multicolumn{1}{c|}{ After } \\
\hline $\begin{array}{l}\text { Self: } \\
\text { Mis puntos fuertes cuando me } \\
\text { propongo algo lo cumplo y no } \\
\text { tengo miedo de que vaya a fallar. }\end{array}$ & $\begin{array}{l}\text { Self: } \\
\text { Pues yo creo que fue eso, la independencia, que es } \\
\text { algo muy increíble que es algo que yo nunca había } \\
\text { experimentado y para mí fue así algo muy } \\
\text { satisfactorio depender de mi misma yo otras } \\
\text { personas, igual no trabaje ni nada, pero es algo que } \\
\text { tendré que hacer en algún punto de mi vida. } \\
\text { Mas fuerte es mi independencia, y la relación que llevo } \\
\text { con las personas, en especial con la familia, en especial } \\
\text { con mi mama." }\end{array}$ \\
\hline Weakness & $\begin{array}{l}\text { Self: } \\
\text { Me distraigo muy fácil entonces } \\
\text { al igual y eso puede ser un poco } \\
\text { mi debilidad, me distraen: mis } \\
\text { amigas, la televisión, todo." }\end{array}$ & $\begin{array}{l}\text { Una de mis debilidades después del viaje, la verdad no } \\
\text { tuve ninguna debilidad. Pero tal vez el acostumbrarme } \\
\text { a viajar". }\end{array}$ \\
\hline
\end{tabular}

(p. 165).

"Bueno me fui con tres clases... pero la que estaba tomando economía política... el primer día que llegue me di cuenta que era una clase de tercer año de política (licenciatura), y como mi carrera es medicina entonces, pues no tiene nada que ver, estaban muy avanzados... Esa clase entonces preferí darla de baja, porque no sabía absolutamente nada..." (p.166).

"Lo que no espere de este programa en Argentina fue el sistema que tiene la escuela allá, es completamente diferente al sistema que tienen aquí en Estados Unidos. Allá el sistema consiste, en cuestión de exámenes, es un parcial y un final, el parcial consiste en 5 preguntas y tienes que desarrollar sobre ellas. Acá en (USA) estoy acostumbrada a la opción múltiple y es como..., te dan ahí la respuesta y no tienes que escribir nada, y allá (Argentina) tienes que escribir todo lo que has aprendido, y es completamente diferente. 
Me costó muchísimo trabajo, fue por eso que no aprobé, le eche muchísimas ganas, pero nada mas no dio el resultado que yo quería. Pero de que aprendí, aprendí! (p. 166-167).

"Si, la verdad que sí. A la hora de estar tomando estas clases...o sea si me gustaba porque era interesante, pero no me llenaba, y pues medicina es lo que me gusta la verdad si, ya muero de ganas por entrar a la escuela acá para seguir con mis clases de biología y química que la verdad si extraño muchísimo. Si, si, si tomando esas clases reforzó my interés vocacional por mi carrera de medicina, de hecho cuando me hartaba de eso me metía al Internet para leer de biología y me lleve varios cuadernos de mis clases pasadas como para que no se me olvidara, porque si, me gusta mucho. De hecho el periódico de allá se llama "el Clarin" y justo cuando llegue todos los miércoles regalaban un folleto que se llamaba el atlas del cuerpo humano, y claro que cada miércoles me tenias a mi, puse una alarma en mi celular y todo, porque si me di cuenta, bueno yo ya sabía que la medicina era lo mío, pero esto sirve para comprobar que la medicina es lo mío". (p.168).

"Si, pues... muchas veces estaba sola en el departamento, si no tenia tarea ni nada de eso, pues me salía a caminar a los parques de Buenos Aires y me ponía a leer... y la verdad si me ayudo muchísimo en pensar mucho en mi y en mi futuro...” (p.168).

\section{Chapter 5}

\section{Adriana after study abroad in France:}

"Cambie bastante. Antes de ir, era una persona que miraba a mí alrededor siempre... y después al último era yo. Ahora, pienso primero en mi, primero soy yo, lo que me conviene en mi futuro, y lo demás sale sobrando, primero soy yo, en eso cambie bastante...te ensenas a ser más independiente y aprendes de eso, aprendes a vivir tomando tus propias decisiones. Aprendes a vivir con tus decisiones pensarlas antes de hacerlas. Maduras más en general. Si contribuye mucho porque te sientes que estas más madura, ya sabes lo que quieres, ya no tienes dudas ya ahora si estas decidía a lo que tú quieras".

\section{Darian after study abroad in France:}

"La verdad si, madure mas. Me ayudo a madurar más y a economizar mas el dinero. Si aprendí más a como llevar el manejo del dinero y saber resolver los problemas, tener que estar al pendiente de las clases. Yo creo que antes era una persona que no tenía la mente 
abierta a otras cosas, me cerraba mucho. Si, la verdad si, antes yo era diferente, dejaba mis cosas a un lado para estar con mi familia y ahora ya no. Si estoy con ellos igual pero ahora trato de darle más tiempo a mi vida, y eso era lo que necesitaba yo, un empujoncito y salir adelante".

\section{Cecilia after study abroad in Spain:}

"Pues si me hice más responsable digo yo, como mas responsable, antes era menos ordenada, pero como quiera la tímida no se me quito. Me hice más responsable para cuidar el dinero y todo, y me motivo saber que puedo estar fuera de mi casa, y poder yo ser responsable de lo que hago y más ordenada. Me hice más independiente, y más organizada. Sé que soy capaz de hacer las cosas”.

\section{Mariana after studying abroad in Spain:}

Yo creo que un poquito más feliz, más alegre. Ya supe lo que es vivir sola. Empecé a ser mas desenvuelta y no tan reprimida, o sea de decir - no voy a hacer esto, no voy a hacer lo otro-, ahora todo lo contrario, me digo -voy a hacer esto, y lo voy a hacer-. Yo creo que eso fue lo que me beneficio como persona, ahora me describiría más independiente, yo se las cosas que tengo que hacer, (porque allá nadie me decía nada, y a veces te da flojera, y no quieres hacer las cosas, las haces a un lado y luego cuando se te regresan dices, ahora si las tengo que hacer, y las hubiera hecho hace tiempo) entonces aprendí que las cosas que tengo que hacer las tengo que hacer cuando las tenga que hacer y no dejar todo para el ultimo, aprendí a tomar mi vida y organizarme todo lo que entonces me siento más lista y más preparada, mas independiente".

\section{Antonio after study abroad in Spain:}

"La experiencia en España, para mí, me sirvió mucho vivir solo, no me conocía, solo todavía, entonces eso para mí, me sirvió. Me sirvió mucho. Consiste en cuidarte, lavar ropa etc., todo eso, para mí, fue muy importante, me quería conocer, no sabía cómo iba a reaccionar".

"Pues las clases (Microeconomía, literatura Española y Contabilidad) dentro del programa que tome en España no me ayudo mucho en mi carrera, es decir, nada. Porque pues en 
cierto sentido, sentí que perdí el semestre. Pues al llegar allá tenía yo pensado tomar ciertas clases de ingeniería allá, pero por falta de comunicación entre las dos universidades este salió que el campus de ingeniería estaba en otro pueblo, en si era casi otra institución creo, entonces perdí las de ingeniería y metí esas que siempre me llamaron la atención”.

"Si reforcé mi elección de carrera. Pues, estuve haciendo prácticas en Madrid, entonces...me acerque a la industria un poco más. Antes de irme, si me gustaba [ingeniería] pero le empecé a perder el cariño [interés], porque no tenía la oportunidad de ir a prácticas, además aquí como Estados Unidos no es mi país, no es tan fácil acercarme a una industria y hacer prácticas, y en cambio allá en España, lo pude hacer y me gusto. Y ahora conozco un país más... hice relaciones, no se también me sirvió para tener ideas nuevas respecto al futuro, nuevos planes profesionales. Si claro mi interés de carrera, aun que no estudie ingeniería allá, sigue siendo ingeniería. Tenía la duda en que área especializarme, en manufactura o en mecánica, pero ahorita ya regrese con ganas de seguir estudiando lo que estaba estudiando, manufactura."

\section{Adriana after study abroad in France:}

Mis intereses por la carrera siguen en pie, pero ahora estuve allá en Francia...me interesa saber más de la cultura francesa. Me interesa elegir una segunda carrera (major) en francés. Quisiera aprender más, no solo enfocarme solo en eso (Español) sino aprender otro idioma aprender de la cultura y ensenar (dar clases). Mi carrera se queda en `donde mismo pero con un poco mas de conocimiento... o sea como con ganas e interés de saber más. Ahora mi interesa hacer doble carrera (Español and Francés). Dejar mi carrera como está hecha, pero quiero enfocarme más en francés..."

$\mathrm{Si}$, estar en el extranjero, te ayuda más a no ser conformista a querer buscar más. Cuando vas a allá, te encuentras con personas muy profesionales, te da cuenta que de todo lo que puedes aprender, y pues, si quieres ser alguien más, no detenerse en lograrlo. Mis intereses vocacionales si se reforzaron. Aprendes mucho y... mis interese son reforzados porque cambias, para bien. Ahora, quiero un futuro mejor. Ahora que regrese de mi viaje, primero es mi superación plenamente y después vendrá eso (familia). Ahora me pongo metas y continuar hasta terminarlas. 


\section{Curriculum Vitae}

Name

Address:

Place and date of birth:

Nationality:

Education

Dates:

1979-1983

1987-1993

1999-2001

2008

2010

Professional experience

2004-2007

2007

2001-2003

1996-1998

1996-1997
Leticia Rangel-Chavez

5102 North $24^{\text {th }}$ Lane, McAllen, Texas, 78504 USA

Jan. 04.1964 in Monterrey, Mexico

Mexican and American

\section{School - University}

Teacher certification for elementary education" at the Esc. "Normal Miguel F. Martinez"

MA Study Program at the Pedagogic Seminar at the Georg-August University of Göttingen

Doctoral fellowship from DAAD at the Pedagogic Seminar at the Georg-August University of Göttingen

MA Study Program in Counseling and Guidance at the University of Texas Pan-American

Fulfillment of Doctoral Program in Pedagogic

\section{University of Texas Pan-American, Texas USA}

Graduate Research Assistant at CASSO Project: Curricular Assessment for Students Outcomes at the Department of Education

Study Abroad Advisor at the Office of International Programs

Instructor of "German I" at the College of Communication Arts and Science

Universidad Autónoma de Nuevo León (UANL), Monterrey, México

Lecturer of Educational Psychology at the Post-grade Department of Psychology

Lecturer of Educational and Vocational Orientation at the Post grade Department of Philosophy

Instructor of "German I and II" at the Language Institute 